\title{
Symptoms in patients with cancer
}

Citation for published version (APA):

van den Beuken-van Everdingen, M. H. J. (2009). Symptoms in patients with cancer. [Doctoral Thesis, Maastricht University]. Datawyse / Universitaire Pers Maastricht. https://doi.org/10.26481/dis.20090115mb

Document status and date:

Published: 01/01/2009

DOI:

10.26481/dis.20090115mb

Document Version:

Publisher's PDF, also known as Version of record

\section{Please check the document version of this publication:}

- A submitted manuscript is the version of the article upon submission and before peer-review. There can be important differences between the submitted version and the official published version of record.

People interested in the research are advised to contact the author for the final version of the publication, or visit the DOI to the publisher's website.

- The final author version and the galley proof are versions of the publication after peer review.

- The final published version features the final layout of the paper including the volume, issue and page numbers.

Link to publication

\footnotetext{
General rights rights.

- You may freely distribute the URL identifying the publication in the public portal. please follow below link for the End User Agreement:

www.umlib.nl/taverne-license

Take down policy

If you believe that this document breaches copyright please contact us at:

repository@maastrichtuniversity.nl

providing details and we will investigate your claim.
}

Copyright and moral rights for the publications made accessible in the public portal are retained by the authors and/or other copyright owners and it is a condition of accessing publications that users recognise and abide by the legal requirements associated with these

- Users may download and print one copy of any publication from the public portal for the purpose of private study or research.

- You may not further distribute the material or use it for any profit-making activity or commercial gain

If the publication is distributed under the terms of Article $25 \mathrm{fa}$ of the Dutch Copyright Act, indicated by the "Taverne" license above, 


\section{Symptoms in}

\section{Patients with Cancer}


(C) Marieke van den Beuken, Maastricht 2009

University Hospital Maastricht, Department of Anaesthesiology, Pain Management and Research Centre, P.O. Box 5800, 6202 AZ Maastricht, The Netherlands e-mail: m.vanden.beuken@mumc.nl

All rights reserved. No part of this thesis may be reproduced or transmitted in any form or by any means, without the permission in writing from the author

ISBN: 978-90-5278-797-8

Layout: Tiny Wouters

Cover design: adapted from www.xanga.com

Production: Datawyse / Universitaire Pers Maastricht

Printing of this thesis was financially supported by Grünenthal BV, Therabel BV, Pfizer BV and Mundipharma BV. 


\title{
Symptoms in
}

\section{Patients with Cancer}

\author{
Proefschrift
}

ter verkrijging van de graad van doctor

aan de Universiteit Maastricht,

op gezag van de Rector Magnificus, Prof. mr. G.P.M.F. Mols,

volgens het besluit van het College van Decanen,

in het openbaar te verdedigen

op donderdag 15 januari 2009 om 14.00 uur

door

Maria Henrica Johanna van den Beuken-van Everdingen

Geboren op 20 oktober 1960 te Utrecht

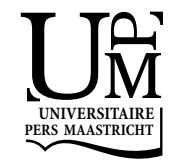




\section{Promotores}

Prof. dr. M. van Kleef

Prof. dr. H.C. Schouten

\section{Copromotores}

Dr. J. Patijn

Mw. Dr. J.M. de Rijke

\section{Beoordelingscommissie}

Prof. dr. M.F. von Meyenfeldt (voorzitter)

Prof. dr. S.H. Ahmedzai, University of Sheffield Medical School

Prof. dr. C.D.A. Stehouwer

Prof. dr. R. de Wit

Prof. dr. W.W. Zuurmond, Academisch Ziekenhuis, Vrije Universiteit te Amsterdam 
Wie niets weet

en weet dat hij niets weet

weet meer

dan hij die iets weet

en niet weet wat hij niet weet

Voor "mijn" mannen:

Loek

Joop, Sef, Wisse en Dirk 



\section{Contents}

Chapter 1 General introduction

Chapter $2 \quad$ Prevalence of pain in patients with cancer.

A systematic review of the past 40 years

Chapter $3 \quad$ High Prevalence of Pain in Patients with Cancer

Chapter 4 Quality of Life and Symptoms in Patients with Cancer

Chapter 5

A randomised clinical trial of an intensive nursing-based pain education programme for cancer outpatients with pain

Chapter 6 Concerns of Former Breast Cancer Patients about Disease Recurrence. A validation and prevalence study

Chapter $7 \quad$ Summary and General discussion

Samenvatting

Appendices

Appendix I: Quality criteria for prevalence studies of pain in patients with cancer.

Appendix II: Dutch version of the CARS

Dankwoord

Curriculum vitae 



\section{Chapter 1}

General introduction 
$10 \mid$ Chapter 1 


\section{General Introduction}

Patients with cancer face many problems as well during the active treatment phase, after curative treatment as near the end of life. In addition, the problem is growing: in 2002, an estimated eleven million new cancer cases and seven million cancer deaths were reported worldwide; nearly 25 million persons were living with cancer (five-year prevalence). ${ }^{1}$ The world-wide incidence rate of cancer is expected to grow to 15 million new cases in $2020{ }^{2}$

In the Netherlands, in 2005, 74.500 new cancer cases and 38.500 cancer deaths were reported. ${ }^{3}$ The age-adjusted incidence of cancer until 2015 will level for men and show a slight increase for women. However, due to aging of the Dutch population the absolute number of new cancer cases will rise to 50.000 in men and to 45.000 in women in $2015 .{ }^{4}$

Since 1990 the rate of cancer deaths is decreasing in man and is stable in women. The expectation is that this trend will hold to $2015 .{ }^{(4)}$ Due to the stabile or slight increasing incidence in combination with the decreasing death rate, the age-adjusted cancer prevalence will rise considerably. It is expected that the 20-year prevalence of cancer will rise from 366.000 in 2000 to 692.000 in 2015: The prevalence will be doubled in 15 years! $!^{4}$

The problems these patients with cancer meet, have as well physical as psychological, social and spiritual aspects.

As a result on "too often a patient's distress is narrowly defined by the health care system and their illness is described in terms of biology of disease.....while associated suffering of the patient is ignored" ${ }^{\prime 5}$ a huge literature has developed around the idea of quality of life.

"Quality of life" naturally follows from the World Health Organisation's definition of health as complete physical, mental and social well-being, not merely the absence of disease. ${ }^{6}$ However, despite the increased interest in quality of life, there is still no consensus on the definition of this concept. ${ }^{7}$ The most suitable approach for defining quality of life is "satisfaction with life".

Cancer clinicians have long recognized that their treatment must strike a balance between quantity and quality of life. Cancer-care shifts to "patientcentred" care, which shares the same aspirations as palliative care e.g.: quality of life, including good symptom control, holistic patient-centred care and open and sensitive communication that addresses the physical, psychological, social and spiritual needs of patients and their families. ${ }^{8}$

Looking at the physical problems, pain is one of the most feared and burdensome symptoms. Despite the abundant literature on this topic, accurate prevalence estimates of pain in cancer patients are not available. Early reports on the prevalence of pain in cancer patients draw attention to high figures that 
ranged from 52 to $77 \% .^{9-13}$ More recent studies on the prevalence of pain in patients with cancer showed figures that ranged from $24-60 \%$ in patients on active anti-cancer treatment ${ }^{14-17}$ and $62-86 \%$ in patients with advanced cancer, ${ }^{18-23}$ which illustrates that this problem has not been solved.

These high prevalence figures contrast sharply with the rapidly increasing interest in pain and pain relief in the past decade. Apparently, greater insight into the pathophysiological mechanisms of pain and the wider availability of anti-nociceptive therapies, such as opioids, co-analgesics and NMDA-receptorantagonists, have not influenced the prevalence of pain in cancer patients. Moreover, the WHO introduced a pain ladder ${ }^{24}$ in 1986 that has been accepted worldwide. Combined with appropriate dosage guidelines, it should be able to provide tools for adequate pain relief in $70-90 \%$ of the patients. ${ }^{25-28}$

The prevalence of non-pain physical symptoms is much less addressed and mainly in patients with advanced or metastatic disease. ${ }^{18,29-33} \mathrm{~A}$ recent systematic review on symptom prevalence in patients with incurable cancer $^{34}$ identified 37 symptoms, almost all occurring in $>10 \%$ of the patients. Five symptoms (fatique, pain, lack of energy, weakness and appetite loss) occurred in more than $50 \%$ of the patients. The authors concluded that more studies are needed based on symptom intensity, symptom burden and impact on quality of life to improve individually tailored treatment. ${ }^{34}$

Studies on non-pain symptoms in ambulatory or cured patients are scarce and mainly focussed on a particular type of cancer (e.g. breathlessness in patients with lung cancer, ${ }^{35}$ fatigue in breast cancer survivors ${ }^{36}$ or vertigo in nasopharyngeal carcinoma survivors ${ }^{37}$ ).

Cancer related psychological distress occurs in one third of patients. ${ }^{38}$ Major depressive disorder is estimated to occur in $10-25 \%$ of patients with cancer. ${ }^{38}$ Anxiety disorders are found in $15-28 \%$ of the patients. ${ }^{39}$ These estimates were made around the time of diagnosis. Hardly any research is done to establish the prevalence of anxiety, depressive disorders or other psychological distress in the years after the diagnosis.

Psychiatric morbidity and other psychological aspects are best studied among breast cancer patients, while fewer reports regard cancer of other sites. ${ }^{40-42}$ In breast cancer patients, $30 \%$ of the women were still experiencing psychological distress many years after the completion of treatment. ${ }^{43}$ Specific problems often persisted, such as poor body image, decreased sexuality and fear of disease recurrence. ${ }^{44,45}$ Even twenty years after the initial treatment, there was an increased prevalence of post-traumatic stress disorder (PTSD), which indicated unremitting psychological sequelae long after diagnosis and treatment. $^{46}$

Reasons for the still too high prevalence of physical symptoms in patients with cancer is best studied in patients with pain. The gap between what is possible 
in pain control and what is achieved is caused by many different patient centred, care provider centred and government centred factors. Fear for medication in general and opioids in particular, patients wanting to be "good" patients, lack of knowledge, lack of interest and requests from care providers, are well-known barriers against adequate pain control. ${ }^{47-56}$

In a recent systematic review of institutional interventions designed to improve the assessment and treatment of pain ${ }^{57}$ no clinical trials that specifically targeted physicians behaviour could be targeted. Nursing educational interventions involving didactic sessions have been shown to improve nurses' knowledge and correct misperceptions about pain and analgesic prescribing but have not been shown to improve pain or patient's satisfaction. ${ }^{57}$ Several studies suggest that educational interventions using tailored counselling sessions directed at the patients can improve pain scores and alter negative pain beliefs and misconceptions. ${ }^{57}$

There is an ongoing discussion whether psychological symptoms are associated with survival in patients with cancer. Depression has been associated with shortened survival after five years but not after ten years. ${ }^{58}$ Psychological interventions have found to be beneficial and non-beneficial with respect to survival. ${ }^{38} \mathrm{~A}$ recent review concerning psychotherapy and survival in cancer concluded: there is no reason to assume that psychotherapy promotes survival. ${ }^{59}$

However, psychological symptoms do have a considerable negative influence on quality of life in patients with chronic diseases. ${ }^{60-63}$

\section{Summary}

The number of patients who have survived cancer or are living with cancer is growing. These patients are confronted with numerous physical, psychological, social and spiritual problems. However, most research on symptoms and symptom management has been performed in patients with breast cancer and in patients with advanced disease. Very few studies focussed on symptoms in other cancers, in cured patients or in patients during active treatment.

In this thesis we attempt 1. to make reliable estimations of the prevalence and severity of pain in cancer patients and to map predictors of cancer pain, 2. to make reliable estimations of the prevalence of non-pain symptoms in order to find whether treating physicians should be extra alert on a particular symptom in a particular type of cancer or treatment phase, 3. to determine the quality of life of patients with cancer in different cancer types and treatment phases and to investigate the impact of physical and psychological symptoms on quality of life, 4. to evaluate whether an intensive home-based pain education 
programme given by nurses can affect levels of pain, pain knowledge, quality of life, anxiety and depression, 5. to evaluate the psychometric properties of the Dutch version of the CARS (Concerns About Recurrence Scale) and 6. to measure the prevalence of concerns about disease recurrence in former breast cancer patients, to identify potential predictors and to establish how fear of recurrence affects quality of life.

With this thesis we hope to make things better.

\section{Outline of this thesis}

In chapter 2 we report on a systematic review of the literature on the prevalence of pain. Despite the abundant literature on this topic, accurate prevalence estimates of pain in cancer patients are not available. We investigated the prevalence of pain in cancer patients according to the different disease stages and types of cancer.

A systematic review of the literature was conducted. An instrument especially designed for judging prevalence studies on their methodological quality was used. Methodological acceptable articles were used in a meta-analyses.

In chapter 3 we describe a population-based study on the prevalence of pain in patients with cancer.

At present, no definite conclusions can be drawn about the real extent of the pain suffered by cancer patients. A population-based study was conducted to obtain reliable information about the prevalence and severity of pain in cancer patients (all phases) and about predictors of pain. A representative sample of cancer patients was recruited in the area from a cancer registry. Pain was assessed by the Brief Pain Inventory (BPI). Adequacy of pain treatment was assessed with the Pain Management Index (PMI).

In chapter 4 we describe a population-based study on the prevalence of nonpain physical symptoms and psychological symptoms in patients with cancer.

The objective of this study was: to measure the prevalence of non-pain physical symptoms and psychological symptoms in patients with cancer, to investigate the impact of physical and psychological symptoms on quality of life and to enquire whether treatment had been received for the complaints/ symptoms .

Quality of life and non-pain symptoms were measured by the EORTC-C30 version 3. We added two items: 1 . did you have a dry mouth? and 2. did you feel listless? Depression and anxiety were measured by the Dutch version of the Hospital Anxiety and Depression Scale (HADS).

Chapter 5 describes a randomised clinical trial of an intensive nursing intervention for cancer patients suffering from pain their home situation. 
The prevalence of pain in patients with cancer is still too high. Factors related to ineffective pain treatment fall into three categories: the health care system, professional care providers and patients. In patients, various barriers lead to non-compliance. Previous educational interventions have increased their pain knowledge and decreased short-term pain levels. In this randomised controlled trial, we investigated how an intensive home-based education programme given by nurses affected short-term and long-term pain levels.

One hundred and twenty cancer patients were randomised to receive either the Pain Education Programme (PEP) or usual care. Pain, knowledge, quality of life, anxiety and depression were measured at baseline, after four weeks and after eight weeks. In the intervention group, results of symptom levels were communicated to the treating physician.

Chapter 6 describes the validation of the Dutch version of the Concerns About Recurrence Scale (CARS).

The present study had three aims: first, to evaluate the psychometric properties of the Dutch version of the CARS (CARS-DLV). Second, to measure the prevalence of concerns about disease recurrence in former breast cancer patients and identify potential predictors and third, to establish how fear of recurrence was effecting quality of life

A prospective study was carried out on breast cancer patients $(n=136)$ who had undergone curative treatment. Eligible patients completed an extensive questionnaire consisting of the CARS (fear of recurrence), HADS (anxiety and depression), BPI (pain), RAND (quality of life), LOT (optimism) and the PCS (catastrophzing).

Finally, in chapter 7 , the main findings of this thesis are discussed in the context of the recent literature. Furthermore, we give practical advices to improve symptom care in patients with cancer. 


\section{References}

1. Kamangar F, Dores GM, Anderson WF. Patterns of cancer incidence, mortality, and prevalence across five continents: defining priorities to reduce cancer disparities in different geographic regions of the world. J Clin Oncol. 2006;24:2137-50.

2. Kanavos P. The rising burden of cancer in the developing world. Ann Oncol. 2006;17 Suppl 8:viii15-viii23.

3. Visser O, Noord van KJ. (Vereniging va Integrale ankercentra). Feiten en Fabels over kanker in Nederland. 2005.

4. Coebergh JWW. Kanker in Nederland, trends, prognoses en implicaties voor zorgvraag Den Haag: KWF kankerbestrijding; 2004.

5. Cohen SR, Mount BM, MacDonald N. Defining quality of life. Eur J Cancer. 1996;32A:753-4.

6. WHO. (World Health Organisation). Preamble of the constitution of the World Health Organisation. 1946.

7. Moons P, Budts W, Geest de S. Critique on the conceptualisation of quality of life: A review and evaluation of different conceptual appraoches. International Journal of Nursing Studies. 2006;43:891-901.

8. Jeffrey D. What do we mean by psychosocial care in palliative care? Oxford: Oxford University Press; 2003. (Lloyd-Williams M, ed. Psychosocial issues in palliative care).

9. Aitken-Swan J. Nursing the late cancer patient at home; the family's impressions. Practitioner. 1959;183:64-9.

10. Sung JL, Wang TH, Yu JY. Clinical study on primary carcinoma of the liver in Taiwan. Am J Dig Dis. 1967;12:1036-49.

11. Lempinen M. Carcinoma of the stomach. I. Diagnostic considerations. Ann Chir Gynaecol Fenn. 1971;60:135-40.

12. Ross AP, Braasch JW, Warren KW. Carcinoma of the proximal bile ducts. Surg Gynecol Obstet. 1973;136:923-8.

13. Twycross RG. The terminal care of patients with lung cancer. Postgrad Med J. 1973;49: 732-7.

14. Pignon T, Fernandez L, Ayasso S, Durand MA, Badinand D, Cowen D. Impact of radiation oncology practice on pain: a cross-sectional survey. Int $\mathrm{J}$ Radiat Oncol Biol Phys. 2004;60:1204-10.

15. Puts MT, Versloot J, Muller MJ, Dam van FS. [The opinion on care of patients with cancer undergoing palliative treatment in day care]. Ned Tijdschr Geneeskd. 2004;148:277-80.

16. Rietman J, Dijkstra P, Debreczeni R, Geertzen J, Robinson D, De Vries J. Impairments, disabilities and health related quality of life after treatment for breast cancer: a follow-up study 2.7 years after surgery. Disabil Rehabil. 2004;26:78-84.

17. Taylor KO. Morbidity associated with axillary surgery for breast cancer. ANZ J Surg. 2004;74:314-7.

18. Bradley N, Davis L, Chow E. Symptom distress in patients attending an outpatient palliative radiotherapy clinic. J Pain Symptom Manage. 2005;30:123-31.

19. Di Maio M, Gridelli C, Gallo C, Manzione L, Brancaccio L, Barbera S, Robbiati SF, lanniello GP, Ferrau F, Piazza E, Frontini L, Rosetti F, Carrozza F, Bearz A, Spatafora M, Adamo V, Isa L, laffaioli RV, Di Salvo E, Perrone F. Prevalence and management of pain in Italian patients with advanced non-small-cell lung cancer. $\mathrm{Br}$ J Cancer. 2004;90:2288-96.

20. Wilson KG, Graham ID, Viola RA, Chater S, de Faye BJ, Weaver LA, Lachance LA. Structured interview assessment of symptoms and concerns in palliative care. Can $\mathrm{J}$ Psychiatry. 2004:49:350-8.

21. Hwang SS, Chang VT, Cogswell J, Alejandro Y, Osenenko P, Morales E, Srinivas S, Kasimis B. Study of unmet needs in symptomatic veterans with advanced cancer: incidence, independent predictors and unmet needs outcome model. J Pain Symptom Manage. 2004;28:421-32. 
22. Stromgren AS, Groenvold M, Petersen MA, Goldschmidt D, Pedersen L, Spile M, IrmingPedersen G, Sjogren P. Pain characteristics and treatment outcome for advanced cancer patients during the first week of specialized palliative care. J Pain Symptom Manage. 2004;27:104-13.

23. Lin MH, Wu PY, Tsai ST, Lin CL, Chen TW, Hwang SJ. Hospice palliative care for patients with hepatocellular carcinoma in Taiwan. Palliat Med. 2004;18:93-9.

24. WHO. (World Health Organisation). Cancer Pain Relief. 1986.

25. Ventafridda $V$, Oliveri $E$, Caraceni A. A retrospective study on the use of oral morphine in cancer pain. J Pain Symptom Manage. 1987;2:77-82.

26. Walker VA, Hoskin PJ, Hanks GW, White ID. Evaluation of the WHO analgesic guidelines for cancer pain in a hospital-based palliative care unit. Journal of Pain and Symptom Management. 1988;3:145-9.

27. Goisis A, Gorini M, Ratti R, Luliri P. Application of a WHO protocol on medical therapy for oncologic pain in an internal medicine hospital. Tumori. 1989;75:470-2.

28. Caraceni A, Martini C, Zecca E, Portenoy RK, Ashby MA, Hawson G, Jackson KA, Lickiss N, Muirden N, Pisasale M, Moulin D, Schulz VN, Rico Pazo MA, Serrano JA, Andersen H, Henriksen HT, Mejholm I, Sjogren P, Heiskanen T, Kalso E, Pere P, Poyhia R, Vuorinen E, Tigerstedt I, Ruismaki P, Bertolino M, Larue F, Ranchere JY, Hege-Scheuing G, Bowdler I, Helbing F, Kostner E, Radbruch L, Kastrinaki K, Shah S, Vijayaram S, Sharma KS, Devi PS, Jain PN, Ramamani PV, Beny A, Brunelli C, Maltoni M, Mercadante S, Plancarte R, Schug S, Engstrand P, Ovalle AF, Wang X, Alves MF, Abrunhosa MR, Sun WZ, Zhang L, Gazizov A, Vaisman M, Rudoy S, Gomez Sancho M, Vila P, Trelis J, Chaudakshetrin P, Koh ML, Van Dongen RT, Vielvoye-Kerkmeer A, Boswell MV, Elliott T, Hargus E, Lutz L; Working Group of an IASP Task Force on Cancer Pain. Breakthrough pain characteristics and syndromes in patients with cancer pain. An international survey. Palliat Med. 2004;18:177-83.

29. Hoekstra J, Vos de R, Duijn van NP, Schade E, Bindels PJ. Using the symptom monitor in a randomized controlled trial: the effect on symptom prevalence and severity. J Pain Symptom Manage. 2006;31:22-30.

30. Labori KJ, Hjermstad MJ, Wester T, Buanes T, Loge JH. Symptom profiles and palliative care in advanced pancreatic cancer: a prospective study. Support Care Cancer. 2006;14:1126-33.

31. Moro C, Brunelli C, Miccinesi G, Fallai M, Morino P, Piazza M, Labianca R, Ripamonti C. Edmonton symptom assessment scale: Italian validation in two palliative care settings. Support Care Cancer. 2006;14:30-7.

32. Tsai JS, Wu CH, Chiu TY, Hu WY, Chen CY. Symptom patterns of advanced cancer patients in a palliative care unit. Palliat Med. 2006;20:617-22.

33. Stromgren AS, Sjogren P, Goldschmidt D, Petersen MA, Pedersen L, Groenvold M. Symptom priority and course of symptomatology in specialized palliative care. J Pain Symptom Manage. 2006;31:199-206.

34. Teunissen S, Wesker W, Kruitwagen C, Haes de H, Voest E, Graeff de A. Symptom Prevalence in patients with Incurable Cancer: A Systematic Review. J Pain Symptom Manage. 2007;34:94-104

35. O'Driscoll M, Corner $\mathrm{J}$, Bailey $\mathrm{C}$. The experience of breathlessness in lung cancer. Eur $\mathrm{J}$ Cancer Care (Engl). 1999;8:37-43.

36. Carpenter JS, Elam JL, Ridner SH, Carney PH, Cherry GJ, Cucullu HL. Sleep, fatigue, and depressive symptoms in breast cancer survivors and matched healthy women experiencing hot flashes. Oncol Nurs Forum. 2004;31:5591-8.

37. Young YH, Ko JY, Sheen TS. Postirradiation vertigo in nasopharyngeal carcinoma survivors. Otol Neurotol. 2004;25:366-70.

38. Levin T, Kissane DW. Psychooncology - the state of its development in 2006. European Journal of Psychiatry. 2006;20:183-97.

39. Kerrihard T, Breitbart W, Dent R, Strout D. Anxiety in patients with cancer and human immunodeficiency virus. Seminars in Clinical Neuropsychiatry. 1999;4:114-32.

40. Prieto JM, Atala J, Blanch J, Carreras E, Rovira M, Cirera E, Espinal A, Gasto C. Role of depression as a predictor of mortality among cancer patients after stem-cell transplantation. $\mathrm{J}$ Clin Oncol. 2005;23:6063-71. 
41. Zabora J, BrintzenhofeSzoc K, Curbow B, Hooker C, Piantadosi S. The prevalence of psychological distress by cancer site. Psychooncology. 2001;10:19-28.

42. Korfage IJ, Essink-Bot ML, Janssens AC, Schroder FH, Koning de HJ. Anxiety and depression after prostate cancer diagnosis and treatment: 5-year follow-up. $\mathrm{Br} \mathrm{J}$ Cancer. 2006;94:1093-8.

43. Kornblith $A B$, Ligibel J. Psychosocial and sexual functioning of survivors of breast cancer. Semin Oncol. 2003;30:799-813.

44. Stanton AL. Psychosocial concerns and interventions for cancer survivors. J Clin Oncol. 2006;24:5132-7.

45. Hartl K, Janni W, Kastner R, Sommer H, Strobl B, Rack B, Stauber M. Impact of medical and demographic factors on long-term quality of life and body image of breast cancer patients. Ann Oncol. 2003;14:1064-71.

46. Kornblith AB, Herndon JE, 2nd, Weiss RB, Zhang C, Zuckerman EL, Rosenberg S, Mertz M, Payne D, Jane Massie M, Holland JF, Wingate P, Norton L, Holland JC. Long-term adjustment of survivors of early-stage breast carcinoma, 20 years after adjuvant chemotherapy. Cancer. 2003;98:679-89.

47. Von Roenn JH, Cleeland CS, Gonin R, Hatfield AK, Pandya KJ. Physician attitudes and practice in cancer pain management. A survey from the Eastern Cooperative Oncology Group. Ann Intern Med. 1993;119:121-6.

48. Ward SE, Goldberg N, Miller-McCauley V, Mueller C, Nolan A, Pawlik-Plank D, Robbins A, Stormoen D, Weismann DE. Patient-related barriers to management of cancer pain. Pain. 1993;52:319-24.

49. Glajchen M, Fitzmartin RD, Blum D, Swanton R. Psychosocial barriers to cancer pain relief. Cancer Pract. 1995;3:76-82.

50. Grossman SA. Undertreatment of cancer pain: barriers and remedies. Support Care Cancer. 1993;1:74-8.

51. Johnson DC, Kassner CT, Houser J, Kutner JS. Barriers to effective symptom management in hospice. J Pain Symptom Manage. 2005;29:69-79.

52. Lin CC. Barriers to the analgesic management of cancer pain: a comparison of attitudes of Taiwanese patients and their family caregivers. Pain. 2000;88:7-14.

53. Miaskowski C, Dodd MJ, West C, Paul SM, Tripathy D, Koo P, Schumacher K. Lack of adherence with the analgesic regimen: a significant barrier to effective cancer pain management. J Clin Oncol. 2001;19:4275-9.

54. Ferrell BR, McCaffery $M$, Rhiner $M$. Pain and addiction: an urgent need for change in nursing education. J Pain Symptom Manage. 1992;7:117-24.

55. Paice JA, Toy C, Shott S. Barriers to cancer pain relief: fear of tolerance and addiction. J Pain Symptom Manage. 1998;16:1-9.

56. Pargeon KL, Hailey BJ. Barriers to effective cancer pain management: a review of the literature. J Pain Symptom Manage. 1999;18:358-68.

57. Goldberg GR, Morrison RS. Pain management in hospitalized cancer patients: a systematic review. J Clin Oncol. 2007;25:1792-801.

58. Watson M, Homewood J, Haviland J, Bliss JM. Influence of psychological response on breast cancer survival: 10-year follow-up of a population-based cohort. Eur J Cancer. 2005;41: 1710-4.

59. Coyne JC, Stefanek M, Palmer SC. Psychotherapy and survival in cancer: the conflict between hope and evidence. Psychol Bull. 2007;133:367-94.

60. Mols F, Vingerhoets AJ, Coebergh JW, Poll-Franse van de LV. Quality of life among longterm breast cancer survivors: a systematic review. Eur J Cancer. 2005;41:2613-9.

61. Ola BA, Adewuya AO, Ajayi OE, Akintomide AO, Oginni OO, Ologun YA. Relationship between depression and quality of life in Nigerian outpatients with heart failure. J Psychosom Res. 2006;61:797-800.

62. Uguz F, Dursun R, Kaya N, Cilli AS. Quality of life in patients with Behcet's disease: the impact of major depression. Gen Hosp Psychiatry. 2007;29:21-4.

63. Stafford L, Berk M, Reddy P, Jackson HJ. Comorbid depression and health-related quality of life in patients with coronary artery disease. J Psychosom Res. 2007;62:401-10. 


\section{Chapter 2}

\section{Prevalence of Pain in Patients with Cancer}

A systematic review of the past 40 years

Marieke HJ van den Beuken-van Everdingen, Janneke M de Rijke, Alfons G Kessels, Harry C Schouten, Maarten van Kleef, Jacob Patijn Ann Oncol. 2007;18:1437-49 


\section{Abstract}

\section{Background/aim}

Despite the abundant literature on this topic, accurate prevalence estimates of pain in cancer patients are not available. We investigated the prevalence of pain in cancer patients according to the different disease stages and types of cancer.

\section{Methods}

A systematic review of the literature was conducted. An instrument especially designed for judging prevalence studies on their methodological quality was used. Methodological acceptable articles were used in the meta-analyses.

\section{Results}

Fifty- two studies were used in the meta-analysis. Pooled prevalence rates of pain were calculated for four subgroups: 1: studies including patients after curative treatment: $33 \%$ (95\% confidence interval $(\mathrm{Cl}) 21-46 \%)$; 2: studies including patients under anti-cancer treatment: $59 \%$ (Cl 44-73\%); 3: studies including patients characterised as advanced/metastatic/terminal disease: $64 \%(\mathrm{Cl} 58-$ $69 \%)$ and 4: studies including patients at all disease stages: $53 \%(\mathrm{Cl} 43-63 \%)$. Of the patients with pain more than one-third graded their pain as moderate or severe. Pooled prevalence of pain was more than $50 \%$ in all cancer types with the highest prevalence in head /neck cancer patients (70\%; $95 \% \mathrm{Cl} 51-88 \%)$.

\section{Conclusion}

Despite the clear World Health Organisation recommendations, cancer pain still is a major problem. 


\section{Introduction}

In cancer patients, pain is one of the most feared and burdensome symptoms. Early reports on the prevalence of pain in cancer patients draw attention to high figures that ranged from 52 to $77 \% .^{1-5}$ More recent studies on the prevalence of pain in patients with cancer showed figures that ranged from $24-60 \%$ in patients on active anti-cancer treatment ${ }^{6-9}$ and $62-86 \%$ in patients with advanced cancer, ${ }^{10-15}$ which illustrates that this problem has not been solved.

These high prevalence figures contrast sharply with the rapidly increasing interest in pain and pain relief in the past decade. Apparently, greater insight into the pathophysiological mechanisms of pain and the wider availability of anti-nociceptive therapies, such as opioids, co-analgesics and NMDA-receptorantagonists, have not influenced the prevalence of pain in cancer patients. Moreover, the WHO introduced a pain ladder ${ }^{16}$ in 1986 that has been accepted worldwide. Combined with appropriate dosage guidelines, it should be able to provide tools for adequate pain relief in $70-90 \%$ of the patients. ${ }^{17-22}$

In 1985, Bonica attempted to evaluate the prevalence of cancer pain worldwide by extrapolating the prevalence rates retrieved from 47 selected reports published in 15 countries. ${ }^{23}$ The mean pain prevalence in patients with various stages of cancer was $50 \%$. In patients with advanced/metastatic/terminal cancer, the percentage was $71 \%$. However, these prevalence figures have to be interpreted with caution, because sample size differences were not taken into account in the calculation of the mean prevalence and no information was given about the search methods used to select the articles or about differences between patient groups other than type and stage of cancer.

It took almost two decades before another systematic review was performed to estimate the prevalence of cancer pain. ${ }^{24}$ The authors included the review by Bonica and made an additional literature search (period 1980-2000), which resulted in 54 more studies. Although the search method was described, it was not clear how these articles had been selected, because the total number of articles retrieved in the search was not mentioned. Furthermore, the methodological quality of the studies that reported pain prevalence rates was not taken into account. ${ }^{25}$

The end result was a very heterogeneous sample of articles, for example, with respect to the methods of data collection: six studies had surveyed medical records and five studies had used retrospective data collected from proxies (bereaved care providers or other informants). It is well-known that these two methods can result in prevalence figures that differ from data obtained directly from the patient. ${ }^{26-32}$ Although the authors stated that it was not possible to perform a meta-analysis owing to the variation in measurements, they reported combined weighted mean prevalences of pain in patients with all/various stages versus patients with metastatic or terminal disease. No description was 
given of how the weighted mean average had been calculated. Prevalence rates were $40 \%$ (range $18-100 \%$ ) and $74 \%$ (range $53-100 \%$ ), respectively.

In 2005, Goudas et al. ${ }^{33}$ aimed to present an literature overview of epidemiological data on cancer- related pain over the period 1982 to 2001. They restricted their search to the field of epidemiology and found 464 studies. Only surveys that explicitly targeted the prevalence of cancer pain were included, which left 28 studies. The authors argued that it was not possible to combine these surveys, because of differences in settings, study populations, primary cancer sites and the methods employed. The only classification they could make was by sample size: $<1000$ patients $(n=22), 1000-10,000 \quad(n=4)$ and $>10,000 \quad(n=2)$. In this way, a comprehensive but fairly unstructured enumeration of prevalence figures was presented. ${ }^{33}$

Despite the large body of literature on pain in cancer patients, none of the previous reviews provided accurate prevalence estimates. We performed a systematic review that included statistical pooling of the study results in an attempt to obtain accurate figures on the prevalence of cancer pain over the period 1966-2005.

\section{Methods}

A systematic literature search was performed using the following databases: Medline 1966-Sept 2005, Embase 1989- Sept 2005, Pubmed1975- Sept 2005, Cinahl 1982- Sept 2005, Cochrane Systematic reviews, Cochrane Central, the Cancer Library 2002.

Our keywords comprised "pain" and "prevalence", or "symptom" and "prevalence" in combination with each of the following terms: "cancer", "neoplasm", "terminal", "end-stage", "advanced", "hospice" or "palliative" in the title, abstract or keywords. Reference lists of the retrieved articles were inspected manually to identify any papers that had been missed.

\section{Inclusion / exclusion criteria}

Studies were included if they reported on the prevalence, irrespectively of the type of prevalence used, of cancer pain in an adult cancer population and were written in the languages English or Dutch. Publications were excluded if they comprised case studies, letters, prevalence studies performed at pain clinics (institute bias), or had only selected patients with pain. 


\section{Study characteristics}

\section{Subgroups}

A consistent finding in earlier reviews on cancer pain was that pain was more prevalent in the more advanced stages. ${ }^{23,24,34}$ In anticipation of this difference, we a priori subdivided the studies into four groups based on the disease characteristics described in the methods/results sections:

1) studies that included patients after finishing curative treatment, 2) studies that included patients receiving anti-cancer treatment, with curative or palliative intention 3) studies that included patients with advanced, metastatic and/or with terminal disease and 4) studies that included all disease stages (1 to 3 ).

\section{Pain prevalence}

Data were documented on pain prevalence, pain severity, recall periods for pain (point prevalence, pain in the past week / month(s) / year) and the scale or instrument used to measure pain: VAS (Visual Analogue Scale), NRS (numerical rating scale), VRS (verbal rating scale), pain "yes"/"no". When pain was reported as VAS scores or numeric scores, the rating of Serlin ${ }^{35}$ was used to convert severity into none (0), mild (1-4), moderate (5-6) or severe $(\geq 7)$.

\section{General study characteristics}

General characteristics were recorded from each study: author(s), year of publication, aim of the study (prevalence or other), sample size, setting (inpatient, out-patient, home, hospice or palliative care unit, referred to palliative care service), method of data collection (questionnaire patient or proxy, interview patient or proxy, medical record), type of prevalence (point, week, month, year), use of validated or non-validated instruments, distribution of gender, distribution of age and type of cancer (head and neck, gastro-intestinal, lung / bronchus, breast, urogenital, gynaecological, all types of cancer).

\section{Methodological quality and pooling of data}

In addition to documenting the general characteristics mentioned above, a more detailed analysis was conducted on the quality of the articles. The studies were evaluated using methodological criteria based on Leboeuf-Yde and Lauritsen ${ }^{36}$ (Table 2.1), which were the first to be especially constructed for prevalence studies. Walker ${ }^{37}$ improved the criteria by adding a criterion to identify proxy reporting and suggested that some weighting should be given to the different criteria. In our paper, the criteria specifically for lower back pain were substituted by an adequate description of the disease stage and/or condition of the cancer patients and a weighting factor was introduced for each 
criterion (Table 2.1). This resulted in a quality score that ranged from 0 to 19 points. The cut-off level for methodological acceptability was set at 14 points, which was $75 \%$ of the total points that could be achieved. ${ }^{36}$ All the studies were reviewed independently by two researchers (MvdB, MdR). Differences between interpretations were resolved using a discussion and consensus approach. The quality score was used to determine whether the data were suitable for inclusion in the meta-analysis. Only articles with a quality score of $\geq 14$ were selected and subsequently divided into the four groups described above. To obtain pooled prevalence rates related to the type of cancer, a separate metaanalysis was performed on the studies that reported pain prevalence in patients with specific types of cancer. We were able to identify 41 data-sets that reported on head and neck, gastro-intestinal, lung, breast, urogenital, or gynaecological cancer. In the meta-analysis, we used the reciprocal of the variance from individual studies as a weighting factor, which relates closely to sample size. This weighting factor was chosen to reflect the amount of information that each study contains. ${ }^{25}$ Then, the pooled prevalence was calculated for each group and the precision (95\% confidence interval) and statistical significance of the overall estimate were determined. To investigate whether the variation in prevalence rates between the studies was more than could be attributed to chance alone, a test for homogeneity was carried out, which turned out to be statistically significant. The extra variation was incorporated into the analysis using a random effects model. Bivariate analyses were performed to explore whether the study period (before 1990, 1990-1999, 2000 and later), location of the study (continent of origin), average age of the population ( $<65$ years, $\geq 65$ years), type of prevalence (point, week, month) and type of cancer were associated with the outcome. All the analyses were performed using STATA SE 8 (meta, metareg). 
Table 2.1 Quality criteria for prevalence studies.

A. The final sample should be representative of the target population

B. Quality of Data

C. General description of the method and results should include: definitions of pain prevalence
1. At least one of the following should apply for the study: an entire target population, randomly selected sample, or sample stated to represent the target population (2 points).

2. At least one of the following: reasons for nonresponse described, non-responders described, comparison of responders and non-responders, or comparison of sample and target population (2 points).

3. Response rate $\geq 90 \%$ ( 2 points). Response rate $70-90 \%$ (1 point). Response rate $<70 \%$ (0 point).

4. Were the data primary from a prevalence study (2 points) or was it taken from a survey not specifically designed for that purpose (1 point)?

5. The same mode of data collection should be used for all subjects ( 2 points) if not ( 1 point).

6. The data have been collected directly from the patient by means of a validated questionnaire/interview (3 points).

No validated questionnaire/interview (2 points).

Data have been collected from proxies or retrospectively from medical record (1 point).

7. Description of the target population and setting where patients were found (2 points).

8. Description of stage of disease, type of cancer, sex, age. All: 2 points, 2 or 3: 1 point.

9. Final sample size (1 point).

10. Prevalence recall periods should be stated (1 point).

\section{Results}

\section{Selected articles}

Based on the keywords, we found 4737 articles. After removing double hits, the abstracts were screened for figures on the prevalence of cancer pain and the inclusion and exclusion criteria were applied. This left 356 articles, of which another 196 had to be excluded. Reasons for exclusion were: no study had been performed $(n=36)$, no pain prevalence was mentioned $(n=68)$, all the patients had pain $(n=45)$, the pain prevalence was indistinguishable between cancer and non-cancer patients $(n=21)$, a secondary analysis had been conducted on combined articles $(n=3)$, the publication comprised an overview 
article $(n=14)$, the same population had been reported on twice $(n=5)$, other $(n=4)$.

The quality score of $34 \%(n=54)$ of the remaining 160 articles was 14 points or more (Figure 2.1). A combination of shortcomings in representativeness and data collection method (the two criteria with the heaviest weighting) was the main reason for not reaching the required score of 14 points: response rate of less than $70 \%$, response rate not mentioned, data retrieved from medical records prospectively, or retrospectively, lack of description of the nonresponders, sample not representative and/or data collected by proxy or from medical record. A more detailed description of the excluded articles is given in the appendix. All included studies were published in English.

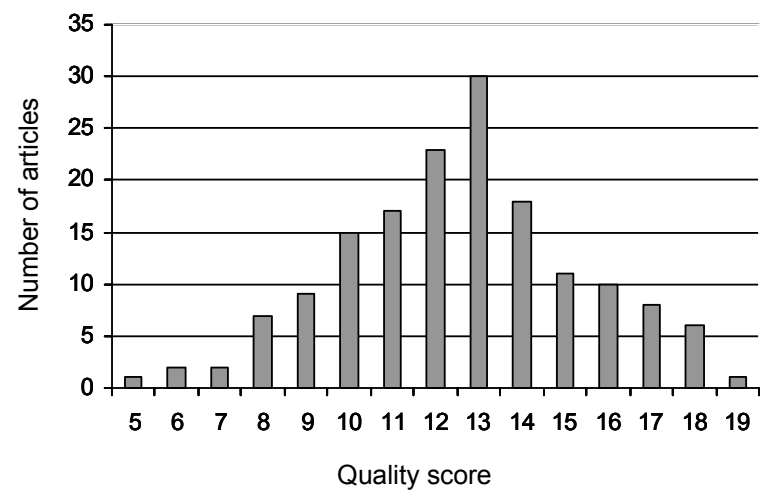

Figure 2.1 Distribution of the methodological quality scores.

\section{General characteristics}

General characteristics of the 54 articles are listed in Table 2.2. In 46 studies, (part of) the aim of the study had been to determine the prevalence of pain in cancer patients. This had not been a primary goal in the other eight studies. $^{11,13,38-44}$ One study looked at unmet needs, one described the experiences of a palliative care program, two compared usual care with intensive care, one was on the influence of demographic and disease specific variables on pain and one compared differences in symptoms between cancer and non-cancer patients. 


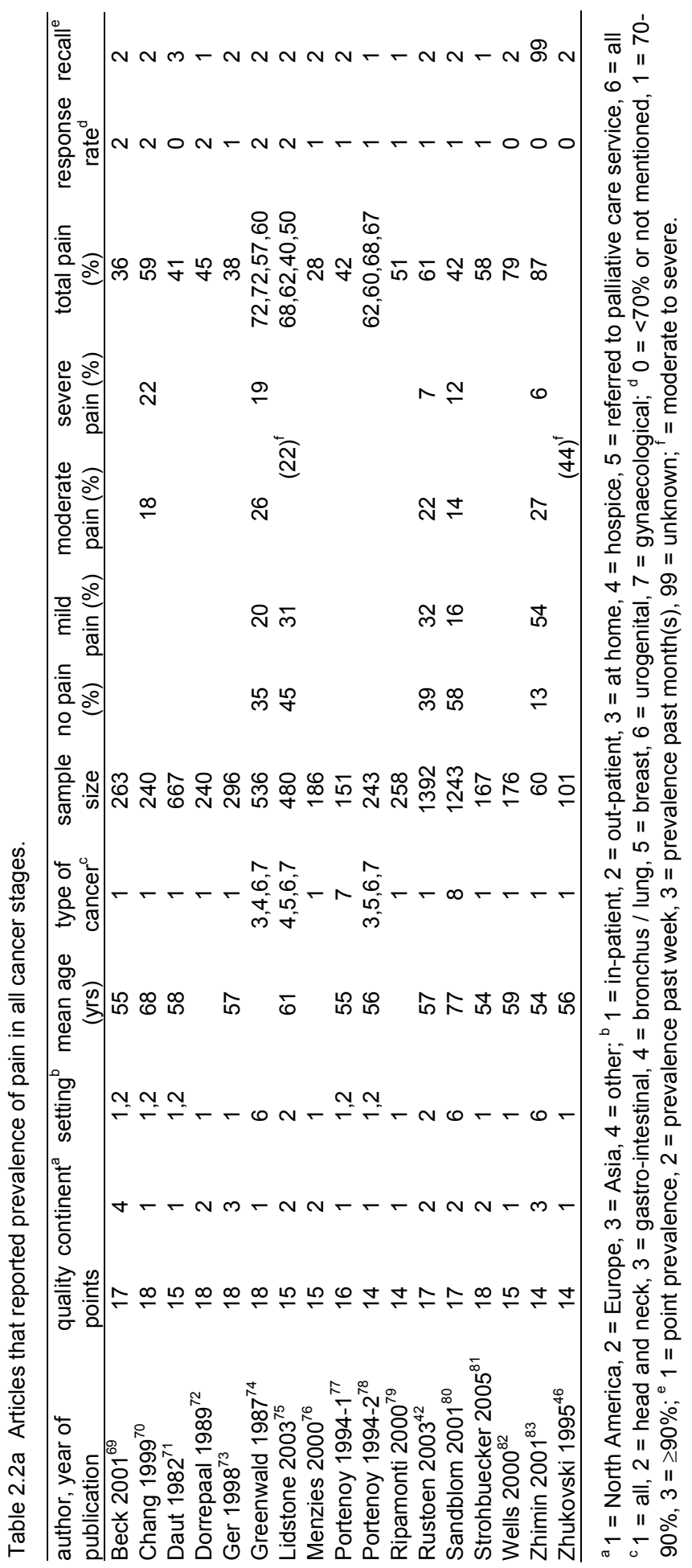



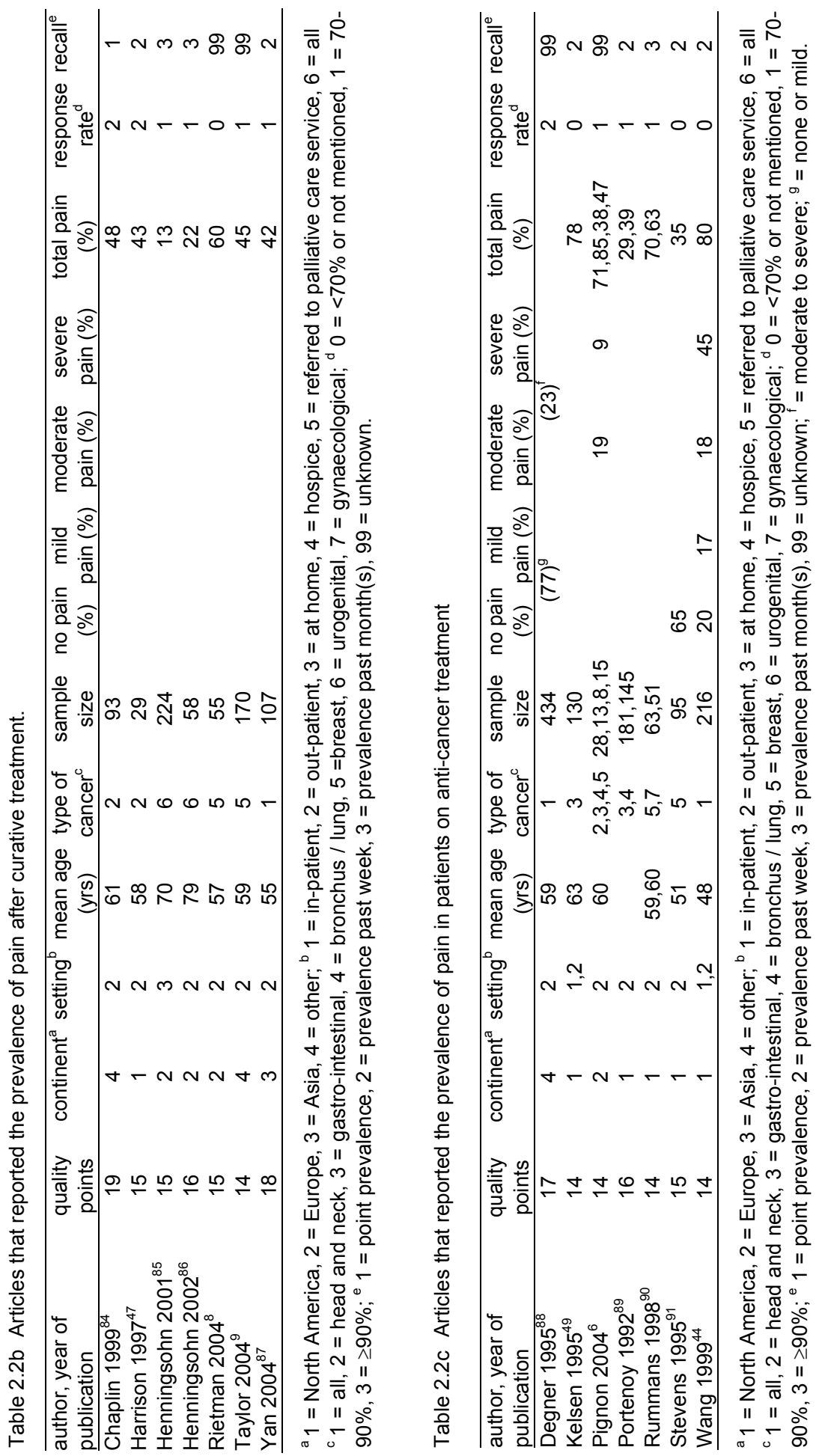


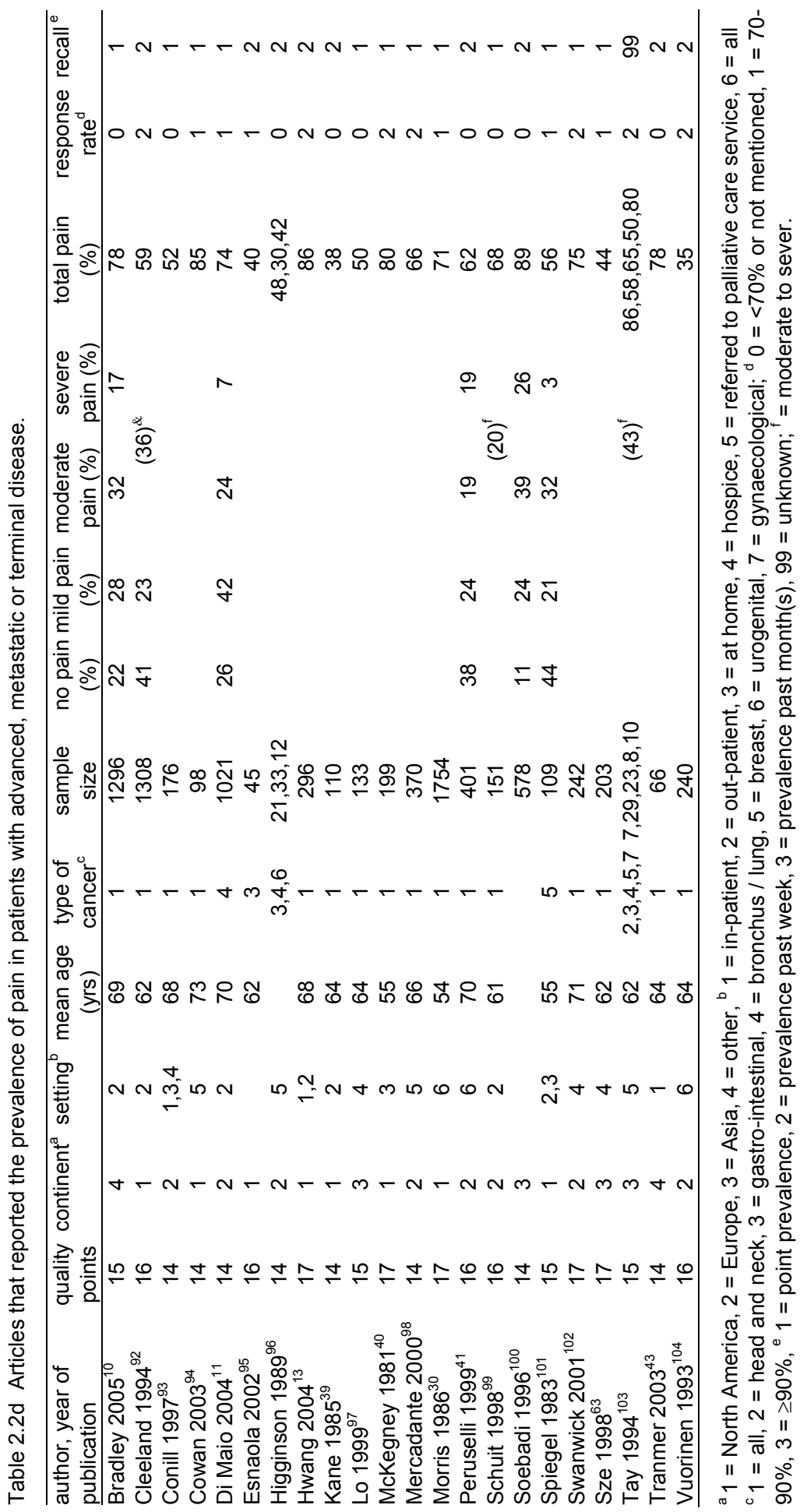




\section{Prevalence of pain}

A total of 54 articles reached the cut-off level of 14 points, but two articles ${ }^{45,46}$ reported the prevalence of moderate to severe pain alone and were therefore excluded from the meta-analyses.

The results of the stratified meta-analyses on the prevalence of pain, yes or no, in the 4 patient groups are presented in Figure 2.2.
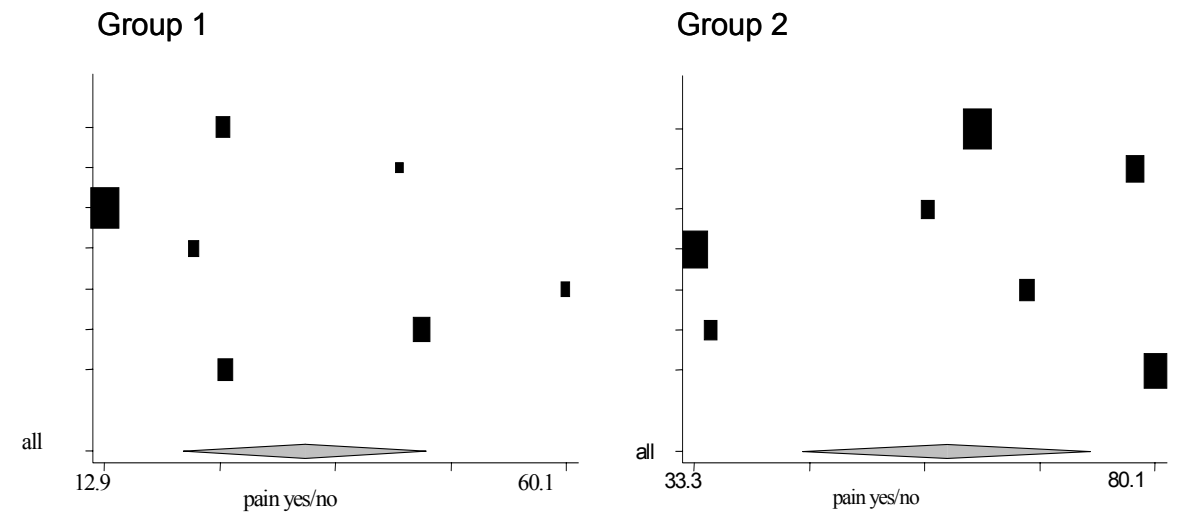

\section{Group 3}

\section{Group 4}
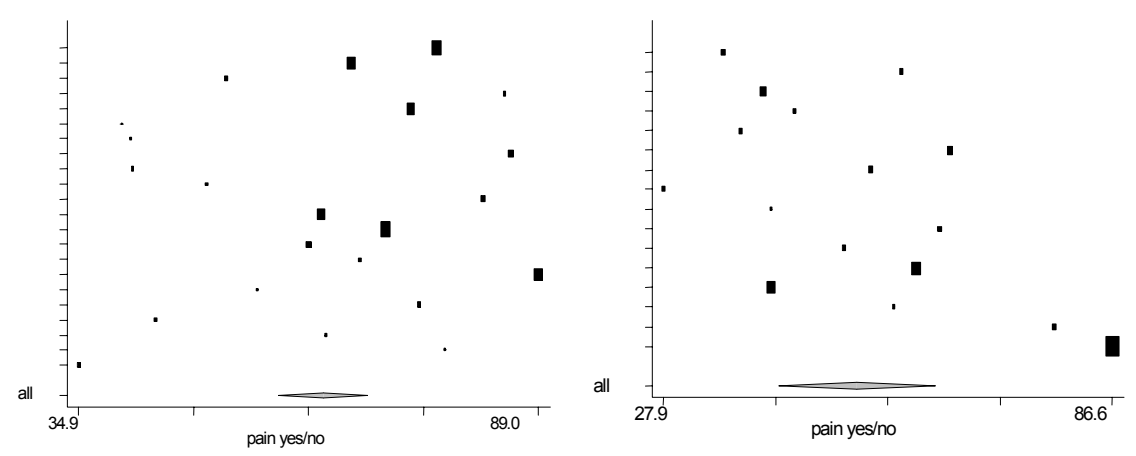

Figure 2.2 The prevalence of pain per disease group ${ }^{a}$.

Forest plots $^{b}$ indicating the number of studies included, the number of patients per study, the prevalence rate of pain per study and the overall prevalence found in the meta-analyses (diamond).

${ }^{a}$ group 1 = patients after curative treatment, group 2 = patients during anti-cancer treatment, group $3=$ patients with advanced, metastatic or terminal disease and group $4=$ all disease stages

${ }^{b}$ The number of boxes indicates the number of studies included. The area of the boxes indicates the number of patients in this study. The diamonds at the bottom show the results of the meta-analyses with the $95 \%$ confidence intervals 
In group 1, seven studies included patients after curative treatment $(n=726)$, in group 2, seven studies included patients on anti-cancer treatment $(n=1408)$, in group 3, 22 studies included patients with advanced, metastatic or terminal disease $(n=9763)$ and in group 4, 16 studies included cancer patients with all stages $(n=8088)$. The prevalence rates of pain were $33 \%(95 \%$ confidence interval $(\mathrm{Cl}) 21-46 \%), 59 \%(\mathrm{Cl} 44-73 \%), 64 \%(\mathrm{Cl} 58-69 \%)$ and $53 \%(\mathrm{Cl} 43-$ $63 \%$ ), respectively.

Pooled prevalence of pain was significantly higher in groups 2, 3 and 4 than in group $1(p=0.004, p<0.004, p=0.009)$, respectively. No significant differences were found between patients on treatment and patients with advanced or metastatic disease $(p=0.51)$.

Assessment of pain severity was described in 17 studies. None of the articles in group 1 (patients after curative treatment) mentioned the severity of pain. One study ${ }^{47}$ reported moderate to severe distress in $89 \%$ of the patients because of pain.

In group 2, the severity of pain was measured in four studies: $36 \%$ of the patients $(n=743)$ rated their pain as moderate to severe (VAS $>4)$. In group 3 , the severity of pain was measured in six studies and the pain was rated as moderate to severe by $45 \%$ of the patients $(n=3405)$.

In group 4, the severity of pain was described in seven studies: $31 \%(n=5441)$ of the patients rated their pain as moderate to severe.

In the bivariate regression analyses, none of the covariates (type of cancer, period of publication, continent of origin, mean age of the study population, type of prevalence, use of validated or non-validated questionnaires or interviews) were significantly associated with the pain prevalence rates.

\section{Type of cancer}

A total of 36 data-sets (11 studies) were made of pain prevalence in six specific types of cancer (Table 2.3). Prevalence rates in groups 2-4 were pooled (3300 patients). In all the cancer types, prevalence of pain was more than $50 \%$; the highest prevalence was found in the head and neck cancer patients $(70 \%)$. Bivariate regression analysis did not reveal any significant associations between the pain prevalence rate and type of cancer. 
Table 2.3 Results of the meta-analyses: pooled pain prevalence in 6 types of cancer (cured patients were excluded).

\begin{tabular}{|c|c|c|c|}
\hline \multirow[b]{2}{*}{ Type of cancer } & \multicolumn{3}{|c|}{ Groups 2-4 } \\
\hline & $\%$ pain $(95 \% \mathrm{Cl})^{\mathrm{a}}$ & $\mathrm{N}^{\mathrm{b}}$ & no. of patients \\
\hline Head/neck & $70 \%(51-88)$ & 3 & 95 \\
\hline Gastro-intestinal & $59 \%(44-74)$ & 9 & 564 \\
\hline Lung/bronchus & $55 \%(44-67)$ & 7 & 1546 \\
\hline Breast & $54 \%(44-64)$ & 7 & 420 \\
\hline Urogenital & $52 \%(40-60)$ & 4 & 336 \\
\hline Gynaecological & $60 \%(50-71)$ & 6 & 372 \\
\hline
\end{tabular}

${ }^{\mathrm{a}} \mathrm{Cl}=$ confidence interval; ${ }^{\mathrm{b}} \mathrm{N}=$ number of reports

\section{Discussion}

This systematic review on prevalence of pain in cancer patients was the first to pool only articles that met the quality criteria formulated specifically to review prevalence studies.

A total of 54 articles met the predefined quality standards and the data from 52 could be pooled. Pain prevalence in patients with cancer was high: $64 \%(\mathrm{Cl}$ $58-69 \%)$ in patients with metastatic, advanced or terminal disease, $59 \%(\mathrm{Cl}$ $44-73 \%)$ in patients on anti-cancer treatment and $33 \%(\mathrm{Cl} 21-46 \%)$ in patients who had been cured of cancer.

Pain prevalence in patients with advanced/metastatic disease was lower $(64 \%)$ than that previously reported. ${ }^{23,24,33,48}$ The higher prevalence rates $(71-74 \%)$ found in earlier reviews ${ }^{23,24}$ were probably due to the inclusion of studies on data obtained by proxy. Ratings of pain control given by the family were significantly poorer than those given by the patients ${ }^{29,30}: 75 \%$ of the care providers overestimated the patient's pain intensity by an average of $35 \mathrm{~mm}$ $(11-97 \mathrm{~mm})$ on a $100 \mathrm{~mm}$ scale. ${ }^{31}$

The prevalence of pain found in studies including patients with all stages was higher than previously reported. ${ }^{24}$ This result has to be interpreted with caution: There may have been too much difference in the condition of the patients included in these studies to allow pooling of the data.

The prevalence of pain in patients during anti-cancer treatment and in patients after finishing curative anti-cancer treatment was not earlier published in a review. The prevalence of pain in patients during anti-cancer treatment (59\%) was not significantly different from that in patients with advanced/metastatic disease $(64 \%)$. It is likely that there was considerable overlap in the condition of the patients in these two groups, because only two studies ${ }^{6,49}$ on anti-cancer treatment patients included patients on curative/radical treatment alone. The other studies included more patients who were on palliative treatment than on curative treatment, so patients with and without metastases were combined. 
A total of eighteen studies reported, at least some, information about pain severity. More than one third of the patients with pain rated their pain as moderate to severe (VAS>4). Although distinction between the presence or absence of pain in a population will enable the calculation of pain prevalence, it cannot provide information about the severity, duration, frequency or amount of interference. To facilitate the comparison of studies and coordinate the planning of needs from pain services, multi-dimensional tools should be used in research. Most patients will accept mild pain, whereas moderate and severe pain will require attention. ${ }^{35}$

In our meta analyses, the variation in prevalence rates between the studies was more than could be attributed to chance alone. The hypothesis was that factors like type of cancer studied, study period, continent of origin, mean age of the study population, type of prevalence or the use of validated or nonvalidated questionnaires would be associated with the prevalence of cancer pain. No significant relationship was found between pain prevalence and type of cancer. However, we used fairly broad categories, due to the limited number of studies. For example, the gastro-intestinal cancer group included colon, oesophagus, and pancreas tumours, while the urogenital cancer group included prostate and bladder cancer. Although many books refer to malignancies with a high risk of pain (bone, pancreas, oesophagus) or a low risk of pain (lymphoma, leukaemia, soft tissue) ${ }^{50} 51$ it is not clear which studies provided arguments for these statements.

Contrary to our expectations, period of publication and/or continent of origin were not responsible for the heterogeneity. There has been growing attention to pain and pain management over the past fifty years and our knowledge is increasing. The gap between what is possible in pain control and what is achieved is caused by many different patient centred, care provider centred and government centred factors. Fear of medication in general and opioids in particular, patients wanting to be "good" patients, lack of knowledge, lack of interest and requests from care providers, are well-known barriers against adequate pain control. ${ }^{26,52-60}$

Since 1984, the global consumption of morphine has more than tripled. ${ }^{61}$ Although an increase in opioid consumption in cancer patients is considered to reflect an increased awareness towards pain treatment ${ }^{62}$, the effect on the prevalence of pain is yet unknown. Unfortunately, from this systematic review, it did not become clear either, whether the increased opioid consumption is associated with the prevalence of pain. Studies conducted in the ten countries responsible for $90 \%$ of the increase showed the same prevalence rates as studies from Africa and Asia where the availability of essential drugs for medical purposes is insufficient. However, the Asian studies were probably non-representative of the continent due to the adequate use of the WHO ladder 
at the special palliative care units..$^{63}$ Only one study that was included in the meta analyses originated from Africa.

Age is another study characteristic that might explain the heterogeneity. However, it is not necessarily associated with a larger number of symptoms in patients with cancer ${ }^{64}$ and the literature on age and cancer pain is scarce and conflicting. In this review, no differences were found in prevalence of pain between elderly and younger patients. Less pain was reported by 903 cancer patients in the SUPPORT study ${ }^{65}$ on 3571 older subjects. The adjusted odds ratio for higher levels of pain was 0.85 per increasing decade of age. Compared to the age group 65-74 years in a retrospective study on 13625 elderly cancer patients, ${ }^{66}$ the odds ratios in the age group 75-84 years and the age group $\geq 85$ years were 0.68 and 0.52 , respectively. In contrast, other studies found a relation between more advanced age and undermedication. ${ }^{26,66}$ Type of prevalence (point, week or month) did not influence the prevalence of pain. The difference between a period prevalence and a point prevalence is the number of new cases that occur within the defined period. ${ }^{67}$ Although cancer pain can fluctuate in severity, it does not tend to disappear for a few weeks or even months, in contrast with headaches for example that occur more episodically.

The use of validated or non-validated questionnaires or interviews did not appear to be responsible for the heterogeneity in prevalence rates. This implies that in daily practice, simply asking "the pain question" without the use of extensive and time-consuming questionnaires will detect any patients with pain. Symptom detection relies on three types of data collection method: documented, elicited and volunteered. ${ }^{68}$ All the studies included in our metaanalyses used questionnaires or interviews. Pain questionnaires may amplify true morbidity due to over-endorsement bias, i.e. the tendency for patients to answer questions concerning symptoms written on a checklist in a particularly enthusiastic manner. ${ }^{68}$ Nevertheless the results of questionnaires are probably more reliable than those of documented symptoms, because $57-76 \%$ of medical oncologists do not ask about pain. ${ }^{26}$ In addition, pain was only mentioned in $10 \%$ of the medical records kept by oncologists. ${ }^{26}$ Therefore, $^{2}$ reliance on data noted in medical records underestimates the prevalence and severity of pain. Also, volunteered symptoms will underestimate symptom prevalence, because of the patient barriers mentioned above.

Other explanations for the heterogeneity could be differences in patient characteristics caused by variation in the selection processes between the studies, or the absence or ill-defined description of the pain severity or level that caused systematic discrepancies. Furthermore, differences in response rate might still have influenced the prevalence of pain. 
Our systematic review had some flaws. It should be taken into consideration that the instrument used to judge methodological quality (Table 2.1) was devised subjectively to review the prevalence of lower back pain. ${ }^{36,37}$ The $75 \%$ threshold for acceptability was set arbitrarily. ${ }^{36,37}$ To make the instrument suitable to review the prevalence of cancer pain, we substituted the criteria for the definition of lower back pain for the criteria on disease stage in cancer. These may be points for further improvement. Proxy reporting and retrospective studies on medical records probably deserve even less weighting. The adequate description of disease stage probably deserves more weighting, but subdivision of the use of validated or non-validated questionnaires does not seem to be necessary.

All included studies dealt with period prevalences and not with point prevalences. However, considering the long duration of the disease the difference of the two prevalence measures is small. Another limitation is that we did not know to what extent other pain conditions influenced the reported prevalence of pain.

Future studies on the prevalence of pain in cancer patients should take representativeness, response rates and the description of non-responders into full consideration and provide information on the severity, duration, frequency and amount of interference. The use of multi-dimensional tools in research will facilitate the comparison of studies and the planning of needs from pain services.

Studies on the prevalence of pain in cancer survivors are scarce. This topic should be addressed in future studies.

\section{Conclusion}

The pooled data from 52 articles showed that pain was prevalent in cancer patients: $64 \%$ in patients with metastatic or advanced stage disease, $59 \%$ in patients on anti-cancer treatment and $33 \%$ in patients after curative treatment. More than one third of the patients with pain in the reviewed articles graded their pain as moderate or severe. Despite the clear WHO recommendations, cancer pain still is a major problem. The increasing number of cancer survivors who live to an advanced age means that it is of paramount importance to reduce the prevalence of pain at all stages of the disease process. 


\section{Appendix}

Reasons for not reaching the quality score of 14 points

Response rate of less than $70 \%,{ }^{14,105-114}$

Response rate not mentioned, ${ }^{1,12,66,115-135}$

Data retrieved from medical records prospectively, ${ }^{22,136-150}$

Data retrieved from medical records retrospectively, ${ }^{2-5,15,114,151-173}$

Lack of description of the non-responders, ${ }^{1-4,7,12,14,15,22,41,52,66,105-109,112,113,115-}$ 129,132-149,151-192

Sample not representative $1,7,12,14,15,52,106,109-113,117,119,122,123,125,127,130,131,133-135,144-$ 146,148,151,153-155,158,165-168,171,175,177,179-182,184,188,189,192-194

Data collected by proxy or from medical record. ${ }^{1-5,15,66,105,108,118,120,129,136,137,139-}$ $142,145,147,148,151,152,154,155,157-168,171,172,174,178,185,187,191,194-197$ 


\section{References}

1. Aitken-Swan J. Nursing the late cancer patient at home; the family's impressions. Practitioner. 1959;183:64-9.

2. Sung JL, Wang TH, Yu JY. Clinical study on primary carcinoma of the liver in Taiwan. Am J Dig Dis. 1967;12:1036-49.

3. Lempinen M. Carcinoma of the stomach. I. Diagnostic considerations. Ann Chir Gynaecol Fenn. 1971;60:135-40.

4. Ross AP, Braasch JW, Warren KW. Carcinoma of the proximal bile ducts. Surg Gynecol Obstet. 1973;136:923-8.

5. Twycross RG. The terminal care of patients with lung cancer. Postgrad Med J. 1973;49: 732-7.

6. Pignon T, Fernandez L, Ayasso S, Durand MA, Badinand D, Cowen D. Impact of radiation oncology practice on pain: a cross-sectional survey. Int J Radiat Oncol Biol Phys. 2004;60:1204-10.

7. Puts MT, Versloot J, Muller MJ, van Dam FS. [The opinion on care of patients with cancer undergoing palliative treatment in day care]. Ned Tijdschr Geneeskd. 2004;148:277-80.

8. Rietman J, Dijkstra P, Debreczeni R, Geertzen J, Robinson D, De Vries J. Impairments, disabilities and health related quality of life after treatment for breast cancer: a follow-up study 2.7 years after surgery. Disabil Rehabil. 2004;26:78-84.

9. Taylor KO. Morbidity associated with axillary surgery for breast cancer. ANZ J Surg. 2004;74: 314-7.

10. Bradley N, Davis L, Chow E. Symptom distress in patients attending an outpatient palliative radiotherapy clinic. J Pain Symptom Manage. 2005;30:123-31.

11. Di Maio M, Gridelli C, Gallo C, Manzione L, Brancaccio L, Barbera S, Robbiati SF, lanniello GP, Ferrau F, Piazza E, Frontini L, Rosetti F, Carrozza F, Bearz A, Spatafora M, Adamo V, Isa L, laffaioli RV, Di Salvo E, Perrone F. Prevalence and management of pain in Italian patients with advanced non-small-cell lung cancer. Br J Cancer. 2004;90:2288-96.

12. Wilson KG, Graham ID, Viola RA, Chater S, de Faye BJ, Weaver LA, Lachance LA. Structured interview assessment of symptoms and concerns in palliative care. Can J Psychiatry. 2004;49:350-8.

13. Hwang SS, Chang VT, Cogswell J, Alejandro Y, Osenenko P, Morales E, Srinivas S, Kasimis Study of unmet needs in symptomatic veterans with advanced cancer: incidence, independent predictors and unmet needs outcome model. J Pain Symptom Manage. 2004;28:421-32.

14. Stromgren AS, Groenvold M, Petersen MA, Goldschmidt D, Pedersen L, Spile M, IrmingPedersen G, Sjogren P. Pain characteristics and treatment outcome for advanced cancer patients during the first week of specialized palliative care. J Pain Symptom Manage. 2004;27:104-13.

15. Lin MH, Wu PY, Tsai ST, Lin CL, Chen TW, Hwang SJ. Hospice palliative care for patients with hepatocellular carcinoma in Taiwan. Palliat Med. 2004;18:93-9.

16. WHO. (World Health Orgensation). Cancer Pain Relief. 198.

17. Ventafridda VO, E. Caraceni, A. A retrospective study on the use of oral morphine in cancer pain. J Pain Symptom Manage. 1987;2:77-82.

18. Walker VA, Hoskin PJ, Hanks GW, White ID. Evaluation of WHO analgesic guidelines for cancer pain in a hospital-based palliative care unit. J Pain Symptom Manage. 1988;3:145-9.

19. Goisis A, Gorini M, Ratti R, Luliri P. Application of a WHO protocol on medical therapy for oncologic pain in an internal medicine hospital. Tumori. 1989;75:470-2. 
20. Caraceni A, Martini C, Zecca E, Portenoy RK, Ashby MA, Hawson G, Jackson KA, Lickiss N, Muirden N, Pisasale M, Moulin D, Schulz VN, Rico Pazo MA, Serrano JA, Andersen H, Henriksen HT, Mejholm I, Sjogren P, Heiskanen T, Kalso E, Pere P, Poyhia R, Vuorinen E, Tigerstedt I, Ruismaki P, Bertolino M, Larue F, Ranchere JY, Hege-Scheuing G, Bowdler I, Helbing F, Kostner E, Radbruch L, Kastrinaki K, Shah S, Vijayaram S, Sharma KS, Devi PS, Jain PN, Ramamani PV, Beny A, Brunelli C, Maltoni M, Mercadante S, Plancarte R, Schug S, Engstrand P, Ovalle AF, Wang X, Alves MF, Abrunhosa MR, Sun WZ, Zhang L, Gazizov A, Vaisman M, Rudoy S, Gomez Sancho M, Vila P, Trelis J, Chaudakshetrin P, Koh ML, Van Dongen RT, Vielvoye-Kerkmeer A, Boswell MV, Elliott T, Hargus E, Lutz L; Working Group of an IASP Task Force on Cancer Pain. Breakthrough pain characteristics and syndromes in patients with cancer pain. An international survey. Palliat Med. 2004;18:177-83.

21. Zech DF, Grond S, Lynch J, Hertel D, Lehmann KA. Validation of World Health Organization Guidelines for cancer pain relief: a 10-year prospective study. Pain. 1995;63:65-76.

22. Mercadante S. Pain treatment and outcomes for patients with advanced cancer who receive follow-up care at home. Cancer. 1999;85:1849-58.

23. Bonica JJ. Treatment of cancer pain: Current status and future needs. In: F FHLDRC, ed. Advances in Pain Research and Therapy. Vol. 9. New York: Raven Press; 1985:589-616.

24. Hearn JH, I. Cancer pain epidemiology: a systematic review. In: Bruera EP, R., ed. Cancer Pain. Cambridge: Cambridge University Press; 2003:19-37.

25. Egger M. Systematic Reviews. 2nd ed London: BMJ Publishing Group; 2001.

26. Von Roenn JH, Cleeland CS, Gonin R, Hatfield AK, Pandya KJ. Physician attitudes and practice in cancer pain management. A survey from the Eastern Cooperative Oncology Group. Ann Intern Med. 1993;119:121-6.

27. Nekolaichuk CL, Bruera E, Spachynski K, MacEachern T, Hanson J, Maguire TO. A comparison of patient and proxy symptom assessments in advanced cancer patients. Palliat Med. 1999;13:311-23.

28. Grossman SA, Sheidler VR, Swedeen K, Mucenski J, Piantadosi S. Correlation of patient and caregiver ratings of cancer pain. J Pain Symptom Manage. 1991;6:53-7.

29. Higginson I, Wade A, McCarthy M. Palliative care: views of patients and their families. Bmj. 1990;301:277-81.

30. Morris JN, Mor V, Goldberg RJ, Sherwood S, Greer DS, Hiris J. The effect of treatment setting and patient characteristics on pain in terminal cancer patients: a report from the National Hospice Study. J Chronic Dis. 1986;39:27-35.

31. Miaskowski C, Zimmer EF, Barrett KM, Dibble SL, Wallhagen M. Differences in patients' and family caregivers' perceptions of the pain experience influence patient and caregiver outcomes. Pain. 1997;72:217-26.

32. Klinkenberg M, Smit JH, Deeg DJ, Willems DL, Onwuteaka-Philipsen BD, van der Wal G. Proxy reporting in after-death interviews: the use of proxy respondents in retrospective assessment of chronic diseases and symptom burden in the terminal phase of life. Palliat Med. 2003;17:191-201.

33. Goudas LC, Bloch R, Gialeli-Goudas M, Lau J, Carr DB. The epidemiology of cancer pain. Cancer Invest. 2005;23:182-90.

34. Potter J, Hami F, Bryan T, Quigley C. Symptoms in 400 patients referred to palliative care services: prevalence and patterns. Palliat Med. 2003;17:310-4.

35. Serlin RC, Mendoza TR, Nakamura Y, Edwards KR, Cleeland CS. When is cancer pain mild, moderate or severe? Grading pain severity by its interference with function. Pain. 1995;61: 277-84.

36. Leboeuf-Yde C, Lauritsen JM. The prevalence of low back pain in the literature. A structured review of 26 Nordic studies from 1954 to 1993. Spine. 1995;20:2112-8.

37. Walker BF. The prevalence of Low Back Pain: A Systmatic Review of the Literature from 1966 to 1998. Journal of Spinal Disorders. 2000;13:205-17.

38. Cowan JD, Walsh D, Homsi J. Palliative medicine in a United States cancer center: a prospective study. Am J Hosp Palliat Care. 2002;19:240-50.

39. Kane RL, Berstein L, Wales J, Rothenberg R. Hospice effectiveness in controlling pain. JAMA. 1985;253:2683-6. 
40. McKegney FP, Bailey LR, Yates JW. Prediction and management of pain in patients with advanced cancer. Gen Hosp Psychiatry. 1981;3:95-101.

41. Peruselli C, Di Giulio P, Toscani F, Galluzzi M, Brunelli C, Costantini M, Tamburini M, Paci E, Miccinesi G, Addington-Hall JM, Higginson IJ. Home palliative care for terminal cancer patients: a survey on the final week of life. Palliat Med. 1999;13:233-41.

42. Rustoen T, Fossa SD, Skarstein J, Moum T. The impact of demographic and disease-specific variables on pain in cancer patients. J Pain Symptom Manage. 2003;26:696-704.

43. Tranmer JE, Heyland D, Dudgeon D, Groll D, Squires-Graham M, Coulson K. Measuring the symptom experience of seriously ill cancer and noncancer hospitalized patients near the end of life with the memorial symptom assessment scale. J Pain Symptom Manage. 2003;25: 420-9.

44. Wang XS, Cleeland CS, Mendoza TR, Engstrom MC, Liu S, Xu G, Hao X, Wang Y, Ren XS. The effects of pain severity on health-related quality of life: a study of Chinese cancer patients. Cancer. 1999;86:1848-55.

45. Cleeland CS, Mendoza TR, Wang XS, Chou C, Harle MT, Morrissey M, Engstrom MC. Assessing symptom distress in cancer patients: the M.D. Anderson Symptom Inventory. Cancer. 2000;89:1634-46.

46. Zhukovsky DS, Gorowski E, Hausdorff J, Napolitano B, Lesser M. Unmet analgesic needs in cancer patients. J Pain Symptom Manage. 1995;10:113-9.

47. Harrison LB, Zelefsky MJ, Pfister DG, Carper E, Raben A, Kraus DH, Strong EW, Rao A, Thaler $\mathrm{H}$, Polyak $\mathrm{T}$, Portenoy R. Detailed quality of life assessment in patients treated with primary radiotherapy for squamous cell cancer of the base of the tongue. Head Neck. 1997; 19:169-75.

48. Potter J, Higginson IJ. Pain experienced by lung cancer patients: a review of prevalence, causes and pathophysiology. Lung Cancer. 2004;43:247-57.

49. Kelsen DP, Portenoy RK, Thaler HT, Niedzwiecki C, Passik SD, Tao Y, Banks W, Brennan MF, Foley KM. Pain and depression in patients with newly diagnosed pancreas cancer. J Clin Oncol. 1995;13:748-55.

50. Woodruff RK. Cancerpain Victoria, Australia: Asperula Pty Ltd; 1997.

51. Graeff de A VEH, Besse T.C., Crul B.J.P., Krol R.J.A. Palliatieve zorg: richtlijnen vor de praktijk. Vol. 1 Utrecht: Vereniging va Integrale Kankercentra; 2006.

52. Ward SE, Goldberg N, Miller-McCauley V, Mueller C, Nolan A, Pawlik-Plank D, Robbins A, Stormoen D, Weismann DE. Patient-related barriers to management of cancer pain. Pain. 1993;52:319-24.

53. Glajchen M, Fitzmartin RD, Blum D, Swanton R. Psychosocial barriers to cancer pain relief. Cancer Pract. 1995;3:76-82.

54. Grossman SA. Undertreatment of cancer pain: barriers and remedies. Support Care Cancer. 1993;1:74-8.

55. Johnson DC, Kassner CT, Houser J, Kutner JS. Barriers to effective symptom management in hospice. J Pain Symptom Manage. 2005;29:69-79.

56. Lin CC. Barriers to the analgesic management of cancer pain: a comparison of attitudes of Taiwanese patients and their family caregivers. Pain. 2000;88:7-14.

57. Miaskowski C, Dodd MJ, West C. Lack of adherence with the analgesic regimen: a significant barrier to effective cancer pain management. J Clin Oncol. 2001;19:4275-9.

58. Ferrell BR, McCaffery M, Rhiner M. Pain and addiction: an urgent need for change in nursing education. J Pain Symptom Manage. 1992;7:117-24.

59. Paice JA, Toy C, Shott S. Barriers to cancer pain relief: fear of tolerance and addiction. J Pain Symptom Manage. 1998;16:1-9.

60. Pargeon KL, Hailey BJ. Barriers to effective cancer pain management: a review of the literature. J Pain Symptom Manage. 1999;18:358-68.

61. (World Health Organisation). Cancer Pain Relief: a guide to opioid availability. 1996. Report No.: www.medsch.wisc.edu/.

62. Jarlbaek L, Andersen M, Hallas J, Engholm G, Kragstrup J. Use of opioids in a Danish population-based cohort of cancer patients. J Pain Symptom Manage. 2005;29:336-43. 
63. Sze FK, Chung TK, Wong E, Lam KK, Lo R, Woo J. Pain in Chinese cancer patients under palliative care. Palliat Med. 1998;12:271-7.

64. Grond S, Zech D, Diefenbach C, Bischoff A. Prevalence and pattern of symptoms in patients with cancer pain: a prospective evaluation of 1635 cancer patients referred to a pain clinic. $J$ Pain Symptom Manage. 1994;9:372-82.

65. Desbiens NA, Wu AW, Broste SK, Wenger NS, Connors AF, Lynn J, Yasui Y, Pillips RS, Fulkerson W. Pain and satisfaction with pain control in seriously ill hospitalized adults: findings from the SUPPORT research investigations. For the SUPPORT investigators. Study to Understand Prognoses and Preferences for Outcomes and Risks of Treatmentm. Crit Care Med. 1996;24:1953-61.

66. Bernabei R, Gambassi G, Lapane K, Landi F, Gatsonis C, Dunlop R, Lipsitz L, Steel K, Mor V. Management of pain in elderly patients with cancer. SAGE Study Group. Systematic Assessment of Geriatric Drug Use via Epidemiology. Jama. 1998;279:1877-82.

67. Kleinbaum DG, Kupper, L.L., Morgensteen, H. Epidemiologic Research: principles and quantitative methods. 1 ed New York: von Nostrand Reinhold compagny; 1982.

68. Kroenke K. Studying symptoms: sampling and measurement issues. Ann Intern Med. 2001;134:844-53.

69. Beck SL, Falkson G. Prevalence and management of cancer pain in South Africa. Pain. 2001;94:75-84.

70. Chang VT, Hwang SS, Feuerman M, Kasimis BS. Symptom and quality of life survey of medical oncology patients at a veterans affairs medical center: a role for symptom assessment. Cancer. 2000;88:1175-83.

71. Daut RL, Cleeland CS. The prevalence and severity of pain in cancer. Cancer. 1982;50: 1913-8.

72. Dorrepaal KL, Aaronson NK, van Dam FS. Pain experience and pain management among hospitalized cancer patients. A clinical study. Cancer. 1989;63:593-8.

73. Ger LP, Ho ST, Wang JJ, Cherng CH. The prevalence and severity of cancer pain: a study of newly-diagnosed cancer patients in Taiwan. J Pain Symptom Manage. 1998;15:285-93.

74. Greenwald HP, Bonica JJ, Bergner M. The prevalence of pain in four cancers. Cancer. 1987;60:2563-9.

75. Lin CC, Lai YL, Ward SE. Effect of cancer pain on performance status, mood states, and level of hope among Taiwanese cancer patients. J Pain Symptom Manage. 2003;25:29-37.

76. Menzies K, Murray J, Wilcock A. Audit of cancer pain management in a cancer centre. Int J Palliat Nurs. 2000;6:443-7.

77. Portenoy RK, Kornblith AB, Wong G, Vlamis V, Lepore JM, Loseth DB, Hakes T, Foley KM, Hoskins WJ. Pain in ovarian cancer patients. Prevalence, characteristics, and associated symptoms. Cancer. 1994;74:907-15.

78. Portenoy RK, Thaler HT, Kornblith AB, Lepore JM, Friedlander-Klar H, Coyle N, Smart-Curley T, Kemeny N, Norton L, Hoskins W, et al. Symptom prevalence, characteristics and distress in a cancer population. Qual Life Res. 1994;3:183-9.

79. Ripamonti C, Zecca E, Brunelli C, Groff L, Caraceni A, Galeaxxi G, Martini C, Panzeri C, Saita L, Viggiano V, De Conno F. Pain experienced by patients hospitalized at the National Cancer Institute of Milan: research project "towards a pain-free hospital". Tumori. 2000;86:412-8.

80. Sandblom G, Carlsson P, Sigsjo P, Varenhorst E. Pain and health-related quality of life in a geographically defined population of men with prostate cancer. $\mathrm{Br} \mathrm{J}$ Cancer. 2001;85: 497-503.

81. Strohbuecker B, Mayer H, Evers G, Sabatowski R. Pain Prevalence in Hospitalized Patients in a German University Teaching Hospital. Journal of Pain and Symptom Management. 2005;29:498-506.

82. Wells N. Pain intensity and pain interference in hospitalized patients with cancer. Oncol Nurs Forum. 2000;27:985-91.

83. Zhimin L, Zhi L, Weihua Z, Yue M, Xiangxiang L, Dong Z, Zhiji C, Jiaqi C, Zhenghong R. National Survey on Prevalence of Cancer Pain. Chinese Medical Sciences Journal. 2001;16:175-8. 
84. Chaplin JM, Morton RP. A prospective, longitudinal study of pain in head and neck cancer patients. Head Neck. 1999;21:531-7.

85. Henningsohn L, Wijkstrom H, Dickman PW, Bergmark K, Steineck G. Distressful symptoms after radical cystectomy with urinary diversion for urinary bladder cancer: a Swedish population-based study. Eur Urol. 2001;40:151-62.

86. Henningsohn L, Wijkstrom H, Dickman PW, Bergmark K, Steineck G. Distressful symptoms after radical radiotherapy for urinary bladder cancer. Radiother Oncol. 2002;62:215-25.

87. Yan H, Sellick K. Quality of life of Chinese patients newly diagnosed with gastrointestinal cancer: a longitudinal study. Int J Nurs Stud. 2004;41:309-19.

88. Degner LF, Sloan JA. Symptom distress in newly diagnosed ambulatory cancer patients and as a predictor of survival in lung cancer. J Pain Symptom Manage. 1995;10:423-31.

89. Portenoy RK, Miransky J, Thaler HT, Hornung J, Bianchi C, Cibas-Kong I, Feldhamer E, Lewis F, Matamoros I, Sugar MZ, et al. Pain in ambulatory patients with lung or colon cancer. Prevalence, characteristics, and effect. Cancer. 1992;70:1616-24.

90. Rummans TA, Frost M, Suman VJ, Taylor M, Gendron T, Johnson R, Hartmann L, Dose AM, Evans RW. Quality of life and pain in patients with recurrent breast and gynecologic cancer. Psychosomatics. 1998;39:437-45.

91. Stevens PE, Dibble SL, Miaskowski C. Prevalence, characteristics, and impact of postmastectomy pain syndrome: an investigation of women's experiences. Pain. 1995;61: 61-8.

92. Cleeland CS, Gonin R, Hatfield AK, Edmonson JH, Blum RH, Stewart JA, Pandya KJ. Pain and its treatment in outpatients with metastatic cancer. N Engl J Med. 1994;330:592-6.

93. Conill C, Verger E, Henriquez I, Saiz N, Espier M, Lugo F, Garrigos A. Symptom prevalence in the last week of life. J Pain Symptom Manage. 1997;14:328-31.

94. Cowan JD, Burns D, Palmer TW, Scott J, Feeback E. A palliative medicine program in a community setting: 12 points from the first 12 months. Am J Hosp Palliat Care. 2003;20: 415-33.

95. Esnaola NF, Cantor SB, Johnson ML, Mirza AN, Miller AR, Curley SA, Crane CH, Cleeland CS, Janjan NA, Skibber JM. Pain and quality of life after treatment in patients with locally recurrent rectal cancer. J Clin Oncol. 2002;20:4361-7.

96. Higginson I, McCarthy M. Measuring symptoms in terminal cancer: are pain and dyspnoea controlled? J R Soc Med. 1989;82:264-7.

97. Lo RS, Ding A, Chung TK, Woo J. Prospective study of symptom control in 133 cases of palliative care inpatients in Shatin Hospital. Palliat Med. 1999;13:335-40.

98. Mercadante S, Casuccio A, Fulfaro F. The course of symptom frequency and intensity in advanced cancer patients followed at home. J Pain Symptom Manage. 2000;20:104-12.

99. Schuit KW, Sleijfer DT, Meijler WJ, Otter R, Schakenraad R, Bergh van den FC, Meyboom-de Jong B. Symptoms and functional status of patients with disseminated cancer visiting outpatient departments. J Pain Symptom Manage. 1998;16:290-7.

100. Soebadi RD, Tejawinata S. Indonesia: status of cancer pain and palliative care. J Pain Symptom Manage. 1996;12:112-5.

101. Spiegel D, Bloom JR. Pain in metastatic breast cancer. Cancer. 1983;52:341-5.

102. Swanwick M, Haworth M, Lennard RF. The prevalence of episodic pain in cancer: a survey of hospice patients on admission. Palliat Med. 2001;15:9-18.

103. Tay WK, Shaw RJ, Goh CR. A survey of symptoms in hospice patients in Singapore. Ann Acad Med Singapore. 1994;23:191-6.

104. Vuorinen E. Pain as an early symptom in cancer. Clin J Pain. 1993;9:272-8.

105. Edmonds $P$, Karlsen S, Khan S, Addington-Hall J. A comparison of the palliative care needs of patients dying from chronic respiratory diseases and lung cancer. Palliat Med. 2001;15:287-95.

106. Fitch M, Deane K, Howell D, Gray RE. Women's experiences with ovarian cancer: reflections on being diagnosed. Can Oncol Nurs J. 2002;12:152-68.

107. Goncalves JF, Alvarenga M, Silva A. The last forty-eight hours of life in a Portuguese palliative care unit: does it differ from elsewhere? J Palliat Med. 2003;6:895-900. 
108. Parkes CM. Home or hospital? Terminal care as seen by surviving spouses. J R Coll Gen Pract. 1978;28:19-30.

109. Sarna L. Women with lung cancer: impact on quality of life. Qual Life Res. 1993;2:13-22.

110. Sarna L, Brecht ML. Dimensions of symptom distress in women with advanced lung cancer: a factor analysis. Heart Lung. 1997;26:23-30.

111. Shannon MM, Ryan MA, D'Agostino N, Brescia FJ. Assessment of pain in advanced cancer patients. J Pain Symptom Manage. 1995;10:274-8.

112. Stromgren AS, Groenvold M, Pedersen L, Olsen AK, Spile M, Sjogren P. Does the medical record cover the symptoms experienced by cancer patients receiving palliative care? A comparison of the record and patient self-rating. J Pain Symptom Manage. 2001;21:189-96.

113. Stromgren AS, Goldschmidt D, Groenvold M, Olsen AK, Sjogren P. Self-assessment in cancer patients referred to palliative care: a study of feasibility and symptom epidemiology. Cancer. 2002;94:512-20.

114. Bucher JA, Trostle GB, Moore M. Family reports of cancer pain, pain relief, and prescription access. Cancer Pract. 1999;7:71-7.

115. Ahles TA, Ruckdeschel JC, Blanchard EB. Cancer-related pain--I. Prevalence in an outpatient setting as a function of stage of disease and type of cancer. J Psychosom Res. 1984;28:115-9.

116. Bercovitch M, Waller A, Adunsky A. Pain and symptom management. Multidimensional continuous pain assessment chart (MCPAC) for terminal cancer patients: a preliminary report. American Journal of Hospice and Palliative Care. 2002;19:419-25.

117. Chen ML, Chang HK, Yeh $\mathrm{CH}$. Anxiety and depression in Taiwanese cancer patients with and without pain. J Adv Nurs. 2000;32:944-51.

118. Chiu TY, Hu WY, Chen CY. Prevalence and severity of symptoms in terminal cancer patients: a study in Taiwan. Support Care Cancer. 2000;8:311-3.

119. Chung JW, Yang JC, Wong TK. The significance of pain among Chinese patients with cancer in Hong Kong. Acta Anaesthesiol Sin. 1999;37:9-14.

120. Curtis EB, Krech R, Walsh TD. Common symptoms in patients with advanced cancer. J Palliat Care. 1991;7:25-9.

121. Ellershaw JE, Peat SJ, Boys LC. Assessing the effectiveness of a hospital palliative care team. Palliat Med. 1995;9:145-52.

122. Epstein JB, Stewart KH. Radiation therapy and pain in patients with head and neck cancer. Eur J Cancer B Oral Oncol. 1993;29B:191-9.

123. Gift AG, Stommel M, Jablonski A, Given W. A cluster of symptoms over time in patients with lung cancer. Nurs Res. 2003;52:393-400.

124. Given CW, Given B, Azzouz F, Kozachik S, Stommel M. Predictors of pain and fatigue in the year following diagnosis among elderly cancer patients. J Pain Symptom Manage. 2001; 21:456-66.

125. Hyun MS, Lee JL, Lee KH, Shin SO, Kwon KY, Song HS, Kim OB, Sohn SK, Lee KB, Rhu HM, Park GW, Shin DG. Pain and its treatment in patients with cancer in Korea. Oncology. 2003;64:237-44.

126. McMurray MB, Warren MR. Evaluation of a new hospice: the relief of symptoms in cancer patients in the first year. Palliat Med. 1989;3:135-40.

127. Miaskowski C, Dibble SL. The problem of pain in outpatients with breast cancer. Oncol Nurs Forum. 1995;22:791-7.

128. Morita T, Tsunoda J, Inoue S, Chihara S. Contributing factors to physical symptoms in terminally-ill cancer patients. J Pain Symptom Manage. 1999;18:338-46.

129. Pannuti ER, A.P. Marraro, D. Natural history of cancer pain. In: Twycross RGV, V., ed. The Continuing Care of Terminal Cancer Patients. New York: Pergamon; 1980:75-89.

130. Peruselli C, Camporesi E, Colombo AM, Cucci M, Mazzoni G, Paci E. Quality-of-life assessment in a home care program for advanced cancer patients: a study using the Symptom Distress Scale. J Pain Symptom Manage. 1993;8:306-11.

131. Saxena A, Gnanasekaran N, Andley M. An epidemiological study of prevalence of pain in head \& neck cancers. Indian J Med Res. 1995;102:28-33. 
132. Sebastian P, Varghese C, Sankaranarayanan R, Zaina CP, Nirmala G, Jeevy G, Nair MK. Evaluation of symptomatology in planning palliative care. Palliat Med. 1993;7:27-34.

133. Trotter JM, Scott R, Macbeth FR, McVie JG, Calman KC. Problems of the oncology outpatient: role of the liaison health visitor. Br Med J (Clin Res Ed). 1981;282:122-4.

134. Yu S, Wang XS, Cheng Y, Yang J, Cleeland CS. Special aspects of cancer pain management in a Chinese general hospital. Eur J Pain. 2001;5 Suppl A:15-20.

135. Yun YH, Heo DS, Lee IG, Jeong HS, Kim HJ, Kim SY, KimYH, Ro YJ, Yoon SS, Lee KH, Huh BY. Multicenter study of pain and its management in patients with advanced cancer in Korea. J Pain Symptom Manage. 2003;25:430-7.

136. Brescia F, Adler D, Gray G, Anwar R, Mamtani R, Cimino J. The advanced cancer patient--a clinical profile. Prog Clin Biol Res. 1988;278:137-46.

137. Brescia FJ, Portenoy RK, Ryan M, Krasnoff L, Gray G. Pain, opioid use, and survival in hospitalized patients with advanced cancer. J Clin Oncol. 1992;10:149-55.

138. Donnelly S, Walsh D. The symptoms of advanced cancer. Semin Oncol. 1995;22(2 Suppl 3):67-72.

139. Higginson IJ, Hearn J. A multicenter evaluation of cancer pain control by palliative care teams. J Pain Symptom Manage. 1997;14:29-35.

140. Krech RL, Davis J. Walsh D, Curtis EB. Symptoms of lung cancer. Palliat Med. 1992;6:30915.

141. Krech RL, Walsh D. Symptoms of pancreatic cancer. J Pain Symptom Manage. 1991;6: 360-7.

142. Kutner JS, Kassner CT, Nowels DE. Symptom burden at the end of life: hospice providers' perceptions. J Pain Symptom Manage. 2001;21:473-80.

143. McMillan SC. Pain and pain relief experienced by hospice patients with cancer. Cancer Nurs. 1996;19:298-307.

144. Morton RP. Studies in the quality of life of head and neck cancer patients: results of a twoyear longitudinal study and a comparative cross-sectional cross-cultural survey. Laryngoscope. 2003;113:1091-103.

145. Parvin S, Firouz S. A study of 415 cases of esophageal carcinoma in northwest of Iran. Med J Malaysia. 2003;58:429-31.

146. Reuben DB, Mor V, Hiris J. Clinical symptoms and length of survival in patients with terminal cancer. Arch Intern Med. 1988;148:1586-91.

147. Stromgren AS, Groenvold M, Pedersen L, Olsen AK, Sjogren P. Symptomatology of cancer patients in palliative care: content validation of self-assessment questionnaires against medical records. Eur J Cancer. 2002;38:788-94.

148. Turner K, Chye R, Aggarwal G, Philip J, Skeels A, Lickiss JN. Dignity in dying: a preliminary study of patients in the last three days of life. J Palliat Care. 1996;12:7-13.

149. Vainio A, Auvinen A. Prevalence of symptoms among patients with advanced cancer: an international collaborative study. Symptom Prevalence Group. J Pain Symptom Manage. 1996;12:3-10.

150. Walsh TD, West TS. Controlling symptoms in advanced cancer. Br Med J (Clin Res Ed). 1988;296:477-81.

151. Bassett ML, Bennett SA, Goulston KJ. Colorectal cancer. A study of 230 patients. Med J Aust. 1979;1:589-92.

152. Brescia FJ, Adler D, Gray G, Ryan MA, Cimino J, Mamtani R. Hospitalized advanced cancer patients: a profile. J Pain Symptom Manage. 1990;5:221-7.

153. Coyle N, Adelhardt J, Foley KM, Portenoy RK. Character of terminal illness in the advanced cancer patient: pain and other symptoms during the last four weeks of life. J Pain Symptom Manage. 1990;5:83-93.

154. DeMaria LC, Jr., Cohen HJ. Characteristics of lung cancer in elderly patients. J Gerontol. 1987;42:540-5.

155. de Souza LJ, Lobo ZM. Symptom control problems in an Indian hospice. Ann Acad Med Singapore. 1994;23:287-91.

156. Dobratz MC, Burns KM, Oden RV. Pain in home hospice patients: an exploratory descriptive study. Hosp J. 1989;5:117-33. 
157. Fainsinger R, Miller MJ, Bruera E, Hanson J, Maceachern T. Symptom control during the last week of life on a palliative care unit. J Palliat Care. 1991;7:5-11.

158. Furuta M, Hayakawa K, Saito Y, Nakayama Y, Katano S, Sakurai H, Takahashi T, Ohno T, Mitsuhashi N, Niibe $\mathrm{H}$. Clinical implication of symptoms in patients with non-small cell lung cancer treated with definitive radiation therapy. Lung Cancer. 1995;13:275-83.

159. Gupta RC, Purohit SD, Sharma MP, Bhardwaj S. Primary bronchogenic carcinoma: clinical profile of 279 cases from mid-west Rajasthan. Indian J Chest Dis Allied Sci. 1998;40:109-16.

160. Henteleff PD. Symptom prevalence and control during cancer patients' last days of life. $J$ Palliat Care. 1991;7:50-1.

161. Lichter I, Hunt E. The last 48 hours of life. J Palliat Care. 1990;6:7-15.

162. Martins SJ, Pereira JR. Clinical factors and prognosis in non-small cell lung cancer. Am J Clin Oncol. 1999;22:453-7.

163. Medina FM, Barrera RR, Morales JF, Echegoyen RC, Chavarria JG, Rebora FT. Primary lung cancer in Mexico city: a report of 1019 cases. Lung Cancer. 1996;14:185-93.

164. Najem AZ, Hennessey M, Malfitan RC, Cheung NK, Hobson RW. Colon and rectal carcinoma: clinical experience. Am Surg. 1977;43:583-8.

165. Olearchyk AS. Gastric carcinoma. A critical review of 243 cases. Am J Gastroenterol. 1978;70:25-45.

166. Oster MW, Vizel M, Turgeon LR. Pain of terminal cancer patients. Arch Intern Med. 1978;138:1801-2.

167. Pheils MT, Barnett JE, Newland RC, Macpherson JG. Colorectal carcinoma: a prospect clinicopathological study. Med J Aust. 1976;1(2 suppl):17-21.

168. Reid DS. Ovarian cancer at Kent General Hospital during the years 1975-1979. Del Med J. 1981;53:399-405.

169. Schonwetter RS, Robinson BE, Ramirez G. Prognostic factors for survival in terminal lung cancer patients. J Gen Intern Med. 1994;9:366-71.

170. Schutte HE. The influence of bone pain on the results of bone scans. Cancer. 1979;44: 2039-43.

171. Stein WM, Miech RP. Cancer pain in the elderly hospice patient. J Pain Symptom Manage. 1993;8:474-82.

172. Turnbull $F$. The nature of pain that may accompany cancer of the lung. Pain. 1979;7:371-5.

173. Wilkes E. Some problems in cancer management. Proc R Soc Med. 1974;67:1001-5.

174. Addington-Hall J, McCarthy M. Dying from cancer: results of a national population-based investigation. Palliative Medicine. 1995;9:295-305.

175. Ashbury FD, Findlay H, Reynolds B, McKerracher K. A Canadian survey of cancer patients' experiences: are their needs being met? J Pain Symptom Manage. 1998;16:298-306.

176. Carpenter RJ, 3rd, DeSanto LW, Devine KD, Taylor WF. Cancer of the hypopharynx. Analysis of treatment and results in 162 patients. Arch Otolaryngol. 1976;102:716-21.

177. Carpenter JS, Andrykowski MA, Sloan P, CunninghamL, Cordova MJ, Studts JL, McGrath PC, Sloan D, Kenady DE. Postmastectomy/postlumpectomy pain in breast cancer survivors. J Clin Epidemiol. 1998;51:1285-92.

178. Chan A, Woodruff RK. Palliative care in a general teaching hospital. 1. Assessment of needs. Med J Aust. 1991;155:597-9.

179. Cork RC, Saleemi S, Ibrahim I, Mansour R, Alexander L. A survey of the adequacy of pain management in end-stage cancer patients. J La State Med Soc. 2003;155:150-3.

180. Dudgeon DJ, Raubertas RF, Doerner K, O'Connor T, Tobin M, Rosenthal SN. When does palliative care begin? A needs assessment of cancer patients with recurrent disease. J Palliat Care. 1995;11:5-9.

181. Elliott TE, Murray DM, Oken MM, Johnson KM, Braun BL, Elliot BA, Post-Whit J. Improving cancer pain management in communities: main results from a randomized controlled trial. $J$ Pain Symptom Manage. 1997;13:191-203.

182. Hopwood P, Stephens RJ. Symptoms at presentation for treatment in patients with lung cancer: implications for the evaluation of palliative treatment. The Medical Research Council (MRC) Lung Cancer Working Party. Br J Cancer. 1995;71:633-6. 
183. Huhti E, Sutinen S, Reinila A, Poukkula A, Saloheimo M. Lung cancer in a defined geographical area: history and histological types. Thorax. 1980;35:660-7.

184. Koldjeski D, Kirkpatrick MK, Swanson M, Everett L, Brown S. Ovarian cancer: early symptom patterns. Oncol Nurs Forum. 2003;30:927-33.

185. Kuo CW, Chen YM, Chao JY, Tsai CM, Perng RP. Non-small cell lung cancer in very young and very old patients. Chest. 2000;117:354-7.

186. Larue F, Colleau SM, Brasseur L, Cleeland CS. Multicentre study of cancer pain and its treatment in France. BMJ. 1995;310:1034-7.

187. Nowels D, Lee JT. Cancer pain management in home hospice settings: a comparison of primary care and oncologic physicians. J Palliat Care. 1999;15:5-9.

188. Pollen JJ, Schmidt JD. Bone pain in metastatic cancer of prostate. Urology. 1979;13:129-34.

189. Simpson M. The use of research to facilitate the creation of a hospital palliative care team. Palliat Med. 1991;5:122-9.

190. Walsh D, Donnelly S, Rybicki L. The symptoms of advanced cancer: relationship to age, gender, and performance status in 1,000 patients. Support Care Cancer. 2000;8:175-9.

191. Ward AW. Terminal care in malignant disease. Soc Sci Med. 1974;8:413-20.

192. Sarna L, Brown JK, Cooley ME, Williams RD, Chernecky C, Padilla G, Danao LL. Quality of life and meaning of illness of women with lung cancer. Oncol Nurs Forum. 2005;32:E9-19.

193. Hinton JM. The physical and mental distress of the dying. Q J Med. 1963;32:1-21.

194. Mercadante S, Armata M, Salvaggio L. Pain characteristics of advanced lung cancer patients referred to a palliative care service. Pain. 1994;59:141-5.

195. Cartwright A. Changes in life and care in the year before death 1969-1987. J Public Health Med. 1991;13:81-7.

196. Hinton J. How reliable are relatives' retrospective reports of terminal illness? Patients and relatives' accounts compared. Soc Sci Med. 1996;43:1229-36.

197. Woodruff RK, Jordan L, Eicke JP, Chan A. Palliative care in a general teaching hospital. 2. Establishment of a service. Med J Aust. 1991;155:662-5. 



\section{Chapter 3}

High Prevalence of Pain in Patients with Cancer in a Large Population-Based Study in the Netherlands

Marieke HJ van den Beuken-van Everdingen, Janneke M de Rijke, Alfons G Kessels, Harry C Schouten, Maarten van Kleef, Jacob Patijn Pain. 2007;132:312-20 


\section{Abstract}

\section{Objective}

At present, no definite conclusions can be drawn about the real extent of the pain suffered by cancer patients.

\section{Methods}

A population-based study was conducted to obtain reliable information about the prevalence and severity of pain in cancer patients (all phases) and about predictors of pain. A representative sample of cancer patients was recruited in the area from a cancer registry. Pain was assessed by the Brief Pain Inventory (BPI). Adequacy of pain treatment was assessed with the Pain Management Index (PMI).

\section{Results}

We found that $55 \%$ of the 1429 respondents had experienced pain past week; in $44 \%(n=351)$, the pain was moderate to severe pain (BPI score $\geq 4$ ).

Total prevalence of pain / moderate to severe pain was present in $49 \% / 41 \%$ in patients with curative treatment $\geq 6$ months ago, $57 \% / 43 \%$ in patients with current curative treatment or treatment $<6$ months ago, $56 \% / 43 \%$ in patients with current palliative anti-cancer treatment and in $75 \% / 70 \%$ in patients for whom treatment was no longer feasible).

Positive predictors of the prevalence of pain were lower education level, more advanced disease and haematological (excluding (non)-Hodgkin lymphoma), gastro-intestinal, lung, or breast malignancies.

According to the PMI, analgesic treatment was inadequate in $42 \%$ of the patients. Negative predictors of adequate treatment were current curative anti-cancer treatment and low education level.

\section{Conclusion}

A substantial proportion of cancer patients does suffer from moderate to severe pain and does not receive adequate pain treatment. 


\section{Introduction}

By using a combination of appropriate dosage guidelines and the use of the WHO pain ladder, ${ }^{1}$ it should be possible to achieve adequate pain relief in 70 $90 \%$ of patients with cancer. ${ }^{2-7}$ Studies described in the literature give the impression that this level of pain relief is not being fulfilled. Early publications drew attention to high prevalence rates that ranged from 52 to $77 \%{ }^{8-12}$ More recent studies showed prevalence figures that ranged from $24-60 \%$ in patients on active anti-cancer treatment ${ }^{13-17}$ and $62-86 \%$ in patients with advanced cancer. ${ }^{18-23}$ These data illustrate that the problem of cancer pain has not yet been solved. A systematic review ${ }^{24}$ performed by our research group revealed methodological flaws in many prevalence studies. Only 54 out of 160 (33\%) cancer pain prevalence studies appeared to be of acceptable quality for further analysis. Based on pooled data, prevalence rates of cancer pain were high: $54 \%$ in all disease phases combined, $60 \%$ in patients with metastatic or advanced disease and $58 \%$ in patients under anti-cancer treatment. Few data were available on the severity of the pain in different phases of cancer they were mostly inconclusive. ${ }^{13,18,19,25-39}$ The same applied to the relation between the prevalence of cancer pain and the type of cancer, ${ }^{13,16,28,29,36,40-42}$ phase of disease, ${ }^{43-46}$ age, ${ }^{47,48}$ gender, ${ }^{49}$ marital status and education level. More studies with well-designed methodology are needed to gain greater insight into the real extent of the pain suffered by cancer patients.

To make reliable estimations of the prevalence and severity of pain in cancer patients and to map predictors of cancer pain, a population-based study was conducted on a large group of patients that included all disease phases.

\section{Methods}

\section{Patients}

Over a 5 month period between November 2004 and June 2005, cancer patients were recruited at 4 general hospitals, one university hospital, one clinic for radiotherapy, 11 nursing home organisations, 5 hospices and by a large number of general practitioners (GPs), in the area of a comprehensive cancer centre (Comprehensive Cancer Centre Limburg), in the Netherlands. Patients were eligible if they 1 . had been diagnosed with cancer, 2. had been informed of their diagnosis, 3 . were 18 years or older, 4. able to understand and complete the questionnaire and 5 . agreed to participate in the study.

A consistent finding in reviews on cancer pain was that the prevalence of pain was higher in the patients with more advanced disease. ${ }^{24,43,44,50}$ Therefore, we 
subdivided the patients into four categories: group 1a. patients who had been treated with curative intent, last treatment more than six months ago, group $1 \mathrm{~b}$. patients receiving anti-cancer treatment with curative intent or last treatment less than six months ago, group 2. patients who were receiving palliative anticancer treatment and group 3. patients for whom anti-cancer treatment was not or no longer feasible. These categories are indicated as disease group 1a, disease group $1 \mathrm{~b}$ etc.

\section{Measurements}

A self-report patient questionnaire and a medical data form filled in by the treating physician were developed for this study to obtain the following sets of measurements:

Demographic data: gender, age, marital status (cohabiting, widow(er), divorced, single) and education level: low (none or primary education), middle (lower and higher general secondary education and intermediate vocational education and high (pre-university education, higher vocational education, university).

Medical data: cancer type, disease group and date of last treatment (medical form) and information about medication received (patient questionnaire).

Pain was measured by the pain questions from the EORTC-C $30^{51}$ (verbal rating scale) and by four questions (pain now and pain over the past week: least, worst and average) derived from the Brief Pain Inventory (BPI). ${ }^{52}$ Scores could be given on an 11-point Likert scale that ranged from 0 (no pain) to 10 (worst pain ever). The BPI has a high internal consistency with coefficient alphas that ranged from .78 to .97 in various cancer population samples in different countries. ${ }^{39,53-61}$

Adequacy of pain treatment was measured by Ward's variation ${ }^{(62)}$ of the Pain Management Index (PMI), ${ }^{26}$ which is based on the patient's worst level of pain, categorized as 0 (no pain), 1 (VAS 1-3) mild pain, 2 (VAS 4-7) moderate pain, or 3 (VAS 8-10) severe pain. The pain level is then subtracted from the most potent level of analgesic treatment received by the patient, scored as 0 (no analgesic dug), 1 (non-opioids), 2 (weak opioids), or 3 (strong opioids). Scores can range from -3 (a patient had not received analgesic drugs, but had severe pain) to +3 (a patient had received strong opioids and did not have pain). These scores are then dichotomised: negative scores indicate the inadequate prescription of analgesic drugs, whereas scores of 0 or higher are considered to indicate acceptable pain treatment. 


\section{Procedure}

At the outpatient clinics of the medical institutes, the treating physician filled out the medical data form on all the consecutive patients with cancer over a period of 10 days and gave them a flyer that explained the goals of this study.

The day after the visit to the outpatient clinic, each patient was sent the selfreport questionnaire, an patient information brochure and an informed consent form at their home address. Patients were asked to return the questionnaire even if they did not wish to participate.

To identify patients for disease group 3 all the GPs in the region were informed about the study and invited to recruit suitable patients. Every four weeks, they were contacted by telephone. The GPs informed eligible patients about the study and gave them the necessary papers. At the nursing homes and hospices, a physician and/or nurse were asked to recruit patients for disease group 3, to inform them about the study and give them the necessary papers. GPs and nursing home doctors filled in separate medical forms.

\section{Statistics}

Descriptive statistics were obtained with SPSS version 12.0. All the regression analyses were performed using STATA SE 8.

Outcome variables were the presence of moderate to severe pain (yes/no) and inadequate use of analgesia according to the PMI (yes/no). The results of the BPI were used for the pain analyses. Pain was considered mild with the BPI score 1-3, moderate with score 4-6 and severe with score 7-10. Logistic regression analyses were used to identify factors associated with the dichotomous outcome variables. In a stepwise regression model, the contribution of the following variables was examined: age, gender, marital status (living alone vs not living alone), education (low, middle, high (reference group), cancer type (prostate cancer as reference category) and disease group with $p<0.10$ as the criterion to add a variable.

To account for selection bias namely the underrepresentation of patients aged 80 years or older, all regression analyses were performed using the sampling weight option with weight equal to the inverse of the probability to be included in the study.

The study was approved by the Medical Ethics Committee of the University Hospital Maastricht, by the local ethics committees of the hospitals and by the group that coordinates studies involving general practitioners (CEL). 


\section{Results}

In the out-patient settings, 1782 questionnaires were given to eligible patients and 1348 were returned correctly filled in (response 76\%). Only 81 questionnaires were offered to patients by the 87 participating GPs (out of 417), 5 hospices and 12 nursing home organisations. All the patients returned the questionnaire; a total of 1429 could be analysed.

Patient characteristics are listed in Table 3.1. Most patients were between 60 and 80 years of age, married and living at home. The sample was representative for tumour types according to the cancer registration of the comprehensive cancer centres in the Netherlands. ${ }^{63}$

No significant differences in the distribution of gender, cancer types or disease group were found between the participants $(n=1429)$ and non-participants $(n=434)$ (Table 3.1). However, there was significant overrepresentation of patients aged $\geq 80$ years among the non-participants. To account for this potential selection bias, weighting was used in all the analyses.

The informed consent form was not returned by $64 \% \quad(n=276)$ of the nonparticipants. No reason for refusal was given by 59 of the 158 non-participants who returned the informed consent form. Reasons for non-participation in the remaining 99 patients were: too ill or too tired $(6 \%)$, no longer have cancer $(4 \%)$, no pain (2\%), too blind/deaf/old or demented $(2 \%)$, deceased $(2 \%)$, comorbidity (1\%), psychological problems (1\%) and miscellaneous(4\%).

In the total study population, $55 \%$ of the patients had pain. In $44 \%(n=351)$ pain moderate to severe (VAS $\geq 4$ ). Pain percentages and confidence intervals per disease group are shown in Figure 3.1. In group 1a $(n=388), 49 \%$ of the patients were suffering from pain $(n=190)$, of whom $41 \%(n=78)$ had moderate to severe pain. In group $1 b(n=385), 57 \%$ were suffering from pain $(n=218)$, of whom $43 \%(n=94)$ had moderate to severe pain. In group $2(n=575), 56 \%$ experienced pain $(n=320)$, of whom $43 \%(n=136)$ had moderate to severe pain. In group $3(n=81), 75 \%$ were suffering from pain $(n=61)$, of whom $70 \%(n=43)$ had moderate to severe pain.

No striking differences were found in the prevalence of average pain in the past week and the different cancer types (Figure 3.2). 
Table 3.1 Demographic characteristics.

\begin{tabular}{|c|c|c|}
\hline & & $\begin{array}{c}\text { Participants } \\
\text { n (\%) }\end{array}$ \\
\hline \multirow[t]{3}{*}{ Gender } & Men & $686(48)$ \\
\hline & Women & $743(52)$ \\
\hline & Missing & \\
\hline \multirow[t]{4}{*}{ Age groups (years) } & $20-40$ & $55(4)$ \\
\hline & $40-60$ & $475(33)$ \\
\hline & $60-80$ & $800(56)$ \\
\hline & $\geq 80$ & $99(7)$ \\
\hline \multirow[t]{5}{*}{ Marital status } & Cohabiting & $1059(74)$ \\
\hline & Widow(er) & $179(13)$ \\
\hline & Divorced & $76(5)$ \\
\hline & Single & $94(7)$ \\
\hline & Missing & 21 (1) \\
\hline \multirow[t]{3}{*}{ Education } & Primary school & $812(57)$ \\
\hline & Secondary school & $360(25)$ \\
\hline & College/university & 257 (18) \\
\hline \multirow[t]{6}{*}{ Residence } & Home (not alone) & $1082(76)$ \\
\hline & Home (alone) & $278(20)$ \\
\hline & Nursing home & 19 (1) \\
\hline & Hospice & $23(1)$ \\
\hline & Hospital & $1(0)$ \\
\hline & Other & $26(2)$ \\
\hline \multirow[t]{10}{*}{ Type of cancer } & Head and neck & $65(4)$ \\
\hline & Gastrointestinal & $222(15)$ \\
\hline & Lung & $141(10)$ \\
\hline & Breast & $367(26)$ \\
\hline & Prostate & $203(14)$ \\
\hline & Urogenital other & $103(7)$ \\
\hline & Gynaecological & $109(8)$ \\
\hline & (Non)Hodgkin & $64(4)$ \\
\hline & Haematological other & $89(6)$ \\
\hline & Other & $66(6)$ \\
\hline \multirow[t]{4}{*}{ Disease group ${ }^{a}$} & Group 1a & $388(27)$ \\
\hline & Group 1b & $385(27)$ \\
\hline & Group 2 & $575(40)$ \\
\hline & Group 3 & $81(6)$ \\
\hline
\end{tabular}

${ }^{a} 1 \mathrm{a}=$ patients who received anti-cancer treatment with curative intent $\geq 6$ months ago, $1 \mathrm{~b}=$ patients receiving anti-cancer treatment with curative intent or last treatment less than 6 months ago, $2=$ patients receiving palliative anti-cancer treatment and group $3=$ treatment not or no longer feasible.

Logistic regression analysis revealed that gender, age and marital status were not found to be significant predictors of the prevalence of pain, whereas the status of "treatment not feasible" held a significantly greater risk (odds ratio (OR) 3.3, 95\% confidence interval $(\mathrm{Cl})$ 1.9-5.6) than the status of "current 
palliative anti-cancer treatment" (Table 3.2). In addition, a low (OR 2.0, Cl 1.42.8) or middle education level (OR 1.7, $\mathrm{Cl} 1.2-2.3$ ) held a significantly higher risk than a high education level.

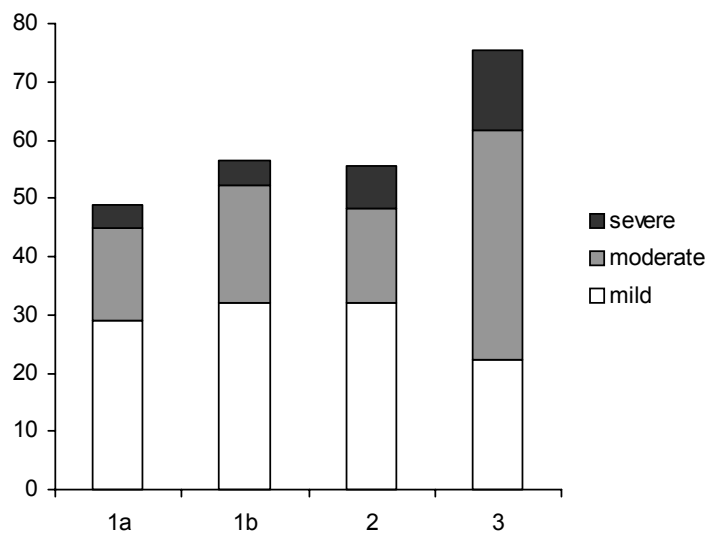

Figure 3.1 Prevalence of pain in patients with cancer per disease group ${ }^{a}$.

a $1 \mathrm{a}=$ patients who received anti-cancer treatment with curative intent $\geq 6$ months ago, $1 \mathrm{~b}=$ patients receiving anti-cancer treatment with curative intent or last treatment less than 6 months ago, $2=$ patients receiving palliative anti-cancer treatment and group $3=$ treatment not or no longer feasible

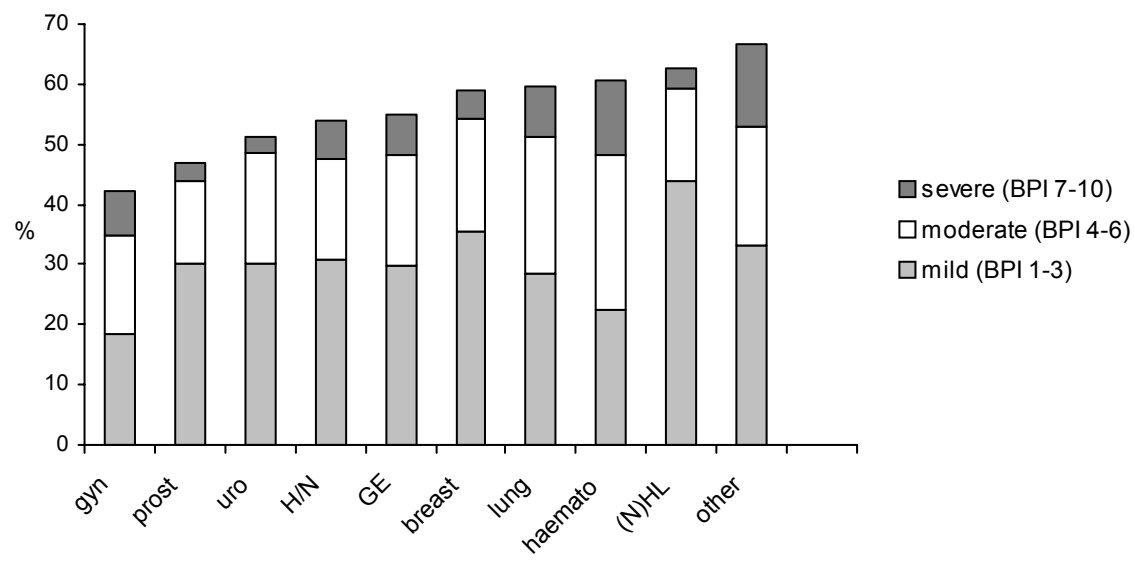

Figure 3.2 Prevalence of pain in patients with cancer by type ${ }^{a}$.

${ }^{\mathrm{a}}$ gyn = gynaecological, prost $=$ prostate, uro $=$ other urogenital, $\mathrm{H} / \mathrm{N}=$ head and neck, $\mathrm{GE}=$ gastro-intestinal, haemato $=$ other haematological, $(\mathrm{N}) \mathrm{HL}=\mathrm{m}$. Hodgkin and nonHodgkin. 
The risk of moderate to severe pain was significantly higher in patients with gastro-intestinal (OR 1.5, Cl 0.9-2.5), lung (OR 1.7, Cl 1.0-2.9), breast (OR 1.6, $\mathrm{Cl}$ 1.0-2.5), other haematological malignancies, including $27 \%$ multiple myeloma (OR 3.0, $\mathrm{Cl} 1.7-5.4$ ), or "other" malignancies, including $8 \%$ two different tumours, $18 \%$ central nervous system and $23 \%$ melanomas (OR 2.5, Cl 1.3-4.9) than in patients with prostate cancer (Table 3.2).

Table 3.2 Significant predictors of the prevalence of moderate to severe pain in patients with cancer $^{\mathrm{a}}$.

\begin{tabular}{|c|c|c|c|c|}
\hline & $N^{b}$ & Odds ratio & Confidence interval & $p$-value ${ }^{c}$ \\
\hline \multicolumn{5}{|l|}{ Education level } \\
\hline Low & 812 & 1.97 & $1.38-2.82$ & $<0.001$ \\
\hline Middle & 360 & 1.66 & $1.21-2.28$ & 0.002 \\
\hline High & 257 & 1.00 (reference) & & \\
\hline \multicolumn{5}{|l|}{ Disease group ${ }^{d}$} \\
\hline $1 a$ & 388 & 0.84 & $0.60-1.16$ & 0.291 \\
\hline $1 \mathrm{~b}$ & 385 & 1.13 & $0.82-1.55$ & 0.459 \\
\hline 2 & 575 & 1.00 (reference) & & \\
\hline 3 & 81 & 3.28 & $1.93-5.56$ & $<0.001$ \\
\hline \multicolumn{5}{|l|}{ Cancer type } \\
\hline head and neck & 65 & 1.61 & $0.80-3.24$ & 0.183 \\
\hline gastro-intestinal & 222 & 1.53 & $0.94-2.47$ & 0.085 \\
\hline lung & 141 & 1.71 & $0.98-2.97$ & 0.057 \\
\hline breast & 367 & 1.57 & $1.01-2.46$ & 0.046 \\
\hline prostate & 203 & 1.00 (reference) & & \\
\hline other urogenital & 103 & 1.38 & $0.75-2.54$ & 0.304 \\
\hline gynaecological & 109 & 1.63 & $0.90-2.93$ & 0.106 \\
\hline (non)-Hodgkin & 64 & 1.16 & $0.55-2.43$ & 0.693 \\
\hline other haematological & 89 & 3.01 & $1.69-5.38$ & 0.001 \\
\hline other & 66 & 2.53 & $1.31-4.89$ & 0.006 \\
\hline
\end{tabular}

${ }^{a}$ age and gender appeared not to be significant factors; ${ }^{b} \mathrm{~N}=$ number of patients; ${ }^{\mathrm{c}} \mathrm{p}$-value was considered significant at $p \leq 0.10 ;{ }^{d} 1 a=$ patients who received anti-cancer treatment with curative intent $\geq 6$ months ago, $1 \mathrm{~b}=$ patients receiving anti-cancer treatment with curative intent or last treatment less than 6 months ago, $2=$ patients receiving palliative anti-cancer treatment and group $3=$ treatment not or no longer feasible.

According to the pain management index (PMI), the treatment of pain was insufficient in $42 \%$ of the 1383 patients (Table 3.3). Less than $30 \%$ of the patients used medication belonging to the WHO 3-step pain ladder: 15\% $(n=202)$ used step 1 medication (paracetamol and/or NSAID's), 6\% $(n=78)$ used step 2 medication (weak opioids) and $7 \%(n=95)$ used step 3 medication (strong opioids). Adjuvant pain medication (tricyclic antidepressants, antiepileptics, N-Methyl-D-Aspartate antagonists) was being used by $7 \%(n=95)$ of the patients (Table 3.3). In many cases, pain medication was not being used according to the WHO guidelines: $42 \%$ of the patients using a weak opioid 
were not on step 1 medication, while this applied to $53 \%$ of the patients using strong opioids. Seven patients who were using strong opioids were also on weak opioids.

Table 3.3 Management in patients with cancer by disease group ${ }^{\mathrm{a}}$.

\begin{tabular}{lccccc}
\hline & $\begin{array}{c}1 \mathrm{a}(\mathrm{n}=374) \\
\mathrm{n}(\%)\end{array}$ & $\begin{array}{c}1 \mathrm{~b}(\mathrm{n}=375) \\
\mathrm{n}(\%)\end{array}$ & $\begin{array}{c}2(\mathrm{n}=559) \\
\mathrm{n}(\%)\end{array}$ & $\begin{array}{c}3(\mathrm{n}=75) \\
\mathrm{n}(\%)\end{array}$ & $\begin{array}{c}\text { Total }(\mathrm{n}=1383) \\
\mathrm{n}(\%)\end{array}$ \\
\hline $\begin{array}{l}\mathrm{PMI}^{2} \\
\text { Insufficient }\end{array}$ & $154(41)$ & $183(48)$ & $226(40)$ & $18(24)$ & $581(42)$ \\
\hline & & & & & \\
\hline Medication & & & & & \\
WHO 1 & $48(13)$ & $42(11)$ & $79(14)$ & $33(44)$ & $202(15)$ \\
WHO 2 & $9(2)$ & $16(4)$ & $39(7)$ & $14(19)$ & $78(6)$ \\
WHO 3 & $9(2)$ & $11(3)$ & $41(7)$ & $34(45)$ & $95(7)$ \\
Co-analgesics & $19(5)$ & $23(6)$ & $35(6)$ & $18(24)$ & $95(7)$ \\
\hline
\end{tabular}

${ }^{a} 1 a=$ patients who received anti-cancer treatment with curative intent $\geq 6$ months ago, $1 \mathrm{~b}=$ patients receiving anti-cancer treatment with curative intent or last treatment less than 6 months ago, $2=$ patients receiving palliative anti-cancer treatment and group $3=$ treatment not or no longer feasible; Pain Management Index insufficient meant a negative score on the PMI; ${ }^{\mathrm{b}}$ WHO 1, 2, $3=$ World Health Organisation 3-step analgesic ladder 1, 2 and 3, co-analgesics included are tricyclic antidepressants, anti-epileptics and NMDA-receptor antagonists.

Current curative anti-cancer treatment (OR 1.3, $\mathrm{Cl}$ 1.0-1.7) and a low education level (OR 1.5, $\mathrm{Cl} 1.1-2.0$ ) were negative predictors (Figure 3.3) of adequate pain treatment. Advanced age (OR $0.8, \mathrm{Cl} 0.6-0.9)$ and more advanced disease (OR $0.5, \mathrm{Cl} 0.27-0.82$ ) were positive predictors of adequate pain treatment.

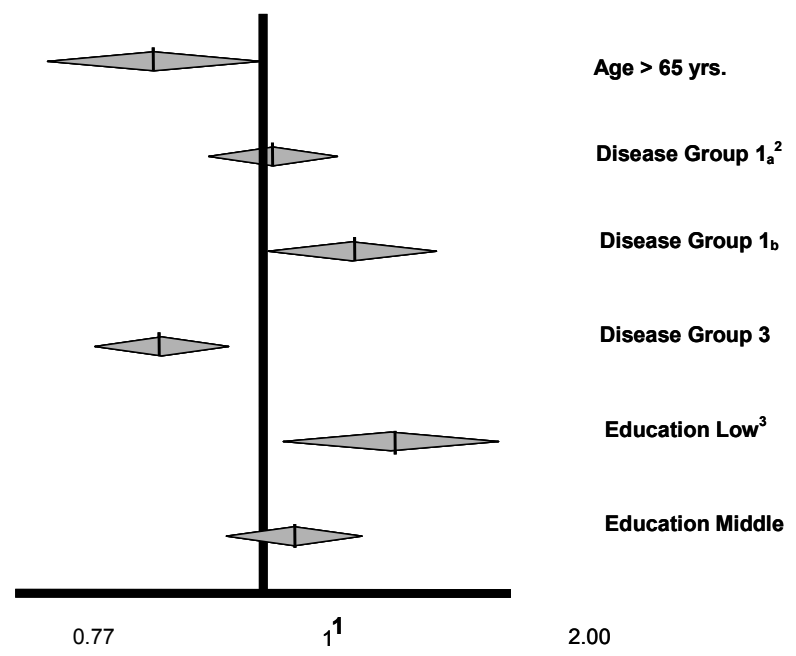

Figure 3.3 Predictors of under-treatment of pain in patients with cancer ${ }^{1}$ (Odds ratios and confidence intervals). ${ }^{1}$ gender and cancer localisation were not significant factors; ${ }^{2}$ disease group 2 as reference; ${ }^{3}$ high education level as reference. 


\section{Discussion}

A high prevalence of pain (55\%) was found in our total study population of 1429 cancer patients; $44 \%$ had moderate to severe pain.

In group 1a, $20 \%$ of the patients were suffering from moderate to severe pain, which was an even higher percentage than that reported in patients with chronic postoperative pain $(5-10 \%),{ }^{65}$ osteoarthritis of the knee $(10-14 \%)^{66}$ or back pain $(18-32 \%){ }^{67}$

Moderate to severe pain was reported by $22 \%$ and $23 \%$ of the patients currently under anti-cancer treatment, respectively curative or palliative. Earlier studies reported prevalences of between 23 and $63 \%$. $^{13,17,27,68}$

In the patients for whom treatment was not feasible, $75 \%$ had pain. In a recent systematic review ${ }^{69}$ of symptom prevalence in 37 studies on patients with incurable cancer, the pooled prevalence rate of pain was $71 \%$ in 21917 patients. In our population, 53\% reported moderate to severe pain. Other studies found $20-65 \%$ with moderate to severe pain. ${ }^{18,19,26,30,33-35}$

In the literature, little information is available about predictors of the prevalence of cancer pain. In our study, a low or middle education level held a significantly higher risk of pain than a high education level (OR 2.0 and 1.6 respectively). One study ${ }^{31}$ found a higher (non-significant) prevalence of pain in cancer patients with basic schooling than in patients with high education levels. Studies on chronic pain in the general population reported that persons with low education had more pain complaints (occurrence and intensity); the difference was highly significant. ${ }^{70-73}$ Explanations might be less involvement of these patients in treatment issues ${ }^{74}$ and increased financial strain. ${ }^{70}$ Another prominent predictor of moderate to severe pain was the disease group (phase), which was in accordance with the consistent finding in reviews on the prevalence of cancer pain. ${ }^{43,44,50,75}$

Although textbooks associate particular malignancies with a high risk of pain (bone, pancreas, oesophagus) or a low risk (lymphoma, leukaemia, soft tissue), ${ }^{76,77}$ it is not clear what evidence these statements are based on. Previously, ${ }^{75}$ we did not find any significant relationships between pain prevalence and tumour type. A recent study on a cohort of end-stage cancer patients ${ }^{78}$ concluded that cancer pain was not restricted to specific sites. Reyes-Gibby et al studied patients under anti-cancer treatment and found high prevalences of moderate to severe pain in patients with head and neck, gastrointestinal and breast malignancies. ${ }^{17}$ Nevertheless, type of cancer did not prove to be a predictor, although our patients with gastro-intestinal, lung, breast, other haematological and "other" malignancies had a significantly higher risk of moderate to severe pain than the prostate cancer patients. This was remarkable, because $46 \%$ of our prostate cancer patients were in the palliative 
groups 2 and 3 . Our linear regression analyses showed that head and neck cancer held a fairly high risk of mild pain.

The focus of attention should lie on providing relief to patients with moderate to severe pain. Subdivision of pain severity into mild, moderate or severe is arbitrary. Especially the NRS scores 4 (mild $^{17,32,39,53,59,79-82}$ or moderate ${ }^{13,18,83-86}$ ) and 7 (moderate (m,82,84,86 $_{\text {or severe }}{ }^{13,17,25,32,39,53,59,79,82,83,85,87}$ ) give rise to discussion. In our study, the brief pain inventory pain and the EORTC quality of life questionnaire were used to measure pain. Therefore we were able to examine how our patients interpreted their pain: more of the patients considered a score of 4 to represent moderate pain than mild pain, while slightly more patients considered a score of 7 to represent severe pain rather than moderate pain.

On the pain management index (PMI), 42\% of our patients had negative scores, which indicated inadequate analgesic treatment. Previous studies reported negative PMI-scores in $30-82 \%$ of the patients. ${ }^{19,55,59,61,62,84,88-93}$ Although the PMI is widely used to determine the adequacy of pain management, it does not take into account adequate dosage and the use of coanalgesics. ${ }^{94}$ This probably explains why patients with metastatic disease (who make greater use of strong opioids) have the highest pain scores despite their encouraging PMI rates. ${ }^{94,95}$

Patients on curative anti-cancer treatment had a significantly higher risk of not being treated adequately for their pain than patients on palliative anti-cancer treatment. This is in agreement with earlier reports in which patients with better performance status $^{17,91,96}$ or without metastases ${ }^{91}$ were at risk of having negative PMI scores. This suggests that cancer patients experience the wellknown barriers against adequate pain relief, such as fear of medication in general and opioids in particular and fear of starting opioids too early so no treatment will be available when the disease progresses. ${ }^{62,97-101}$

Our results showed that patients with low education levels were at greater risk of receiving inadequate pain treatment than patients with high education levels. Possible explanations are that people with lower education communicate less effectively with their care providers about their pain, or are more afraid of opioids than people with higher education levels. This should be investigated in further studies. In contrast with our finding that older age protected against undertreatment of pain, earlier reports did not find any age differences in treatment $^{86,92}$ or poorer PMI scores in elderly patients. ${ }^{26,90}$ Gender did not appear to be a predictor of PMI scores. This was in agreement with two recent studies, ${ }^{90,92}$ whereas Cleeland reported poorer scores in women. ${ }^{96}$

There were some limitations in this study. Despite the proper format and effort made to encourage GPs, nursing home physicians and nursing staff at the 
hospices to recruit patients with advanced disease, the number of patients was small. Therefore, this group may not have been representative of all patients with metastatic/advanced disease. Selection by GPs, nursing home physicians and nursing staff at the hospices could have excluded patients in the most terminal phase of illness. It is not clear how this selection influenced the prevalence of pain. Several studies showed that the prevalence of pain decreased at the very end of life ${ }^{40,102-104}$ which would mean that we slightly overestimated the prevalence of pain in group 3. However, some studies showed an increase in the prevalence of pain at that phase. ${ }^{78,105}$

The fairly broad categories of cancer types make it difficult to translate pain risk to the individual patients.

It was not possible to make more detailed subdivisions into specific types (e.g. pancreas, stomach, oesophagus, etc. instead of gastrointestinal), because of the limited numbers in each group.

\section{Conclusion}

The number of people who have ${ }^{106}$ cancer is growing due to early detection and progress in anti-cancer treatment. ${ }^{107}$ In 2005, the 20-year prevalence of cancer in the Netherlands was estimated to be over 450,000 persons $(2.8 \%)$ and is expected to reach 692000 in $2015 .^{107}$

Our pain prevalence rate of $55 \%$ was far too high. The prevalence of moderate to severe pain in patients treated with curative intent was as high as that of back pain. A quarter of the patients under anti-cancer treatment and more than half of the patients with advanced/terminal disease were suffering from moderate to severe pain. Pain management was insufficient in almost half of the patients in this study. This illustrates the need for better education about pain and pain control in the curricula of medical professionals. Systematic recording of pain intensity in cancer patients, irrespective of the phase of disease, is mandatory. 


\section{References}

1. WHO. (World Health Organisation). Cancer Pain Relief. 1986.

2. Ventafridda V, Tamburini M, Caraceni A, De Conno F, Naldi F. A validation study of the WHO method for cancer pain relief. Cancer. 1987;59:850-6.

3. Walker VA, Hoskin PJ, Hanks GW, White ID. Evaluation of the WHO analgesic guidelines for cancer pain in a hospital-based palliative care unit. Journal of Pain and Symptom Management. 1988;3:145-9.

4. Goisis A, Gorini M, Ratti R, Luliri P. Application of a WHO protocol on medical therapy for oncologic pain in an internal medicine hospital. Tumori. 1989;75:470-2.

5. Zech DF, Grond S, Lynch J, Hertel D, Lehmann KA. Validation of World Health Organization Guidelines for cancer pain relief: a 10-year prospective study. Pain. 1995;63:65-76.

6. Mercadante S. Pain treatment and outcomes for patients with advanced cancer who receive follow-up care at home. Cancer. 1999;85:1849-58.

7. Meuser T, Pietruck C, Radbruch L, Stute $P$, Lehmann KA, Grond S. Symptoms during cancer pain treatment following WHO-guidelines: a longitudinal follow-up study of symptom prevalence, severity and etiology. Pain. 2001;93:247-57.

8. Aitken-Swan J. Nursing the late cancer patient at home; the family's impressions. Practitioner. 1959;183:64-9.

9. Sung JL, Wang TH, Yu JY. Clinical study on primary carcinoma of the liver in Taiwan. Am J Dig Dis. 1967;12:1036-49.

10. Lempinen M. Carcinoma of the stomach. I. Diagnostic considerations. Ann Chir Gynaecol Fenn. 1971;60:135-40.

11. Ross AP, Braasch JW, Warren KW. Carcinoma of the proximal bile ducts. Surg Gynecol Obstet. 1973;136:923-8.

12. Twycross RG. The terminal care of patients with lung cancer. Postgrad Med J. 1973;49: 732-7.

13. Pignon T, Fernandez L, Ayasso S, Durand MA, Badinand D, Cowen D. Impact of radiation oncology practice on pain: a cross-sectional survey. Int J Radiat Oncol Biol Phys. 2004;60:1204-10.

14. Puts MTE VJ, Muller MJ, van Dam FSAM. De opinie over de zorgverlening van patiënten met kanker die op de dagbehandeling een palliatieve behandeling ondergaan. Nederlands Tijdschrift voor Geneeskunde. 2004;148:277-280.

15. Rietman J, Dijkstra P, Debreczeni R, Geertzen J, Robinson D, De Vries J. Impairments, disabilities and health related quality of life after treatment for breast cancer: a follow-up study 2.7 years after surgery. Disabil Rehabil. 2004;26:78-84.

16. Rummans TA, Frost M, Suman VJ, Taylor M, Gendron T, Johnson R, Hartmann L, Dose AM, Evans RW. Quality of life and pain in patients with recurrent breast and gynecologic cancer. Psychosomatics. 1998;39:437-45.

17. Reyes-Gibby CC, Duc BN, Yen PN, Nga NH, Tran TV, Guo H, Bhat S, Cleeland CS. Status of cancer Pain in Hanoi, Vietnam: A Hospital-Wide Survey in a Tertiary Cancer Treatment Center. J Pain Symptom Manage. 2006;31:431-9.

18. Bradley N, Davis L, Chow E. Symptom distress in patients attending an outpatient palliative radiotherapy clinic. J Pain Symptom Manage. 2005;30:123-31.

19. Di Maio M, Gridelli C, Gallo C, Manzione L, Brancaccio L, Barbera S, Robbiati SF, lanniello GP, Ferrau F, Piazza E, Frontini L, Rosetti F, Carrozza F, Bearz A, Spatafora M, Adamo V, Isa L, laffaioli RV, Di Salvo E, Perrone F. Prevalence and management of pain in Italian patients with advanced non-small-cell lung cancer. $\mathrm{Br}$ J Cancer. 2004;90:2288-96.

20. Wilson KG, Graham ID, Viola RA, Chater S, de Faye BJ, Weaver LA, Lachance LA. Structured interview assessment of symptoms and concerns in palliative care. Can $\mathrm{J}$ Psychiatry. 2004;49:350-8.

21. Hwang SS, Chang VT, Kasimis B. Dynamic cancer pain management outcomes: the relationship between pain severity, pain relief, functional interference, satisfaction and global quality of life over time. J Pain Symptom Manage. 2002;23:190-200. 
22. Stromgren AS, Groenvold M, Petersen MA, Goldschmidt D, Pedersen L, Spile M, IrmingPedersen G, Sjogren P. Pain characteristics and treatment outcome for advanced cancer patients during the first week of specialized palliative care. J Pain Symptom Manage. 2004;27:104-13.

23. Ganz PA, Kwan L, Stanton AL, Krupnick JL, Rowland JH, Meyerowtz BE Bower JE, Belin TR. Quality of life at the end of primary treatment of breast cancer: first results from the moving beyond cancer randomized trial. J Natl Cancer Inst. 2004;96:376-87.

24. Beuken-van Everdingen van den M, de Rijke J, Kessels A, Schouten $\mathrm{H}$, Kleef van M, Patijn J. Prevalence of pain in patients with cancer: a systematic review of the past 40 years. Ann Oncol. 2007;18:1437-49.

25. Chang VT, Hwang SS, Feuerman M, Kasimis BS. Symptom and quality of life survey of medical oncology patients at a veterans affairs medical center: a role for symptom assessment. Cancer. 2000;88:1175-83.

26. Cleeland CS, Gonin R, Hatfield AK, Edmonson JH, Blum RH, Stewart JA, Pandya KJ. Pain and its treatment in outpatients with metastatic cancer. N Engl J Med. 1994;330:592-6.

27. Degner LF, Sloan JA. Symptom distress in newly diagnosed ambulatory cancer patients and as a predictor of survival in lung cancer. J Pain Symptom Manage. 1995;10:423-31.

28. Greenwald HP, Bonica JJ, Bergner M. The prevalence of pain in four cancers. Cancer. 1987;60:2563-9.

29. Lidstone V, Butters E, Sinnott C, Beynon T, Richards M. Symptoms and concerns amongst cancer outpatients: identifying the need for specialist palliative care. Palliative Medicine. 2003;17:588-95.

30. Peruselli C, Di Giulio P, Toscani F, Galluzzi M, Brunelli C, Costantini M, Tamburini M, Paci E, Miccinesi G, Addington-Hall JM, Higginson IJ. Home palliative care for terminal cancer patients: a survey on the final week of life. Palliat Med. 1999;13:233-41.

31. Rustoen T, Fossa SD, Skarstein J, Moum T. The impact of demographic and disease-specific variables on pain in cancer patients. J Pain Symptom Manage. 2003;26:696-704.

32. Sandblom G, Carlsson $P$, Sigsjo $P$, Varenhorst E. Pain and health-related quality of life in a geographically defined population of men with prostate cancer. $\mathrm{Br} J$ Cancer. 2001;85:497-503.

33. Schuit KW, Sleijfer DT, Meijler W, Otter R, Schakenraad R, Bergh van den FC, Meyboom-de Jong B. Symptoms and functional status of patients with disseminated cancer visiting outpatient departments. J Pain Symptom Manage. 1998;16:290-7.

34. Soebadi RD, Tejawinata S. Indonesia: status of cancer pain and palliative care. J Pain Symptom Manage. 1996;12:112-5.

35. Spiegel D, Bloom JR. Pain in metastatic breast cancer. Cancer. 1983;52:341-5.

36. Tay WK, Shaw RJ, Goh CR. A survey of symptoms in hospice patients in Singapore. Ann Acad Med Singapore. 1994;23:191-6.

37. Zhimin L, Zhi L, Weihua Z, Yue M, Xiangxiang L, Dong Z, Zhiji C, Jiaqi C, Zhenghong R. National Survey on Prevalence of Cancer Pain. Chinese Medical Sciences Journal. 2001;16:175-8.

38. Zhukovsky DS, Gorowski E, Hausdorff J, Napolitano B, Lesser M. Unmet analgesic needs in cancer patients. J Pain Symptom Manage. 1995;10:113-9.

39. Ger LP, Ho ST, Sun WZ, Wang MS, Cleeland CS. Validation of the Brief Pain Inventory in a Taiwanese population. J Pain Symptom Manage. 1999;18:316-22.

40. Higginson I, McCarthy M. Measuring symptoms in terminal cancer: are pain and dyspnoea controlled? J R Soc Med. 1989;82:264-7.

41. Portenoy RK, Miransky J, Thaler HT, Hornung J, Bianchi C, Cibas-Kong I, Feldhamer E, Lewis F, Matamoros I, Sugar MZ Lepore JM, Friedlander-Klar H, Coyle N, Smart-Curley T, Kemeny N, Norton L, Hoskins $\mathrm{W}$ et al. Pain in ambulatory patients with lung or colon cancer. Prevalence, characteristics, and effect. Cancer. 1992;70:1616-24.

42. Portenoy RK, Thaler HT, Kornblith AB, Lepore JM, Friedlander-Klar H, Coyle N, Smart-Curley T, Kemeny N, Norton L, Hoskins W, et al. Symptom prevalence, characteristics and distress in a cancer population. Qual Life Res. 1994;3:183-9. 
43. Bonica JJ. Treatment of cancer pain: Current status and future needs. In: F FHLDRC, ed. Advances in Pain Research and Therapy. Vol. 9. New York: Raven Press; 1985:589-616.

44. Hearn J, Higginson IJ. Cancer pain epidemiology: a systematic review. In: Bruera ED PR, ed. Cancer pain. Assessment and management. first ed. Cambridge: Cambridge University Press; 2003.

45. Goudas LC, Bloch R, Gialeli-Goudas M, Lau J, Carr DB. The epidemiology of cancer pain. Cancer Invest. 2005;23:182-90.

46. Potter J, Higginson IJ. Pain experienced by lung cancer patients: a review of prevalence, causes and pathophysiology. Lung Cancer. 2004;43:247-57.

47. Desbiens NA, Wu AW, Broste SK, Wenger NS, Connors AF, Lynn J, Yasui Y, Pillips RS, Fulkerson W. Pain and satisfaction with pain control in seriously ill hospitalized adults: findings from the SUPPORT research investigations. For the SUPPORT investigators. Study to Understand Prognoses and Preferences for Outcomes and Risks of Treatmentm. Crit Care Med. 1996;24:1953-61.

48. Bernabei R, Gambassi G, Lapane K, Landi F, Gatsonis C, Dunlop R, Lipsitz L, Steel K, Mor V. Management of pain in elderly patients with cancer. SAGE Study Group. Systematic Assessment of Geriatric Drug Use via Epidemiology. JAMA. 1998;279:1877-82.

49. Morris JN, Mor V, Goldberg RJ, Sherwood S, Greer DS, Hiris J. The effect of treatment setting and patient characteristics on pain in terminal cancer patients: a report from the National Hospice Study. J Chronic Dis. 1986;39:27-35.

50. Potter J, Hami F, Bryan T, Quigley C. Symptoms in 400 patients referred to palliative care services: prevalence and patterns. Palliat Med. 2003;17:310-4.

51. Aaronson NK, Ahmedzai S, Bergman B, Bullinger M, Cull A, Duez NJ, Filiberti A, Flechtner H, Fleishman SB, de Haes SJ et al. The European Organization for Research and Treatment of Cancer QLQ-C30: a quality-of-life instrument for use in international clinical trials in oncology. J Natl Cancer Inst. 1993;85:365-76.

52. Daut RL, Cleeland CS, Flanery RC. Development of the Wisconsin Brief Pain Questionnaire to assess pain in cancer and other diseases. Pain. 1983;17:197-210.

53. Serlin RC, Mendoza TR, Nakamura Y, Edwards KR, Cleeland CS. When is cancer pain mild, moderate or severe? Grading pain severity by its interference with function. Pain. 1995;61:277-84.

54. Caraceni A, Mendoza TR, Mencaglia E, Baratella C, Edwards K, Forjaz MJ, Martini C, Serlin $\mathrm{RC}$, de Conno F, Cleeland CS. A validation study of an Italian version of the Brief Pain Inventory (Breve Questionario per la Valutazione del Dolore). Pain. 1996;65:87-92.

55. Wang XS, Mendoza TR, Gao SZ, Cleeland CS. The Chinese version of the Brief Pain Inventory (BPI-C): its development and use in a study of cancer pain. Pain. 1996;67:407-16.

56. Uki J, Mendoza T, Cleeland CS, Nakamura Y, Takeda F. A brief cancer pain assessment tool in Japanese: the utility of the Japanese Brief Pain Inventory--BPI-J. J Pain Symptom Manage. 1998;16:364-73.

57. Radbruch L, Loick G, Kiencke P. Validation of the German version of the Brief Pain Inventory. J Pain Symptom Manage. 1999;18:180-7.

58. Radbruch L, Sabatowski R, Elsner F, Everts J, Mendoza T, Cleeland C. Validation of the German version of the brief fatigue inventory. J Pain Symptom Manage. 2003;25:449-58.

59. Saxena A, Mendoza T, Cleeland CS. The assessment of cancer pain in north India: the validation of the Hindi Brief Pain Inventory--BPI-H. J Pain Symptom Manage. 1999;17:27-41.

60. Mystakidou K, Mendoza T, Tsilika E, Befon S, Parpa E, Bellos G, Vlahos L, Cleeland CS. Greek brief pain inventory: validation and utility in cancer pain. Oncology. 2001;60:35-42.

61. Larue F, Colleau SM, Brasseur L, Cleeland CS. Multicentre study of cancer pain and its treatment in France. BMJ. 1995;310:1034-7.

62. Ward SE, Goldberg N, Miller-McCauley V, Mueller C, Nolan A, Pawlik-Plank D, Robbins A, Stormoen D, Weismann DE. Patient-related barriers to management of cancer pain. Pain. 1993;52:319-24.

63. Janssen-Heijnen MLG, Louwman WJ, Poll-Franse van de LV, Coebergh JWW. (Integraal Kankecentrum Zuid (IKZ)). Van meten naar weten. 2005. 
64. Kornblith AB, Herndon JE, 2nd, Weiss RB, Zhang C, Zuckerman EL, Rosenberg S, Mertz M, Payne D, Jane Massie M, Holland JF, Wingate P, Norton L, Holland JC. Long-term adjustment of survivors of early-stage breast carcinoma, 20 years after adjuvant chemotherapy. Cancer. 2003;98:679-89.

65. Kehlet $\mathrm{H}$, Jensen TS, Woolf CJ. Persistent postsurgical pain: risk factors and prevention. Lancet. 2006;367:1618-25.

66. Arden N, Nevitt MC. Osteoarthritis: epidemiology. Best Pract Res Clin Rheumatol. 2006;20: 3-25.

67. Manek NJ, MacGregor AJ. Epidemiology of back disorders: prevalence, risk factors, and prognosis. Curr Opin Rheumatol. 2005;17:134-40.

68. Wang XS, Cleeland CS, Mendoza TR, Engstrom MC, Liu S, Xu G, Hao X, Wang Y, Ren XS. The effects of pain severity on health-related quality of life: a study of Chinese cancer patients. Cancer. 1999;86:1848-55.

69. Teunissen S, Wesker W, Kruitwagen C, Haes de H, Voest E, Graeff de A. Symptom Prevalence in Patients with Incurable Cancer: A Systematic Review. Journal of Pain and Symptom Management. 2007;34:94-104.

70. Jablonska B, Soares JJ, Sundin O. Pain among women: Associations with socio-economic and work conditions. Eur J Pain. 2006;10:435-47.

71. Torrance N, Smith BH, Bennett MI, Lee AJ. The epidemiology of chronic pain of predominantly neuropathic origin. Results from a general population survey. J Pain. 2006;7: 281-9.

72. Saastamoinen $\mathrm{P}$, Leino-Arjas $\mathrm{P}$, Laaksonen $\mathrm{M}$, Lahelma $\mathrm{E}$. Socio-economic differences in the prevalence of acute, chronic and disabling chronic pain among ageing employees. Pain. 2005;114:364-71.

73. Rustoen T, Wahl AK, Hanestad BR, Lerdal A, Paul S, Miaskowski C. Prevalence and characteristics of chronic pain in the general Norwegian population. Eur J Pain. 2004;8: 555-65.

74. Brekke M, Hjortdahl P, Kvien TK. Self-efficacy and health status in rheumatoid arthritis: a twoyear longitudinal observational study. Rheumatology (Oxford). 2001;40:387-92.

75. van den Beuken-van Everdingen MHJ, de Rijke JM, Kessels AG, Schouten HC, van Kleef M, Patijn J. The Prevalence of Pain in Patients with Cancer. A systematic review of the past 40 years. Annals of Oncology. 2007;18:1437-49.

76. Woodruff RK. Cancerpain Victoria, Australia: Asperula Pty Ltd; 1997.

77. Graeff de A, Besse TC, Crul BJP, Krol RJA. Palliatieve zorg: richtlijnen vor de praktijk. Vol. 1 Utrecht: Vereniging va Integrale Kankercentra; 2006.

78. Peng WL, Wu GJ, Sun WZ, Chen JC, Huang AT. Multidisciplinary management of cancer pain: a longitudinal retrospective study on a cohort of end-stage cancer patients. J Pain Symptom Manage. 2006;32:444-52.

79. Cleeland CS, Mendoza TR, Wang XS, Chou C, Harle MT, Morrissey M, Engstrom MC. Assessing symptom distress in cancer patients: the M.D. Anderson Symptom Inventory. Cancer. 2000;89:1634-46.

80. Ger LP, Ho ST, Wang JJ, Cherng CH. The prevalence and severity of cancer pain: a study of newly-diagnosed cancer patients in Taiwan. J Pain Symptom Manage. 1998;15:285-93.

81. Kelsen DP, Portenoy RK, Thaler HT, Niedzwiecki C, Passik SD, Tao Y, Banks W, Brennan MF, Foley KM. Pain and depression in patients with newly diagnosed pancreas cancer. J Clin Oncol. 1995;13:748-55.

82. Paul SM, Zelman DC, Smith M, Miaskowski C. Categorizing the severity of cancer pain: further exploration of the establishment of cutpoints. Pain. 2005;113:37-44.

83. Dorrepaal KL, Dam van FS, Hanewald GJ, Overweg-van Kints J. Pain in cancer. Ned Tijdschr Geneeskd. 1986;130:634-8.

84. Beck SL, Falkson G. Prevalence and management of cancer pain in South Africa. Pain. 2001;94:75-84.

85. Stevens PE, Dibble SL, Miaskowski C. Prevalence, characteristics, and impact of postmastectomy pain syndrome: an investigation of women's experiences. Pain. 1995;61:61-8. 
86. Gagliese L, Melzack R. Age-related differences in the qualities but not the intensity of chronic pain. Pain. 2003;104:597-608.

87. Sze FK, Chung TK, Wong E, Lam KK, Lo R, Woo J. Pain in Chinese cancer patients under palliative care. Palliat Med. 1998;12:271-7.

88. Cohen MZ, Musgrave CF, McGuire DB, Strumpf NE, Munsell MF, Mendoza TR, Gips M. The cancer pain experience of Israeli adults 65 years and older: the influence of pain interference, symptom severity, and knowledge and attitudes on pain and pain control. Support Care Cancer. 2005;13:708-14

89. Lin CC, Lai YL, Ward SE. Effect of cancer pain on performance status, mood states, and level of hope among Taiwanese cancer patients. J Pain Symptom Manage. 2003;25:29-37.

90. McNeill JA, Sherwood GD, Starck PL. The hidden error of mismanaged pain: a systems approach. J Pain Symptom Manage. 2004;28:47-58.

91. Okuyama T, Wang XS, Akechi T, Mendoza TR, Hosaka T, Cleeland CS, Uchitomi Y. Adequacy of cancer pain management in a Japanese Cancer Hospital. Jpn J Clin Oncol. 2004;34:37-42.

92. Strohbuecker B, Mayer H, Evers G, Sabatowski R. Pain Prevalence in Hospitalized Patients ina German University Teaching Hospital. Journal of Pain and Symptom Management. 2005;29:498-506.

93. Yun YH, Heo DS, Lee IG, Lee IG, Jeong HS, Kim HJ, Kim SY, KimYH, Ro YJ, Yoon SS, Lee $\mathrm{KH}$, Huh BY. Multicenter study of pain and its management in patients with advanced cancer in Korea. J Pain Symptom Manage. 2003;25:430-7.

94. Cleeland CS. Research in Cancer Pain. Cancer. 1991;67(3 Suppl.):823-7.

95. de Wit R, van Dam F, Loonstra S, Zandbelt L, Buuren van A, Heijden van der K, Leenhouts $\mathrm{G}$, Abu-Saad HH. The Amsterdam Pain Management Index compared to eight frequently used outcome measures to evaluate the adequacy of pain treatment in cancer patients with chronic pain. Pain. 2001;91:339-49.

96. Cleeland CS, Gonin R, Baez L, Loehrer P, Pandya KJ. Pain and treatment of pain in minority patients with cancer. The Eastern Cooperative Oncology Group Minority Outpatient Pain Study. Ann Intern Med. 1997;127:813-6.

97. Von Roenn JH, Cleeland CS, Gonin R, Hatfield AK, Pandya KJ. Physician attitudes and practice in cancer pain management. A survey from the Eastern Cooperative Oncology Group. Ann Intern Med. 1993;119:121-6.

98. Glajchen M, Fitzmartin RD, Blum D, Swanton R. Psychosocial barriers to cancer pain relief. Cancer Pract. 1995;3:76-82.

99. Grossman SA. Undertreatment of cancer pain: barriers and remedies. Support Care Cancer. 1993;1:74-8.

100. Lin CC. Barriers to the analgesic management of cancer pain: a comparison of attitudes of Taiwanese patients and their family. Pain. 2000;88:7-14.

101. Paice JA, Toy C, Shott S. Barriers to cancer pain relief: fear of tolerance and addiction. J Pain Symptom Manage. 1998;16:1-9.

102. Conill C, Verger E, Henriquez I, Saiz N, Espier M, Lugo F, Garrigos A. Symptom prevalence in the last week of life. J Pain Symptom Manage. 1997;14:328-31.

103. Lo RS, Ding A, Chung TK, Woo J. Prospective study of symptom control in 133 cases of palliative care inpatients in Shatin Hospital. Palliat Med. 1999;13:335-40.

104. Mercadante S, Casuccio A, Fulfaro $F$. The course of symptom frequency and intensity in advanced cancer patients followed at home. J Pain Symptom Manage. 2000;20:104-12.

105. McKegney FP, Bailey LR, Yates JW. Prediction and management of pain in patients with advanced cancer. Gen Hosp Psychiatry. 1981;3:95-101.

106. Hoekstra J, Vos de R, Duijn van NP, Schade E, Bindels PJ. Using the symptom monitor in a randomized controlled trial: the effect on symptom prevalence and severity. J Pain Symptom Manage. 2006;31:22-30.

107. Coebergh JWW, Poll-Franse van de LV, Alers JC, Berg van de FA, Duijn van NP. (KWF Kankerbestrijding). Kanker in Nederland, Trends, prognoses en implicaties voor zorgvraag. 2004. 


\section{Chapter 4}

\section{Quality of Life and Non-Pain Symptoms in}

\section{Patients with Cancer}

Marieke HJ van den Beuken-van Everdingen, Janneke M de Rijke, Alfons G Kessels, Harry C Schouten, Maarten van Kleef, Jacob Patijn In press Journal of Pain and Symptom Management 


\section{Abstract}

\section{Objective}

To measure the prevalence of non-pain physical symptoms and psychological symptoms in patients with cancer, to investigate the impact of physical and psychological symptoms on their quality of life and to enquire whether treatment had been received for the complaints/symptoms .

\section{Methods}

A representative sample of 1429 cancer patients were recruited and classified according to their treatment status ( 1 a. curative treatment $>6$ months ago, $1 \mathrm{~b}$. curative treatment $\leq 6$ months ago, 2 . palliative treatment and 3. treatment no longer feasible) and tumour type. Quality of life and nonpain symptoms were measured by the EORTC-C30 version 3 . We added two items: 1 . did you have a dry mouth? and 2. did you feel listless? We also asked whether the patients had received treatment for their symptoms. Depression and anxiety were measured by the Dutch version of the Hospital Anxiety and Depression Scale (HADS). Oneway Anova was used to detect differences in global quality of life between patients with different types of cancer. When Anova was significant, post-hoc tests (Tukey hsd) were performed to identify significant differences between cancer types. Linear regression analyses (forced entrance procedure) were performed (STATA SE 8) to investigate the influence of physical and psychological symptoms on global quality of life.

\section{Results}

The prevalence of moderate to severe symptoms increased significantly with each disease group. Vomiting and irritability were the least prevalent symptoms, fatigue and worries were the most prevalent symptoms in all groups. Patients in group 1 (curative treatment) experienced symptoms that were independent of cancer type. Patients in group 2 (palliative treatment) experienced symptoms that varied with cancer type. Quality of life decreased significantly each step from group 1 through 3. Fatigue, appetite loss, constipation, dry mouth, depression and anxiety had independent negative influences on quality of life. Patients with gastro-intestinal cancer, malignant lymphoma and other haematological malignancies had significantly poorer quality of life than patients with prostate cancer. In $45-90 \%$ of patients, symptoms remained untreated.

\section{Conclusion}

Non-pain physical symptoms and psychological symptoms are frequent in patients with cancer at all disease phases. Many symptoms remain untreated. Systematic recording of symptom intensity is mandatory, irrespective of the phase of disease. 


\section{Introduction}

Due to early detection and progress in anti-cancer treatment the number of people who have cancer is growing. ${ }^{1}$ In 2005 , the 20 -year prevalence of cancer in the Netherlands was estimated to be over 450,000 persons $(2.8 \%)$ and it is expected to increase to 692,000 in $2015 .^{1}$

Many patients with cancer have multiple symptoms that affect their feeling of well-being and their physical and social functioning. Several investigations showed that multiple symptoms were associated with poorer patient outcome. $^{2-11}$ The prevalence of pain in patients with cancer has been studied extensively and recently reviewed. ${ }^{12}$ In contrast, non-pain physical symptoms have received far less attention and have mainly been assessed in patients with advanced or metastatic disease. ${ }^{13-18} \mathrm{~A}$ recent systematic review on symptom prevalence in patients with incurable cancer $^{19}$ has identified 37 symptoms. Each symptom had a prevalence of $>10 \%$. More than $50 \%$ of the patients reported five specific symptoms (fatigue, pain, lack of energy, weakness and loss of appetite). It was concluded that to improve individuallytailored treatment, more studies are needed based on symptom intensity, symptom burden and impact on quality of life. ${ }^{19}$

Very few studies have been performed on non-pain symptoms in outpatients and long-term cancer survivors. Their main focus was on one symptom in relation with a specific cancer type (e.g. breathlessness in patients with lung cancer, ${ }^{20}$ fatigue in breast cancer survivors ${ }^{21}$ or vertigo in nasopharyngeal carcinoma survivors). ${ }^{22}$

Cancer-related psychological distress occurs in one third of patients, ${ }^{23}$ while major depressive disorders are estimated to occur in $10-25 \% .{ }^{23}$ Most authors consider the criteria over-inclusive and prefer to focus on "depressive symptoms". In three systematic reviews, $7-58 \%{ }^{24,25}$ of patients with cancer have depressive symptoms; in the case of solid tumours the range is $20-50 \%{ }^{26}$ Anxiety disorders are found in $15-28 \%{ }^{27}$ These percentages are based on measurements taken at around the time of diagnosis. Very little research has addressed the prevalence of depressive disorders over the course of many years after diagnosis. Psychiatric morbidity and other psychological symptoms have been well-documented in breast cancer patients, but there has been less focus on other types. ${ }^{28-30}$

The aims of this study on cancer patients were 1. to measure the prevalence of non-pain symptoms (classified according to treatment status and tumour type) in order to find whether treating physicians should be extra alert on a particular symptom in a particular type of cancer or treatment phase, 2. to determine the quality of life of patients with cancer in different cancer types and treatment 
phases and to investigate the impact of physical and psychological symptoms on quality of life and 3 . to enquire whether the patients had received treatment for their complaints/symptoms.

\section{Methods}

\section{Patients}

Between November 2004 and June 2005, a representative sample of cancer patients were recruited at 4 general hospitals, one university hospital, one clinic for radiotherapy, 11 nursing home organisations, 5 hospices and by a large number of general practitioners (GPs) in the province Limburg, the Netherlands. Patients were eligible to participate in the study if they 1. had been diagnosed with cancer, 2 . had been informed about their diagnosis, 3. were 18 years or older, 4 . were able to understand and complete the questionnaire and 5. gave informed consent.

The treating physicians were asked to classify the patients into four disease groups according to their treatment status: $1 \mathrm{a}$. curative treatment $>6$ months ago, 1 b. current (or $\leq 6$ months ago) curative treatment, 2. palliative anti-tumour treatment and 3 . treatment no longer feasible. ${ }^{31}$

\section{Measurements}

A patient self-report questionnaire and a medical data form (to be filled in by the treating physician) were developed to obtain the following sets of measurements:

Demographic data: gender, age, marital status (cohabiting, widow(er), divorced, single) and education level (low, middle, high).

Medical data: cancer type, disease group and date of last treatment (medical form) and information about symptom management received (patient questionnaire).

Quality of life and non-pain symptoms were measured using the EORTC-C30 version $3 .^{32}$ The EORTC-C30 is 1 . cancer-specific, 2. multidimensional, 3. suitable for self-administration and 4. applicable across a range of cultural settings. It has five functional scales, three symptom scales, a global health/quality of life scale and six single items. We added two items: 1. did you have a dry mouth? and 2. did you feel listless? We also asked whether the patients had received treatment for their symptoms.

Depression and anxiety were measured using the Dutch version of the Hospital Anxiety and Depression Scale (HADS). ${ }^{33}$ The HADS showed good 
performance to assess symptom severity and caseness of anxiety disorders (Cronbach's $\alpha: .68$ - .93) and depression (Cronbach's $\alpha: .67$ - .90) in somatic, psychiatric and primary care patients, with a sensitivity and specificity of approximately $0.80 .{ }^{34}$ Patients are grouped according to their depression and anxiety subscale scores 0-7 non-cases, 8-10 borderline and 11-21 definite. ${ }^{33}$

\section{Data collection}

At all the outpatient clinics, the treating physician filled out the medical data form on all the consecutive cancer patients over a period of ten days and gave them a flyer that explained the goals of this study.

The day after the visit to the outpatient clinic, each patient was sent the selfreport questionnaire, a patient information brochure and an informed consent form at their home address. Patients were asked to return the questionnaire even if they did not wish to participate.

To identify patients for disease group 3, all the GPs in the region were informed about the study and invited to recruit suitable patients. Every four weeks, research assistants contacted the GPs by telephone. The GPs informed eligible patients about the study and gave them the necessary papers. At the nursing homes and hospices, a physician and/or nurse were asked to recruit patients for disease group 3, to inform them about the study and give them the necessary papers. GPs and nursing home doctors filled in separate medical forms.

\section{Statistics}

Descriptive statistics were obtained with SPSS version 12.0. Chi-square tests were used to reveal significant differences in the prevalence of moderate to severe symptoms between the patients with different types of cancer.

Oneway Anova was used to detect differences in global quality of life between patients with different types of cancer. When Anova was significant, post-hoc tests (Tukey hsd) ${ }^{35}$ were performed to identify significant differences between cancer types.

To obtain a clear view of the influence of different variables on global quality of health, two linear regressions models were built. In the first model, only demographic variables and disease-specific variables were entered, using a forced entrance procedure. In the second model, all the physical and psychological variables were entered, adjusted for age and sex, also using a forced entrance procedure. These linear regression analyses were performed with STATA SE 8. To account for selection bias, namely the underrepresentation of patients aged 80 years or older, the regression analyses were performed using the sampling weight option, i.e. weight was equal to the inverse of the probability. 
The study was approved by the Medical Ethics Committee of the University Hospital Maastricht, by the local ethics committees of the hospitals and by the group that coordinates studies involving general practitioners. All the participants gave informed consent.

\section{Results}

In the outpatient settings, 1782 questionnaires were sent to eligible patients and 1348 were returned correctly filled in (response 76\%). Only 81 questionnaires were offered to patients by the 87 participating GPs (out of 417), five hospices and twelve nursing home organisations; all the patients returned the questionnaire. A total of 1429 could be analysed.

Most patients were between 60 and 80 years of age, married and living at home. The sample was representative for tumour types according to the cancer registration of the comprehensive cancer centres in the Netherlands. ${ }^{36}$ Detailed patient characteristics can be found in our earlier report on the prevalence of pain. ${ }^{31}$

No significant differences in the distribution of gender, cancer type or disease group were found between the participants $(n=1429)$ and non-participants $(n=434)$. However, there was significant overrepresentation of patients aged $\geq 80$ years among the non-participants.

The informed consent form was not returned by $64 \%(n=276)$ of the nonparticipants. No reason for refusal was given by 59 of the 158 non-participants who returned the informed consent form. Reasons for non-participation in the remaining 99 patients were: too ill or too tired $(6 \%)$, no longer have cancer $(4 \%)$, no pain $(2 \%)$, too blind/deaf/old or demented $(2 \%)$, deceased $(2 \%)$, comorbidity (1\%), psychological problems (1\%) and miscellaneous (4\%).

\section{Prevalence of moderate to severe non-pain physical symptoms per disease group}

The prevalence of moderate to severe physical symptoms (EORTC score of 3 or 4) differed significantly between the four disease groups. Except for diarrhoea, all the prevalences increased with increasing group number (Figure 4.1a). Vomiting was the least prevalent physical symptom in all four groups. In groups 1a (curative treatment $>6$ months ago), 1b (current curative treatment), 2 (palliative treatment) and 3 (treatment no longer feasible) the percentages were $1 \%, 3 \%, 6 \%$ and $10 \%$, respectively. Moderate to severe physical complaints of feeling weak, feeling tired and need to rest had the highest prevalences in all four groups. Percentages varied from $16 \%, 28 \%$ and $24 \%$ in group 1 a to $65 \%, 69 \%$ and $74 \%$ in group 3 . 


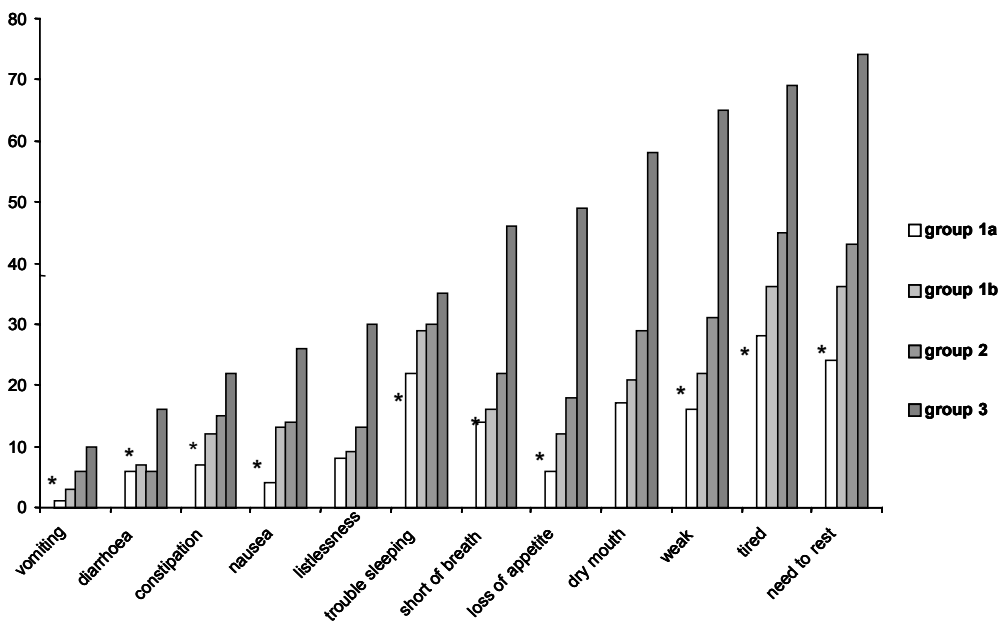

Figure 4.1a Prevalence of moderate to severe physical non-pain symptoms in patients with cancer per disease Group.

${ }^{*}$ EORTC reference values ${ }^{46}$ no reference values were found for listlessness and dry mouth.

\section{Prevalence of moderate to severe psychological symptoms per disease group}

The prevalence of moderate to severe psychological symptoms (EORTC score 3 or 4) differed significantly between the disease groups and increased with increasing group number, except for irritability (Figure 4.1b). Irritability was the least prevalent psychological symptom in all four groups. In groups 1a, 1b, 2 and 3 , the percentages were $15 \%, 17 \%, 22 \%$ and $18 \%$, respectively. Moderate to severe worries had the highest prevalence in all four groups, with percentages of $20 \%, 28 \%, 38 \%$ and $55 \%$, respectively. 


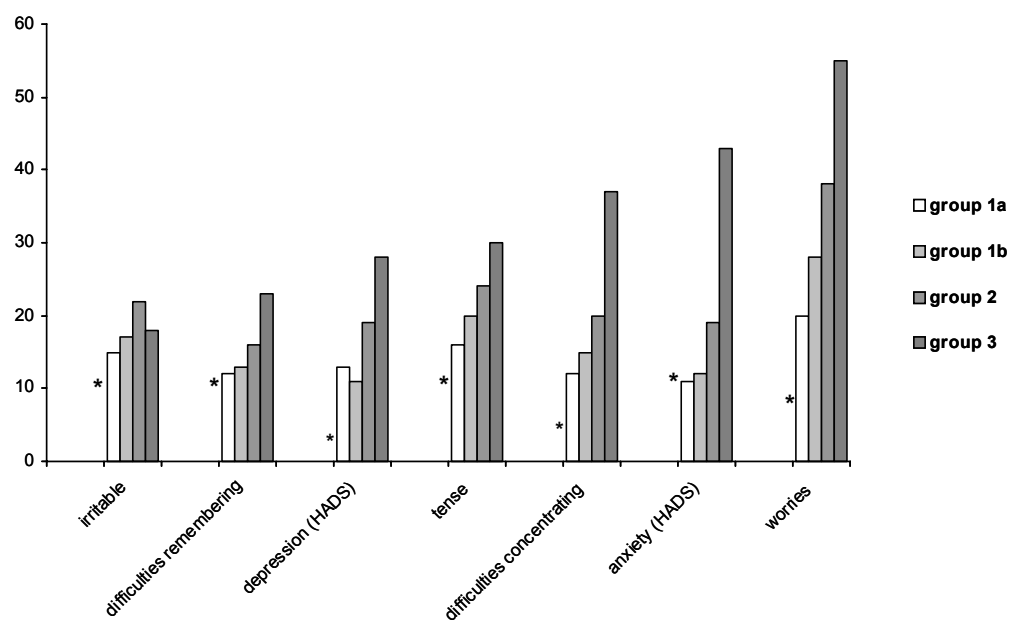

Figure 4.1b Prevalence of moderate to severe psychological symptoms in patients with cancer per disease group.

${ }^{*}$ EORTC reference values: irritable, difficulties remembering, tense, difficulties concentrating and worries. ${ }^{46}$ HADS reference values: depression, anxiety. ${ }^{113}$

\section{Prevalence of moderate to severe non-pain physical and psychological symptoms per cancer type}

Tables $4.1 \mathrm{a}, \mathrm{b}$ and $\mathrm{c}$ show the prevalences of moderate to severe symptoms in different types of cancer per disease group. Group 3 contained too few patients to compare the prevalences of symptoms between the different cancer types.

Prevalences of nine out of 19 symptoms (twelve physical and seven psychological) did not differ significantly between the cancer types. Prevalences of eight physical symptoms (dyspnoea (groups 1a, 1b and 2), trouble sleeping (group 2), feeling weak (group 2), loss of appetite (group 1b), diarrhoea (group 2), tiredness (groups 1a and 2), need to rest (groups 1a, 1b, 2) and dry mouth (groups 1a, 1b)) were significantly different between the cancer types in at least one group. This also applied to the psychological symptoms anxiety (1a) and difficulties concentrating (1a).

In all four disease groups the prevalence of dyspnoea was significantly different among the different cancer types. When the lung cancer patients were excluded from the analyses, the prevalence rates of dyspnoea were no longer significantly different in groups $1 \mathrm{a}$ and $1 \mathrm{~b}$. The same applied to tiredness in groups $1 \mathrm{a}$ and 2 , concentrating in group 1a, appetite and need to rest in group $1 b$. 


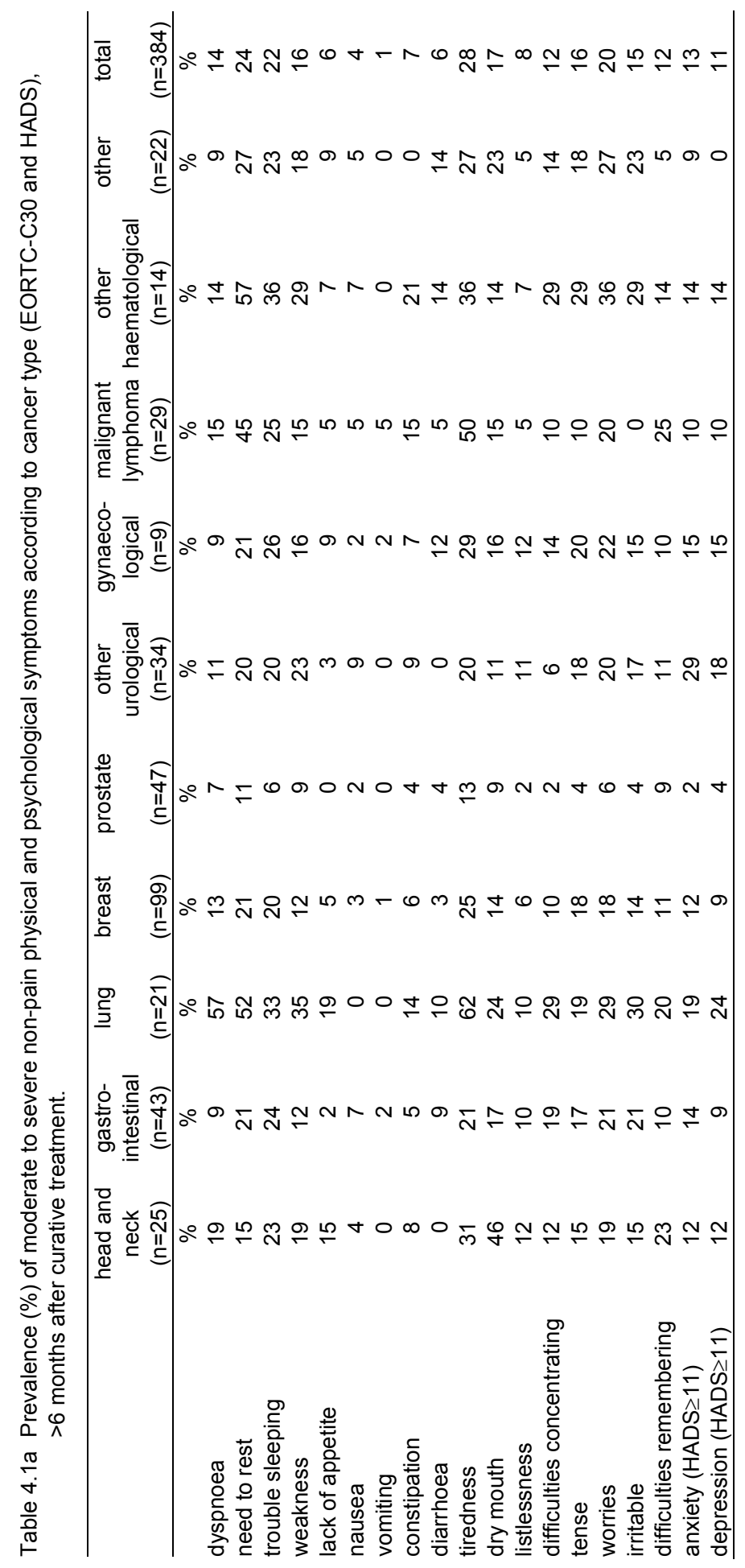




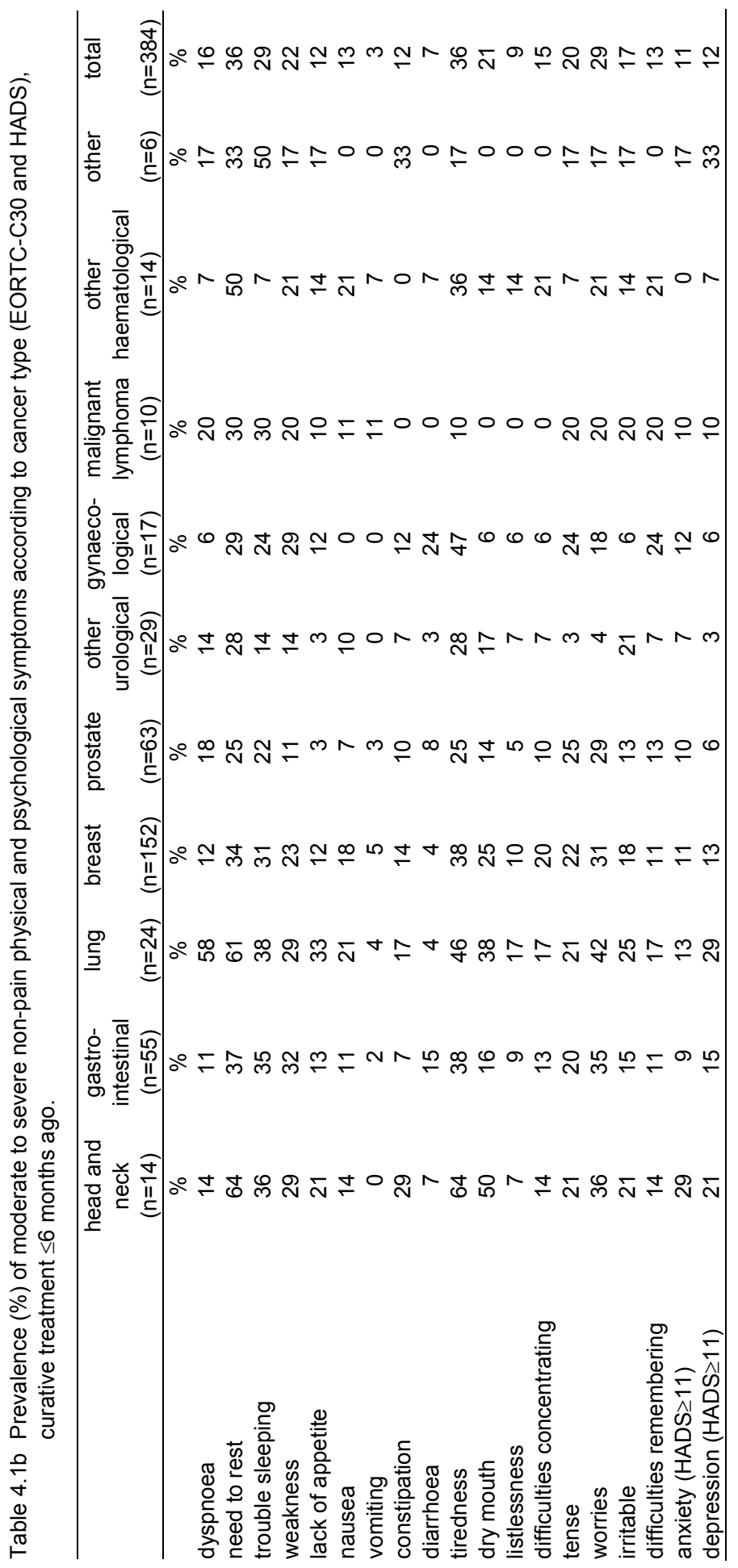




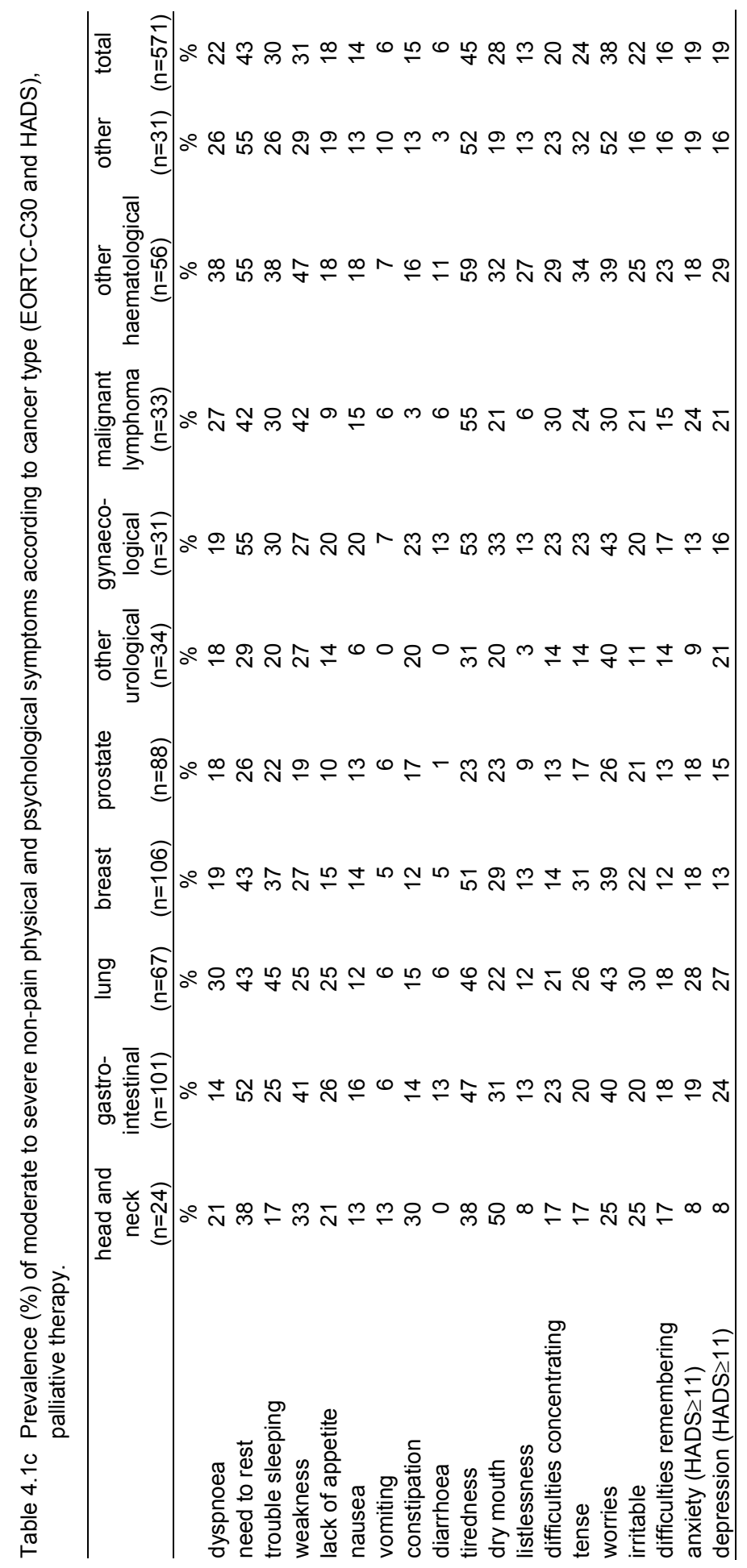


Diarrhoea was significantly more prevalent in the gastro-intestinal cancer patients in all disease groups. As expected dry mouth was especially prevalent in the head and neck cancer patients. Also anxiety was especially prevalent in the head and neck cancer patients.

\section{Quality of Life (QoL)}

Figure 4.2 shows the overall quality of life (QoL) per disease group per cancer type.
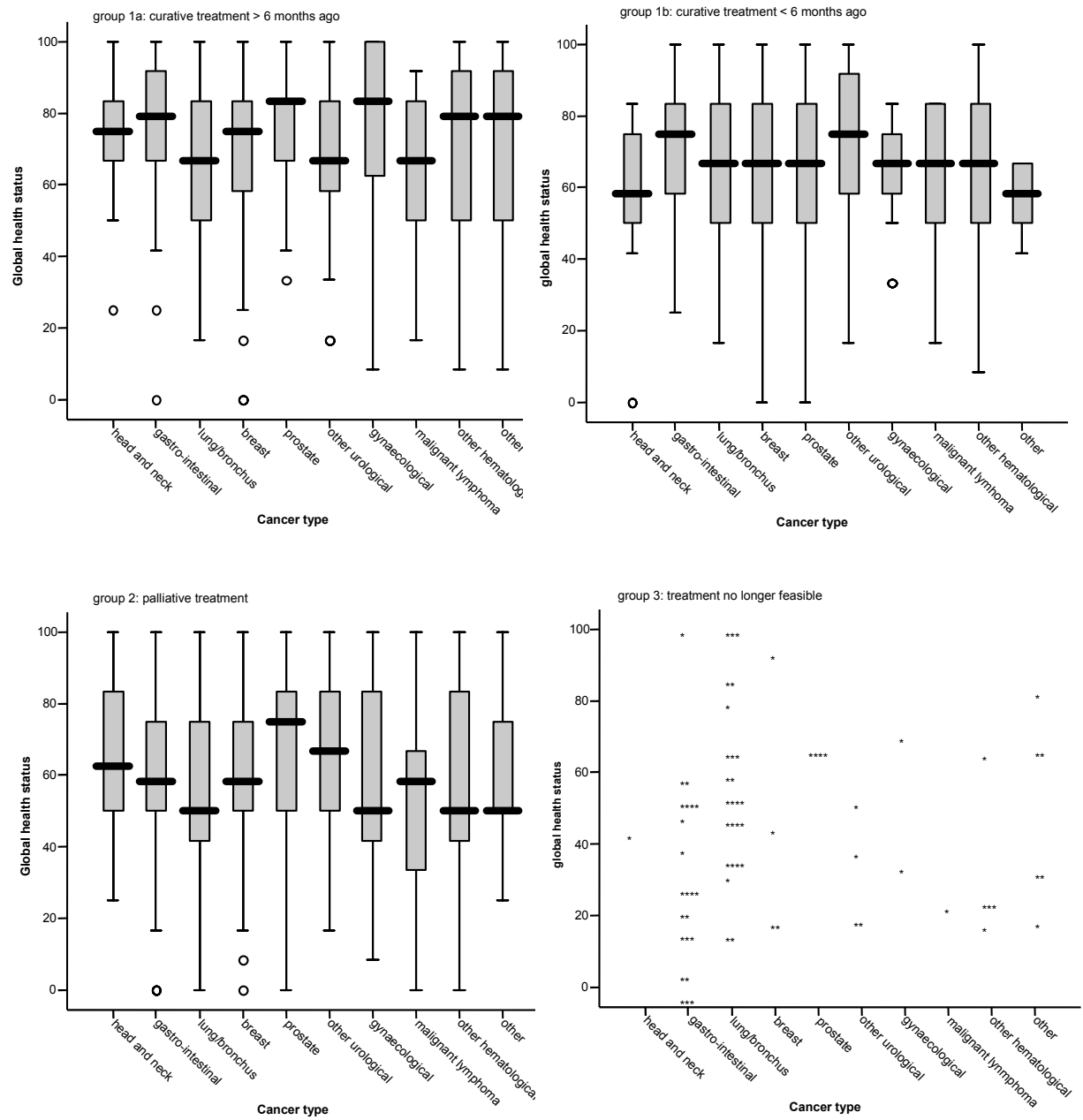

Figure 4.2 Quality of Life (median, first and third quartiles and range ${ }^{\mathrm{a}}$ ) per group per cancer type. ${ }^{a}$ open circles represent patients whose scores were $>1.5$ times lower than the first quartile; * individual cases. 
Linear regression analysis with demographic and disease-specific variables (type of cancer and disease group) showed that the patients in groups $1 \mathrm{a}$ and $1 \mathrm{~b}$ had significantly better quality of life than the patients in group $2(p=0.00)$. Patients in group 3 had significantly poorer quality of life than the patients in group $2(p=0.00)$. Patients with gastro-intestinal cancer $(p=0.03)$, malignant lymphoma $(p=0.00)$ and other haematological malignancies $(p=0.03)$ had significantly poorer quality of life than the patients with prostate cancer (Table 4.2).

Table 4.2 Global quality of life (linear regression) according to demographic characteristics, treatment status and cancer type.

\begin{tabular}{|c|c|c|c|c|}
\hline Independent variables & Coefficient (ß) & Standard Error & $\begin{array}{c}\text { Confidence } \\
\text { Interval }\end{array}$ & P-value \\
\hline Gender & -2.322 & 1.797 & $-5.85-1.20$ & .196 \\
\hline Age & .045 & .056 & $-.06-.15$ & .420 \\
\hline \multicolumn{5}{|l|}{ Education } \\
\hline Primary school & -3.269 & 1.759 & $-6.72-.18$ & .063 \\
\hline $\begin{array}{l}\text { Secondary school } \\
\text { College/university }^{\text {a }}\end{array}$ & -2.458 & 1.455 & $-5.31-.40$ & .091 \\
\hline \multicolumn{5}{|l|}{ Groupc ${ }^{c}$} \\
\hline $1 a$ & 11.807 & 1.544 & $8.78-14.84$ & $.000^{\mathrm{b}}$ \\
\hline $\begin{array}{l}1 \mathrm{~b} \\
2^{\mathrm{a}}\end{array}$ & 5.698 & 1.521 & $2.72-8.68$ & $.000^{b}$ \\
\hline 3 & -14.900 & 2.982 & $-20.75--9.05$ & $.000^{\mathrm{b}}$ \\
\hline \multicolumn{5}{|l|}{ Cancer type } \\
\hline Head and neck & -4.614 & 1.544 & $-10.92-1.69$ & .151 \\
\hline Gastrointestinal & -4.940 & 1.521 & $-9.46--.42$ & $.032^{\mathrm{b}}$ \\
\hline Lung & -4.797 & 2.601 & $-9.90-.31$ & .065 \\
\hline \multicolumn{4}{|l|}{ Prostate $^{a}$} & .367 \\
\hline Urogenital other & -1.995 & 2.663 & $-7.22-3.23$ & .454 \\
\hline Gynaecological & -2.202 & 3.262 & $-8.60-4.20$ & .500 \\
\hline (non-) Hodgkin & -10.271 & 3.320 & $-16.78-3.76$ & $.002^{\mathrm{b}}$ \\
\hline Haematological & -7.378 & 3.335 & $-13.92--.83$ & $.027^{\mathrm{b}}$ \\
\hline Other & -5.464 & 3.389 & $-12.11-1.18$ & .107 \\
\hline
\end{tabular}

a reference category; ${ }^{\mathrm{b}}$ significant variable; ${ }^{\mathrm{c}} 1 \mathrm{a}=$ curative treatment $\geq 6$ months ago, $1 \mathrm{~b}=$ curative treatment $<6$ months ago, 2=palliative treatment and group $3=$ treatment no longer feasible.

Linear regression analysis with demographic variables and physical and psychological symptoms showed that fatigue $(p=0.00)$, pain $(p=0.00)$, loss of appetite $(p=0.00)$ and constipation $(p=0.05)$ had significantly negative effects on quality of life. Dry mouth had a marginally $(p=0.058)$ negative effect. Patients with an anxiety disorder had significantly poorer quality of life than patients without such a disorder $(p=0.00)$. Depressed patients had significantly poorer quality of life than patients without depression $(p=0.00)$ (Table 4.3). 
Table 4.3 Global quality of life (linear regression) according to demographic characteristics, physical and psychological symptoms.

\begin{tabular}{|c|c|c|c|c|}
\hline Independent variables & Coefficient (ß) & Standard Error & Confidence Interval & P-value \\
\hline Gender & -.161 & .864 & $-1.86-1.53$ & .852 \\
\hline Age & .011 & .039 & $-.07-.89$ & .772 \\
\hline \multicolumn{5}{|l|}{ Education } \\
\hline Primary school & -3.269 & 1.759 & $-6.72-.18$ & .063 \\
\hline $\begin{array}{l}\text { Secondary school } \\
\text { College/university }\end{array}$ & -2.458 & 1.455 & $-5.31-.40$ & .091 \\
\hline \multicolumn{5}{|l|}{ Anxiety $(\mathrm{HADS})^{\mathrm{c}}$} \\
\hline No anxiety & 6.721 & 1.709 & $3.37-10.07$ & $.000^{\mathrm{b}}$ \\
\hline $\begin{array}{l}\text { Borderline } \\
\text { Anxious* }\end{array}$ & 2.245 & 1.707 & $-1.10-5.59$ & .189 \\
\hline \multicolumn{5}{|l|}{ Depression (HADS) ${ }^{d}$} \\
\hline Borderline & 11.067 & 1.805 & $7.53-14.61$ & $.000^{\mathrm{b}}$ \\
\hline Depressed $^{a}$ & 1.822 & 1.803 & $-1.71-5.36$ & .312 \\
\hline Dyspnoea & -.023 & .016 & $-.06-.01$ & .166 \\
\hline Fatigue & -.261 & .024 & $-.31--.21$ & $.000^{\mathrm{b}}$ \\
\hline Nausea and vomiting & .011 & .034 & $-.06-.08$ & .746 \\
\hline Pain $^{\mathrm{e}}$ & -.155 & .020 & $-.19--.12$ & $.000^{\mathrm{b}}$ \\
\hline Insomnia & .013 & .016 & $-.02-.04$ & .421 \\
\hline Appetite loss & -.082 & .023 & $-.13--.04$ & $.000^{\mathrm{b}}$ \\
\hline Constipation & -.036 & .018 & $-.07--.00$ & $.050^{\mathrm{b}}$ \\
\hline Diarrhoea & -.003 & .022 & $-.05-.04$ & .871 \\
\hline Dry mouth & -.032 & .017 & $-.07-.00$ & .058 \\
\hline Listlessness & -005 & .025 & $-.05-.04$ & .846 \\
\hline
\end{tabular}

a reference category; ${ }^{\mathrm{b}}$ significant variable; ${ }^{\mathrm{c}}$ Hospital Anxiety and Depression Scale: no anxiety = $\operatorname{HADS}<8$, borderline anxiety = HADS 8-10, anxiety = HADS $\geq 11 ;{ }^{d}$ Hospital Anxiety and Depression Scale: no depression $=$ HADS $<8$, borderline depression $=$ HADS 8-10, depression $=$ HADS $\geq 11$; ${ }^{\text {e }}$ although this manuscript deals with non-pain symptoms, pain was included in the regression analysis to prevent confounding.

\section{Treatment}

In answer to the question whether the patients had received treatment for their symptoms, it appeared that $45-90 \%$ of the moderate to severe non-pain physical symptoms had remained untreated (Figure 4.3). The symptoms with significantly negative impacts on quality of life (fatigue, loss of appetite, dry mouth) had received the least treatment. 


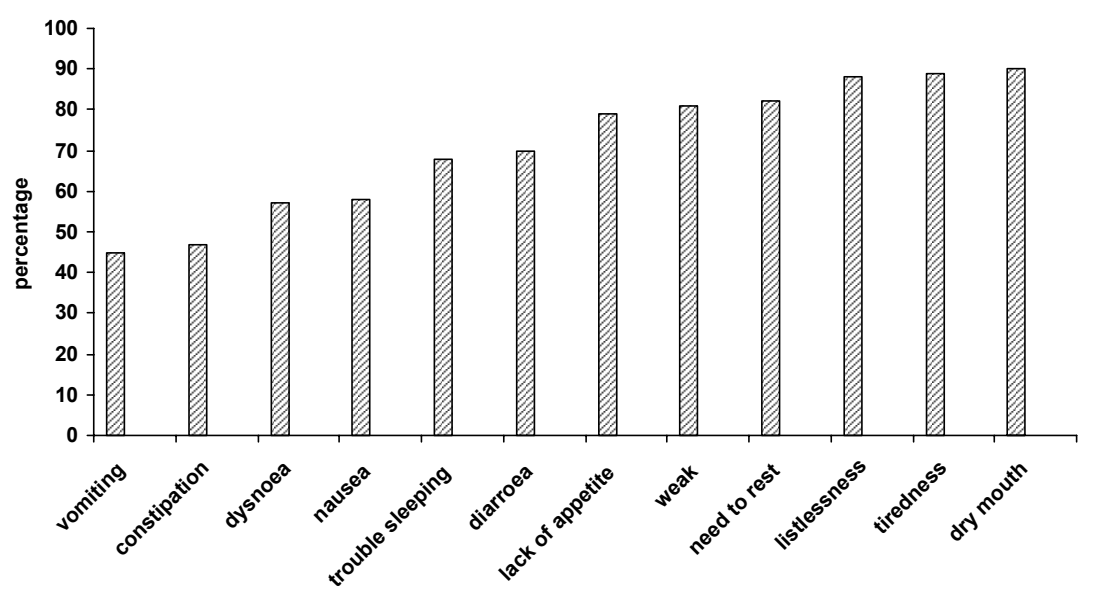

Figure 4.3 Non-treatment rates of various moderate to severe symptoms.

\section{Discussion}

Many patients with cancer are poly-symptomatic., ${ }^{3,13,37-40}$ In our study, the prevalence of physical and psychological symptoms increased with increasing group number. Patients in the curative treatment groups $1 \mathrm{a}$ and $1 \mathrm{~b}$ experienced symptoms that were independent of the cancer type. Symptoms reported in the patients in the palliative treatment group varied with cancer type. In terms of disabling symptoms, cancer type was only important in more advanced disease. An exception was head-and-neck cancer, in which the curative treatment groups had significantly higher prevalences of dry mouth (expected as consequence of the therapy) and anxiety complaints.

Although symptom management research has generally focused on individual symptoms, patients and clinicians know clearly that symptoms may occur in combination and are often detrimental to each other. ${ }^{41}$ In 2001 the concept of symptom clusters was introduced. ${ }^{4}$ However, at present, the clinical implications of symptom clusters are limited. ${ }^{42}$ Therefore, we discussed the symptoms individually per disease group, ${ }^{31}$ while keeping in mind the impact they may have had on each other.

\section{Disease group 1a (curative treatment $>6$ months ago)}

Only a few studies have been performed on the prevalence of symptoms after curative treatment. They mainly focussed on one symptom and a specific 
cancer type (e.g. fatigue in breast cancer, ${ }^{21}$ Hodgkin's disease ${ }^{43}$ or ovarian cancer, ${ }^{44}$ vertigo in nasopharyngeal carcinoma, ${ }^{22}$ or xerostomia in head-andneck cancer ${ }^{45}$ ). In our study, the prevalences of most of the moderate to severe physical and psychological symptoms after curative treatment were comparable with those in the general Norwegian population. ${ }^{46} \mathrm{~A}$ few of our prevalences were higher than in the general Norwegian population: trouble sleeping $(22 \%$ vs $16 \%)$, tiredness $(28 \%$ vs $22 \%)$, difficulties concentrating $(12 \%$ vs $6 \%)$ and worries $(20 \%$ vs $9 \%)$. No differences were found in the prevalence of moderate to severe symptoms between the different cancer types in this group. Cella et al. reported cancer-related fatigue in $33 \%$ of a mixed group of cancer survivors who had completed treatment more than five years before. ${ }^{47}$ Our findings were in accordance with this $(30 \%)$ and with earlier reports on cancer-related fatigue in breast cancer survivors $(30-35 \%)^{48-50}$ and Hodgkin's disease survivors (24-27\%). ${ }^{51,52}$ In contrast, other groups did not find any differences in fatigue between healthy controls and survivors of breast cancer, $^{21}$ ovarian cancer $^{44}$ or Hodgkin's disease. ${ }^{53}$ Consensus exists on a number of issues: fatigue may endure for many months or years, ${ }^{49,54,55}$ there is a strong correlation between fatigue and psychological distress ${ }^{56-58}$ and fatigue has a significantly negative effect on overall quality of life. ${ }^{59-61}$

As expected, far more former head and neck patients had moderate to severe complaints of a dry mouth (46\%) than all other patients. This is in accordance with the literature that $41 \%$ of the head and neck patients still had moderate to severe complaints of a dry mouth $>5$ years after treatment. ${ }^{45}$ We found that the presence of a dry mouth was a negative predictor (borderline significance) of quality of life.

More research has been done into global health outcomes in cancer survivors. In our patients, self-perceived global health was the same as that in the general Norwegian population. ${ }^{46}$ This was in accordance with a recent study on cancer survivors $5-10$ years post-diagnosis. Their physical and mental health status was comparable with population norms. ${ }^{62}$ In contrast, another recent population-based comparison between cancer survivors and matched controls found substantially increased burden of illness in the cancer survivors, even $\geq 11$ years after diagnosis, which manifested itself in various concerns and included: absenterism from work, poor general health perception and needing help with daily activities. ${ }^{63}$ Earlier studies found conflicting results: the typical cancer survivor of multiple primary cancers experienced modest but lasting QoL deficits; ${ }^{64}$ cancer survivors had similar health-related QoL to the general population without chronic co-morbidity; ${ }^{65}$ ovarian cancer survivors reported good physical health and energy, excellent psychological health and improved pleasure in life and personal relationships. ${ }^{44}$ Increasing numbers of authors are advocating Survivor Care Plans, ${ }^{66,67}$ because many cancer survivors become lost in the transition from cancer patient to cancer survivor. ${ }^{68}$ Such plans should 
contain guidelines for surveillance, long-term and late effects of treatment, noncancer care and health maintenance and address issues such as psychological concerns, employment, insurance and economic status. ${ }^{66}$

\section{Disease group $1 \mathrm{~b}$ (current curative treatment)}

Physical and psychological symptoms were reported more frequently by patients in group $1 \mathrm{~b}$ than by the general Norwegian population. ${ }^{46}$ No differences were found in the prevalence of burdensome symptoms between the cancer types. Unfortunately, hardly any research could be found on symptom burden during curative treatment. Studies that addressed non-pain symptoms were mostly out-patient-based and it was impossible to separate the curative patients from the palliative patients. ${ }^{20,69-72}$ Only one study addressed the problem of fatigue in patients treated with curative intent. ${ }^{73}$

Quality of life was significantly better in group $1 \mathrm{~b}$ than in group 2 . Therefore, future research should address curative patients separately from palliative patients.

Our finding of moderate to severe fatigue in $40.5 \%$ was in accordance with the rates in curative patients $(26-45 \%),{ }^{73}$ but lower than those in the out-patient (mixed groups) studies (55\% and 54\%). ${ }^{69,72}$ Far more head and neck patients had moderate to severe complaints of a dry mouth $(50 \%)$ than the other patients. Surprisingly, they were suffering from significantly more anxiety (HADS $\geq 11)(29 \%)$ than the patients with other cancer types in group 1b (mean $13 \%$ ), while anxiety disorders in group $1 \mathrm{~b}(\mathrm{HADS} \geq 8$ ) were much more prevalent than in the general population $(27<->18 \%) .{ }^{74}$ In earlier reports, anxiety disorders were found in $22-34 \%$ of cancer outpatients. ${ }^{29,75,76}$ Korfage measured anxiety in prostate cancer patients over a period of five years. High pre-treatment anxiety was present in $28 \%$ of the patients, but it decreased significantly post-treatment. The sensitivity of anxiety at baseline as a screening tool was $71 \%{ }^{30}$ In a cohort of breast cancer patients, the prevalence of anxiety decreased from $40 \%$ post-surgery to $16 \%$ six months later. ${ }^{77}$ Anxiety had a significantly negative influence on quality of life, so we recommend screening for anxiety in daily practice.

\section{Disease group 2 (palliative therapy)}

In group 2, all the symptoms occurred more frequently than in the general population ${ }^{46}$ and group $1 \mathrm{~b}$. The number and type of symptoms depended on the cancer type. Dyspnoea was significantly more prevalent in patients with lung cancer and in patients with haematological malignancies. Diarrhoea was associated with gastro-intestinal cancer and gynaecological cancer; sleeping problems were associated with lung, breast and other haematological malignancies and fatigue-related symptoms were associated with gastro- 
intestinal and other haematological malignancies. The most prevalent symptoms were feeling weak, feeling tired and need to rest (i.e. the EORTC construct fatigue). Earlier studies reported some degree of fatigue in more than $80 \%$ of outpatients receiving chemotherapy or radiotherapy.

Only two studies were found that explicitly focussed on patients during palliative treatment. ${ }^{13,78}$ When the three studies were combined, prevalence rates of moderate to severe symptoms were: dyspnoea 10-29\%, need to rest $43 \%$, sleeping problems $22-33 \%$, feeling weak $31 \%$, appetite loss $18-51 \%$, nausea $14-15 \%$, vomiting $6 \%$, constipation $15-23 \%$, diarrhoea $6 \%$, feeling tired $45-69 \%$, dry mouth $17-28 \%$, listlessness $13-45 \%$, difficulties concentrating $20 \%$, feeling tense $15-24 \%$, worries $38 \%$, feeling irritated $22 \%$, difficulties remembering $16 \%$, anxiety $13-40 \%$ and depression $19-30 \%$. An explanation for the wide variation in the prevalence of loss of appetite is that Bradley's population were undergoing radiotherapy. The prevalence ranges for anxiety and depression might be due to differences in definition: anxiety/depressive disorder (HADS $\geq 8$ ) or anxiety/depression (HADS $\geq 11$ ). ${ }^{33}$ In our study, $45-90 \%$ of the moderate to severe symptoms remained untreated. These were much higher percentages than those in earlier reports. Puts et al. ${ }^{78}$ stated that symptoms had received insufficient treatment in $17 \%$ while $27 \%$ gave answers such as "nothing can be done", or "it is a side-effect", or "this symptom comes with having cancer". In one study, $44 \%$ of the patients stated that the healthcare professionals were aware of their symptoms. ${ }^{78}$ Those findings suggest an analogy with the reasons for undertreatment of cancer-related pain that included care provider as well as patient-related barriers: physicians and nurses did not have formal assessment procedures, ${ }^{79-81}$ patients were reluctant to inform their care providers about pain because of concerns that they would bother their physician or distract him/her from treating the cancer, ${ }^{82,83}$ patients wanted to be "good" patients and a good patient does not complain, ${ }^{83-85}$ patients believed that nothing could be done to ease the pain (fatalism), ${ }^{84,86}$ or thought they had to endure the pain because they have cancer. ${ }^{86}$ In addition, patients may fear that their pain is indicative of disease progression and they do not want to face that possibility. ${ }^{87}$ Patients were reluctant to take medication: fear of addiction continues to be a major concern of patients and their families $(27-83 \%){ }^{82,84,86}$ Thirty to seventy-two per cent of the patients expressed concerns about tolerance ${ }^{84,86}$ and about $25 \%$ of patients believe that pain medications are "bad" for the body.

\section{Disease group 3 (treatment no longer feasible)}

Physical and psychological symptoms were most frequent in these patients. Unfortunately, the group was too small to compare the prevalences of symptoms between cancer types. The $46 \%$ prevalence of moderate to severe 
dyspnoea was in accordance with the literature. A review by Ripamonti ${ }^{89}$ showed moderate to severe dyspnoea in $10-63 \%$ of advanced cancer patients. More recently, dyspnoea was reported in 35\% (19-77\%) of advanced cancer patients in a review. ${ }^{19}$ In the last two weeks of life $39 \%$ had dyspnoea. ${ }^{19}$ The prevalence of constipation in our group 3 patients was considerably lower than the $40-60 \%$ previously reported. ${ }^{19,90,91}$ Apparently, ongoing education has paid off and increased the awareness of physicians, nurses and pharmacists.

Moderate to severe complaints of a dry mouth $(58 \%)$ were less frequent than the rates reported in earlier studies (78-97\%). ${ }^{92-94}$ As expected, a dry mouth was most prevalent in head and neck cancer. It had a considerably negative impact on QoL. In the literature a dry mouth was ranked as the third most distressing symptom, ${ }^{93}$ or was described as "very distressing". ${ }^{95}$

A complaint that mainly applied to group 3 patients was moderate to severe listlessness (30\%). In earlier studies the prevalence was $12-32 \% .{ }^{19}$ Problems with cognitive functioning were also found exclusively in group 3.

Our patients had highly compromised quality of life compared to the general population (45 vs 74 ). ${ }^{46}$

\section{Quality of life (QoL)}

None of the demographic parameters exerted a significant influence on QoL.

Quality of life was significantly better in patients in disease group 1a than in patients under palliative treatment. However, also patients under curative anticancer treatment (group 1b) had a significantly better QoL than patients during palliative anti-cancer treatment, while the later group was significantly better than group 3.

Gastro-intestinal cancer, malignant lymphoma and other haematological malignancies were associated with significantly poorer QoL than other types. In group 2 high prevalences of symptoms that compromised QoL were present in the patients with other haematological malignancies (fatigue, sleeping problems and dyspnoea) and in patients with gastro-intestinal cancer (fatigue). In the malignant lymphoma patients, none of the separate symptom prevalences were significantly higher than those in the patients with other cancer types. An explanation for this might be a combination of many non significant symptoms that put a heavy burden on QoL in malignant lymphoma patients.

Quality of life was significantly better in the patients without depression or anxiety. The literature on anxiety is discussed above in the section on group $1 \mathrm{~b}$.

A strong body of evidence demonstrated the coexistence of depression and cancer. ${ }^{26}$ The prevalence rates of depression in patients with solid tumours ranged from 20 to $50 \% .{ }^{26}$ In a cohort of breast cancer patients the prevalence 
of anxiety and depression was $33 \%$ at diagnosis, $15 \%$ after one year and $45 \%$ after the diagnosis of recurrence. ${ }^{96}$ Improvement in mental health in men with prostate cancer was statistically significant and clinically meaningful at 6months follow-up. ${ }^{30}$ Contrastingly, in two other studies, one on early versus late breast cancer $^{97}$ and one on early versus late chronic lymphatic leukaemia (CLL), depression and anxiety disorders and quality of life were not statistically different between the early and late groups. ${ }^{23}$ Pancreatic cancer had the highest rates of depression $(56.3 \%)$ and anxiety $(56.7 \%){ }^{29}$ Distress was significantly higher in lung cancer $(43 \%)$ and brain cancer $(42.7 \%)$ patients, but lower in gynaecological (29.6\%), prostate (30.5\%) and colon (31.6\%) cancer patients. $^{29}$

The other literature showed that psychological symptoms had a considerably negative effect on quality of life in patients with chronic diseases ${ }^{98-101}$ and cancer. $^{26,102}$ In our study, the influence of depression was significant. Inadequate diagnosis of distress, particularly depression, among cancer patients caused higher rates of non-compliance ${ }^{101}$ and shorter survival. ${ }^{103}$

Other symptoms associated with significantly poorer quality of life were the fatigue (group 1a), loss of appetite, constipation and (marginally) dry mouth (group 1a). The incidence of the anorexia cachexia syndrome was difficult to determine, but in general, it occurred in $15 \%$ to $40 \%$ of patients with cancer and in more than $80 \%$ of patients with advanced disease. ${ }^{104}$ In the literature, loss of appetite was ranked as one of the five most challenging symptoms by at least $60 \%$ of the patients. ${ }^{105}$ Furthermore, loss of appetite and weight loss were associated with poorer prognosis. ${ }^{106,107}$

Patients on opioid therapy reported that the most common and often most debilitating side- effect was constipation. ${ }^{108}$ However, the aetiology of constipation is multifactorial: the chief culprits include immobility, inadequate fluid intake, poor nutrition and medication (e.g. opioids, anti-emetics, anticholinergics and NSAIDs). ${ }^{109}$ Constipation not only had significantly negative effects on QoL, but also generated high health-care-related financial cost (medical and nursing time). ${ }^{109}$

Many symptoms remained untreated. Although, adequate therapy is not always available, there is a striking resemblance with the undertreatment of pain. Probably, the barriers in pain treatment ${ }^{83,110}$ hold truth for the non-pain symptoms.

\section{Limitations}

This study has some limitations. Despite the proper format and effort made to encourage GPs, nursing home physicians and nursing staff at the hospices to recruit patients for group 3 , the numbers remained small. Therefore, this group may not have fulfilled our intention of being representative of patients with 
metastatic/advanced disease. Selection by GPs, nursing home physicians and nursing staff at the hospices may have excluded many terminal patients. It is not clear how this selection influenced the prevalence of symptoms. Mostly, no differences in symptom prevalence were reported between the palliative and terminal (last two weeks) phase. ${ }^{18,111}$ Labori in contrast found that all symptoms increased from baseline to 1-4 weeks before death. ${ }^{15}$ Dry mouth and fatigue, ${ }^{112}$ nausea and urinary symptoms ${ }^{19}$ were found to improve toward the end of life.

The fairly broad range of cancer types made it difficult to translate symptom burden to individual patients. Owing to the limited numbers in each group, it was not possible to make more detailed subdivisions (e.g. pancreas, stomach, oesophagus, etc. versus gastrointestinal).

Our analyses showed significant differences in the prevalences of 10 out of the 19 symptoms between the various cancer types in at least one group. However, when lung cancer was excluded, only seven symptoms differed significantly and mainly in the patients in group 2. Possibly, many of our patients with lung cancer were misclassified into groups $1 \mathrm{a}$ and $1 \mathrm{~b}$, because 5year survival in non-small-cell-lung carcinoma is $10-15 \%$, while 3 -year survival in small-cell-lung cancer is $<10 \%{ }^{36}$

The patients themselves provided the data on the treatment of symptoms. Lack of awareness of what all the medication was for could have overestimated the rate of undertreatment.

\section{Conclusion}

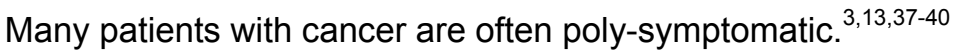

The prevalence of all symptoms increases with increasing group number. Patients (being) treated with curative intent experience symptoms that are independent of cancer type. In patients treated with palliative therapy, symptoms vary with cancer type. Quality of life decreases significantly with increasing group number.

In clinical practice and future research, it is advisable to divide patients according to their treatment status, instead of dividing them into outpatients and patients with advanced disease.

Fatigue, loss of appetite, constipation, dry mouth, depression and anxiety have independent negative influences on quality of life.

Many of the non-pain symptoms remain untreated, although (partly) effective treatment is available for most symptoms. This illustrates the need for better education about symptoms and symptom control in the curricula of medical professionals. Systematic recording of symptom intensity is mandatory in patients with cancer, irrespective of the phase of the disease. 


\section{References}

1. Coebergh JWW, Poll-Franse van de LV, Alers JC, Berg van de FA, Duijn van NP. (KWF Kankerbestrijding). Kanker in Nederland, Trends, prognses en implicaties voor zorgvraag. 2004.

2. Barsevick AM, Dudley WN, Beck SL. Cancer-related fatigue, depressive symptoms, and functional status: a mediation model. Nurs Res. 2006;55:366-72.

3. Chang VT, Hwang SS, Feuerman M, Kasimis BS. Symptom and quality of life survey of medical oncology patients at a veterans affairs medical center: a role for symptom assessment. Cancer. 2000;88:1175-83.

4. Dodd MJ, Miaskowski C, Paul SM. Symptom clusters and their effect on the functional status of patients with cancer. Oncol Nurs Forum. 2001;28:465-70.

5. Gaston-Johansson F, Ohly KV, Fall-Dickson JM, Nanda JP, Kennedy MJ. Pain, psychological distress, health status, and coping in patients with breast cancer scheduled for autotransplantation. Oncol Nurs Forum. 1999;26:1337-45.

6. Gift AG, Jablonski A, Stommel M, Given CW. Symptom clusters in elderly patients with lung cancer. Oncol Nurs Forum. 2004;31:202-12.

7. Gift AG, Stommel M, Jablonski A, Given W. A cluster of symptoms over time in patients with lung cancer. Nurs Res. 2003;52:393-400.

8. Given B, Given C, Azzouz F, Stommel M. Physical functioning of elderly cancer patients prior to diagnosis and following initial treatment. Nurs Res. 2001;50:222-32.

9. Redeker NS, Lev EL, Ruggiero J. Insomnia, fatigue, anxiety, depression, and quality of life of cancer patients undergoing chemotherapy. Sch Inq Nurs Pract. 2000;14:275-90; discussion 291-8.

10. Visser MR, Smets EM. Fatigue, depression and quality of life in cancer patients: how are they related? Support Care Cancer. 1998;6:101-8.

11. Williamson GM, Schulz R. Activity restriction mediates the association between pain and depressed affect: a study of younger and older adult cancer patients. Psychol Aging. 1995;10:369-78.

12. van den Beuken-van Everdingen M, de Rijke J, Kessels A, Schouten H, van Kleef M, Patijn J. Prevalence of pain in patients with cancer: a systematic review of the past 40 years. Ann Oncol. 2007;18:1437-49.

13. Bradley N, Davis L, Chow E. Symptom distress in patients attending an outpatient palliative radiotherapy clinic. J Pain Symptom Manage. 2005;30:123-31.

14. Hoekstra J, Vos de R, Duijn van NP, Schade E, Bindels PJ. Using the symptom monitor in a randomized controlled trial: the effect on symptom prevalence and severity. J Pain Symptom Manage. 2006;31:22-30.

15. Labori KJ, Hjermstad MJ, Wester T, Buanes T, Loge JH. Symptom profiles and palliative care in advanced pancreatic cancer: a prospective study. Support Care Cancer. 2006;14:1126-33.

16. Moro C, Brunelli C, Miccinesi G, Fallai M, Morino P, Piazza M, Labianca R, Ripamonti C. Edmonton symptom assessment scale: Italian validation in two palliative care settings. Support Care Cancer. 2006;14:30-7.

17. Tsai JS, Wu CH, Chiu TY, Hu WY, Chen CY. Symptom patterns of advanced cancer patients in a palliative care unit. Palliat Med. 2006;20:617-22.

18. Stromgren AS, Sjogren P, Goldschmidt D, Petersen MA, Pedersen L, Groenvold M. Symptom priority and course of symptomatology in specialized palliative care. J Pain Symptom Manage. 2006;31:199-206.

19. Teunissen SC, Wesker W, Kruitwagen C, de Haes HC, Voest EE, de Graeff A. Symptom prevalence in patients with incurable cancer: a systematic review. J Pain Symptom Manage. 2007;34:94-104.

20. O'Driscoll M, Corner J, Bailey C. The experience of breathlessness in lung cancer. Eur J Cancer Care (Engl). 1999;8:37-43. 
21. Carpenter JS, Elam JL, Ridner SH, Carney PH, Cherry GJ, Cucullu HL. Sleep, fatigue, and depressive symptoms in breast cancer survivors and matched healthy women experiencing hot flashes. Oncol Nurs Forum. 2004;31:5591-8.

22. Young YH, Ko JY, Sheen TS. Postirradiation vertigo in nasopharyngeal carcinoma survivors. Otol Neurotol. 2004;25:366-70.

23. Levin T, Kissane DW. Psychooncology - the state of its development in 2006. European Journal of Psychiatry. 2006;20):183-97.

24. Pirl WF. Evidence report on the occurrence, assessment, and treatment of depression in cancer patients. J Natl Cancer Inst Monogr. 2004:32-9.

25. Massie MJ. Prevalence of depression in patients with cancer. J Natl Cancer Inst Monogr. 2004:57-71.

26. Pasquini M, Biondi M. Depression in cancer patients: a critical review. Clin Pract Epidemol Ment Health. 2007;3:2.

27. Kerrihard T, Breitbart W, Dent R, Strout D. Anxiety in patients with cancer and human immunodeficiency virus. Seminars in Clinical Neuropsychiatry. 1999;4:114-32.

28. Prieto JM, Atala J, Blanch J, Carreras E, Rovira M, Cirera E, Espinal A, Gasto C. Role of depression as a predictor of mortality among cancer patients after stem-cell transplantation. $\mathrm{J}$ Clin Oncol. 2005;23:6063-71.

29. Zabora J, BrintzenhofeSzoc K, Curbow B, Hooker C, Piantadosi S. The prevalence of psychological distress by cancer site. Psychooncology. 2001;10:19-28.

30. Korfage IJ, Essink-Bot ML, Janssens AC, Schroder FH, Koning de HJ. Anxiety and depression after prostate cancer diagnosis and treatment: 5-year follow-up. $\mathrm{Br} \mathrm{J}$ Cancer. 2006;94:1093-8.

31. Beuken-van Everdingen van den MHJ, de Rijke JM, Kessels AG, Schouten HC, van Kleef M, Patijn J. High prevalence of pain in patients with cancer in a large population-based study in The Netherlands. Pain. 2007;132:312-20.

32. Aaronson NK, Ahmedzai S, Bergman B, Bullinger M, Cull A, Duez NJ, Filiberti A, Flechtner H, Fleishman SB, de Haes JC, et al. The European Organization for Research and Treatment of Cancer QLQ-C30: a quality-of-life instrument for use in international clinical trials in oncology. J Natl Cancer Inst. 1993;85:365-76.

33. Zigmond AS, Snaith RP. The hospital anxiety and depression scale. Acta Psychiatr Scand. 1983;67:361-70.

34. Bjelland I, Dahl AA, Haug TT, Neckelmann D. The validity of the Hospital Anxiety and Depression Scale. An updated literature review. J Psychosom Res. 2002;52:69-77.

35. Field A. Discovering Statistics Using SPSS. second edition ed London: SAGE Publications Ltd; 2005.

36. Janssen-Heijnen MLG, Louwman WJ, Poll-Franse van de LV, Coebergh JWW. (Integraal Kankercentrum Zuid (IKZ)). Van meten naar weten. 2005.

37. Hwang SS, Chang VT, Cogswell J, Alejandro Y, Osenenko P, Morales E, Srinivas S, Kasimis B. Study of unmet needs in symptomatic veterans with advanced cancer: incidence, independent predictors and unmet needs outcome model. J Pain Symptom Manage. 2004;28:421-32.

38. Lidstone V, Butters E, Sinnott C, Beynon T, Richards M. Symptoms and concerns amongst cancer outpatients: identifying the need for specialist palliative care. Palliative Medicine. 2003;17:588-95.

39. Portenoy RK, Thaler HT, Kornblith AB, Lepore JM, Friedlander-Klar H, Coyle N, Smart-Curley T, Kemeny N, Norton L, Hoskins W, Scher H. Symptom prevalence, characteristics and distress in a cancer population. Qual Life Res. 1994;3:183-9.

40. Schuit KW, Sleijfer DT, Meijler WJ, Otter R, Schakenraad J, van den Bergh FC, Meyboom-de Jong B. Symptoms and functional status of patients with disseminated cancer visiting outpatient departments. J Pain Symptom Manage. 1998;16: 290-7.

41. Williams LA. Clinical management of symptom clusters. Semin Oncol Nurs. 2007;23:113-20.

42. Barsevick AM. The concept of symptom cluster. Semin Oncol Nurs. 2007;23:89-98.

43. Ganz PA, Bower JE. Cancer related fatigue: a focus on breast cancer and Hodgkin's disease survivors. Acta Oncol. 2007;46:474-9. 
44. Stewart DE, Wong F, Duff S, Melancon CH, Cheung AM. "What Doesn't Kill You Makes You Stronger": An Ovarian Cancer Survivor Survey. Gynecol Oncol. 2001;83:537-42.

45. Braam PM, Roesink JM, Raaijmakers CPJ, Busschers WB, Terhaard CHJ. Quality of life and salivary output in atients with head-and-neck cancer five years after raditherapy. Radiation Oncology. 2007;2:3.

46. The EORTC Quality of Life Reference Values program]. Version 2003. EORTC Quality of Life group Brussels; 2003.

47. Cella D, Davis K, Breitbart W, Curt GA. Cancer-related fatigue: prevalence of proposed diagnostic criteria in a United States sample of cancer survivors. J Clin Oncol. 2001;19: 3385-91.

48. Servaes $P$, Verhagen $C$, Bleijenberg $G$. Fatigue in cancer patients during and after treatment: Prevalence, correlates and interventions. Eur J Cancer. 2002;38:27-43.

49. Bower JE, Ganz PA, Desmond KA, Bernaards C, Rowland JH, Meyerowitz BE, Belin TR. Fatigue in long-term breast carcinoma survivors: a longitudinal investigation. Cancer. 2006;106:751-8.

50. Lindley CM, Vasa S, Sawyer WT, Winer EP. Quality of life and preferences for treatment following systemic adjuvant therapy for early-stage breast cancer. 1998;16:1380-7.

51. Loge JH, Abrahamsen AF, Ekeberg, Kaasa S. Fatigue and psychiatric morbidity among Hodgkin's disease survivors. J Pain Symptom Manage. 2000;19:91-9.

52. Loge $\mathrm{JH}$, Abrahamsen AF, Ekeberg $\mathrm{O}$, Kaasa S. Hodgkin's disease survivors more fatigued than the general population. J Clin Oncol. 1999;17:253-61.

53. Ng AK, Li S, Recklitis C, Neuberg D, Chakrabarti S, Silver B. A comparison between longterm survivors of Hodgkin's disease and their siblings on fatigue level and factors predicting for increased fatigue. Ann Oncol. 2005;16:1949-55.

54. Dow KH, Ferrell BR, Leigh SA, Ly J, Gulasekaram P. An evaluation of the quality of life among long-term survivors of breast cancer. Breast Cancer Res Treat. 1996;39:261-73.

55. Jacobsen $\mathrm{PB}$, Stein $\mathrm{K}$. Is fatigue a long-term side effect of breast cancer treatment? Cancer Control. 1999;6:256-63.

56. Andrykowski MA, Curran SL, Lightner R. Off-treatment fatigue in breast cancer survivors: $\mathrm{A}$ controlled comparison. J Behav Med. 1998;21:1-18.

57. Bower JE, Ganz PA, Desmond KA, Rowland JH, Meyerowitz BE, Belin TR. Fatigue in breast cancer survivors: Occurence, correlates, and impact on quality of life. J Clin Oncol 2000;18:743-53.

58. Goldstein D, Bennett B, Friedlander M, Davenport T, Hickie I, Lloyd A. Fatigue states after cancer treatment occur both in association with, and independent of, mood disorder: a longitudinal study. BMC cancer. 2006;6:240.

59. Mitchell SA, Berger AM. Cancer-related fatigue: The evidence base for assessment and management. Cancer J. 2006;12:374-87.

60. Andrykowski MA, Schmidt JE, Salsman JM, Beachman AO, Jacobsen PB. Use of a case definition approach to identify cancer-related fatigue in women undergoing adjuvant therapy for breast cancer. J Clin Oncol. 2005;23:6613-22.

61. Hjermstad MJ, Oldervoll L, Fossa SD, Holte H, Jacobsen AB, Loge JH. Quality of life in longterm Hodgkin's disease survivors with chronic fatigue. Eur J Cancer. 2006;42:327-33.

62. Zebrack BJ, Yi J, Petersen L, Ganz PA. The impact of cancer and quality of life for long-term survivors. Psychooncology. 2007;17:891-900.

63. Yabroff KR, Lawrence WF, Clauser S, Davis WW, Brown ML. Burden of illness in cancer survivors: findings from a population-based national sample. J Natl Cancer Inst. 2004; 96:1322-30.

64. Gotay CC, Ransom S, Pagano IS. Quality of life in survivors of multiple primary cancers compared with cancer survivor controls. Cancer. 2007;110:2101-9.

65. Fossa SD, Hess SL, Dahl AA, Hjermstad MJ, Veenstra M. Stability of health-related quality of life in the Norwegian general population and impact of chronic morbidity in individuals with and without a cancer diagnosis. Acta Oncol. 2007;46:452-61.

66. Earle CC. Failing to plan is planning to fail: improving the quality of care with survivorship care plans. J Clin Oncol. 2006;24:5112-6. 
67. Hoffman B, Stovall E. Survivorship perspectives and advocacy. J Clin Oncol. 2006;24:5154-9.

68. Hewitt M, Greenfield S, Stovall E. From cancer patient to cancer survivor: Lost in transition. Washington DC: National Academies Press; 2005.

69. Hickok JT, Morrow GR, Roscoe JA, Mustian K, Okunieff P. Occurrence, severity, and longitudinal course of twelve common symptoms in 1129 consecutive patients during radiotherapy for cancer. J Pain Symptom Manage. 2005;30:433-42.

70. Guo Y, Young BL, Hainley S, Palmer JL, Bruera E. Evaluation and pharmacologic management of symptoms in cancer patients undergoing acute rehabilitation in a comprehensive cancer center. Arch Phys Med Rehabil. 2007;88:891-5.

71. Dudgeon DJ, Kristjanson L, Sloan JA, Lertzman M, Clement K. Dyspnea in cancer patients: prevalence and associated factors. J Pain Symptom Manage. 2001;21:95-102.

72. Davidson JR, MacLean AW, Brundage MD, Schulze K. Sleep disturbance in cancer patients. Soc Sci Med. 2002;54:1309-21.

73. Jong de N, Candel MJ, Schouten HC, Abu-Saad HH, Courtens AM. Prevalence and course of fatigue in breast cancer patients receiving adjuvant chemotherapy. Ann Oncol. 2004;15: 896-905.

74. Symreng I, Fishman SM. Anxiety and Pain. Pain, clinical Updates. 2004;12:1-6.

75. Grassi L, Travado L, Moncayo FL, Sabato S, Rossi E. Psychosocial morbidity and its correlates in cancer patients of the Mediterranean area: findings from the Southern European Psycho-Oncology Study. J Affect Disord. 2004;83:243-8.

76. Strong V, Waters R, Hibberd C, Rush R, Cargill A, Storey D, Walker J, Wall L, Fallon M, Sharpe M. Emotional distress in cancer patients: the Edinburgh Cancer Centre symptom study. Br J Cancer. 2007;96:868-74.

77. Hugel H, Ellershaw JE, Cook L, Skinner J, Irvine C. The prevalence, key causes and management of insomnia in palliative care patients. J Pain Symptom Manage. 2004;27: 316-21.

78. Puts MT, Versloot J, Muller MJ, Dam van FS. [The opinion on care of patients with cancer undergoing palliative treatment in day care]. Ned Tijdschr Geneeskd. 2004;148:277-80.

79. Rawal N, Hylander J, Arner S. Management of terminal cancer pain in Sweden: a nationwide survey. Pain. 1993;54:169-79.

80. Brunelli C, Costantini M, Di Giulio P, Gallucci M, Fusco F, Miccinesi G, Paci E, Peruselli C, Morino P, Piazza M, Tamburini M, Toscani F. Quality-of-life evaluation: when do terminal cancer patients and health-care providers agree? J Pain Symptom Manage. 1998;15:151-8.

81. Cleeland CS, Gonin R, Hatfield AK, Edmonson JH, Blum RH, Stewart JA, Pandya KJ. Pain and its treatment in outpatients with metastatic cancer. N Engl J Med. 1994;330:592-6.

82. Paice JA, Toy C, Shott S. Barriers to cancer pain relief: fear of tolerance and addiction. J Pain Symptom Manage. 1998;16:1-9.

83. Lin CC. Barriers to the analgesic management of cancer pain: a comparison of attitudes of Taiwanese patients and their family caregivers. Pain. 2000;88:7-14.

84. Yun YH, Heo DS, Lee IG, Jeong HS, Kim HJ, Kim SY, Kim YH, Ro YJ, Yoon SS, Lee KH, Huh BY. Multicenter study of pain and its management in patients with advanced cancer in Korea. J Pain Symptom Manage. 2003;25:430-7.

85. Ward SE, Goldberg N, Miller-McCauley V, Mueller C, Nolan A, Pawlik-Plank D, Robbins A, Stormoen D, Weissman DE. Patient-related barriers to management of cancer pain. Pain. 1993;52:319-24.

86. Thomason TE, McCune JS, Bernard SA, Winer EP, Tremont S, Lindley CM. Cancer pain survey: patient-centered issues in control. J Pain Symptom Manage. 1998;15:275-84.

87. Pargeon KL, Hailey BJ. Barriers to effective cancer pain management: a review of the literature. J Pain Symptom Manage. 1999;18:358-68.

88. Riddell A, Fitch MI. Patients' knowledge of and attitudes toward the management of cancer pain. Oncol Nurs Forum. 1997;24:1775-84.

89. Ripamonti C. Management of dyspnea in advanced cancer patients. Support Care Cancer. 1999;7:233-43.

90. Solomon R, Cherny NI. Constipation and diarrhea in patients with cancer. Cancer J. 2006;12:355-64. 
91. Goodman M, Low J, Wilkinson S. Constipation management in palliative care: a survey of practices in the United Kingdom. J Pain Symptom Manage. 2005;29:238-44.

92. Sweeney MP, Bagg J, Baxter WP, Aitchison TC. Oral disease in terminally ill cancer patients with xerostomia. Oral Oncol. 1998;34:123-6.

93. Davies AN, Broadley K, Beighton D. Xerostomia in patients with advanced cancer. J Pain Symptom Manage. 2001;22:820-5.

94. Oneschuk D, Hanson J, Bruera E. A survey of mouth pain and dryness in patients with advanced cancer. Support Care Cancer. 2000;8:372-6.

95. Davies AN. A comparison of artificial saliva and chewing gum in the management of xerostomia in patients with advanced cancer. Palliat Med. 2000;14:197-203.

96. Burgess C, Cornelius V, Love S, Graham J, Richards M, Ramirez A. Depression and anxiety in women with early breast cancer: five year observational cohort study. BMJ. 2005;330:702.

97. Kissane DW, Grabsch B, Love A, Clarke DM, Bloch S, Smith GC. Psychiatric disorder in women with early stage and advanced breast cancer: a comparative analysis. Aust $\mathrm{N} \mathrm{Z} \mathrm{J}$ Psychiatry. 2004;38:320-6.

98. Ola BA, Adewuya AO, Ajayi OE, Akintomide AO, Oginni OO, Ologun YA. Relationship between depression and quality of life in Nigerian outpatients with heart failure. J Psychosom Res. 2006;61:797-800.

99. Uguz F, Dursun R, Kaya N, Cilli AS. Quality of life in patients with Behcet's disease: the impact of major depression. Gen Hosp Psychiatry. 2007;29:21-4.

100. Stafford L, Berk M, Reddy P, Jackson HJ. Comorbid depression and health-related quality of life in patients with coronary artery disease. J Psychosom Res. 2007;62:401-10.

101. Ashbury FD, Madlensky L, Raich P, Thompson M, Whitney G, Hotz K, Kralj B, Edell WS. Antidepressant prescribing in community cancer care. Support Care Cancer. 2003;11:278-85.

102. Wilson KG, Chochinov HM, Skirko MG, Allard P, Chary S, Gagnon PR, Macmillan K, De Luca M, O'Shea F, Kuhl D, Fainsinger RL, Clinch JJ. Depression and anxiety disorders in palliative cancer care. J Pain Symptom Manage. 2007;33:118-29.

103. Watson M, Haviland JS, Greer S, Davidson J, Bliss JM. Influence of psychological response on survival in breast cancer: a population-based cohort study. Lancet. 1999;354:1331-6.

104. Berenstein EG, Ortiz Z. Megestrol acetate for the treatment of anorexia-cachexia syndrome. Cochrane Database Syst Rev. 2005:CD004310.

105. Behl D, Jatoi A. Pharmacological options for advanced cancer patients with loss of appetite and weight. Expert Opin Pharmacother. 2007;8:1085-90.

106. Dewis WB, Begg C, Lavin PT. Prognostic efect of weight loss prior to chemotherapy in cancer patients. Am J Med. 1980;69:491-7.

107. Loprinzi CL, Laurie JA, Wieand HS. Prospective evaluation of prognostic variables from patient-completed questionnaires. J Clin Oncol. 1994;12:601-7.

108. Walsh TD. Prevention of opioid side effects. J Pain Symptom Manage. 1990;5:362-7.

109. Fallon. Costipation in cancer patients:Prevalence, pathogenesis, and cost-related issues. European Journal of Pain. 1999;3(SUPLL. A):3-8.

110. Johnson DC, Kassner CT, Houser J, Kutner JS. Barriers to effective symptom management in hospice. J Pain Symptom Manage. 2005;29:69-79.

111. Doorenbos AZ, Given CW, Given B, Verbitsky N. Symptom experience in the last year of life among individuals with cancer. J Pain Symptom Manage. 2006;32:403-12.

112. Brandt HE, Ooms ME, Deliens L, van der Wal G, Ribbe MW. The last two days of life of nursing home patients--a nationwide study on causes of death and burdensome symptoms in The Netherlands. Palliat Med. 2006;20:533-40.

113. Crawford JR, Henry JD, Crombie C, Taylor EP. Normative data for the HADS from a large non-clinical sample. Br J Clin Psychol. 2001;40:429-34. 


\section{Chapter 5}

\section{A randomised clinical trial of an intensive nursing- based pain education programme for cancer outpatients with pain}

Evelien $\mathrm{H}$ van der Peet, Marieke $\mathrm{HJ}$ van den Beuken-van Everdingen, Janneke M de Rijke, Alfons G Kessels, Harry C Schouten, Maarten van Kleef, Jacob Patijn

Submitted 


\section{Abstract}

\section{Introduction}

The prevalence of pain in patients with cancer is still too high. Factors related to ineffective pain treatment fall into three categories: the health care system, professional care providers and patients. In patients, various barriers lead to non-compliance. Previous educational interventions have increased their pain knowledge and decreased short-term pain levels. In this randomised controlled trial, we investigated how an intensive home-based education programme given by nurses affected short-term and long-term pain levels.

\section{Methods}

120 cancer patients were randomised to receive either the Pain Education Programme (PEP) or usual care. Pain, knowledge, quality of life, anxiety and depression were measured at baseline, after four weeks and after eight weeks. In the intervention group, symptom levels were communicated to the treating physician.

\section{Results}

Pain knowledge increased significantly in the intervention group. Their level of pain had decreased at four weeks, but not at eight weeks. Significant decreases in pain only lasted in the patients with a high pain score at baseline. No correlation was found between increased pain knowledge and decreased pain levels.

\section{Conclusion}

The PEP education programme given by nurses lowered pain intensity levels of cancer patients and increased their pain knowledge. More attention should be paid to patient education and to communication between patients and health professionals about pain and pain management. 


\section{Introduction}

Many patients with cancer have (multiple) symptoms that can affect their feeling of well-being and their physical and social functioning.

One of the most feared and burdensome physical symptoms in patients with cancer is pain. A recent review has shown that the prevalence of pain in patients with cancer is still high: $64 \%$ in patients with metastatic, advanced or terminal disease and $59 \%$ in patients on anti-cancer treatment. ${ }^{1}$

Factors related to ineffective pain management fall in three categories: the health care system, health care providers and patients. ${ }^{2}$ In the health care system, more attention focuses on "curing" patients with cancer than on "caring" for them, which also includes symptom management. ${ }^{3}$ Health care providers tend to lack attention for and knowledge about pain management ${ }^{4-9}$ and as a consequence, do not always treat pain according the WHO guidelines. ${ }^{5,10}$ Patients generally lack knowledge about pain and pain management and are reluctant to report pain to their physician. ${ }^{11,12}$ Fears such as drug addiction, tolerance and concerns about side-effects also influence their pain medication intake $e^{6,11}$. However, patients indicated that they would appreciate help with their physical and psychosocial problems and information about them. ${ }^{13-15}$

With respect to the ineffective pain management in the health care system category, no RCT's have been published whose intention was to focus the attention on the combination of care and pain aspects. In the health care provider category, Goldberg and Morison conducted a systematic review of institutional interventions designed to improve the assessment and treatment of pain in cancer patients. ${ }^{16}$ Their review included three trials that studied the effects of education for nurses on pain-related topics. ${ }^{17-19}$ It was concluded that the education sessions improved the nurses' knowledge about pain and their attitudes towards it. ${ }^{16}$ However, these interventions did not lead to any significant decreases in pain severity in their patients. ${ }^{16}$ None of the RCT's specifically targeted other health care providers or physicians.

In our study, we focussed on the patient-related factors in pain knowledge and management. A review of $17 \mathrm{RCTs}$ on pain and pain management education for patients ${ }^{20-36}$ suggested that tailored education counselling sessions directed at patients improved pain scores ${ }^{20-22,25-27,29,30,33,34,36}$ and altered any negative beliefs and misconceptions about pain..$^{21,22,25,26,28,29,33,35}$ In twelve studies, the pain education was given by nurses ${ }^{20,21,23-25,27-29,31-33,35}$, in two studies it was given by other health care educators (e.g. research assistant, master student) ${ }^{22,26}$, in two studies this aspect was not mentioned ${ }^{30,34}$ and in one study a video was shown. ${ }^{36}$ Although the results of the patient-related RCTs were 
generally positive, there is still a need to gain more insight into the efficacy of pain education programmes. ${ }^{27}$ The existing RCTs had methodological flaws in many areas. In most studies, only short-term effects were measured. ${ }^{21,22,24-}$ $28,30,34,36$ It is not clear whether short-term effects are sustained over longer periods of time. The education programmes were generally fairly light (e.g. one face-to-face education session or one session combined with one or more telephone calls $)^{20-22,28-31,33-36}$, whereas patients and their family care providers are known to require ongoing assistance with problem-solving to optimise their pain management regimen. ${ }^{37}$ Little is known about which subgroups gain more from pain education programmes than other subgroups. This knowledge is necessary to tailor education programmes and maximize their effectiveness. ${ }^{38}$ Only one study indicated that the educational level of the patients might influence the effects of pain education programmes. ${ }^{39}$ A very small proportion of the studies incorporated variables such as gender, age and stage of the disease. ${ }^{28,29}$ None of the studies mentioned incorporated pain scores at baseline, or anxiety and depression scores at baseline, although depression and pain form a well-known cluster $^{40}$ and depressive disorders can affect compliance. ${ }^{41}$ In almost half of the RCTs the study population was small, with less than 35 participants in the intervention group and the control group $^{22,25,26,30-32,36}$. Attention was paid to communication between the nurses who gave the education and the treating physicians in one study alone. ${ }^{21}$ Whereas continuity of care and communication between health care providers is known to be of major importance in the pain management process. ${ }^{39}$

In the present study, we tried to avoid making any of the above-mentioned methodological errors. Our aim was to evaluate how an intensive home-based pain education programme (PEP) given by nurses affected short-term and long-term effects of on levels of pain, pain knowledge, quality of life, anxiety and depression.

\section{Methods}

\section{Source population}

Patients were recruited from two sources, firstly, from our previous prevalence study on pain and other symptoms in the region of Limburg in the south of the Netherlands. The outpatients who scored 4 or higher on the pain intensity scale (range $0-10,10=$ worst pain) and who gave signed consent to participate in the next research project, were asked to participate in this intervention study. This resulted in 54 patients. Secondly, patients were recruited by nurses and 
physicians working at outpatient clinics and the Radiotherapy Department. This resulted in 65 patients. A total of 120 patients was included.

Patients were eligible if they 1 . had been diagnosed with cancer, 2 . had been informed of their diagnosis, 3. were 18 years or older, 4 . were able to understand and complete the questionnaire, 5. had a "present" pain score of 4 or higher on a scale from 0-10 and 6. agreed to participate in the study. Treatment stages included e.g. curative anti-cancer treatment, palliative anticancer treatment and no further treatment options available. Patients were excluded if they had completed their curative anti-cancer treatment before the year 2000 .

The study was approved by the Medical Ethics Committee of the University Hospital Maastricht. All the participants signed the informed consent agreement.

\section{Intervention}

All the patients were allocated at random to the intervention group $(n=58)$ or the control group $(n=62)$ on the basis of a computer-generated randomisation procedure.

Patients in the control group received usual care, while the patients in the intervention group received specialised nursing care at home, in addition to the usual care (Figure 5.1). This specialised care included the Pain Education Programme (PEP) and the monitoring of symptoms other than pain.

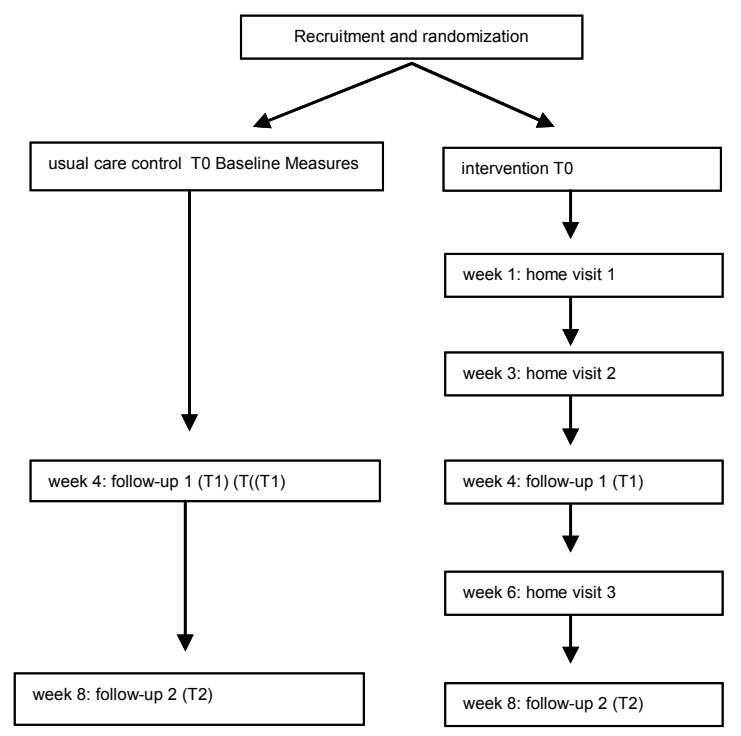

Figure 5.1 Study design. 
The PEP was developed by de Wit et al. ${ }^{33}$ and has three components: 1. enhancing a patient's knowledge about pain and pain management by means of a pain brochure, 2. instructing patients how to record their pain intensity in a pain diary and 3. stimulating a patient's help-seeking behaviour. An extensive description of the PEP can be found in the original article. ${ }^{33}$. In the intervention group, palliative care nurses made three home visits, each with a duration of 1 to 1.5 hours.

The pain brochure offers information about the following topics: possible causes of pain, pain control, non-adherence, misconceptions and different nonpharmacological pain management techniques (cold, heat, relaxation and massage). This brochure was tested in an earlier study. ${ }^{42}$

\section{First home visit}

The first home visit took place within one week after the baseline measurement. Intake data were recorded by the nurses to tailor the PEP to the patient's situation. These concerned pain intensity, location of pain, type of pain, medication prescription, medication adherence, emotional well-being and other physical symptoms. A pain brochure was given to the patients and were discussed, if possible in the presence of a family caregiver. Patients was invited to ask questions. The patients also received a pain diary with a clear explanation about how to record their pain intensity twice daily on a numeric rating scale from 0 to 10 . If any pain problems or other physical and emotional symptoms arose, the patient was encouraged to contact their health care provider.

After the first visit, the nurse reported the findings to the treating physician by letter. If indicated, advice was formulated concerning the pain medication, in all cases in consultation with a specialist in pain treatment in oncology patients. Advices concerned: starting new pain medication, increasing dosages of pain medication, or rotating to other pain medication and was enclosed with the letter.

\section{Second home visit}

During the second home visit, which took place in week three, the nurse reviewed the pain intensity scores in the pain diary to detect any changes in pain intensity levels. Note was also made of any changes in type of pain, location of pain, prescription of pain medication and medication adherence. Patients were asked whether they had read the "Pain brochure" themselves and fully understood all the information. Care was taken to discuss anything in the brochure unclear to them and/or to repeat relevant information. If necessary, the patients were encouraged to contact their health care provider about their pain problems and/or other symptoms. 


\section{Third home visit}

The third (final) home visit, which took place in week 6 , dealt with the same components as the second visit. Afterwards, the nurse wrote to the treating physician about the patient's situation. If indicated advice was formulated concerning a change in pain medication and enclosed with the letter.

\section{Measurements}

Outcome measurements were assessed in the intervention group and the control group at baseline (T0), week 4 (T1) and week 8 (T2) (Table 5.1).

Table 5.1 Study measurements at T0 (baseline), T1 (week 4) and T2 (week 8)

\begin{tabular}{llcc}
\hline & T0 & T1 & T2 \\
\hline Outcome Measures & & & \\
\hline Pain intensity & + & + & + \\
Pain Knowledge & + & & + \\
Quality of Life & + & + & + \\
Anxiety and Depression & + & & + \\
Process variables (intervention group only ) & & & + \\
Patient Satisfaction & & & + \\
Use of pain diary & & & + \\
Use of cd & & & + \\
Use of information booklet & & & + \\
Medication Prescription & + & + & + \\
\hline
\end{tabular}

Relevant medical data and information about other interventions that targeted pain were obtained from the medical records.

Pain was measured by 4 questions derived from the Brief Pain Inventory $(\mathrm{BPI})^{43}$ (numeric rating scale). It has high internal consistency with coefficient alphas that ranged from .78 to .97 in various cancer population samples in different countries. ${ }^{44-53}$ The "present" pain score was chosen as a primary outcome, because it is less subject to the biases that affect recall measurements ${ }^{54}$ and patient recall accuracy depends, in part, on the stability of the pain. ${ }^{39}$

Patients' knowledge about pain was measured with a translated version of Ferrell's Pain Questionnaire. ${ }^{55,56}$ The questionnaire has eight items, e.g., 'patients are often given too much pain medication', 'most patients will become addicted to the medication over time', 'it is better to take pain medication around the clock (following a schedule) than only when needed'. All the scores were transformed linearly into a scale from $0-100$ ( 0 is the lowest score on knowledge, 100 the highest score on knowledge). The PKQ-DLV has demonstrated acceptable levels of validity and reliability. ${ }^{39}$ 
Quality of life and non-pain symptoms were measured using the EORTC-C30 version $3 .^{57}$ The EORTC-C30 is 1 . cancer-specific, 2. multidimensional, 3. suitable for self-administration and 4 . applicable across a range of cultural settings. It has five functional scales, three symptom scales, a global health/quality of life scale and six single items. The EORTC QLQ-C30 has shown acceptable levels of validity and reliability. ${ }^{57}$

Depression and anxiety were measured using the Dutch version of the Hospital Anxiety and Depression Scale (HADS). ${ }^{58}$ The HADS has shown good performance to assess symptom severity and caseness of anxiety disorders (Cronbach's $\alpha: .68$ - .93) and depression (Cronbach's $\alpha$ : .67 - .90) in somatic, psychiatric and primary care patients, with a sensitivity and specificity of approximately $0.80 .^{59}$

Participation satisfaction with the intervention was measured by asking the subject the following two questions: 1 . Would you like to continue following the Pain Education Programme? 2. Would you advise other patients to take part in the Pain Education Programme? Response options were 'yes' and 'no'.

Use of materials was evaluated at the end of the study by asking the patients whether they had used the pain diary, cd and read the information booklet. Response options were 'yes' and 'no'.

Advice concerning a change in pain medication prescription at T0, T1 and T2 was analysed by comparing the advice (as formulated in the letters to the treating physician) to the patients' reports about pain medication.

\section{Statistics}

To achieve adequate power to test the main effect of treatment group on pain intensity, a total of 80 patients were needed. During the study period, many patients dropped-out because they were too ill or died. Therefore, 120 patients were recruited instead of 80 to ensure adequate power. The power analysis conducted in this study was based on the data from an earlier study on the Pain Education Programme. ${ }^{39}$. It was necessary to have 40 patients in the intervention group and the control group to detect a clinically relevant difference of 1.5 points on a 10 point scale, with an alpha of 0.05 , a beta of 0.20 and a sd of 2.4. Data were analysed using the Statistical Package for the Social Science (SPSS) version 12. Descriptive Statistics were used to evaluate the demographic variables, medical variables, pain, knowledge about pain and pain treatment, quality of life, depression and anxiety. At T0, comparability between the intervention group and control group was analysed by using Independent Student's $t$ tests and Chi-square tests.

Mixed regression models were used to evaluate the longitudinal data on the effects of the PEP and changes over time. The many drop-outs in this study, 
mainly due to severe illness and death, led to an unbalanced data set that could not be analysed using for traditional methods such as repeatedmeasures analysis of variance (ANOVA). In the literature mixed regression models offer an alternative to deal with unbalanced data sets. ${ }^{60}$. Therefore, the changes in outcome measures and pain over time were tested using the Random Intercept Model.

\section{Results}

A total of 120 patients entered the study (Figure 5.2); 83 of them had completed the follow-up at T2. After randomisation, 13 patients were excluded (eight in the control group and five in the intervention group) because they did not meet the inclusion criteria: seven patients were not suffering from cancerrelated pain (3x arthrosis, 1x osteoporosis, 1x rheumatic disease, 1x dialysis and $1 \mathrm{x}$ carpal tunnel syndrome), four patients had completed their curative treatment before 2000 and one patient had previous exposure to the PEP brochure. Data were missing at baseline, T1 or T2 in 27 patients (10 in the control group and 17 in the intervention group). For further details, see Figure 5.2 .

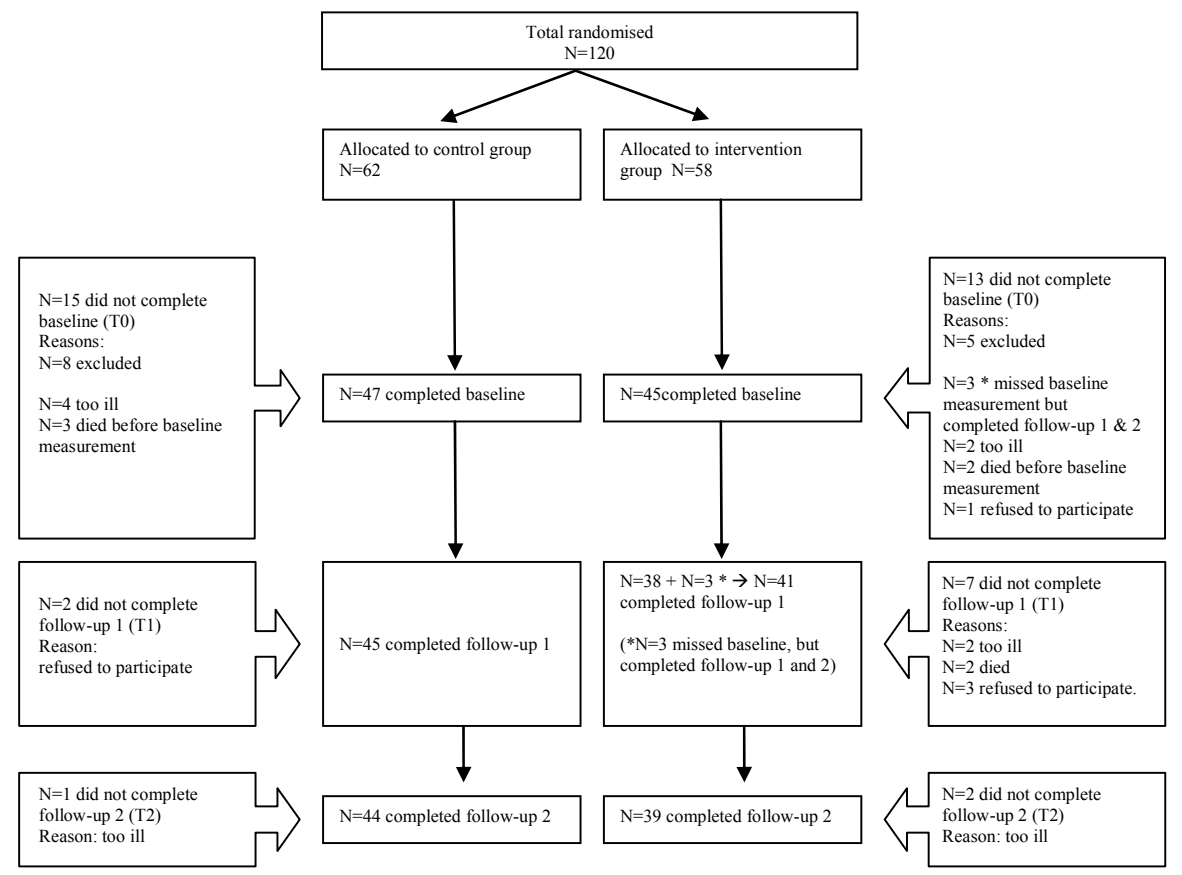

Figure 5.2 Flowchart of participants. 
At baseline, no significant differences were found in the demographic characteristics, treatment group and baseline pain level between the intervention and the control group (Table 5.2). Despite the randomisation procedure, the baseline level of pain knowledge was significantly better in the control group than in the intervention group $(p=0.017)$. In the intervention group and the control group, the lowest score at baseline was observed on the item 'take the lowest dose of medication possible' (16.9 and 27.7, respectively). No significant differences were found in domains of quality of life (except for role functioning).

Table 5.2 Baseline characteristics in the intervention group and the control group.

\begin{tabular}{|c|c|c|c|}
\hline & Intervention group & Control group & $\mathrm{p}$ \\
\hline \multicolumn{4}{|l|}{ Age, years } \\
\hline Mean (SD) & $62.0(10.3)$ & $60.5(10.0)$ & NS \\
\hline \multicolumn{4}{|l|}{ Gender, \% } \\
\hline Men & 52.1 & 38.3 & NS \\
\hline Women & 47.9 & 61.7 & NS \\
\hline \multicolumn{4}{|l|}{ Education, \% } \\
\hline Primary school & 77.1 & 70.2 & NS \\
\hline Secondary school & 6.3 & 4.3 & NS \\
\hline College/university & 10.4 & 23.4 & NS \\
\hline Missing & 6.3 & 2.1 & NS \\
\hline \multicolumn{4}{|l|}{ Treatment group ${ }^{\mathrm{a}} \%$} \\
\hline Group 1 & 20.8 & 27.7 & NS \\
\hline Group 2 & 58.3 & 53.2 & NS \\
\hline Group 3 & 18.8 & 17.0 & NS \\
\hline Missing & 2.1 & 2.1 & NS \\
\hline Baseline pain ${ }^{b}$ & 4.43 & 4.71 & NS \\
\hline Pain knowledge & 52.8 & 59.5 & 0.017 \\
\hline
\end{tabular}

${ }^{a}$ Group 1: Patient is currently under curative anticancer treatment or this treatment has finished $(<5$ years). Group 2: Patient is currently under palliative anticancer treatment, or this is a treatment option. Group 3: No further treatment options available; ${ }^{\mathrm{b}}$ Present pain

\section{Changes in the level of pain, level of pain knowledge, quality of life, anxiety and depression}

At the short-term measurement (week 4), the intervention group showed significant pain reduction $(p=0.02)$ compared to the control group (Figure 5.3a). No significant $(p=0.14)$ long-term effect was found (Table 5.3). 
3a: changes in "present" pain over time

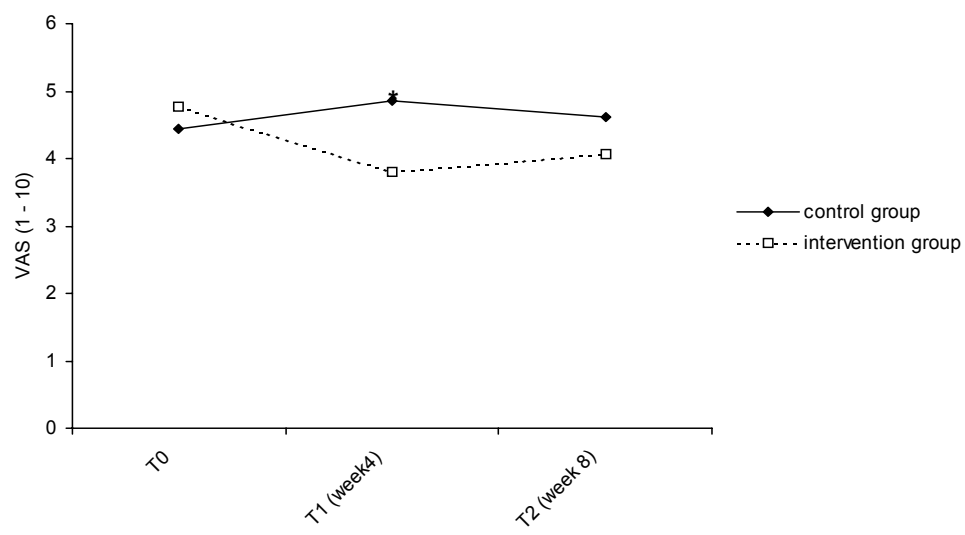

Figure 5.3a Changes in the level of pain and the level of pain knowledge in the intervention and the control group over time.

* $p=0.02$

Table 5.3 Mean "present" pain scores in the intervention group and the control group at baseline (T0), week 4 (T1) and week 8 (T2).

\begin{tabular}{lccc}
\hline & "present" & Pain & P-value \\
\cline { 2 - 3 } & $\begin{array}{c}\text { Intervention group } \\
\text { Mean (SD) }\end{array}$ & $\begin{array}{c}\text { Control group } \\
\text { Mean (SD) }\end{array}$ & \\
& & & \\
T0 & $4.71(2.21)$ & $4.43(2.33)$ & 0.72 \\
T1 (week 4) & $3.78(2.63)$ & $4.84(2.62)$ & 0.02 \\
T2 (week 8) & $4.00(2.17)$ & $4.62(2.25)$ & 0.14 \\
\hline
\end{tabular}

The level of pain knowledge was measured at baseline (T0) and after eight weeks (T2). At week 8 , the level of pain knowledge was significantly better in the intervention group $(p<0.00)$ than in the control group (Figure 5.3b). Significant improvement was seen on the items 'take the lowest dose of medication possible', 'use of routine medication instead of on demand' and 'becoming addicted' in the intervention group. Levels of pain knowledge in the control group did not improve.

No correlation was found between the increase in pain knowledge and the change in "present" pain scores (Pearson correlation 0.03, p=0.860).

Quality of life, did not show any significant effects over time. 
3b: change of knowledge over time

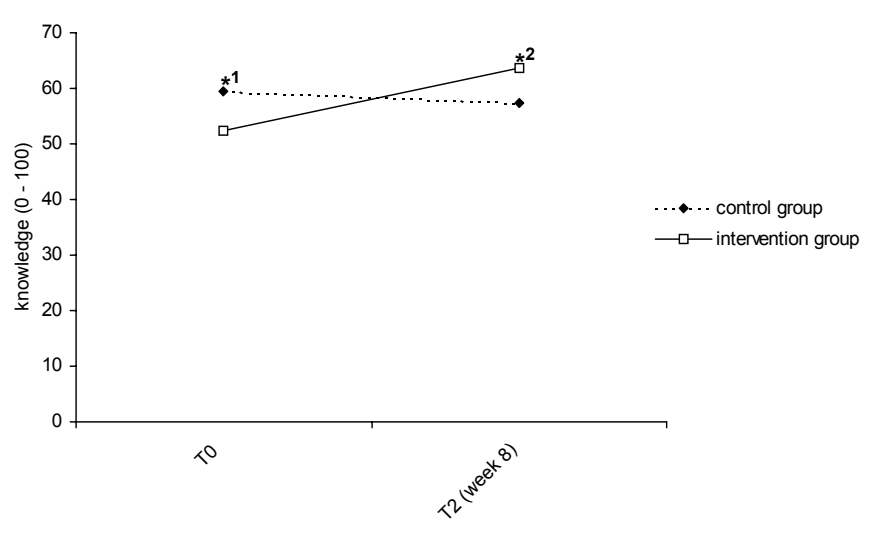

Figure 5.3b Changes in the level of pain and the level of pain knowledge in the intervention and the control group over time.

*1 $p=0.017 ;{ }^{*} 2 p<0.00$

\section{Factors related to short-term and long-term change in pain scores}

The "present" pain intensity at baseline had significant influence on the "present" pain intensity at the short-term and long-term measurements (Figure 5.4).

In the patients with a baseline pain score of 1-3, there were no differences in pain scores at T1 (week 4) and T2 (week 8) between the intervention group and the control group. In the patients with a baseline pain score of 4-6, pain at T1 was significantly lower in the intervention group than in the control group $(p=0.02)$. However, at $T 2$, this difference had disappeared $(p=0.13)$. In the patients with a baseline score of 7-10, significant differences in pain were found between the intervention group and the control group at T1 $(p=0.00)$ and T2 $(p=0.00)$.

Gender, age, education level, severity of illness and baseline levels of anxiety and depression at baseline did not have any significant influence on the "present" pain intensity levels in the intervention group or the control group. 
4a: changes in "present" pain over time in subgroups according to baseline pain in the intervention group

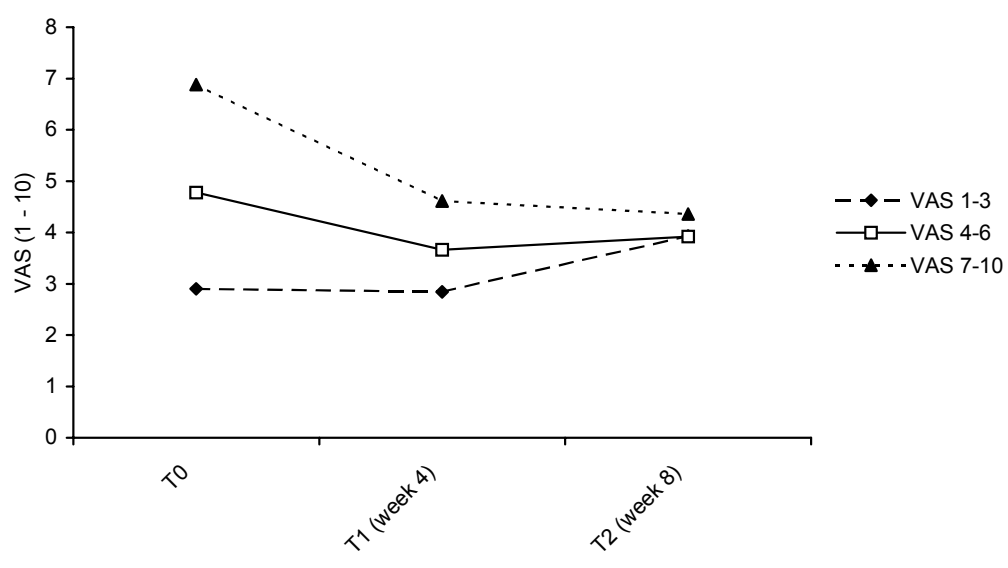

4b: changes in "present" pain overtime in subgroups according to baseline pain in the control group

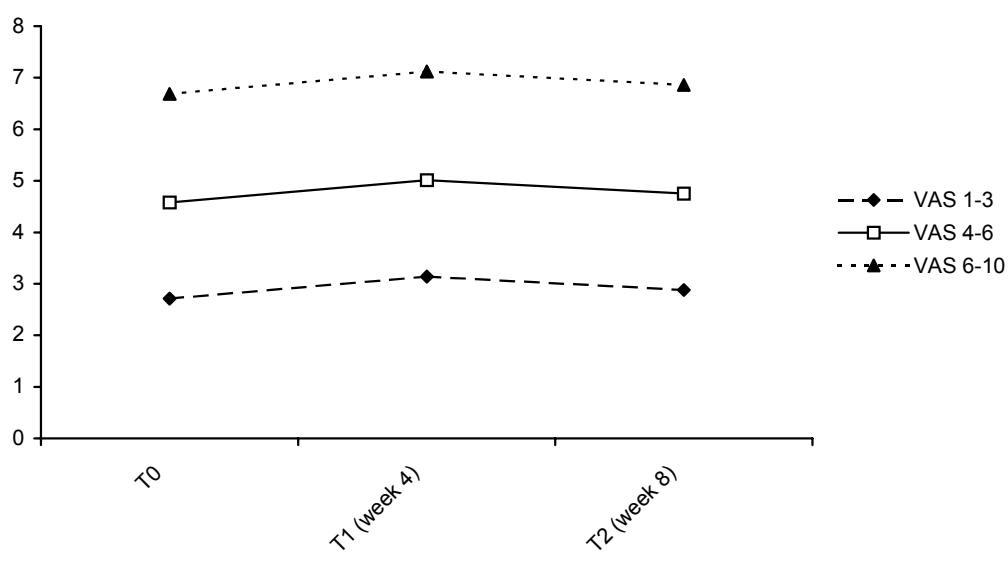

Figure 5.4 Changes in "present" pain over time in three subgroups according baseline pain (mild, moderate and severe baseline pain).

\section{Advices}

After the first and third home visits the nurse send a letter at about the patients' pain problems (pain intensity, pain location and type of pain) and situation to the treating physician. If indicated, it was accompanied by advice concerning a change in pain medication. Such advice had accompanied 37 letters. However, 
based on the patients' reports about pain medication prescriptions at baseline (T0), week 4 (T1) and week 8 (T2), this advice had not been followed 22 times. In 8 cases, it was unclear whether or not the advice had been followed.

\section{Patients' opinions about the Pain Education Programme}

When the patients with complete data sets were asked whether they would like to continue to follow the Pain Education Programme, $66 \%$ of 29 patients would have liked to continue to receive support from the specialised nurse. Their most important reasons were: support and somebody to answer questions about pain medication. The patients who did not want continue reported that the three education sessions had been enough for them to understand the information about pain and pain medication. In answer to the question whether they would advise other patients with pain complaints to take part in the Pain Education Programme all the patients would do so. The response to the third question on the pain brochure, the pain diary and the cd with education revealed that $73 \%$ of these patients had read the pain brochure and used the pain diary.

\section{Discussion}

In this randomised controlled trial, an intensive pain intervention programme given by nurses resulted in short-term pain reduction in patients with moderate pain at baseline and in long-term pain reduction in patients with severe pain at baseline. The intervention improved patients' knowledge about pain and pain medication. Furthermore, they were satisfied with the intervention and would recommend it to other patients.

In most RCTs concerning educational interventions in patients, pain reduction was found in the short-term (1-4 weeks). ${ }^{20-22,25,26,29,30,33,34,36}$ These interventions differed greatly in type and intensity that ranged from showing a video ${ }^{36}$, holding a single face-to-face meeting ${ }^{21,22,30,34}$, setting up a combination of one to three face-to-face meetings and one or more telephone consultations $\mathrm{s}^{20,26,29,33}$, to conducting five face-to-face meetings in five days. ${ }^{25}$ However, not all the results of short-term studies were positive. ${ }^{24,28,31,35}$ Again, these interventions differed in type and intensity. Far fewer studies focussed on long-term effects. The majority did not find any long-term (6 weeks -6 months) effects of an intervention on pain intensity ${ }^{20,29,31,32,35}$, one showed a trend ${ }^{23}$ and two studies reported long-term pain reduction. ${ }^{27,33}$ These interventions differed widely in type and intensity.

Apparently, the intensity of an intervention is not the only effective component of pain education programmes because neither the type, nor the intensity could 
predict a positive outcome. In our study, the patients with more severe pain at baseline (VAS 7-10) derived the most benefit from the intervention, in the shortterm and long-term. We found that gender, age, education level, severity of illness and baseline levels of anxiety and depression did not significantly influence the "present" pain intensity levels in the intervention group or the control group. None of the other studies were suitable for comparison purposes. Only one study mentioned that demographic parameters did not greatly affect the impact of the intervention, but, it remained unclear what the authors meant exactly. ${ }^{28}$ Another study classified the population according to race and found a positive short-term effect in African-Americans, but not in Hispanics. $^{20}$

Besides better patient selection, other possible factors that can improve the long-term effectiveness of an intervention are: 1. close involvement of family caregivers in the education programme ${ }^{27,33}$ and 2 . direct feedback from the nurse to the treating physician about the pain levels and other problems. The only other study in which the nurses directly communicated the results of the intervention to the patient's treating physician was that by Aubin. ${ }^{21}$ However, it was unclear how they reported the results to the treating physicians and what effects this had. In our study, the specialised nurses wrote a letter to the treating physicians that contained details about the patient's pain level, and further observations. If a patient had rated their pain as VAS $>4$, the letter also advised the physician to change the pain medication prescription. The contents of the advice were formulated in cooperation with a physician from the Palliative Care Team and according the Dutch guidelines for pain management. ${ }^{61}$ We observed that a great deal of this advice was not followed, which suggests that this mode of communication was inadequate. Possible explanations are that the letter was stored unread in the patient's medical file, too much time had elapsed between receiving the letter and actual patientphysician contact, or reluctance from the physicians to follow uninvited advice. Another explanation could be the scarce involvement of the treating physicians in the implementation of this intervention. Future comparable research projects might benefit from closer communication with the treating physicians. Support for this argument can be found in the study conducted by Vallieres. ${ }^{30}$ Direct access to a physician who could adjust the analgesic regimen formed part of the intervention. Patients were clearly instructed when (at which pain level, or after three rescue doses in 24 h.) to contact their doctor. In addition, they were asked to bring their pain diary to the consultation, which helped the doctor to adjust the analgesic prescription and also improved the communication between the patient and the doctor. Although the study sample was small, the results seemed promising. Unfortunately, no long-term effects have been reported. ${ }^{30}$ In all the above-mentioned RCTs, part of the education programme was to encourage the patients to talk to their treating physician about their pain. 
However, no data are available on the effect of patient education on communication with treating physicians.

In agreement with almost all the other RCTs our study showed an increase in pain knowledge following the intervention. In one trial, only the informal caregiver gained knowledge ${ }^{32}$, whereas in two trials, there was no effect on pain knowledge. $^{31,35}$ The rationale behind pain education programmes for patients is based on the presumption that better educated patients will be more adherent to their medication and communicate more adequately with their treating physician. In our study, no correlation was found between increases in pain knowledge and decreases in pain level. In the field of cardiology, it was shown that patient education led to significantly lower levels of LDL cholesterol in high-risk patients $(n=3053)^{62}$ and to significantly fewer admissions for heart failure. ${ }^{63}$ Three studies confirmed that fewer barriers (mainly e.g. less fear of addiction and tolerance and a better sense of control) led to better adherence to pain medication. ${ }^{22,26,28}$ In contrast, two other studies did not find any correlation between decreases in barriers and pain levels. ${ }^{29,32}$ Another study $(n=342)$ showed that patients' beliefs were not associated with reports about pain or adherence to medication. ${ }^{64}$ Probably, an intervention should have a multifaceted design that not only incorporates education about various diseaserelated topics, but also implements strategies to change patient behaviour. ${ }^{65}$

\section{Limitations}

Our study population knew that they were enrolled in pain research, which may have stimulated the intervention and control groups to talk about their pain with their treating physicians or other health care providers and diminished the distinction between the two groups. Another factor that might have effected the comparability between the intervention and control groups is the very severely nature of illness in the patient population and the inherent inability to control disease progression.

\section{Recommendations}

We recommend that researchers consider the following components in future education programmes, because of their potential ability to reduce pain levels in the longer-term: 1. Involve patient and family caregivers as much as possible. ${ }^{27,38}$ 2. Communicate with the patient by telephone to reinforce the information and to monitor pain. ${ }^{23,27,38} 3$. Integrate medical care into the 
nursing-based education programme: e.g., direct contact between the nurse and a physician who can adjust the analgesic regimen 4. Formulate clear instructions how and when to contact the doctor ${ }^{30} 5$. Have the patients keep a pain diary and refer to it during communication with their health care providers. $^{30}$

Further research is needed to test the effectiveness of the separate components and to establish the most effective intensity of pain education programmes. To investigate the exact mechanism of how pain levels can be reduced in the longer-term, we recommend that studies not only measure knowledge, pain, symptoms and quality of life, but also the pain medication prescription $^{30}$, medication adherence (e.g. by using a pillbox) ${ }^{27}$ and communication between the patients and their physicians.

\section{Conclusion}

This study showed that a pain education programme given by nurses could lower the pain intensity in cancer patients. The patients with higher pain scores benefited more from the intervention and the effects lasted longer.

Our results supported those from earlier studies in which nurses gave pain education to patients and increased their pain knowledge. However, no correlation was found between increases in pain knowledge and decreases in pain levels. Apart from educating patients, more attention should be paid to the communication between patients and professional care providers about pain and pain management. 


\section{References}

1. Beuken-van Everdingen van den M, Rijke de J, Kessels A, Schouten H, Kleef van M, Patijn J. Prevalence of pain in patients with cancer: a systematic review of the past 40 years. Ann Oncol. 2007;18:1437-49.

2. Fazeny B, Muhm M, Hauser I, Wenzel C, Mares P, Berzlanovich A, Hagmeister H, Marosi C. Barriers in cancer pain management. Wien Klin Wochenschr. 2000;112:978-81.

3. Patrick DL, Ferketich SL, Frame PS, Harris JJ, Hendricks CB, Levin B, Link MP, Lustig C, McLaughlin J, Reid LD, Turrisi AT 3rd, Unützer J, Vernon SW; National Institutes of Health State-of-the-Science Panel. National Institutes of Health State-of-the-Science Conference Statement: Symptom management in cancer: pain, depression, and fatigue, July 15-17, 2002. J Natl Cancer Inst Monogr. 2004:9-16.

4. Von Roenn JH, Cleeland CS, Gonin R, Hatfield AK, Pandya KJ. Physician attitudes and practice in cancer pain management. A survey from the Eastern Cooperative Oncology Group. Ann Intern Med. 1993;119:121-6.

5. Hill CS, Jr. The barriers to adequate pain management with opioid analgesics. Semin Oncol. 1993;20(2 S1):1-5.

6. Ward SE, Goldberg N, Miller-McCauley V, Mueller C, Nolan A, Pawlik-Plank D, Robbins A, Stormoen D, Weissman DE. Patient-related barriers to management of cancer pain. Pain. 1993;52:319-24.

7. Kissane DW, Grabsch B, Love A, Clarke DM, Bloch S, Smith GC. Psychiatric disorder in women with early stage and advanced breast cancer: a comparative analysis. Aust $\mathrm{N} \mathrm{Z} \mathrm{J}$ Psychiatry. 2004;38:320-6.

8. Ferrell BR, McCaffery M, Rhiner M. Pain and addiction: an urgent need for change in nursing education. J Pain Symptom Manage. 1992;7:117-24.

9. Taylor EJ, Ferrell BR, Grant M, Cheyney L. Managing cancer pain at home: the decisions and ethical conflicts of patients, family caregivers, and homecare nurses. Oncol Nurs Forum. 1993;20:919-27.

10. Du Pen SL, Du Pen AR, Polissar N, Hansberry J, Kraybill BM, Stillman M, Panke J, Everly R, Syrjala K. Implementing guidelines for cancer pain management: results of a randomized controlled clinical trial. J Clin Oncol. 1999;17:361-70.

11. Riddell A, Fitch MI. Patients' knowledge of and attitudes toward the management of cancer pain. Oncol Nurs Forum. 1997;24:1775-84.

12. Yeager KA, Miaskowski C, Dibble SL, Wallhagen M. Differences in pain knowledge and perception of the pain experience between outpatients with cancer and their family caregivers. Oncol Nurs Forum. 1995;22:1235-41.

13. Liang LP, Dunn SM, Gorman A, Stuart-Harris R. Identifying priorities of psychosocial need in cancer patients. Br J Cancer. 1990;62:1000-3.

14. Snyder CF, Dy SM, Hendricks DE, Brahmer JR, Carducci MA, Wolff AC, Wu AW. Asking the right questions: investigating needs assessments and health-related quality-of-life questionnaires for use in oncology clinical practice. Support Care Cancer. 2007;15:1075-85.

15. Bender JL, Hohenadel J, Wong J, Katz J, Ferris LE, Shobbrook C, Warr D, Jadad AR. What patients with cancer want to know about pain: a qualitative study. J Pain Symptom Manage. 2008;35:177-87.

16. Goldberg GR, Morrison RS. Pain management in hospitalized cancer patients: a systematic review. J Clin Oncol. 2007;25:1792-801.

17. Camp-Sorrell D, O'Sullivan P. Effects of continuing education. Pain assessment and documentation. Cancer Nurs. 1991;14:49-54.

18. Kravitz RL, Delafield JP, Hays RD, Drazin R, Conolly M. Bedside charting of pain levels in hospitalized patients with cancer: a randomized controlled trial. J Pain Symptom Manage. 1996;11:81-7.

19. Morrison RS, Meier DE, Fischberg D, Moore C, Degenholtz H, Litke A, Maroney-Galin C, Siu AL. Improving the management of pain in hospitalized adults. Arch Intern Med. 2006;166:1033-9. 
20. Anderson KO, Mendoza TR, Payne R, Valero V, Palos GR, Nazario A, Richman SP, Hurley J, Gning I, Lynch GR, Kalish D, Cleeland CS. Pain education for underserved minority cancer patients: a randomized controlled trial. J Clin Oncol. 2004;22:4918-25.

21. Aubin M, Vézina L, Parent R, Fillion L, Allard $P$, Bergeron R, Dumont $S$, Giguère A. Impact of an educational program on pain management in patients with cancer living at home. Oncol Nurs Forum. 2006;33:1183-8.

22. Chang MC, Chang YC, Chiou JF, Tsou TS, Lin CC. Overcoming patient-related barriers to cancer pain management for home care patients. A pilot study. Cancer Nurs. 2002;25:470-6.

23. Given B, Given CW, McCorkle R, Kozachik S, Cimprich B, Rahbar MH, Wojcik C. Pain and fatigue management: results of a nursing randomized clinical trial. Oncol Nurs Forum. 2002;29:949-56.

24. Keefe FJ, Ahles TA, Sutton L, Dalton J, Baucom D, Pope MS, Knowles V, McKinstry E, Furstenberg C, Syrjala K, Waters SJ, McKee D, McBride C, Rumble M, Scipio C. Partnerguided cancer pain management at the end of life: a preliminary study. J Pain Symptom Manage. 2005;29:263-72.

25. Lai YH, Guo SL, Keefe FJ, Tsai SL, Chien CC, Sung YC, Chen ML. Effects of brief pain education on hospitalized cancer patients with moderate to severe pain. Support Care Cancer. 2004;12:645-52.

26. Lin CC, Chou PL, Wu SL, Chang YC, Lai YL. Long-term effectiveness of a patient and family pain education program on overcoming barriers to management of cancer pain. Pain. 2006;122:271-81.

27. Miaskowski C, Dodd M, West C, Schumacher K, Paul SM, Tripathy D, Koo P. Randomized clinical trial of the effectiveness of a self-care intervention to improve cancer pain management. J Clin Oncol. 2004;22:1713-20.

28. Rimer B, Levy MH, Keintz MK, Fox L, Engstrom PF, MacElwee N. Enhancing cancer pain control regimens through patient education. Patient Educ Couns. 1987;10:267-77.

29. Syrjala KL, Abrams JR, Polissar NL, Hansberry J, Robison J, DuPen S, Stillman M, Fredrickson M, Rivkin S, Feldman E, Gralow J, Rieke JW, Raish RJ, Lee DJ, Cleeland CS, DuPen A. Patient training in cancer pain management using integrated print and video materials: A multisite randomized controlled trial. Pain. 2008;135:175-86.

30. Vallieres I, Aubin M, Blondeau L, Simard S, Giguere A. Effectiveness of a clinical intervention in improving pain control in outpatients with cancer treated by radiation therapy. Int $\mathrm{J}$ Radiat Oncol Biol Phys. 2006;66:234-7.

31. Ward S, Donovan HS, Owen B, Grosen E, Serlin R. An individualized intervention to overcome patient-related barriers to pain management in women with gynecologic cancers. Res Nurs Health. 2000;23:393-405.

32. Wells N, Hepworth JT, Murphy BA, Wujcik D, Johnson R. Improving cancer pain management through patient and family education. J Pain Symptom Manage. 2003;25: 344-56.

33. de Wit R, van Dam F, Zandbelt L, van Buuren A, van der Heijden K, Leenhouts G, Loonstra S. A pain education program for chronic cancer pain patients: follow-up results from a randomized controlled trial. Pain. 1997;73:55-69.

34. Oliver JW, Kravitz RL, Kaplan SH, Meyers FJ. Individualized patient education and coaching to improve pain control among cancer outpatients. J Clin Oncol. 2001;19:2206-12.

35. Yates P, Edwards H, Nash R, Aranda S, Purdie D, Najman J, Skerman H, Walsh A. A randomized controlled trial of a nurse-administered educational intervention for improving cancer pain management in ambulatory settings. Patient Educ Couns. 2004;53:227-37.

36. Clotfelter CE. The effect of an educational intervention on decreasing pain intensity in elderly people with cancer. Oncol Nurs Forum. 1999;26:27-33.

37. Schumacher KL, West C, Dodd M, Paul SM, Tripathy D, Koo P, Miaskowski CA. Pain management autobiographies and reluctance to use opioids for cancer pain management. Cancer Nurs. 2002;25:125-33.

38. de Wit R, van Dam F, Loonstra S, Zandbelt L, van Buuren A, van der Heijden K, Leenhouts $\mathrm{G}$, Duivenvoorden $\mathrm{H}$, Huijer Abu-Saad $\mathrm{H}$. Improving the quality of pain treatment by a tailored pain education programme for cancer patients in chronic pain. Eur J Pain. 2001;5:241-56. 
39. de Wit R, van Dam F, Vielvoye-Kerkmeer A, Mattern C, Abu-Saad HH. The treatment of chronic cancer pain in a cancer hospital in The Netherlands. J Pain Symptom Manage. 1999;17:333-50.

40. Reyes-Gibby CC, Aday LA, Anderson KO, Mendoza TR, Cleeland CS. Pain, depression, and fatigue in community-dwelling adults with and without a history of cancer. J Pain Symptom Manage. 2006;32:118-28.

41. Pasquini M, Biondi M. Depression in cancer patients: a critical review. Clin Pract Epidemol Ment Health. 2007;3:2.

42. Zandbelt LC. Pijn bij kanker en wat er aan te doen is. De ontwikkeling en pretest van een brochure over pijn en pijnbestrijding voor kankerpatiënten met langdurige pijn. Doctoraalscriptie. Rijksuniversiteit Limburg; 1993.

43. Daut RL, Cleeland CS, Flanery RC. Development of the Wisconsin Brief Pain Questionnaire to assess pain in cancer and other diseases. Pain. 1983;17:197-210.

44. Serlin RC, Mendoza TR, Nakamura Y, Edwards KR, Cleeland CS. When is cancer pain mild, moderate or severe? Grading pain severity by its interference with function. Pain. 1995;61:277-84.

45. Caraceni A, Mendoza TR, Mencaglia E, Baratella C, Edwards K, Forjaz MJ, Martini C, Serlin $\mathrm{RC}$, de Conno F, Cleeland CS. A validation study of an Italian version of the Brief Pain Inventory (Breve Questionario per la Valutazione del Dolore). Pain. 1996;65:87-92.

46. Wang XS, Mendoza TR, Gao SZ, Cleeland CS. The Chinese version of the Brief Pain Inventory (BPI-C): its development and use in a study of cancer pain. Pain. 1996;67:407-16.

47. Uki J, Mendoza T, Cleeland CS, Nakamura Y, Takeda F. A brief cancer pain assessment tool in Japanese: the utility of the Japanese Brief Pain Inventory--BPI-J. J Pain Symptom Manage. 1998;16:364-73.

48. Ger LP, Ho ST, Sun WZ, Wang MS, Cleeland CS. Validation of the Brief Pain Inventory in a Taiwanese population. J Pain Symptom Manage. 1999;18:316-22.

49. Radbruch L, Loick G, Kiencke P, Lindena G, Sabatowski R, Grond S, Lehmann KA, Cleeland CS. Validation of the German version of the Brief Pain Inventory. J Pain Symptom Manage. 1999;18:180-7.

50. Radbruch L, Sabatowski R, Elsner F, Everts J, Mendoza T, Cleeland C. Validation of the German version of the brief fatigue inventory. J Pain Symptom Manage. 2003;25:449-58.

51. Saxena A, Mendoza T, Cleeland CS. The assessment of cancer pain in north India: the validation of the Hindi Brief Pain Inventory--BPI-H. J Pain Symptom Manage. 1999;17:27-41.

52. Mystakidou K, Mendoza T, Tsilika E, Befon S, Parpa E, Bellos G, Vlahos L, Cleeland C. Greek brief pain inventory: validation and utility in cancer pain. Oncology. 2001;60:35-42.

53. Larue F, Colleau SM, Brasseur L, Cleeland CS. Multicentre study of cancer pain and its treatment in France. Bmj. 1995;310:1034-7.

54. Stone AA, Broderick JE, Shiffman SS, Schwartz JE. Understanding recall of weekly pain from a momentary assessment perspective: absolute agreement, between- and within-person consistency, and judged change in weekly pain. Pain. 2004;107:61-9.

55. Ferrell BR, Rhiner MR, Rivera LM. Development and evaluation of the family pain questionnaire. J. Psychosoc. Oncol. 1993b;10 21-35.

56. Ferrell BR, Ferrell BA, Ahn C, Tran K. Pain management for elderly patients with cancer at home. Cancer. 1994;74(7 Suppl):2139-46.

57. Aaronson NK, Ahmedzai S, Bergman B, Bullinger M, Cull A, Duez NJ, Filiberti A, Flechtner H, Fleishman SB, de Haes JC, et al. The European Organization for Research and Treatment of Cancer QLQ-C30: a quality-of-life instrument for use in international clinical trials in oncology. J Natl Cancer Inst. 1993;85:365-76.

58. Zigmond AS, Snaith RP. The hospital anxiety and depression scale. Acta Psychiatr Scand. 1983;67:361-70.

59. Bjelland I, Dahl AA, Haug TT, Neckelmann D. The validity of the Hospital Anxiety and Depression Scale. An updated literature review. J Psychosom Res. 2002;52:69-77.

60. Blackwell E, de Leon CF, Miller GE. Applying mixed regression models to the analysis of repeated-measures data in psychosomatic medicine. Psychosom Med. 2006;68:870-8. 
61. Vissers KCP. (Nederlandse Vereniging voor Anesthesie). Richtlijn diagnostiek en behandeling van pijn bij patiënten met kanker. 2007.

62. Grover SA, Lowensteyn I, Joseph L, Kaouache M, Marchand S, Coupal L, Boudreau G. Cardiovascular Health Evaluation to Improve Compliance and Knowledge Among Uninformed Patients (CHECK-UP) Study Group. Patient knowledge of coronary risk profile improves the effectiveness of dylipidemia therapy. Arch Intern Med. 2007;167:2296-303.

63. Krumholz HM, Amatruda J, Smith GL, Mattera JA, Roumanis SA, Radford MJ, Crombie P, Vaccarino $V$. Randomized trial of an education and support intervention to prevent readmission of patients with heart failure. J Am Coll Cardiol. 2002;39:83-9.

64. Dawson R, Sellers DE, Spross JA, Jablonski ES, Hoyer DR, Solomon MZ. Do patient's beliefs act as barriers to effective pain management behaviors and outcomes in patients with cancer-related or noncancer-related pain? Oncol Nurs Forum. 2005;32:363-74.

65. Bourbeau J, Nault D, Dang-Tan T. Self-management and behaviour modification in COPD. Patient Educ Couns. 2004;52:271-7. 



\section{Chapter 6}

\section{Concerns of Former Breast Cancer Patients about Disease Recurrence}

A validation and prevalence study

Marieke HJ van den Beuken-van Everdingen, Madelon L Peters, Janneke M de Rijke, Harry C Schouten, Maarten van Kleef, Jacob Patijn Psychooncology. 2008;17:1137-45 


\section{Abstract}

\section{Objective}

The present study had three aims: first, to evaluate the psychometric properties of the Dutch version of the CARS (CARS-DLV). Second, to measure the prevalence of concerns about disease recurrence in former breast cancer patients and identify potential predictors and third, to establish how fear of recurrence was effecting quality of life

\section{Methods}

A prospective study was carried out on breast cancer patients $(n=136)$ who had undergone curative treatment. Eligible patients completed an extensive questionnaire consisting of the CARS (fear of recurrence), HADS (anxiety and depression), BPI (pain), RAND (quality of life), LOT (optimism) and the PCS (catastrophzing).

\section{Results}

This study confirmed the good internal consistency, test-retest stability and construct validity of the CARS (Dutch Language version). Moderate to high levels of fear of disease recurrence were found in $56 \%$ of 136 breast cancer survivors. Worries about health and death were the most prominent. Pain was a strong predictor of overall fear and of fear on the four sub domains of the CARS. The prevalence of fear decreased significantly with age. Education level, living arrangements and time since the last treatment did not predict the prevalence of overall fear. Fear of recurrence was negatively correlated with quality of life.

\section{Conclusion}

The CARS-DLV proved to be a valuable instrument to measure women's' concerns about breast cancer recurrence. More than half of former breast cancer patients indicated moderate to severe concerns about disease recurrence. Health and death worries were the most prominent. The levels of worry were independent of the time since diagnosis. 


\section{Introduction}

To cover all the relevant domains of quality of life (QoL) in breast cancer survivors, current QoL questionnaires should be complemented by aspects such as body image, sexuality and fear of disease recurrence. ${ }^{1}$ Breast cancer survivors are faced with many demands of illness, particularly across the physical, psychological, social and spiritual domains. ${ }^{2}$ A recent systematic review has shown that long-term survivors of breast cancer were experiencing good overall quality of life. ${ }^{3}$ In most women psychological distress (e.g. anxiety and depression) subsided during the first 24 months after diagnosis. ${ }^{5}$ However, $30 \%$ of the women were still experiencing psychological distress many years after the completion of treatment. ${ }^{4}$ Specific problems often persisted, such as poor body image, decreased sexuality and fear of disease recurrence. ${ }^{1,5}$ Even twenty years after the initial treatment, there was an increased prevalence of post-traumatic stress disorder (PTSD), which indicated unremitting psychological sequelae long after diagnosis and treatment. $^{6}$

Fear of disease recurrence is one of the most prevalent long-term psychological consequences of surviving cancer. In women who survived breast cancer, fear of disease recurrence was reported by 29 to $97 \%{ }^{7-14}$ The most important long-term sources of distress following breast cancer surgery were shoulder-arm morbidity and fear of cancer recurrence. ${ }^{15}$ High levels of fear of recurrence can lead to dysfunctional behavior, including anxious preoccupation and excessive checking. ${ }^{16}$ Several cancer-related fears were found to be positively related to depression and anxiety, e.g. worries about disease recurrence or a second primary tumor. ${ }^{17}$ The aggregate data gathered from individuals concerning the nature of women's fears about recurrence may help oncology professionals to better understand women's coping and adjustment in the presence of such fears and to device more supportive interventions. ${ }^{9}$

In the literature, four different instruments are described to measure fear or concerns about disease recurrence: the Fear of Recurrence Index (2 items), ${ }^{18}$ the Worry about Cancer Scale (4 items), ${ }^{19}$ the Northouse Fear of Recurrence Scale $\left(22\right.$ items $^{20}$ and the Concerns About Recurrence Scale. ${ }^{8}$ The most significant limitation of the first three questionnaires is that they evaluate women's overall fear of tumor recurrence, without identifying which domains the various concerns relate to. In contrast, the Concerns About Recurrence Scale $^{8}$ (CARS) is a multidimensional instrument that addresses different domains of women's fear. Thus, the CARS is able to identify the aspects that patients fear most. Women's fears about recurrence are likely to be influenced by their previous experiences with breast cancer, because expectancies regarding the future are shaped by past experiences. ${ }^{21}$ Research has documented numerous psychosocial effects of breast cancer, including the 
following: emotional difficulties, ${ }^{22}$ problems associated with sexuality, ${ }^{23,24}$ body image, ${ }^{23,25}$ self-concept, ${ }^{26}$ femininity, ${ }^{27}$ financial strain, ${ }^{28}$ disruptions in daily activities, ${ }^{22}$ barriers to fulfilling roles or setting/reaching goals ${ }^{28}$ and/or problems with interpersonal relationships. ${ }^{29}$ Because the consequences of breast cancer are so numerous and varied, women's fears about recurrence should be similar complex.

We recently translated the CARS into Dutch for use in research and clinical work.

The present study had three aims: first, to evaluate the psychometric properties of the Dutch version of the CARS (CARS-DLV) in terms of internal consistency, test-retest reliability and construct validity; second, to measure the prevalence of concerns about disease recurrence in former breast cancer patients and identify potential predictors and the third, to establish how fear of recurrence was effecting quality of life.

\section{Methods}

\section{Study sample}

A prospective study was carried out on breast cancer patients $(n=136)$ who had undergone curative treatment. All the patients had participated in an earlier study on the prevalence of pain in cancer patients (all disease stages, $\mathrm{n}=1429) .{ }^{30}$ Former breast cancer patients were selected if they had indicated in the earlier study that they were willing to provide information for future research. Eligible candidates were contacted by telephone to verify their willingness to cooperate and to check whether any of the exclusion criteria applied. Exclusion criteria were recurrent breast cancer or a new malignancy. Demographic data were available from the earlier study. All the participants gave informed consent.

The study was approved by the Medical Ethics Committee of the University Hospital Maastricht, by the local ethics committees of the hospitals and by the group that coordinates studies that involve general practitioners (CEL).

\section{Instruments}

Concerns about recurrence of cancer were measured with the CARS-DLV. The CARS systematically assesses the extent and nature of women's concerns about breast cancer recurrence. ${ }^{8}$ It has two main parts. In the first part, overall fear of recurrence is assessed with four questions on frequency, potential for upset, consistency and intensity of fear. Scores are given on a 6-point Likert 
scale that can range from 1 (not at all) to 6 (continuously, terribly). In the second part, the nature of women's concerns about recurrence is assessed with 26 items subdivided into four domains: health worries (eleven items), womanhood worries (seven items), role worries (six items) and death worries (two items). Scores are given on a 5-point Likert scale: not at all (0), a little (1), moderately (2), a lot (3) and extremely (4). The original CARS was found to be internally consistent (Cronbach's $\alpha=0.89-0.94$ ) and there is preliminary evidence of its validity. ${ }^{8}$

The CARS was translated into Dutch by two independent translators (MdR, $\mathrm{MvdB}$ ) and translated back into English by two other independent translators, one of who is a native English speaker (JP, C Lawrence). This back-translated English version was approved by Ms Johnson Vickberg who constructed the original version of the CARS.

Pain was measured by four questions (pain now and pain over the past week: least, worst and average) derived from the Brief Pain Inventory (BPI). ${ }^{31}$ Scores could be given on an 11-point Likert scale that ranged from 0 (no pain) to 10 (worst pain ever).

Anxiety was measured by four questions $(1,3,5,7)$ from the Dutch version of the Hospital Anxiety and Depression Scale (HADS). ${ }^{32}$ The HADS was found to make good assessments of symptom severity and case ness of anxiety disorders (Cronbach's $\alpha=0.68-0.93$ ) and depression (Cronbach's $\alpha=0.67-0.90$ ) in somatic, psychiatric and primary care patients, with a sensitivity and specificity of approximately $0.80 .^{33}$ The four questions used in the present study showed high correlation $(\mathrm{Sr}=0.91)$ with the total fear scale of the HADS.

Quality of life was measured with the RAND 36-item Short Form Health Survey 1.0. ${ }^{34}$ The RAND evaluates eight health domains: physical functioning, bodily pain, role limitations due to personal or emotional problems, emotional well being, social functioning, energy/fatigue and general health perceptions. Internal consistency of the different scales varied from 0.71 to 0.92 , while retest correlations varied from 0.58 to 0.82 after two months. ${ }^{35}$

Dispositional optimism was measured with the Life Orientation Test (LOT). ${ }^{36}$ The LOT is a 12-item questionnaire on generalized positive outcome expectancies (four items worded in a positive direction, 4 items worded in a negative direction and 4 filler items).

Scores are given on a 5-point Likert scale that ranges from 0 (strongly disagree) to 4 (strongly agree). The test has shown adequate internal consistency (Cronbach's $\alpha=0.76$ ) and 4-week retest reliability $(0.79){ }^{36}$

Pain catastrophizing was measured using the Pain Catastrophizing Scale (PCS). ${ }^{37}$ The PCS consists of 13 items that are scored on a scale from 1 (not at all) to 5 (very much so). The Dutch version of the PCS (PCS-DV) showed good internal consistency (Cronbach's $\alpha=0.85-0.91$ ) and there is evidence of the construct validity and the concurrent validity. ${ }^{38}$ 


\section{Procedure}

Each participant was sent the questionnaires and an informed consent form at their home address. They were asked to return the questionnaire even if they did not wish to participate. The first 50 respondents who returned a completed questionnaire were asked to complete a second questionnaire two weeks later that comprised the CARS and a health change score inventory.

\section{Statistics}

A confirmatory factor analysis was performed using Lisrel (version 8.30$)^{39}$ to determine the loading of the different items in each domain. The fit was determined by the standardized Root Mean Square Residual (SRMR, adequate if $\leq 0.09)^{40}$ and the Comparative Fit Index (CFI, adequate if $\left.\geq 0.95\right){ }^{40}$

Internal consistency was estimated using Cronbach's $\alpha$ coefficient. ${ }^{41}$ The Intraclass Correlation Coefficient (ICC) was used to determine the test-retest reliability of the CARS in the 50 participants who completed the questionnaire twice.

Construct validity was tested by computing correlations between the CARS and related measures: anxiety (HADS), pain catastrophizing (PCS) and optimism (LOT). ${ }^{42}$ We predicted the various fear domains would correlate especially with anxiety and to a lesser extent with pain catastrophizing and optimism (negative). $^{17}$

Pain catastrophizing was expected to have the strongest correlation with health worries.

As the scores on several of the questionnaires were not normally distributed, we employed nonparametric Spearman rank correlations.

To examine whether fear of disease recurrence was significantly related with age, education level, living arrangements, pain and number of months since treatment, linear regression analyses were performed using SPSS version 12.0.1. Age, number of months since treatment and pain were entered as continuous variables. Education was coded as a dichotomous variable (highest education completed: none, junior school or lower vocational training versus secondary school, advanced vocational training or university degree). The variable "living arrangements" (living alone versus with a partner) was coded dichotomously. Nonparametric Spearman rank correlations were used to investigate the correlation between quality of life and fear of disease recurrence.

To further investigate whether the type of worries varied by time since treatment we created three subgroups: (<1 month, 1-12 months and $>12$ months after treatment) and compared the scores of these subgroups on the different domains of the CARS using ANOVA. The two subgroups with a longer time since treatment were contrasted with the most recently treated group. 


\section{Results}

In the group of 174 eligible patients from the prevalence of pain study, fourteen could not be reached and nine had disease progression. A total of 136 out of the remaining 151 patients agreed to participate (response rate 90\%). The response rate of the first 50 respondents who were asked to complete the second questionnaire for the test-retest was $100 \%$. There were no differences in demographic characteristics between the responders and non-responders. Mean age of the participants was 59 years (SD 12). Most patients $(n=84)$ finished their curative treatment six months or less before participation to this study. Only 12 women finished the therapy four or more years ago. Demographic features of the women are given in Table 6.1.

Table 6.1 Demographic characteristics.

\begin{tabular}{|c|c|c|}
\hline & & $\begin{array}{c}\text { Responders } \\
\mathrm{n}(\%)\end{array}$ \\
\hline Women & & $136(100)$ \\
\hline \multirow[t]{4}{*}{ Age groups (years) } & $20-40$ & $5(4)$ \\
\hline & $40-60$ & $77(56)$ \\
\hline & $60-80$ & $50(37)$ \\
\hline & $\geq 80$ & $4(3)$ \\
\hline \multirow[t]{5}{*}{ Marital status } & Cohabiting & $95(70)$ \\
\hline & Widow & $17(12)$ \\
\hline & Divorced & $11(8)$ \\
\hline & Single & $9(7)$ \\
\hline & Missing & $4(3)$ \\
\hline \multirow[t]{6}{*}{ Employment status } & Working & $28(21)$ \\
\hline & Housewife & $54(40)$ \\
\hline & Old-age pension & $25(18)$ \\
\hline & Disability pension & $21(15)$ \\
\hline & Sick leave & $6(4)$ \\
\hline & Missing & $2(1)$ \\
\hline \multirow[t]{3}{*}{ Education } & Primary school & $76(56)$ \\
\hline & Secondary school & $39(29)$ \\
\hline & College/university & $21(15)$ \\
\hline \multirow[t]{3}{*}{ Living arrangements } & At home with partner & $107(79)$ \\
\hline & At home alone & $27(20)$ \\
\hline & Other & $2(1)$ \\
\hline \multirow[t]{9}{*}{ Months since treatment } & 0 & 42 (31) \\
\hline & $1-6$ & $42(31)$ \\
\hline & $7-12$ & $10(8)$ \\
\hline & $13-24$ & $11(8)$ \\
\hline & $25-36$ & $9(6)$ \\
\hline & $37-48$ & $9(6)$ \\
\hline & $49-60$ & $5(4)$ \\
\hline & $>60$ & $7(5)$ \\
\hline & Missing & $1(1)$ \\
\hline Total & & $136(100)$ \\
\hline
\end{tabular}




\section{Reliability and validity of the Dutch version of the CARS}

Confirmatory factor analysis revealed adequate loading of all the items in each domain (Table 6.2). The SRMR was 0.088 , while the CFI was $0.956 .{ }^{40}$

Internal consistency (Cronbach's $\alpha$ ) was good in all the domains: overall fear $\alpha=0.94$, health worries $\alpha=0.94$, womanhood worries $\alpha=0.90$, role worries $\alpha=0.88$ and death worries $\alpha=0.90$.

Table 6.2 Confirmatory factor analysis of the Dutch version of the Concerns About Recurrence Scale.

\begin{tabular}{|c|c|c|c|c|c|}
\hline \multirow[b]{2}{*}{ Item (mean score) } & \multicolumn{5}{|c|}{ Factor Loading } \\
\hline & $1^{\mathrm{a}}$ & 2 & 3 & 4 & 5 \\
\hline $\begin{array}{l}\text { How frequently do you think about the possibility of recurrence } \\
\text { of the cancer? (item 1) }\end{array}$ & .86 & & & & \\
\hline $\begin{array}{l}\text { How upset are you by the possibility of recurrence of your } \\
\text { cancer? (item 2) }\end{array}$ & .89 & & & & \\
\hline $\begin{array}{l}\text { How frequently are you concerned about the possibility that } \\
\text { the cancer will recur? (item } 3 \text { ) }\end{array}$ & .92 & & & & \\
\hline $\begin{array}{l}\text { How afraid are you about the recurrence of your cancer? } \\
\text { (item 4) }\end{array}$ & .92 & & & & \\
\hline Upset me emotionally (item 5) & & .79 & & & \\
\hline Will prevent me from planned activities (item 6) & & .74 & & & \\
\hline Will threaten my physical health (item 7) & & .83 & & & \\
\hline Require chemotherapy (item 9) & & .76 & & & \\
\hline Make me feel I don't have control over my life (item 11) & & .83 & & & \\
\hline Make me feel less of a woman (item 8) & & & .80 & & \\
\hline Threaten my identity ( how I see myself) (item 12) & & & .70 & & \\
\hline Interfere with my sense of sexuality (item 18) & & & .74 & & \\
\hline Threaten my spirituality or faith (item 23) & & & .62 & & \\
\hline Lead me to feel less feminine (item 25) & & & .90 & & \\
\hline Damage my romantic relationships (item 28) & & & .68 & & \\
\hline Make me feel badly about how my body looks or feels (item 30 ) & & & .86 & & \\
\hline Hurt my relationships with friends and family (item 10 ) & & & & .56 & \\
\hline $\begin{array}{l}\text { Interfere with my physical ability to carry out daily activities } \\
\text { (item 13) }\end{array}$ & & & & .82 & \\
\hline Harm my self-confidence (item 15) & & & & .71 & \\
\hline Cause financial problems (item 17) & & & & .44 & \\
\hline $\begin{array}{l}\text { Keep me from fulfilling my responsibilities (in my home or at } \\
\text { my job) (item 24) }\end{array}$ & & & & .80 & \\
\hline $\begin{array}{l}\text { Keep me from fulfilling important roles (in my home or at my } \\
\text { job) (item 29) }\end{array}$ & & & & .84 & \\
\hline Threaten my life (item 14) & & & & & .97 \\
\hline Cause me to die (item 27) & & & & & .86 \\
\hline
\end{tabular}

${ }^{a}$ Factor $1=$ overall fear, factor $2=$ health worries, factor $3=$ womanhood worries, factor $4=$ role worries, factor $5=$ death worries

The mean interval between the first assessment and the second assessment with the CARS was 22 days (range 9-54 days). There was no correlation between the interval and reproducibility. At the time of completing the second 
list, $94 \%$ of the participants judged their condition to be the same, or slightly better or worse than at the first assessment. Only $6 \%$ of the participants called their condition (very) much better. The ICCs of all the domains were adequate: overall fear 0.78 , health worries 0.86 , womanhood worries 0.89 , role worries 0.79 and death worries 0.77 . Construct validity was confirmed by Spearman's correlation tests between the subscales of the CARS and the HADS, PCS and LOT (Table 6.3). All the correlations proved to be significant at the 0.01 level (two-tailed).

Table 6.3 Construct validity of the CARS: Spearman's correlation coefficients with the HADS, PCS and LOT.

\begin{tabular}{lccc}
\hline & HADS & PCS & LOT \\
\hline Overall worries & $0.629^{\mathrm{a}}$ & $0.336^{\mathrm{a}}$ & $-0.390^{\mathrm{a}}$ \\
Health worries & $0.665^{\mathrm{a}}$ & $0.457^{\mathrm{a}}$ & $-0.307^{\mathrm{a}}$ \\
Womanhood worries & $0.504^{\mathrm{a}}$ & $0.386^{\mathrm{a}}$ & $-0.309^{\mathrm{a}}$ \\
Role worries & $0.670^{\mathrm{a}}$ & $0.375^{\mathrm{a}}$ & $-0.379^{\mathrm{a}}$ \\
Death worries & $0.594^{\mathrm{a}}$ & $0.371^{\mathrm{a}}$ & $-0.335^{\mathrm{a}}$ \\
\hline
\end{tabular}

${ }^{a}$ significant at the 0.01 level (two-tailed)

\section{Prevalence of worries and predictors}

Moderate to high overall levels of fear were reported by $56 \%$ of the women (Figure 6.1).

Health worries (moderate to high (Likert 2-4) levels in 63\%) and death worries (moderate to high levels in 61\%) were the most prevalent. Moderate to high levels of role and womanhood worries were reported by $37 \%$ and $29 \%$, respectively (Figure 6.1).

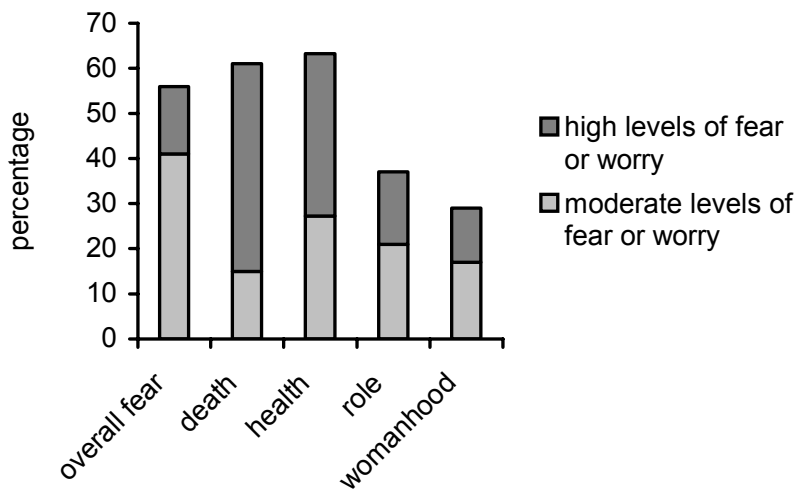

Figure 6.1 Prevalence of moderate to high levels of fear of overall disease recurrence ${ }^{a}$ and for specific worry domains ${ }^{\mathrm{b}}$.

${ }^{\mathrm{a}}$ moderate $=$ CARS score of 3 or 4 , high $=$ CARS score of 5 or $6 ;{ }^{b}$ moderate $=$ CARS score of 2 , high $=$ CARS score of 3 or 4 
Pain was a strong predictor of overall fear and of fear on the four subdomains of the CARS (Table 6.4). The prevalence of fear decreased significantly with age. Education level, living arrangements (at home with partner or at home alone) and time since the last treatment did not have any predictive value on the prevalence of overall fear (Table 6.4). Older women were significantly less worried about health, role and death than the younger women. Women with high education levels had significantly more health and role worries than women with low education levels (Table 6.4). Women living alone had a lower level of role worries than the women living with a partner.

Table 6.4 Results of the backward linear regression with the domains of the CARS as dependents: Predictors of the level of fear of disease recurrence.

\begin{tabular}{|c|c|c|}
\hline & Stand. $\beta$ & $\mathrm{P}$ \\
\hline$R^{2}=0.127, F=9.288, p<0.001$ & & \\
\hline Pain & 0.286 & $0.001^{\mathrm{a}}$ \\
\hline Age & -0.211 & $0.012^{a}$ \\
\hline Months since last treatment & -0.035 & 0.679 \\
\hline Living arrangements & -0.072 & 0.422 \\
\hline Education & -0.046 & 0.587 \\
\hline$R^{2}=0.203, F=10.382, p<0.001$ & & \\
\hline Pain & 0.359 & $<0.001^{\mathrm{a}}$ \\
\hline Age & -0.204 & $0.014^{\mathrm{a}}$ \\
\hline Months since last treatment & 0.019 & 0.822 \\
\hline Living arrangements & -0.005 & 0.956 \\
\hline Education & 0.167 & $0.042^{\mathrm{a}}$ \\
\hline$R^{2}=0.107, F=14.815, p<0.001$ & & \\
\hline Pain & 0.328 & $<0.001^{\mathrm{a}}$ \\
\hline Age & -0.095 & 0.294 \\
\hline Months since last treatment & 0.043 & 0.629 \\
\hline Living arrangements & 0.041 & 0.655 \\
\hline Education & 0.043 & 0.628 \\
\hline$R^{2}=0.295, F=14.282, p<0.001$ & & \\
\hline Pain & 0.429 & $<0.001^{\mathrm{a}}$ \\
\hline Age & -0.300 & $<0.001^{\mathrm{a}}$ \\
\hline Months since last treatment & 0.053 & 0.492 \\
\hline Living arrangements & -0.157 & $0.050^{\mathrm{a}}$ \\
\hline Education & 0.190 & $0.013^{a}$ \\
\hline$R^{2}=0.138, F=9,966, p<0.001$ & & \\
\hline Pain & 0.235 & $0.006^{\mathrm{a}}$ \\
\hline Age & -0.293 & $0.001^{\mathrm{a}}$ \\
\hline Months since last treatment & -0.001 & 0.986 \\
\hline Living arrangements & -0.007 & 0.934 \\
\hline Education & 0.051 & 0.552 \\
\hline
\end{tabular}

${ }^{a}$ significant predictors

Differences in type of worries between the three subgroups of time since treatment ( $<1$ month, 1-12 months and $>12$ months) were examined by ANOVA. Neither on overall fear nor on any of the subdomains significant differences in worries between the subgroups (Figure 6.2) were found (overall 
fear: $F(2,21)=0.12, p=0.89$; health worries: $F(2,21)=0.051, p=0.95$; womanhood worries: $F(2,21)=1.11, p=0.33$; role worries: $F(2,21)=0.08, p=0.92$; death worries: $F(2,21)=0.14, p=0.87)$.

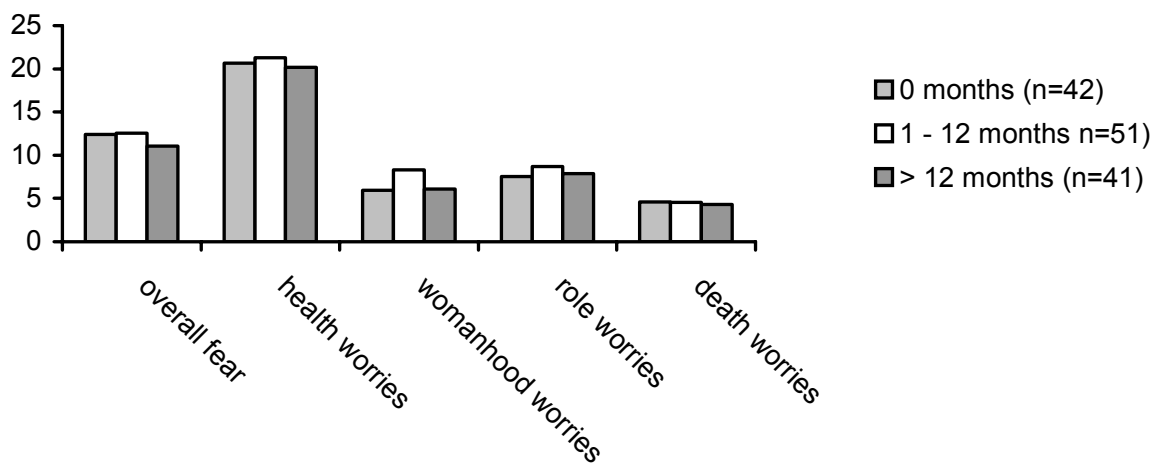

Figure 6.2 Mean scores of health, womanhood, role, death and overall worries at different points after treatment.

\section{Association between quality of life with worries about recurrence}

All the domains of the CARS were negatively associated with all the domains of the RAND (physical functioning, social functioning, role limitations (physical problems), role limitations (emotional problems), mental health, vitality, bodily pain, general health perception) (Table 6.5).

The highest correlation was found between worries and mental health. Role worries had the most negative effect on quality of life.

Table 6.5 Spearman's correlation coefficients ${ }^{\mathrm{a}}$ between fear of disease recurrence and quality of life $^{\mathrm{b}}$.

\begin{tabular}{lccccc}
\hline & $\begin{array}{c}\text { Overall } \\
\text { worries }\end{array}$ & $\begin{array}{c}\text { Death } \\
\text { worries }\end{array}$ & $\begin{array}{c}\text { Health } \\
\text { worries }\end{array}$ & $\begin{array}{c}\text { Role } \\
\text { worries }\end{array}$ & $\begin{array}{c}\text { Womanhood } \\
\text { worries }\end{array}$ \\
\hline RAND $^{2}$ & & & & & \\
Physical functioning & -0.215 & -0.236 & -0.359 & -0.423 & -0.369 \\
Social functioning & -0.390 & -0.289 & -0.375 & -0.538 & -0.350 \\
Role limitations (physical problems) & -0.240 & $-0.179^{c}$ & $-\mathbf{0 . 2 9 2}$ & -0.382 & -0.309 \\
Role limitations (emotional problems) & $-\mathbf{0 . 3 8 8}$ & -0.264 & -0.322 & -0.468 & -0.338 \\
Mental health & -0.574 & -0.417 & -0.499 & -0.599 & -0.489 \\
Vitality & -0.376 & -0.289 & -0.381 & -0.528 & -0.410 \\
Pain & -0.272 & $-0.215^{c}$ & -0.358 & -0.391 & -0.315 \\
General health perception & $-\mathbf{0 . 2 6 8}$ & $-\mathbf{0 . 3 0 2}$ & -0.380 & -0.402 & -0.367 \\
\hline
\end{tabular}

${ }^{a}$ All bold correlations were significant on the 0.01 level (two-tailed); ${ }^{b}$ RAND 36 -item Health Survey $1.0 ;{ }^{c} p=0.05$. 


\section{Discussion}

This study on the Dutch Language version (CARS-DLV) of the CARS confirmed the good internal consistency, test-retest stability and construct validity found in the original study. ${ }^{8}$ In the literature on the four questionnaires constructed to measure fear of recurrence, data on reliability and validity have only been published on the Northouse Fear of recurrence questionnaire ${ }^{20}$ and the CARS. Although all the other available questionnaires will yield similar prevalence rates of fear of recurrence, the CARS gives extra valuable information about what the women fear most.

Moderate to high levels of overall worry were found in $56 \%$ of the women. This is in concordance with earlier studies that reported prevalence rates of moderate to severe fear of recurrence in $55 \%,{ }^{8} 49 \%$ (in post-mastectomy patients) and $46 \%$ (after breast conserving therapy (BCT)). ${ }^{10}$ In a group of elderly patients ( $>70$ years) the prevalence of moderate to severe fear was even as high as $85 \% .{ }^{11}$ Other studies reported an overall (mild, moderate or severe) prevalence of fear of recurrence that ranged from 31 to $70 \%{ }^{7,12-14,17}$ Several authors described fear of recurrence in more general terms: $22 \%$ of the women declared that fear of recurrence was their most distressing problem; ${ }^{15}$ in many patients, fear of recurrence permeated day-to-day life one year postcancer diagnosis; ${ }^{43}$ fear of recurrence ${ }^{29}$ was a very commonly shared experience; fear of recurrence was a major concern ${ }^{45}$ or frequently expressed ${ }^{45}$ or present to a considerable degree. ${ }^{1}$

In agreement with the earlier study by Vickberg, ${ }^{8}$ women predominantly expressed worries about death and health, whereas role worries and womanhood worries seemed to be weaker concerns.

Our data showed a high prevalence of fear of disease recurrence in former breast cancer patients. A few results have also been published on the prevalence of fear of recurrence in patients with other types of cancer, e.g. orofacial: $>80 \%$ and $72 \%$ at three and seven months post-therapy, respectively, ${ }^{46}$ gynecological: between $22-64 \%,{ }^{47-50}$ colorectal: between $27-33 \%{ }^{17}$ and prostate: $39 \%{ }^{17}$ Patients and their partners stated that disease recurrence was their greatest fear after colorectal cancer. ${ }^{51}$

In our study, the time elapsed since the last treatment was not associated with the prevalence of fear of disease recurrence. The literature is contradictory about the influence of time on the fear of recurrence. Some studies suggested that as time progressed the fear of recurrence decreased, ${ }^{12,13,17,52,53}$ whereas most studies found that time made little difference, ${ }^{28,54-57}$ even more than 20 years after diagnosis. Importantly, time since diagnosis was unrelated to the frequency of the most important trigger factors for fear of recurrence, e.g. hearing that someone else has cancer, new aches or pains, environmental 
reminders (e.g. sights, sounds and smells associated with the period surrounding breast cancer diagnosis and treatment), information from the media and doctor's appointments. ${ }^{57}$ In our study, pain was significantly correlated with all the domains of the CARS and thus appeared to be an important trigger.

Women of more advanced age expressed lower levels of worry in the total, health, role and death domains than the younger women. For womanhood worries no differences were found between elder and younger women. These findings are in concordance with the existing literature. ${ }^{8,17,57}$ Explanations could be the generally more aggressive nature of breast cancer in younger women and/or the sense that developing cancer early in life is particularly unexpected or "off schedule". ${ }^{8}$ Previous studies demonstrated that older women reported significantly fewer triggers than younger women. ${ }^{57}$

In our study, the women with a higher education level expressed more health and role worries than the women with a lower education level. This may be explained by the fact that in earlier studies significantly more triggers were reported by the women with a higher education level. ${ }^{57}$

We did not find any relationship between the fear of disease recurrence and living with a partner or alone. Only in the domain of role worries women living with a partner expressed more worries. An earlier study also reported that living arrangements did not influence the level of fear. ${ }^{20}$ However, a strong relationship was found with the presence of significant others, not necessarily living in the same house. ${ }^{20}$ In the present study, we did not record information on the presence of significant others.

Although the literature showed an overall good quality of life in former breast cancer patients, fear of disease recurrence was significantly associated with a poorer quality of life: worries about cancer were negatively associated with all the domains of the RAND. Although the differences were small, especially role worries negatively influenced quality of life. More research into different predictive value of the various domains is warranted. Worries about disease recurrence exerted their negative influence on quality of life predominantly in the mental health domain of the RAND. So, worries about disease recurrence are mainly a psychological burden. This was also demonstrated by the increased prevalence of post-traumatic stress disorder (PTSD) in former breast cancer patients ${ }^{7}$ and the positive relation between cancer-related fears and anxiety and depression. ${ }^{17}$

In our opinion, targeted interventions are warranted, because fear of recurrence can persist for many years after treatment and it has negative effects on quality of life. Unfortunately, very little is known about the effect of psychosocial interventions after the treatment phase. ${ }^{5}$ To bridge this gap, a trial 
recently addressed women's concerns about disease recurrence 5-9 years after breast cancer treatment. ${ }^{58}$ Over a period of eight months, nurses guided the respondents (by means of four weekly telephone sessions) in the use of audio taped cognitive-behavioral strategies to manage concerns about disease recurrence. At ten months after the start of the intervention, the women demonstrated enhanced coping skills directed towards their fear of tumor recurrence.

A potential limitation of our study is the relatively small sample size. This could raise questions about the validity of the confirmatory factor analysis. However, the empirical basis for the common rule that a researcher needs at least 10 participants per variable is unclear. ${ }^{59}$ More recently it was indicated that as communalities become lower the importance of sample size increases. ${ }^{60}$ With communalities above 0.6 , relatively small samples (less than 100) may be perfectly adequate. According to MacCallum ${ }^{60}$ our study with communalities around and above 0.6 , a variables to factor ratio of $30: 5$ and a sample size of 136 will achieve a convergence of $100 \%$.

Another limitation is the use of only one fear of recurrence questionnaire. For further validation of the overall fear component the use of other questionnaires is recommendable. Future research should also include more potential predictors like TNM stage and treatment modalities. Finally, in our study most women had had there last treatment less than one year ago. For long-term conclusions about the worries in the different domains future research should concentrate on women longer after diagnosis and treatment.

\section{Conclusion}

The CARS-DLV proved to be a valuable instrument to measure womens' concerns about breast cancer recurrence. It not only measured the prevalence of overall fear, but also specified worry levels in different domains. More than half of former breast cancer patients indicated moderate to severe concerns about disease recurrence. Health and death worries were the most prominent. The levels of worry were independent of the time since diagnosis, which was in agreement with reports in the literature that worries about recurrence tended to compromise quality of life for many years.

In response to the increasing number of long-term breast cancer survivors, research should focus on quality of life and psychosocial adjustment to the disease. 


\section{References}

1. Härtl K, Janni W, Kästner R, Sommer H, Strobl B, Rack B, Stauber M. Impact of medical and demographic factors on long-term quality of life and body image of breast cancer patients. Ann Oncol. 2003;14:1064-71.

2. Ferrell BR, Grant M, Funk B, Otis-Green S, Garcia N. Quality of life in breast cancer. Part I: Physical and social well-being. Cancer Nurs. 1997;20:398-408.

3. Mols F, Vingerhoets AJ, Coebergh JW, van de Poll-Franse LV. Quality of life among longterm breast cancer survivors: a systematic review. Eur J Cancer. 2005;41:2613-9.

4. Kornblith $A B$, Ligibel J. Psychosocial and sexual functioning of survivors of breast cancer. Semin Oncol. 2003;30:799-813.

5. Stanton AL. Psychosocial concerns and interventions for cancer survivors. J Clin Oncol. 2006;24:5132-7.

6. Kornblith AB, Herndon JE 2nd, Weiss RB, Zhang C, Zuckerman EL, Rosenberg S, Mertz M, Payne D, Jane Massie M, Holland JF, Wingate P, Norton L, Holland JC. Long-term adjustment of survivors of early-stage breast carcinoma, 20 years after adjuvant chemotherapy. Cancer. 2003;98:679-89.

7. Verhoeven K, Crombez G, Van Damme S. Angst voor tergkeer van borstkaner na genezing: de rol van somatosensore amlificatie en trekangst. Gedrag en Gezondheid 2005;33:27-32.

8. Vickberg SM. The Concerns About Recurrence Scale (CARS): a systematic measure of women's fears about the possibility of breast cancer recurrence. Ann Behav Med. 2003;25: 16-24.

9. Johnson Vickberg SM. Fears about Breast Cancer Recurrence. Cancer Pract. 2001;9:237-43.

10. Curran D, van Dongen JP, Aaronson NK, Kiebert G, Fentiman IS, Mignolet F, Bartelink H. Quality of life of early-stage breast cancer patients treated with radical mastectomy or breastconserving procedures: results of EORTC Trial 10801. The European Organization for Research and Treatment of Cancer (EORTC), Breast Cancer Co-operative Group (BCCG). Eur J Cancer. 1998;34:307-14.

11. Aaronson NK, Ahmedzai S, Bergman B, Bullinger M, Cull A, Duez NJ, Filiberti A, Flechtner H, Fleishman SB, de Haes JC, et al. The European Organization for Research and Treatment of Cancer QLQ-C30: a quality-of-life instrument for use in international clinical trials in oncology. J Natl Cancer Inst. 1993;85:365-76.

12. Mast ME. Survivors of breast cancer: illness uncertainty, positive reappraisal, and emotional distress. Oncol Nurs Forum. 1998;25:555-62.

13. King MT, Kenny P, Shiell A, Hall J, Boyages J. Quality of life three months and one year after first treatment for early stage breast cancer: influence of treatment and patient characteristics. Qual Life Res. 2000;9:789-800.

14. Meyer L, Aspegren K. Long-term psychological sequelae of mastectomy and breast conserving treatment for breast cancer. Acta Oncol. 1989;28:13-8.

15. Kuehn T, Klauss W, Darsow M, Regele S, Flock F, Maiterth C, Dahlbender R, Wendt I, Kreienberg R. Long-term morbidity following axillary dissection in breast cancer patients-clinical assessment, significance for life quality and the impact of demographic, oncologic and therapeutic factors. Breast Cancer Res Treat. 2000;64:275-86.

16. Lee-Jones C, Humphris G, Dixon R, Hatcher MB. Fear of cancer recurrence--a literature review and proposed cognitive formulation to explain exacerbation of recurrence fears. Psychooncology. 1997;6:95-105.

17. Deimling GT, Bowman KF, Sterns S, Wagner LJ, Kahana B. Cancer-related health worries and psychological distress among older adult, long-term cancer survivors. Psychooncology. 2006;15:306-20.

18. Lasry JC, Margolese RG. Fear of recurrence, breast-conserving surgery, and the trade-off hypothesis. Cancer. 1992;69:2111-5.

19. Easterling DV, Leventhal $\mathrm{H}$. Contribution of concrete cognition to emotion: neutral symptoms as elicitors of worry about cancer. J Appl Psychol. 1989;74:787-96. 
20. Northouse LL. Mastectomy patients and the fear of cancer recurrence. Cancer Nurs. 1981; 4:213-20

21. Kirsch I. How expectancies Shape Experiences, American Psychological Association. Washington DC. 1999.

22. Parle $\mathrm{M}$, Jones $\mathrm{B}$, Maquire $\mathrm{P}$. Maladaptive coping and affective disorders among cancer patients. Psychol Med. 1996;26:735-44.

23. Schover LR, Yetman RJ, Tuason LJ, Meisler E, Esselstyn CB, Hermann RE, GrundfestBroniatowski S, Dowden RV. Partial mastectomy and breast reconstruction. A comparison of their effects on psychosocial adjustment, body image, and sexuality. Cancer. 1995;75:54-64.

24. Meyerowitz BE, Desmond KA, Rowland JH, Wyatt GE, Ganz PA. Sexuality following breast cancer. J Sex Marital Ther. 1999;25:237-50.

25. Moyer A. Psychosocial outcomes of breast-conserving surgery versus mastectomy: a metaanalytic review. Health Psychol. 1997;16:284-98.

26. Fife BL. The conceptualization of meaning in illness. Soc Sci Med. 1994;38:309-16.

27. Kahane $\mathrm{DH}$. The management of the psychosocial impact of breast cancer. Nurse Pract Forum. 1993;4:105-9.

28. Polinsky ML. Functional status of long-term breast cancer survivors: demonstrating chronicity. Health Soc Work. 1994;19:165-73.

29. Ferrell BR, Grant MM, Funk B, Otis-Green S, Garcia N. Quality of life in breast cancer survivors as identified by focus groups. Psychooncology. 1997;6:13-23.

30. Beuken-van Everdingen van den MHJ, Rijke de JM, Kessels AG, et al: High Prevalence of Pain in Patients with Cancer in a Large Population-Based Study in the Netherlands. Pain. 2007;132:312-20

31. Daut RL, Cleeland CS, Flanery RC. Development of the Wisconsin Brief Pain Questionnaire to assess pain in cancer and other diseases. Pain. 1983;17:197-210.

32. Zigmond AS, Snaith RP. The hospital anxiety and depression scale. Acta Psychiatr Scand. 1983;67:361-70.

33. Bjelland I, Dahl AA, Haug TT, Neckelmann D. The validity of the Hospital Anxiety and Depression Scale. An updated literature review. J Psychosom Res. 2002;52:69-77.

34. Ware JE, Jr., Sherbourne CD. The MOS 36-item short-form health survey (SF-36). I. Conceptual framework and item selection. Med Care. 1992;30:473-83.

35. Zee Klvd, Sanderman R, Heyink J. De psychometrische kwaliteiten van de MOS 36-item Shor orm Health Survey (sf-36) in een Nederlandse populatie. Tijdschrift voor Sociale Gezondheidszorg. 1993;4:183-91.

36. Scheier MF, Carver CS. Optimism, coping, and health: assessment and implications of generalized outcome expectancies. Health Psychol. 1985;4:219-47.

37. Sullivan MJL, Bishop SR, Pivik J. The Pain Catastrophizing Scale: development and validation. Psychol Assess. 1995;7:524-32.

38. Van Damme S, Crombez G, Bijttebier P, Goubert L, Van Houdenhove B. A confirmatory factor analysis of the Pain Catastrophizing Scale: invariant factor structure across clinical and non-clinical populations. Pain. 2002;96:319-24.

39. Jöreskog KG, Sörbom D. Lisrel 8.54, (ed 8.54). Lincolnwood, IL 60712, U.S.A., Scientific Software International. 2006

40. Hu L-t, Bentler PM. Cutoff Criteria for Fit Indexes in Covariance Structure Analysis: Conventional Criteria Versus New Alternatives. Structural Equation Modeling. 1999;6:1-55.

41. Cronbach L. Coefficient alpha and the internal structure of tests. Psychometrika 16, 1951

42. Jellema AP, Langendijk $H$, Bergenhenegouwen $L$, van der Reijden $W$, Leemans $R$, Smeele $L$, Slotman BJ. The efficacy of Xialine in patients with xerostomia resulting from radiotherapy for head and neck cancer: a pilot-study. Radiother Oncol. 2001;59:157-60.

43. Maiedema B, Tatemichi S, MacDonald I. Cancer folow-up care in New Brunswick: cancer surveillance, support issues and fear of recurrence. CJRM. 2004;9:101-7.

44. Fredette SL. Breast cancer survivors: concerns and coping. Cancer Nurs. 1995;18:35-46. 
45. Noguchi M, Kitagawa H, Kinoshita K, Earashi M, Miyazaki I, Tatsukuchi S, Saito Y, Mizukami Y, Nonomura A, Nakamura S, Michigishi T. Psychologic and cosmetic self-assessments of breast conserving therapy compared with mastectomy and immediate breast reconstruction. J Surg Oncol. 1993;54:260-6.

46. Humphris GM, Rogers S, McNally D, Lee-Jones C, Brown J, Vaughan D. Fear of recurrence and possible cases of anxiety and depression in orofacial cancer patients. International Journal of Oral \& Maxillofacial Surgery. 2003;32:486-91.

47. Leake RL, Gurrin LC, Hammond IG. Quality of life in patients attending a low-risk gynaecological oncology follow-up clinic. Psychooncology. 2001;10:428-35.

48. Fitch M, Gray RE, Franssen E. Perspectives on living with ovarian cancer: young women's views. Can Oncol Nurs J. 2000;10:101-8.

49. Fitch MI, Gray RE, Franssen E. Perspectives on living with ovarian cancer: older women's views. Oncol Nurs Forum. 2001;28:1433-42.

50. Wenzel LB, Donnelly JP, Fowler JM, Habbal R, Taylor TH, Aziz N, Cella D. Resilience, reflection, and residual stress in ovarian cancer survivorship: a gynecologic oncology group study. Psychooncology. 2002; 11:142-53.

51. Northouse LL, Schafer JA, Tipton J, Metivier L. The concerns of patients and spouses after the diagnosis of colon cancer: a qualitative analysis. J Wound Ostomy Continence Nurs. 1999;26: 8-17.

52. Utley R. The evolving meaning of cancer for long-term survivors of breast cancer. Oncol Nurs Forum. 1999;26:1519-23.

53. Ellman R, Thomas BA. Is psychological wellbeing impaired in long-term survivors of breast cancer? J Med Screen. 1995;2:5-9.

54. Glynne-Jones R, Chait I, Thomas SF. When and how to discharge cancer survivors in long term remission from follow-up: the effectiveness of a contract. Clin Oncol ( $R$ Coll Radiol). 1997;9:25-9.

55. Thomas SF, Glynne-Jones R, Chait I, Marks DF. Anxiety in long-term cancer survivors influences the acceptability of planned discharge from follow-up. Psychooncology. 1997;6:190-6.

56. Mehta SS, Lubeck DP, Pasta DJ, Litwin MS. Fear of cancer recurrence in patients undergoing definitive treatment for prostate cancer: results from CaPSURE. J Urol. 2003;170:1931-3.

57. Gil KM, Mishel MH, Belyea M, Germino B, Porter LS, Laney IC, Stewart J. Triggers of Uncertainty About Recurrence and Long-Term Treatment Side Effects in Older African American and Caucasian Breast Cancer Survivrs. Oncology Nursing Forum. 2004;31:633-9.

58. Mishel MH, Germino BB, Gil KM, Belyea M, Laney IC, Stewart J, Porter L, Clayton M. Benefits from an uncertainty management intervention for African-American and Caucasian older long-term breast cancer survivors. Psychooncology. 2005;14:962-78.

59. Field A. Discovering Statistics Using SPSS (ed second edition). London, SAGE Publications Ltd. 2005

60. MacCallum RC, Widaman KF, Zhang S, Hong S. Sample size in factor analysis. Psychological Methods. 1999;4:84-99. 

Chapter 7

Summary and General Discussion 
132 Chapter 7 


\section{Summary and general discussion}

The number of people with cancer is growing due to its early detection and the progress being made in anti-cancer treatment. ${ }^{1}$ In 2005, the 20-year prevalence of cancer in the Netherlands was estimated to be over 450,000 persons $(2.8 \%)$, and is expected to rise to 692,000 in $2015 .{ }^{1}$

Patients with cancer often have multiple symptoms that may considerably affect their sense of well-being and physical and social functioning. The aim of this thesis is to gain insight into the prevalence of physical (pain and non-pain) and psychological symptoms in patients with cancer, and the influence these have on quality of life. Both physical and psychological symptoms are addressed in patients with cancer at all stages of the disease, ranging from cured to far-advanced.

The main findings of this thesis will be discussed by addressing our original research questions. Methodological issues including strengths and limitations will be discussed. Thereafter, the results of the studies will be discussed in order to demonstrate the consequences to health care practice, leading to further research.

\section{Main findings}

\section{Review of the literature on prevalence of pain in patients with cancer}

Despite the abundance of literature on pain in cancer patients, no previous reviews provide accurate estimates regarding prevalence. We performed a systematic review that included the statistical pooling of study results in an attempt to obtain accurate figures on the prevalence of cancer pain during the period 1966-2005.

The pooled data from 52 articles showed that pain was prevalent in cancer patients: $64 \%$ of patients with metastatic or advanced-stage disease, $59 \%$ of patients on anti-cancer treatment, and $33 \%$ of patients after curative treatment. More than one-third of patients with pain in the reviewed articles graded their pain as being moderate or severe.

Only $34 \%$ of the retrieved articles reached the predefined quality score. A combination of shortcomings in representativeness and data collection method (the two criteria with the heaviest weighting) was the main reason for not reaching an adequate quality score. In the bivariate regression analyses, none of the covariates (type of cancer, period of publication, continent of origin, mean age of the study population, type of prevalence, use of validated or nonvalidated questionnaires or interviews) were significantly associated with the 
prevalence rates of pain. We concluded that: (1) future studies on the prevalence of pain in cancer patients should take representativeness, response rates, and the description of non-responders into consideration, and should provide information on the severity, duration, frequency, and amount of interference. The use of multi-dimensional tools during research will facilitate the comparison of studies and the planning of what is necessary from pain services.

Studies on the prevalence of pain in cancer survivors are scarce. This topic should be addressed in future studies; and (2) despite the clear WHO recommendations, cancer pain still is a major problem. The increasing number of cancer survivors who live to an advanced age means that it is of paramount importance to reduce the prevalence of pain at all stages of the disease process.

\section{Prevalence of pain in patients with cancer}

A population-based study was conducted in a large group of cancer patients (all disease phases) in order to make reliable estimations of the prevalence and severity of pain in these patients, to map predictors of cancer pain, and to establish the adequacy of pain treatment.

We found that $55 \%$ of the 1429 respondents had experienced pain in the preceding week; in $44 \%(n=351)$, the pain was moderate to severe (BPI score $\geq 4$ ).

Positive predictors of the prevalence of pain were lower educational level, more advanced disease, and haematological (excluding (non)-Hodgkin lymphoma), gastro-intestinal, lung, or breast malignancies. According to the PMI, analgesic treatment was inadequate in $42 \%$ of patients. Negative predictors of adequate treatment were current curative anti-cancer treatment and low educational level.

We concluded that the prevalence of pain in patients with cancer is still far too high. The prevalence of moderate to severe pain in patients treated with curative intent was as high as that of back pain. One-quarter of the patients on anti-cancer treatment and more than half the patients with advanced/terminal disease suffered from moderate to severe pain. Pain management was insufficient in almost half the patients in this study. We recommend better education with regard to pain and pain treatment in the curricula of medical professionals, and systematic recording of pain intensity in cancer patients, irrespective of the phase of the disease. 


\section{Prevalence of non-pain physical and psychological symptoms in patients with cancer}

A population-based study was conducted in a large group of cancer patients in order: (1) to measure the prevalence of non-pain symptoms (classified according to treatment status and tumour type); (2) to determine the quality of life of patients with different types of cancer and at different treatment phases, and to investigate the impact of physical and psychological symptoms on their quality of life; and (3) to inquire whether the patients had received treatment for their complaints/symptoms.

In the 1429 respondents, the prevalence of all non-pain physical and psychological symptoms increased with the progression of the disease. Patients (being) treated with curative intent experienced symptoms that were independent of cancer type. Symptoms experienced by patients treated with palliative anti-cancer therapy varied according to type of cancer. Feelings of weakness, tiredness, and the need to rest were the most prevalent symptoms in patients with moderate to severe physical complaints in all disease groups. Vomiting was the least prevalent physical symptom in all disease groups. With regard to psychological symptoms, moderate to severe worry was the most prevalent in all disease groups and irritability was the least prevalent.

Quality of life decreased significantly as the disease progressed. Fatigue, loss of appetite, constipation, dry mouth, depression, and anxiety all had an independent negative influence on quality of life.

Our study showed that many non-pain symptoms remained untreated, although (partially) effective treatment is available for most symptoms. This illustrates the need for better education with regard to symptoms and symptom control in the curricula of medical professionals. Systematic recording of symptom intensity in patients with cancer, irrespective of the phase of the disease, is mandatory.

\section{An intensive nursing intervention for cancer patients suffering from pain in their home situation}

Factors relating to the ineffective treatment of pain fall into three categories: the health care system, professional care providers, and patients. In patients, various barriers can lead to non-compliance. Previous educational interventions have increased patients' knowledge of pain and decreased shortterm pain levels. In this randomised controlled trial, we investigated how an intensive home-based educational programme given by nurses affected shortand long-term pain levels.

At week four, pain was significantly lower in the intervention group $(n=45)$ than in the control group $(n=48)$. By week eight, this difference had disappeared. During the eight-week intervention period, knowledge of pain was significantly 
increased in the intervention group. Over time, no significant effects were noted with regard to quality of life, anxiety or depression. Of the 37 times that advice was given (in writing to the primary care-giver) with regard to a change of medication in order to optimise pain control, this was only followed in $19 \%$.

We conclude that a nursing intervention programme can help patients with cancer to deal with their pain, increase the level of knowledge of pain, and have a short-term positive effect on pain levels.

\section{Concerns of former breast cancer patients about disease recurrence}

The present study had three aims: firstly, to evaluate the psychometric properties of the Dutch version of CARS (CARS-DLV) in terms of internal consistency, test-retest reliability, and construct validity; secondly, to measure the prevalence of concerns about the recurrence disease in former breast cancer patients and to identify potential predictors; and thirdly, to establish how fear of recurrence effects quality of life.

Moderate to high levels of fear of recurrence were noted in $56 \%$ of 136 breast cancer survivors. Worries about health and death were seen most frequently. Pain was a strong predictor of overall fear and of fear in the four sub-domains of CARS. The prevalence of fear decreased significantly with age. Educational level, living arrangements, and time since the last treatment did not predict the prevalence of overall fear. Fear of recurrence was negatively correlated with quality of life.

CARS appeared to be a valuable tool for researchers and clinicians seeking to understand patients' fears regarding the recurrence of breast cancer.

We concluded that, in response to the increasing number of long-term breast cancer survivors, research should focus on quality of life and psychosocial adjustment to the disease.

\section{Methodological considerations}

\section{Sample size}

We recruited a fairly large sample of patients for the prevalence studies described in Chapters 3 and 4. However, despite the proper format used and all our efforts to encourage GPs, nursing home physicians, and hospice nursing staff to recruit patients with advanced disease, the number of these patients was small. Therefore, this particular group may not be representative of patients with metastatic/advanced disease. Selection by GPs, nursing home physicians, and hospice nursing staff could have excluded those patients in the 
most terminal phase of their illness. It is not clear how this selection influenced the prevalence of pain. Several studies have shown that pain prevalence decreases at the very end of life ${ }^{2-5}$ which would mean that we slightly overestimated the prevalence of pain in group 3. However, other studies have shown an increase in the prevalence of pain at that phase. ${ }^{6,7}$ Very few studies have been published with regard to non-pain symptoms at the very end of life. One such study ${ }^{2}$ showed that the prevalence of confusion, anorexia and dysphagia increased during the final 48 hours of life. On the other hand, a decrease in the prevalence of depression, coughing, and nausea was also seen. Another study showed an increase of dyspnoea during the final week of life, but no differences regarding the other symptoms. ${ }^{3}$

In the CARS validation study (Chapter 6), the sample size of only 136 participants could raise questions with regard to the validity of the confirmatory factor analysis.

However, the empirical basis for the common rule that a researcher needs at least ten participants per variable is unclear. ${ }^{8}$ More recently, it was indicated that as communalities become lower, the importance of sample size increases. ${ }^{9}$ With communalities of above 0.6 , relatively small samples (less than 100) may be perfectly adequate. According to MacCallum, our study with communalities of around and above 0.6 , a variables-to-factor ratio of 30:5, and a sample size of 136 would achieve a convergence of $100 \%$.

\section{Quality criteria}

The studies used for the review in Chapter 2 were evaluated based on the methodological criteria of Leboeuf-Yde and Lauritsen, ${ }^{10}$ which were the first to

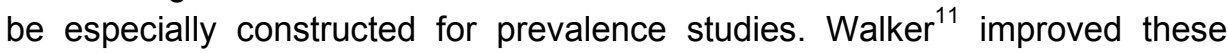
criteria by adding a test to identify proxy reporting, and suggested that some weighting should be given to the various criteria. In our paper, the criteria specific for lower back pain were substituted by an adequate description of the disease stage and/or condition of the cancer patients, and a weighting factor was introduced for each criterion. This resulted in a quality score that ranged from 0 to 19 points. The cut-off level for methodological acceptability was set at 14 points, which was $75 \%$ of the total points that could be achieved. ${ }^{10}$

The fact that the instrument used to judge methodological quality was devised subjectively to review the prevalence of lower back pain should be taken into consideration. $^{10,11}$ The $75 \%$ threshold for acceptability was set as conservatively as possible. In order to make the instrument suitable to review the prevalence of cancer pain, we substituted the criteria for the definition of lower back pain for the criteria on disease stage in cancer. These may be points for further improvement. Proxy reporting and the retrospective study of 
medical records probably merit even less weighting. Adequate description of the disease stage probably merits more weighting, but subdivision of the use of validated or non-validated questionnaires does not appear to be necessary.

\section{When are symptoms mild, moderate or severe?}

Cancer pain has been the model for symptom assessment. In order to derive meaningful classifications of pain severity, on from 0- to 10-point rating scales, patients' reports of each severity level have been paired with ratings on how such pain interferes with their lives. ${ }^{12}$ However, the subdivision of pain severity into mild, moderate, or severe remains arbitrary. In particular, the NRS scores 4 (mild $^{12-20}$ or moderate ${ }^{21-26}$ ) and 7 (moderate $^{18,22,23,26}$ or severe ${ }^{12-15,18-}$ $21,24,25,27,28)$ give rise to discussion. We chose Serlin's criteria for our review (Chapter 2). ${ }^{12}$ However, in our own prevalence study (Chapter 3), both the brief pain inventory and the EORTC quality of life questionnaire were used to measure pain: the majority of our patients considered a score of 4 to represent moderate pain rather than mild pain, while slightly more than half considered a score of 7 to represent severe pain rather than moderate pain. Therefore, we used different criteria for moderate and severe pain in this thesis. It is important to realise that the interpretation of pain by the patient is the most important parameter on which treatment is based, while most patients will accept mild pain, moderate and severe pain will require attention. ${ }^{12}$

Much less work was carried out to establish the cut-of points for mild, moderate, and severe non-pain symptoms. Recently, it was found that cut-of points differ between symptoms. ${ }^{29}$ Cut-points were related to limitations in physical functioning, suggesting differences in the quality of patients' lives. $^{29}$ For example, with fatigue, an NRS score of 1 is considered mild, 2-4 moderate, and $5-10$ severe, whereas with dry mouth, an NRS score of 1-4 is considered mild, 5-6 moderate, and 7-10 severe.

\section{General discussion}

\section{Pain}

In cancer patients, pain is one of the most feared and burdensome symptoms. Our review with the pooled data from 52 articles showed that pain is still highly prevalent in cancer patients: $64 \%$ of patients with metastatic or advanced stage disease, $59 \%$ of patients on anti-cancer treatment, and $33 \%$ of patients after curative treatment. More than one-third of patients with pain in the articles reviewed graded their pain as moderate or severe. Moreover, in our study of 
pain in patients with cancer, the prevalence rate was far too high (55\%). The prevalence of moderate to severe pain in patients treated with curative intent was just as high as that of back pain in the general population. One quarter of patients undergoing anti-cancer treatment and more than half the patients with advanced/terminal disease were suffering from moderate to severe pain. These high prevalence figures contrast sharply with the rapidly increasing interest in pain and pain relief over the past decade. Apparently, greater insight into the pathophysiological mechanisms of pain, and the wider availability of antinociceptive therapies, such as opioids, co-analgesics, and NMDA-receptorantagonists, have not influenced the prevalence rates of pain in cancer patients. Moreover, the WHO introduced a pain ladder in 1986, ${ }^{30}$ which has been accepted worldwide. Combined with appropriate dosage guidelines, this pain ladder should be able to provide the proper tools for adequate pain relief in $70-90 \%$ of patients. ${ }^{31-36}$ The gap between what is possible in pain control and what is actually achieved, is caused by many different care-provider-related, patient-related and society- and tradition-related factors. ${ }^{37}$ Fear of medication in general and opioids in particular, patients wanting to be 'good', lack of knowledge, lack of interest, and requests from care providers, are well-known barriers against adequate pain control. ${ }^{38-47}$

\section{Care providers}

Important barriers to effective pain management created by physicians and nurses are:

1. lack of formal assessment procedures for pain (57-76\%);

2. misconceptions about medications and side effects $(23-61 \%) ;{ }^{51-55}$ and

3. insufficient knowledge of / training in pain (23-54\%). ${ }^{47,48,51-58}$

Addendum 1. In less than half the cancer in-patients did nurses talk about pain with the patient. ${ }^{59}$ In only $27 \%$ of medical and nursing dossiers was the word pain mentioned. ${ }^{59,60}$ Conflicting reports exist on the agreement about symptoms between patients, nurses, and physicians. Some studies found that physicians tend to underestimate the severity of pain, ${ }^{61-64}$ while others found adequate agreement between patients, district nurses and GPs about the severity of pain. ${ }^{65}$ However, physicians do underestimate the influence of pain on daily life $e^{58,66}$

Addendum 2. Approximately half the physicians had misconceptions about drug tolerance, ${ }^{51,54} 20-25 \%$ of nurses and physicians expressed concerns regarding addiction, ${ }^{52,54}$ and $20-30 \%$ of physicians and nurses believed that moderate to severe pain is inevitable in patients who are terminally ill. ${ }^{48,52}$ Moreover, $31 \%$ of physicians waited with optimal pain control until the patient's prognosis was less than six months, ${ }^{47}$ and $41 \%$ of nurses reported that use of 
analgesics should be limited, based on the patient's prognosis. ${ }^{67}$ And finally, only $74 \%$ of in-patients receive their prescribed (breakthrough) pain medication. $^{68}$

Addendum 3. Several studies have attempted to evaluate physicians' knowledge and behaviour in prescribing pain medication. Although the majority of physicians expressed familiarity with the WHO analgesic ladder, and $44 \%$ indicated that they used these guidelines in their clinical practice, when replying to a hypothetical scenario, only $7 \%$ of GPs and $13 \%$ of specialists used the principles of the WHO ladder. ${ }^{56}$ Other studies revealed that, in $54 \%$ of cancer patients, pain specialists disagreed with the pain medication prescribed, ${ }^{69} 23 \%$ of patients only received breakthrough medication, ${ }^{70}$ and $13-20 \%$ of patients were inadequately informed about their medication and how to use it. $^{70}$

A recent review of physician-related barriers to cancer pain management concluded: concerns about the side effects of opioids, prescription of inefficient doses of opioids, and very poor prescription for treatment of the side effects of opioids, are the most general and common physician-related barriers to cancer pain management. $^{71}$

The barriers of care providers lead to the undertreatment of cancer-related pain. In our prevalence study, the treatment of pain was insufficient in $42 \%$ of 1383 patients, according to the pain management index (PMI). Previous studies reported negative $\mathrm{PMI}$ scores in $30-82 \%$ of patients. $^{19,22,38,58,72-80}$ Although PMI is widely used to determine the adequacy of pain management, it does not take into account adequate dosage and the use of co-analgesics. ${ }^{72}$ The not taking into account of adequate dosing probably leads to the underestimation of undertreatment. This explains why patients with metastatic disease (who make greater use of strong opioids) have the highest pain scores, despite their encouraging PMI rates. ${ }^{72,73}$ On the other hand, it could be hypothesized that not taking co-analgesics into account leads to an overestimation of undertreatment. However, both in our study and in others, the use of co-analgesics was extremely low $(5-7 \%),{ }^{74}$ so this hypothesis does not hold.

\section{Interventions}

Goldberg and Morison (2007) conducted a systematic review of institutional interventions designed to improve the assessment and treatment of pain in cancer patients. ${ }^{75}$ This review included three trials which studied the effects of educational sessions for nurses. ${ }^{76-78}$ It was concluded that didactic sessions for nurses can improve their knowledge and attitude. However, these interventions did not result in a significant decrease in the severity of pain. ${ }^{75}$ Only one study compared usual pain management with treatment, based on a multilevel 
treatment algorithm by specialized physicians: a statistically significant reduction in pain intensity was seen. ${ }^{79}$

One interesting study requested 320 patients to complete pain questionnaires ${ }^{80}$ In half these patients, summaries of the questionnaires were placed in their charts and reviewed by their oncologists. Summaries were not provided for patients in the control group. In the experimental group, $25 \%$ of prescriptions were altered, and there was a significant decrease in the reports of pain.

Both from our study and from the literature, it can be concluded that physicians play a major role in undertreatment, and thus in the high prevalence of pain in patients with cancer patients

Several studies have pointed to a wide range of patient-related barriers to adequate pain management in $37-85 \%$ of patients. ${ }^{38}$ There is a significant relationship between the number of concerns and the prevalence of pain and undertreatment. ${ }^{38}$ These include the reluctance of patients to report pain to their care provider and their reluctance to take medication. Patients are loath to inform their care providers about pain because they worry that this would distract their physician from treating their cancer. ${ }^{42,45}$ Half the patients want to be 'good', and a good patient does not complain. ${ }^{38,42,61}$ Twenty to seventy percent of patients believe that nothing can be done to ease their pain (fatalism), ${ }^{61,81}$ or they believe that having to bare pain is part of having cancer. ${ }^{81}$ Moreover, patients may fear that their pain is indicative of the progression of the disease, and they do not want to have to face that possibility. ${ }^{46}$

Patients are reluctant to take medication: fear of addiction continues to be a major concern in patients and their families (27-83\%). ${ }^{45,61,81}$ Thirty to seventytwo percent of patients express concerns about tolerance, ${ }^{61,81}$ and about $25 \%$ believe that pain medication is 'bad' for the body. ${ }^{82}$ Moreover, in our study, the items 'taking the lowest amount of medicine possible', "using routine medication instead of on demand' and 'becoming addicted' had the lowest score levels.

It is widely believed that the barriers perceived by patients lead to nonadherence to analgesic regimens. Self-reported adherence was found to be 40$67 \%$ for all analgesics. ${ }^{83,84}$ The proportion of patients who adhered to 'aroundthe-clock' analgesics varied from $59-91 \% .{ }^{43,74}$ Adherence to 'as needed' analgesics regimens was only $17-27 \%{ }^{43,74}$

\section{Interventions}

Several studies have shown pain education programmes to have a positive effect on patients with respect to the experience of pain, ${ }^{85-91}$ medication adherence ${ }^{85,87,90,91}$ and worries about addiction and tolerance. ${ }^{85,87,90}$ 
Unfortunately, many studies were small in size, used low-intensity education programmes, and only measured the short-term effects. Our study, as well as that of Syrjala ${ }^{91}$ also looked for the long-term effects. However, the chosen outcomes of pain were only found in the short term.

Recently, Bender et al. identified over 200 questions about pain and pain management in 18 patients. ${ }^{92}$ The pain management statistics of 11 patients revealed that the main reasons for being reluctant to take analgesic medication were: previous experience with chronic pain treatment, including stigmatising interactions with clinicians and family; bad experience with pain medication, including constipation; and strongly held conventions about the use of medication, including the belief that all medications are 'poisons'. ${ }^{93}$ It would be hard to address all these questions and worries in the context of a typical consultation. $^{9}$

\section{Health system}

In many European countries (excluding the Netherlands, Belgium and Scandinavia), governments and legislators are very restrictive about the use of opioids. ${ }^{37}$ Other system-related barriers are the lack of one physician being responsible for the treatment of pain and too infrequent contacts. ${ }^{94}$

\section{Summary}

The education of health care providers and patients into pain and the proper use of the tools provided by the WHO is urgently needed. Physicians and nurses should ask about pain, patients should tell their care providers about their pain. Lowering the prevalence of pain in patients with cancer will be time consuming, both for patients and for health care professionals. Nursing services being available to assess symptoms and to train patients and answer questions, could be a step in the right direction.

\section{Non-pain physical symptoms}

Apart from pain, cancer patients suffer from many other symptoms that interfere with their quality of life. By definition, patients with cancer are polysymptomatic. ${ }^{23,27,95-98}$ The prevalence of non-pain physical symptoms has been addressed much less frequently than the prevalence of pain, and then mainly in patients with advanced or metastatic disease. ${ }^{23,99-103}$ Studies of non-pain symptoms in ambulatory or cured patients are rare and mainly focus on a particular symptom in a particular type of cancer. ${ }^{104-106}$ However, non-pain physical symptoms are extremely frequent in cancer patients. In patients who had been cured and who had received their final anti-cancer treatment more than six months earlier, the only symptoms that were more frequent than in a general population were sleeping problems and tiredness. In all other patients, 
all non-pain physical symptoms were more frequent than in a general population. Of the non-pain physical symptoms, fatigue $(p<0.001)$, appetite loss $(p=0.004)$ and dry mouth $(p=0.039)$ had an independent significant negative effect on overall quality of life. In patients after or during curative anti-cancer treatment, both the number of symptoms and their type depended on the type of cancer. However, in patients at the palliative phase, not the type of cancer but the severity of the disease determined the number and type of symptoms. In our study, demographic characteristics were not significant in the regression analyses. However, Bradley et al. ${ }^{23}$ reported significantly higher rates of the prevalence of nausea and anxiety in females, and significantly higher anxiety scores in patients aged 69 years or less. Sex of the patients was also associated with an increased symptom burden, with females scoring higher than males. ${ }^{23}$

As stated earlier, it is important to realise that, in measuring the severity of nonpain symptoms, the cut-of points for mild, moderate and severe, differ between symptoms, due to limitations in physical functioning. ${ }^{29}$ For example, in the case of fatigue, an NRS score of 1 is considered mild, 2-4 moderate, and 5-10 severe, whereas in dry mouth, an NRS score of 1-4 is considered mild, 5-6 moderate, and 7-10 severe.

Although symptom management research has, in general, focused on individual symptoms, patients and the clinicians caring for them know that symptoms clearly occur together and that they may exacerbate the severity of each other. ${ }^{107}$ Several investigations have shown that the presence of multiple symptoms was associated with poorer patient outcome. ${ }^{27,108-116}$ In order to increase our scientific understanding of multiple, complex disease- and treatment-related symptoms that influence patient outcomes, the concept of symptom clusters was introduced in $2001{ }^{109}$ A symptom cluster is defined as a stable group of two or more concurrent symptoms that are related to each other. ${ }^{117}$ Cluster symptoms may or may not share the same aetiology. ${ }^{118}$ However, the clinical implications of the current state of knowledge on symptom clusters are limited. ${ }^{119}$ For example, when symptoms are related, the treatment of one symptom in the cluster should have an impact on the other symptoms in the cluster. As yet, there is no reported research on the treatment of formally identified symptom clusters. ${ }^{107}$ Although they are grouped, we will discuss the various symptoms independently, while realising the impact they may have on each other.

\section{Dyspnoea}

The prevalence of moderate to severe dyspnoea increases with progression of the disease (14\% in group 1 a to $46 \%$ in group 3 ). In a general Norwegian population, moderate to severe dyspnoea was found in $10 \%$ of participants. ${ }^{120}$ 
In a review, Ripamonti ${ }^{121}$ demonstrated moderate to severe dyspnoea in $10-63 \%$ of advanced cancer patients. In a recent review, 35\% (19-77\%) of advanced cancer patients experienced dyspnoea, ${ }^{122}$ while in the final two weeks of life, $39 \%$ experienced dyspnoea. ${ }^{122}$ Much less is known about the prevalence of dyspnoea in general cancer outpatients. One study reported moderate to severe dyspnoea in $15 \%$ of outpatients. ${ }^{123}$ No reports on cancer patients who had been cured were found.

Dyspnoea is most prevalent in patients with lung cancer. Our findings of moderate to severe dyspnoea in $30-58 \%$ of ambulatory lung cancer patients are in accordance with the existing literature. Shortness of breath was found to be as prevalent as $73 \%$ in one study, ${ }^{105}$ and clinical dyspnoea, defined as dyspnoea interfering with daily life, was found in $55 \%$ of ambulatory lung cancer patients. $^{124}$

Fifty-seven percent of patients with moderate to severe dyspnoea indicated that they were not being treated for their complaint. Whenever possible, an attempt should be made to treat the underlying cause of the dyspnoea: by treating the cancer, pleural effusion, thrombo-embolism, infection, etc. However, even when a cause-targeted therapy is no longer possible, much can be done to reduce the feeling of breathlessness (opioids, psychotropic drugs, corticosteroids). ${ }^{125}$

\section{Fatigue and trouble sleeping}

Feelings of weakness, tiredness, and the need to rest (together forming the EORTC construct 'fatigue') were the most prevalent symptoms in all disease groups: moderate to severe complaints in disease group 1a (curative anticancer therapy $>6$ months earlier) compared to a general Norwegian population $(16 \%, 22 \%$ and $21 \%) .{ }^{120}$ As the disease progressed, there was a rapid increase in the prevalence of feelings of weakness, tiredness, and the need to rest to $65 \%, 69 \%$, and $74 \%$ in group 3 . These figures are in accordance with the existing literature. In patients who had survived breast cancer, $35 \%$ and $34 \%$ reported fatigue at one to five years and five to ten years, respectively, after completion of treatment. ${ }^{126}$ More than $80 \%$ of outpatients receiving chemotherapy or radiotherapy reported some degree of fatigue, ${ }^{127}$ and patients with advanced disease reported fatigue, lack of energy, and weakness in $74 \%, 69 \%$ and $60 \%$, respectively. ${ }^{122}$

Moderate to severe sleeping problems (22-35\%) did not differ very much from a general Norwegian population (26\%). ${ }^{120}$ These findings are lower than those seen in previous reports. Sleeping disorders have been reported in $30-50 \%$ of cancer patients, ${ }^{128}$ which is twice as high as in the general population. ${ }^{129}$ In $33 \%$ of 300 breast cancer patients, the onset of insomnia started after the diagnosis of cancer. ${ }^{130}$ Regardless of cancer type, patients diagnosed in the previous six months had more complaints of excessive daytime sleepiness 
(37\%) than those diagnosed five or more years previously $(27 \%){ }^{131}$ Seventy percent of patients in a palliative care setting had symptoms of insomnia. ${ }^{132}$ Finally, approximately $25-50 \%$ of all prescriptions for cancer patients are for hypnotics. ${ }^{133,134}$ The majority of studies that assessed the relationship between fatigue and sleep prospectively in patients with cancer or cancer survivors, revealed strong correlations between fatigue and various sleep parameters. ${ }^{135}$

Fatigue had a significant negative effect on overall quality of life, and therefore treatment of this complaint is of paramount importance.

In patients with moderate to severe fatigue or sleeping difficulties, $89 \%$ and $68 \%$, respectively, reported that they received no treatment for that complaint. The concept that fatigue and insomnia are reciprocally related suggests the possibility that treatment for one may impact the other. ${ }^{135}$ Treating conditions that may contribute to cancer-related fatigue (e.g., anaemia, metabolic disorders, pain, depression) is a reasonable first step in the management of fatigue. ${ }^{136}$ When fatigue persists, both non-pharmacological (exercise, nutritional support) and pharmacological (psycho stimulants, CNS stimulants, corticosteroids, hypnotics) treatment should be considered. ${ }^{136}$

\section{Lack of appetite, nausea and vomiting}

The prevalence of moderate to severe lack of appetite, nausea and vomiting in patients who had finished curative treatment more than six months previously, was similar to a general Norwegian population (12\% lack of appetite, and $3 \%$ nausea and vomiting). ${ }^{120}$

The prevalence of these complaints rose with more advanced disease to $49 \%$, $26 \%$ and $10 \%$, respectively, in patients for whom anti-cancer therapy was no longer an option. These figures are in accordance with an extensive systematic review of symptom prevalence in patients with incurable cancer. ${ }^{122}$

Ninety-seven percent of patients with moderate to severe complaints of loss of appetite indicated that they were not being treated for that symptom. However, loss of appetite has a significant influence on overall quality of life. Corticosteroids, however short-lived, ${ }^{137}$ and megestrol acataat ${ }^{138}$ have proved to be effective in treating appetite loss in cancer patients. Fifty-eight and $45 \%$ received no treatment for nausea and vomiting, respectively. The treatment of nausea and vomiting during chemotherapy or radiotherapy is beyond the scope of this article. In patients with advanced disease, there are often several causes for nausea and vomiting. The identification of triggers and administration of receptor-specific anti-emetics should be successful in $93 \%$ of patients. ${ }^{139}$ 


\section{Constipation and diarrhoea}

Moderate to severe complaints of constipation and diarrhoea were prevalent in $7 \%$ and $6 \%$, respectively, of patients in group $1 \mathrm{a}$, similar to a general Norwegian population. ${ }^{120}$ In group 3 , these figures rose to $22 \%$ and $16 \%$, respectively. No differences were found between the various types of cancer. The prevalence of constipation in advanced cancer was seen to be considerably lower than reported previously. ${ }^{122,140}$ Possibly, the increased awareness of physicians, nurses and pharmacists, due to ongoing education, is paying off. Diarrhoea is increasingly being seen as a complication of anticancer treatment. ${ }^{140}$ Its causes in advanced cancer are diverse. ${ }^{140}$ Forty-seven percent of patients with moderate to severe constipation and $70 \%$ of patients with moderate to severe diarrhoea claimed not to have been treated for those symptoms. If possible, causative treatment is the preferred treatment. In refractory diarrhoea somatostatin analogues have proved to be highly effective. $^{141,142}$

\section{Dry mouth}

Moderate to severe complaints of dry mouth were prevalent in $17 \%$ and $58 \%$ of groups 1a and three patients, respectively. Earlier studies reported complaints of xerostomia in $78-97 \%$ patients with advanced cancer. ${ }^{143-145}$ As expected, dry mouth was most prevalent in head and neck cancer. Xerostomia had a considerable negative impact on quality of life and was ranked the third most distressing symptom in advanced cancer patients. ${ }^{144}$ Patients tend to underreport mouth pain and dryness; ${ }^{145} 90 \%$ of patients indicated that they had received no treatment for this complaint. The usual cause of xerostomia is drug treatment. ${ }^{144}$ Unfortunately, it is not usually possible to discontinue or substitute all xerostomic drugs. Management consists of saliva stimulants or substitutes. Saliva substitutes are rarely effective, ${ }^{146,147}$ but pilocarpine was shown to provide significant improvement of oral dryness in approximately $50 \%$ of patients. ${ }^{148,149}$

\section{Psychological symptoms}

Cancer-related psychological symptoms occur in one-third of patients. ${ }^{150}$ Major depressive disorders are estimated to occur in $10-25 \%$ of cancer patients. ${ }^{150}$ Most authors consider the criteria over-inclusive and prefer to focus on 'depressive symptoms'. In three systematic reviews, depressive symptoms in cancer patients ranged from $7-58 \%{ }^{151,152}$ to $20-50 \%$ for solid tumours. ${ }^{153}$ Anxiety disorders were found in $15-28 \% .{ }^{154}$ These estimates were made around the time of diagnosis. Almost no research has been carried out to establish the prevalence of depressive disorders in the years following diagnosis. Psychiatric morbidity and other psychological symptoms have been 
well studied in breast cancer patients, while fewer reports have studied other types of cancer. ${ }^{155-157}$

\section{Dullness, difficulties concentrating, difficulties remembering}

Moderate to severe dullness was primarily a complaint in group 3 patients $(30 \%)$. In earlier studies, the prevalence was $12-32 \% .{ }^{122}$ Cognitive functioning (composite scale of difficulty in concentrating and difficulty in remembering) in groups $1 \mathrm{a}, 1 \mathrm{~b}$ and 2 , was comparable to a normal reference population. ${ }^{120}$ The main problems in cognitive functioning were seen in advanced cancer patients. No differences were found between the different types of cancer. Most cancer patients receive medication with sedative (side-)effects, such as opioids, tricyclic anti-depressives, hypnotics, etc. Careful examination of all prescriptions is warranted.

\section{Anxiety and depression}

According to the HADS questionnaire, $32 \%$ of patients suffered from an anxiety disorder (HADS $\geq 8$ ). Anxiety was most prevalent (48\%) in patients with advanced disease. In all disease groups, anxiety was more prevalent than in the general population (18\%). ${ }^{158}$ The prevalence of anxiety disorders in cancer patients has been studied the most in patients with advanced disease. Reported prevalence rates range from $3-74 \% .{ }^{122,159,160}$ In breast cancer patients, no significant differences in the prevalence of anxiety were found between stage 1 and stage 4 patients. ${ }^{161}$ Tagay described anxiety in $63 \%$ of hypothyroid patients with thyroid cancer scheduled for the administration of radioiodine. ${ }^{162}$ Anxiety disorders were reported in $22-34 \%$ of outpatients. ${ }^{156,163,164}$ Korfage described the five-year follow-up of anxiety after the diagnosis and treatment of prostate cancer: high anxiety pre-treatment was present in $28 \%$ of patients and decreased significantly post-treatment. The sensitivity of anxiety at baseline as a screenings tool was $71 \% .{ }^{157}$ In a cohort of breast cancer patients, the prevalence of anxiety decreased from $40 \%$ postsurgery to $16 \%$ six months later. ${ }^{165}$

With regard to the presence of anxiety and its influence on overall quality of life, it appears to have a considerable negative impact on quality of life. However, in the regression analysis, anxiety did not appear to be an independent factor. A few studies have assessed the relationship between the presence of symptoms and anxiety. The results are contradictory: in advanced cancer patients, one study found no correlations between symptoms and anxiety, ${ }^{159}$ while another reported significant associations between anxiety and fatigue and nausea after correction for pain and disease severity. ${ }^{166}$

Depression or a depressive disorder were most prevalent in patients with advanced disease (48\%). In all disease groups, depression was more 
prevalent than in the general population (6\%). ${ }^{167} \mathrm{~A}$ strong body of evidence demonstrates the coexistence of depression and cancer. ${ }^{153}$ The prevalence rates of depression in the case of solid tumours range from $20-50 \%{ }^{153}$ In a cohort of breast cancer patients, the prevalence of anxiety and depression was $33 \%$ at diagnosis, $15 \%$ after one year, and $45 \%$ after diagnosis of recurrence. ${ }^{168}$ In a cohort of patients with prostate cancer, the improvement in mental health at the six-month follow-up was statistically significant and clinically meaningful. ${ }^{157}$ In contrast, in two other studies, one in early and late breast cancer ${ }^{169}$ and one in early and late chronic lymphatic leukaemia (CLL), depression and anxiety disorders and quality of life were not statistically different between the two groups. ${ }^{150}$ Pancreatic cancer had the highest rates of depression $(56.3 \%)$ and anxiety $(56.7 \%) .{ }^{156}$ Distress was significantly higher in lung cancer $(43 \%)$ and brain cancer $(42.7 \%)$, while lower levels were seen in gynaecological $(29.6 \%)$, prostate $(30.5 \%)$, and colon $(31.6 \%)$ cancers. $^{156}$ Depression had a significant negative influence on quality of life. Other studies also showed that psychological symptoms had a considerable negative influence on quality of life in patients with chronic diseases ${ }^{170-173}$ and cancer. ${ }^{153}$, 160 Inadequate diagnosis of distress, particularly of depression, in cancer patients can cause higher rates of non-compliance ${ }^{173}$ and possibly shorter survival. $^{174}$

A recent review on the treatment of depression in cancer patients concluded that there is limited evidence for the effectiveness of pharmacological and psychological interventions in the treatment of cancer patients with depressive disorders, and no evidence for the superiority of one modality over another. ${ }^{175}$ Psychological interventions for mixed types of cancers have noted beneficial ${ }^{176-}$ ${ }^{179}$ and non-beneficial ${ }^{180,181}$ effects on survival. Further research is necessary.

\section{Concerns about recurrence}

Another form of psychological distress in patients cured of cancer is the fear of recurrence. Worries about the recurrence of disease have a negative influence on quality of life, predominantly in the mental health domain of the RAND. This was demonstrated by the increased prevalence of post-traumatic stress disorder (PTSD) in former breast cancer patients ${ }^{182}$ and by the positive relationship between cancer-related fears and anxiety and depression. ${ }^{183}$ In former breast cancer patients, the prevalence of fear of recurrence ranges from $31-70 \% .^{183-187} \mathrm{~A}$ few results have also been published on the prevalence of fear of recurrence in patients with other types of cancer, e.g., orofacial: $>80 \%$ and $72 \%$ at three and seven months post-therapy, respectively; ${ }^{188}$ gynecological: between $22 \%$ and $64 \% ;^{189-192}$ colorectal: between $27 \%$ and $33 \%$; $^{183}$ and prostate: $39 \% .{ }^{183}$ Patients and their partners stated that recurrence of disease was their greatest fear after colorectal cancer. ${ }^{193}$ Articles in the literature are contradictory about the influence of time on the fear of recurrence. 
Some studies suggested that, as time progressed, the fear of recurrence subsided, ${ }^{183,186,187,194,195}$ whereas most studies found that time made little difference, ${ }^{196-200}$ even at more than 20 years after diagnosis.

Unfortunately, very little is known about the effect of psychosocial interventions after the treatment phase. ${ }^{201}$

\section{Conclusion}

The education of health care providers and patients into non-pain physical symptoms and psychological symptoms and their treatment is urgently needed. Physicians and nurses should ask patients about symptoms, and patients should tell their care providers about their symptoms. Reducing the prevalence of bothersome symptoms in cancer patients will be time consuming both for patients and health care professionals alike. Nursing services being available to assess symptoms and to train patients and answer questions, could be a step in the right direction.

\section{Final conclusion}

In the last decennia, much progression has been made in the curing of patients with cancer. However, there is still a long way to go in the field of care.

The prevalence of pain and non-pain symptoms is still far too high. Analgesic treatment is inadequate in almost $50 \%$ of patients, and many non-pain symptoms still go untreated. By using the WHO pain ladder, in combination with appropriate dosage guidelines, it should be possible to achieve adequate pain relief in $70-90 \%$ of patients with cancer, and (partially) effective treatment is available for most other symptoms.

The prime responsibility for symptom control lies with the physician. Unfortunately, no studies have yet been published on the effects of the education of physicians on symptom prevalence. However, with misconceptions about medications and side effects in 23-61\%, and insufficient knowledge / training in pain in $23-54 \%$, a positive effect from training might well be expected. On the other hand, a change of attitude and the systematic recording of pain levels have been shown to improve the management of pain. At our RCT, 'not-asked-for' advice with regard to a change in prescriptions for pain medication was rarely followed. Respectful, open communication between professional caregivers on symptom control should speak for itself.

The education of patients has proved to have a positive effect on levels of pain.

This leads us to the following recommendations:

1. The consistent recording of symptoms should be carried out in all patients, e.g., by standardized questionnaires or nurse practitioners. 
2. Patients should be encouraged to discuss their symptoms with the treating physician, and they should be instructed about symptom management and the existing barriers regarding medication.

3. More and better education of all health care professionals with regard to symptoms and symptom management is warranted. and

4. There should be one, easily assessable, telephone number for patients who have questions about their symptoms and/or medication. 


\section{References}

1. Coebergh JWW. Kanker in Nederland, trends, prognoses en implicaties voor zorgvraag. 2004; KWF kankerbestrijding Den Haag.

2. Conill C, Verger E, Henriquez I, Saiz N, Espier M, Lugo F, Garrigos A. Symptom prevalence in the last week of life. J Pain Symptom Manage. 1997;14:328-31.

3. Higginson I, McCarthy M. Measuring symptoms in terminal cancer: are pain and dyspnoea controlled? J R Soc Med. 1989; 82:264-7.

4. Lo RS, Ding A, Chung TK, Woo J. Prospective study of symptom control in 133 cases of palliative care inpatients in Shatin Hospital. Palliat Med. 1999;13:335-40.

5. Mercadante $S$, Casuccio A, Fulfaro $F$. The course of symptom frequency and intensity in advanced cancer patients followed at home. J Pain Symptom Manage. 1999;20:104-12.

6. McKegney FP, Bailey LR, Yates JW. Prediction and management of pain in patients with advanced cancer. Gen Hosp Psychiatry. 1981;3:95-101.

7. Peng WL, Wu GJ, Sun WZ, Chen JC, Huang AT. Multidisciplinary management of cancer pain: a longitudinal retrospective study on a cohort of end-stage cancer patients. J Pain Symptom Manage. 2006;32:444-52.

8. Field A. Discovering Statistics Using SPSS. SAGE Publications Ltd London 2005.

9. MacCallum RC, Widaman KF, Zhang S, Hong S. Sample size in factor analysis. Psychological Methods. 1999;4:84-99.

10. Leboeuf-Yde C, Lauritsen JM. The prevalence of low back pain in the literature. A structured review of 26 Nordic studies from 1954 to 1993. Spine. 1995;20:2112-8.

11. Walker, Bruce F. The prevalence of Low Back Pain: A Systmatic Review of the Literature from 1966 to 1998. Journal of Spinal Disorders. 2000;13:205-17.

12. Serlin RC, Mendoza TR, Nakamura Y, Edwards KR, Cleeland CS. When is cancer pain mild, moderate or severe? Grading pain severity by its interference with function. Pain. 1995;61:277-84.

13. Cleeland CS, Mendoza TR, Wang XS, Chou C, Harle MT, Morrissey M, Engstrom MC. Assessing symptom distress in cancer patients: the M.D. Anderson Symptom Inventory. Cancer. 2000;89:1634-46.

14. Sandblom G, Carlsson $P$, Sigsjo $P$, Varenhorst $E$. Pain and health-related quality of life in a geographically defined population of men with prostate cancer. $\mathrm{Br} J$ Cancer. 2001;85: 497-503.

15. Ger LP, Ho ST, Sun WZ, Wang MS, Cleeland CS. Validation of the Brief Pain Inventory in a Taiwanese population. J Pain Symptom Manage. 11999;8:316-22.

16. Ger LP, Ho ST, Wang JJ, Cheng CH. The prevalence and severity of cancer pain: a study of newly-diagnosed cancer patients in Taiwan. J Pain Symptom Manage. 1998;15:285-93.

17. Kelsen DP, Portenoy RK, Thaler HT, Niedzwiecki D, Passik SD, Tao Y, Banks W, Brennan MF, Foley KM. Pain and depression in patients with newly diagnosed pancreas cancer. J Clin Oncol. 1995;13:748-55.

18. Paul SM, Zelman DC, Smith M, Miaskowski C. Categorizing the severity of cancer pain: further exploration of the establishment of cutpoints. Pain. 2005;113:37-44.

19. Saxena A, Mendoza T, Cleeland CS. The assessment of cancer pain in north India: the validation of the Hindi Brief Pain Inventory--BPI-H. J Pain Symptom Manage. 1999;17:27-41.

20. Reyes-Gibby CC, Duc BN, Yen PN, Nga NH, Tran TV, Guo H, Bhat S, Cleeland CS. Status of cancer Pain in Hanoi, Vietnam: A Hospital-Wide Survey in a Tertiary Cancer Treatment Center. J Pain Symptom Manage. 2006;31:431-9.

21. Dorrepaal KL, Aaronson NK, Dam van FS. Pain experience and pain management among hopitilized cancer patients. A clinical study. Cancer. 1989;63:593-8.

22. Beck SL, Falkson G. Prevalence and management of cancer pain in South Africa. Pain. 2001;94:75-84.

23. Bradley N, Davis L, Chow E. Symptom distress in patients attending an outpatient palliative radiotherapy clinic. J Pain Symptom Manage. 2005;30:123-31. 
24. Pignon T, Fernandez L, Ayasso S, Durand MA, Badinand D, Cowen D. Impact of radiation oncology practice on pain: a cross-sectional survey. Int J Radiat Oncol Biol Phys. 2004;60:1204-10.

25. Stevens PE, Dibble SL, Miaskowski C. Prevalence, characteristics, and impact of postmastectomy pain syndrome: an investigation of women's experiences. Pain. 1995;61:61-8.

26. Gagliese L, Melzack R. Age-related differences in the qualities but not the intensity of chronic pain. Pain. 2003;104:597-608.

27. Chang VT, Hwang SS, Feuerman M, Kasimis BS. Symptom and quality of life survey of medical oncology patients at a veterans affairs medical center: a role for symptom assessment. Cancer. 2000;88:1175-83.

28. Sze FK, Chung TK, Wong E, Lam KK, Lo R, Woo J. Pain in Chinese cancer patients under palliative care. Palliat Med. 1998;12:271-7.

29. Given B, Given CW, Sikorskii A, Jeon S, McCorkle R, Champion V, Decker D. Establishing Mild, Moderate, and Severe Scores for Cancer-Related Symptoms: How Consistent and Clinically Meaningful Are Interference-Based Severity Cut-Points? J Pain Symptom Manage. 2008;35:126-35.

30. WHO. Cancer Pain Relief. World Health Organisation Geneve. 1986.

31. Ventafridda V, Oliveri E, Caraceni A, Spoldi E, De Conno F, Saita L, Ripamonti C. A retrospective study on the use of oral morphine in cancer pain. J Pain Symptom Manage. 1987;2:77-82.

32. Walker VA, Hoskin PJ, Hanks GW, White ID. Evaluation of the WHO analgesic guidelines for cancer pain in a hospital-based palliative care unit. J Pain Symptom Manage. 1988;3:145-9.

33. Goisis A, Gorini M, Ratti R, Luliri P. Application of a WHO protocol on medical therapy for oncologic pain in an internal medicine hospital. Tumori. 1989;75:470-2.

34. Caraceni A, Martini C, Zecca E, Portenoy RK, Ashby MA, Hawson G, Jackson KA, Lickiss N, Muirden N, Pisasale M, Moulin D, Schulz VN, Rico Pazo MA, Serrano JA, Andersen H, Henriksen HT, Mejholm I, Sjogren P, Heiskanen T, Kalso E, Pere P, Poyhia R, Vuorinen E, Tigerstedt I, Ruismaki P, Bertolino M, Larue F, Ranchere JY, Hege-Scheuing G, Bowdler I, Helbing F, Kostner E, Radbruch L, Kastrinaki K, Shah S, Vijayaram S, Sharma KS, Devi PS, Jain PN, Ramamani PV, Beny A, Brunelli C, Maltoni M, Mercadante S, Plancarte R, Schug S, Engstrand P, Ovalle AF, Wang X, Alves MF, Abrunhosa MR, Sun WZ, Zhang L, Gazizov A, Vaisman M, Rudoy S, Gomez Sancho M, Vila P, Trelis J, Chaudakshetrin P, Koh ML, Van Dongen RT, Vielvoye-Kerkmeer A, Boswell MV, Elliott T, Hargus E, Lutz L. Breakthrough pain characteristics and syndromes in patients with cancer pain. An international survey. Palliat Med. 2004;18:177-83.

35. Zech DF, Grond S, Lynch J, Hertel D, Lehmann KA. Validation of World Health Organization Guidelines for cancer pain relief: a 10-year prospective study. Pain. 1995;63:65-76.

36. Mercadante S. Pain treatment and outcomes for patients with advanced cancer who receive follow-up care at home. Cancer. 1999;85:1849-58.

37. Fazeny B, Muhm M, Hauser I, Wenzel C, Mares P, Berzlanovich A, Hagmeister H, Marosi C. Barriers in cancer pain management. Wien Klin Wochenschr. 2000;112:978-81.

38. Ward SE, Goldberg N, Miller-McCauley V, Mueller C, Nolan A, Pawlik-Plank D, Robbins A, Stormoen D, Weissman DE. Patient-related barriers to management of cancer pain. Pain. 1993;52:319-24.

39. Glajchen M, Fitzmartin RD, Blum D, Swanton R. Psychosocial barriers to cancer pain relief. Cancer Pract. 1995;3:76-82.

40. Grossman SA. Undertreatment of cancer pain: barriers and remedies. Support Care Cancer. 1993;1:74-8.

41. Johnson DC, Kassner CT, Houser J, Kutner JS. Barriers to effective symptom management in hospice. J Pain Symptom Manage. 2005;29:69-79.

42. Lin CC. Barriers to the analgesic management of cancer pain: a comparison of attitudes of Taiwanese patients and their family caregivers. Pain. 2000;88:7-14.

43. Miaskowski C, Dodd MJ, West C, Paul SM, Tripathy D, Koo P, Schumacher K. Lack of adherence with the analgesic regimen: a significant barrier to effective cancer pain management. J Clin Oncol. 2001;19:4275-9. 
44. Ferrell BR, McCaffery M, Rhiner M. Pain and addiction: an urgent need for change in nursing education. J Pain Symptom Manage. 1992;7:117-24.

45. Paice JA, Toy C, Shott S. Barriers to cancer pain relief: fear of tolerance and addiction. J Pain Symptom Manage. 1998;16:1-9.

46. Pargeon KL, Hailey BJ. Barriers to effective cancer pain management: a review of the literature. J Pain Symptom Manage. 1999;18:358-68.

47. Von Roenn JH, Cleeland CS, Gonin R, Hatfield AK, Pandya KJ. Physician attitudes and practice in cancer pain management. A survey from the Eastern Cooperative Oncology Group. Ann Intern Med. 1993;119:121-6.

48. Rawal N, Hylander J, Arner S. Management of terminal cancer pain in Sweden: a nationwide survey. Pain. 1993;54:169-79.

49. Brunelli C, Costantini M, Di Giulio P, Gallucci M, Fusco F, Miccinesi G, Paci E, Peruselli C, Morino P, Piazza M, Tamburini M, Toscani F. Quality-of-life evaluation: when do terminal cancer patients and health-care providers agree? J Pain Symptom Manage. 1998;.15:151-8.

50. Cleeland CS, Gonin R, Hatfield AK, Edmonson JH, Blum RH, Stewart JA, Pandya KJ. Pain and its treatment in outpatients with metastatic cancer. N Engl J Med. 1994;330:592-6.

51. Elliott TE, Elliott BA. Physician attitudes and beliefs about use of morphine for cancer pain. $\mathrm{J}$ Pain Symptom Manage. 1992;7:141-8.

52. Elliott TE, Murray DM, Elliott BA, Braun B, Oken MM, Johnson KM, Post-White J, Lichtblau L. Physician knowledge and attitudes about cancer pain management: a survey from the Minnesota cancer pain project. J Pain Symptom Manage. 1995;10:494-504.

53. Oneschuk D, Fainsinger R, Hanson J, Bruera E. Assessment and knowledge in palliative care in second year family medicine residents. J Pain Symptom Manage. 1997;14:265-73.

54. Fife BL, Irick N, Painter JD. A comparative study of the attitudes of physicians and nurses toward the management of cancer pain. J Pain Symptom Manage. 1993;8:132-9.

55. Ger LP, Ho ST, Wang JJ. Physicians' knowledge and attitudes toward the use of analgesics for cancer pain management: a survey of two medical centers in Taiwan. J Pain Symptom Manage. 2000;20:335-44.

56. Vainio A. Treatment of terminal cancer pain in France: a questionnaire study. Pain. 1995;62:155-62.

57. Warncke T, Breivik H, Vainio A. Treatment of cancer pain in Norway. A questionnaire study. Pain. 1994;57:109-16.

58. Larue F, Colleau SM, Brasseur L, Cleeland CS. Multicentre study of cancer pain and its treatment in France. BMJ. 1995;310:1034-7.

59. Donovan M, Dillon P, McGuire L. Incidence and characteristics of pain in a sample of medical-surgical inpatients. Pain. 1987;30:69-78.

60. Weber M, Huber C. Documentation of severe pain, opioid doses, and opioid-related side effects in outpatients with cancer: a retrospective study. J Pain Symptom Manage. 1999;17:49-54.

61. Yun YH, Heo D, Lee IG, Jeong HS, Kim HJ, Kim SY, Kim YH, Ro YJ, Yoon SS, Lee KH, Huh BY. Multicenter study of pain and its management in patients with advanced cancer in Korea. J Pain Symptom Manage. 2003;25:430-7.

62. Nekolaichuk CL, Bruera E, Spachynski K, MacEachern T, Hanson J, Maguire TO. A comparison of patient and proxy symptom assessments in advanced cancer patients. Palliat Med. 1999;13:311-23.

63. Grossman SA, Sheidler VR, Swedeen K, Mucenski J, Piantadosi S. Correlation of patient and caregiver ratings of cancer pain. J Pain Symptom Manage. 1991;6:53-7.

64. Horton R. Differences in assessment of symptoms and quality of life between patients with advanced cancer and their specialist palliative care nurses in a home care setting. Palliat Med. 2002;16:488-94.

65. Ewing G, Rogers M, Barclay S, McCabe J, Martin A, Campbell M, Todd C. Palliative care in primary care: a study to determine whether patients and professionals agree on symptoms. Br J Gen Pract. 2006;56:27-34.

66. Shvartzman P, Friger M, Shani A, Barak F, Yoram C, Singer Y. Pain control in ambulatory cancer patients--can we do better? J Pain Symptom Manage. 2003;26:716-22. 
67. Fife BL. The conceptualization of meaning in illness. Soc Sci Med. 1994;38:309-16.

68. Rond de ME, Wit de R, Dam van FS, Muller MJ. A Pain Monitoring Program for nurses: effect on the administration of analgesics. Pain. 2000;89:25-38.

69. Dorrepaal KL, Aaronson NK, Dam van FS. Pain experience and pain management among hospitalized cancer patients. A clinical study. Cancer. 1989;63:593-8.

70. Wit de R, Dam van F, Vielvoye-Kerkmeer A, Mattern C, Abu-Saad HH. The treatment of chronic cancer pain in a cancer hospital in The Netherlands. J Pain Symptom Manage. 1999;17:333-50.

71. Jacobsen R, Sjogren P, Moldrup C, Christrup L. Physician-related barriers to cancer pain management with opioid analgesics: a systematic review. J Opioid Manag. 2007;3:207-14.

72. Cleeland CS. Research in Cancer Pain. Cancer. 1991;67:823-7.

73. de Wit R, van Dam F, Loonstra S, Zandbelt L, van Buuren A, van der Heijden K, Leenhouts G, Huijer Abu-Saad H. The Amsterdam Pain Management Index compared to eight frequently used outcome measures to evaluate the adequacy of pain treatment in cancer patients with chronic pain. Pain. 2001;91:339-49.

74. Enting RH, Oldenmenger WH, Van Gool AR, van der Rijt CC, Sillevis Smitt PA. The effects of analgesic prescription and patient adherence on pain in a dutch outpatient cancer population. J Pain Symptom Manage. 2007;34:523-31.

75. Goldberg GR, Morrison RS. Pain management in hospitalized cancer patients: a systematic review. J Clin Oncol. 2007;25:1792-801.

76. Camp-Sorrell D, O'Sullivan P. Effects of continuing education. Pain assessment and documentation. Cancer Nurs. 1991;14:49-54.

77. Kravitz RL, Delafield JP, Hays RD, Drazin R, Conolly M. Bedside charting of pain levels in hospitalized patients with cancer: a randomized controlled trial. J Pain Symptom Manage. 1996;11:81-7.

78 . Morrison RS, Meier DE, Fischberg D, Moore C, Degenholtz H, Litke A, Maroney-Galin C, Siu AL. Improving the management of pain in hospitalized adults. Arch Intern Med. 2006;166:1033-9.

79. Du Pen SL, Du Pen AR, Polissar N, Hansberry J, Kraybill BM, Stillman M, Panke J, Everly R, Syrjala K. Implementing guidelines for cancer pain management: results of a randomized controlled clinical trial. J Clin Oncol. 1999;17:361-70.

80. Trowbridge R, Dugan W, Jay SJ, Littrell D, Casebeer LL, Edgerton S, Anderson J, O'Toole $\mathrm{JB}$. Determining the effectiveness of a clinical-practice intervention in improving the control of pain in outpatients with cancer. Acad Med. 199772:798-800.

81. Thomason TE, McCune JS, Bernard SA, Winer EP, Tremont S, Lindley CM. Cancer pain survey: patient-centered issues in control. J Pain Symptom Manage. 1998;15:275-84.

82. Riddell A, Fitch MI. Patients' knowledge of and attitudes toward the management of cancer pain. Oncol Nurs Forum. 1997;24:1775-84.

83. Zeppetella G. How do terminally ill patients at home take their medication? Palliat Med. 1999;13:469-75.

84. Lai YH, Keefe FJ, Sun WZ, Tsai LY, Cheng PL, Chiou JF, Wei LL. Relationship between pain-specific beliefs and adherence to analgesic regimens in Taiwanese cancer patients: a preliminary study. J Pain Symptom Manage. 2002;24:415-23.

85. Rimer B, Levy MH, Keintz MK, Fox L, Engstrom PF, MacElwee N. Enhancing cancer pain control regimens through patient education. Patient Educ Couns. 1987;10:267-77.

86. Lai YH, Guo SL, Keefe FJ, Tsai SL, Chien CC, Sung YC, Chen ML. Effects of brief pain education on hospitalized cancer patients with moderate to severe pain. Support Care Cancer. 2004;12:645-52.

87. Lin CC, Chou PL, Wu SL, Chang YC, Lai YL. Long-term effectiveness of a patient and family pain education program on overcoming barriers to management of cancer pain. Pain. 2006;122:271-81.

88. Vallieres I, Aubin M, Blondeau L, Simard S, Giguere A. Effectiveness of a clinical intervention in improving pain control in outpatients with cancer treated by radiation therapy. Int $\mathrm{J}$ Radiat Oncol Biol Phys. 2006;66:234-7. 
89. Miaskowski C, Dodd M, West C, Schumacher K, Paul SM, Tripathy D, Koo P. Randomized clinical trial of the effectiveness of a self-care intervention to improve cancer pain management. J Clin Oncol. 2004;22:1713-20.

90. Chang MC, Chang YC, Chiou JF, Tsou TS, Lin CC. Overcoming patient-related barriers to cancer pain management for home care patients. A pilot study. Cancer Nurs. 2002;25:470-6.

91. Syrjala KL, Abrams JR, Polissar NL, Hansberry J, Robison J, Dupen S, Stillman M, Fredrickson M, Rivkin S, Feldman E, Gralow J, Rieke JW, Raish RJ, Lee DJ, Cleeland CS, Dupen A. Patient training in cancer pain management using integrated print and video materials: A multisite randomized controlled trial. Pain. 2008;135:175-86.

92. Bender JL, Hohenadel J, Wong J, Katz J, Ferris LE, Shobbrook C, Warr D, Jadad AR. What Patients with Cancer Want to Know About Pain: A Qualitative Study. J Pain Symptom Manage. 2008;35:177-87.

93. Schumacher KL, West C, Dodd M, Paul SM, Tripathy D, Koo P, Miaskowski CA. Pain management autobiographies and reluctance to use opioids for cancer pain management. Cancer Nurs. 2002;25:125-33.

94. Enting $\mathrm{RH}$, Oldenmenger $\mathrm{WH}$, Sillevis Smitt PAE. The prevalence of cancer pain and the quality of treatment in Dutch outpatients. EAPC Prague. 2003.

95. 76. Hwang SS, Chang VT, Cogswell J, Alejandro Y, Osenenko P, Morales E, Srinivas S, Kasimis B. Study of unmet needs in symptomatic veterans with advanced cancer: incidence, independent predictors and unmet needs outcome model. J Pain Symptom Manage. 2004;8:421-32.

96. Lidstone V, Butters E, Sinnott C, Beynon T, Richards M. Symptoms and concerns amongst cancer outpatients: identifying the need for specialist palliative care. Palliative Medicine. 2003;17:588-95.

97. Portenoy RK, Thaler HT, Kornblith AB, Lepore JM, Friedlander-Klar H, Coyle N, Smart-Curley T, Kemeny N, Norton L, Hoskins W, et al. Symptom prevalence, characteristics and distress in a cancer population. Qual Life Res. 1994;3:183-9.

98. Schuit KW, Sleijfer DT, Meijler W, Otter R, Schakenraad J, Bergh van den FC, Meyboom-de Jong B. Symptoms and functional status of patients with disseminated cancer visiting outpatient departments. J Pain Symptom Manage. 1998;16:290-7.

99. Hoekstra J, Vos de R, Duijn van NP, Schade E, Bindels PJ. Using the symptom monitor in a randomized controlled trial: the effect on symptom prevalence and severity. J Pain Symptom Manage. 2006;31:22-30.

100. Labori KJ, Hjermstad MJ, Wester T, Buanes T, Loge JH. Symptom profiles and palliative care in advanced pancreatic cancer: a prospective study. Support Care Cancer. 2006;14:1126-33.

101. Moro C, Brunelli C, Miccinesi G, Fallai M, Morino P, Piazza M, Labianca R, Ripamonti C. Edmonton symptom assessment scale: Italian validation in two palliative care settings. Support Care Cancer. 2006;14:30-7.

102. Tsai JS, Wu CH, Chiu TY, Hu WY, Chen CY. Symptom patterns of advanced cancer patients in a palliative care unit. Palliat Med. 2006;20:617-22.

103. Stromgren AS, Sjogren P, Goldschmidt D, Petersen MA, Pedersen L, Groenvold M. Symptom priority and course of symptomatology in specialized palliative care. J Pain Symptom Manage. 2006;31:199-206.

104. Carpenter JS, Elam JL, Ridner SH, Carney PH, Cherry GJ, Cucullu HL. Sleep, fatigue, and depressive symptoms in breast cancer survivors and matched healthy women experiencing hot flashes. Oncol Nurs Forum. 2004;31:5591-8.

105. O'Driscoll M, Corner J, Bailey $\mathrm{C}$. The experience of breathlessness in lung cancer. Eur $\mathrm{J}$ Cancer Care (Engl). 1999;8:37-43.

106. Young YH, Ko JY, Sheen TS. Postirradiation vertigo in nasopharyngeal carcinoma survivors. Otol Neurotol. 2004;25:366-70.

107. Williams LA. Clinical management of symptom clusters. Semin Oncol Nurs. 2007;23:113-20.

108. Barsevick AM, Dudley WN, Beck SL. Cancer-related fatigue, depressive symptoms, and functional status: a mediation model. Nurs Res. 2006;55:366-72.

109. Dodd MJ, Miaskowski C, Paul SM. Symptom clusters and their effect on the functional status of patients with cancer. Oncol Nurs Forum. 2001;28:465-70. 
110. Gaston-Johansson F, Ohly KV, Fall-Dickson JM, Nanda JP, Kennedy MJ. Pain, psychological distress, health status, and coping in patients with breast cancer scheduled for autotransplantation. Oncol Nurs Forum. 1999;26:1337-45.

111. Gift AG, Jablonski A, Stommel M, Given CW. Symptom clusters in elderly patients with lung cancer. Oncol Nurs Forum. 2004;31:202-12.

112. Gift AG, Stommel M, Jablonski A, Given W. A cluster of symptoms over time in patients with lung cancer. Nurs Res. 2003;52:393-400.

113. Given B, Given C, Azzouz F, Stommel M. Physical functioning of elderly cancer patients prior to diagnosis and following initial treatment. Nurs Res. 2001;50:222-32.

114. Redeker NS, Lev EL, Ruggiero J. Insomnia, fatigue, anxiety, depression, and quality of life of cancer patients undergoing chemotherapy. Sch Inq Nurs Pract. 2000;14:275-90.

115. Visser MR, Smets EM. Fatigue, depression and quality of life in cancer patients: how are they related? Support Care Cancer. 1998;6:101-8.

116. Williamson GM, Schulz R. Activity restriction mediates the association between pain and depressed affect: a study of younger and older adult cancer patients. Psychol Aging. 1995;10:369-78.

117. Kim HJ, McGuire DB, Tulman L, Barsevick AM. Symptom clusters: concept analysis and clinical implications for cancer nursing. Cancer Nurs. 2005;28:270-282; quiz 283-74.

118. Miaskowski C, Dodd M, Lee K. Symptom clusters: the new frontier in symptom management research. J Natl Cancer Inst Monogr. 2004;17-21.

119. Barsevick AM. The concept of symptom cluster. Semin Oncol Nurs. 2007;23:89-98.

120. EORTC QoL. The EORTC Quality of Life Reference Values. EORTC Quality of Life group Brussels Brussels 2003.

121. Ripamonti C. Management of dyspnea in advanced cancer patients. Support Care Cancer. 1999;7:233-43.

122. Teunissen SC, Wesker W, Kruitwagen C, de Haes HC, Voest EE, de Graeff A. Symptom prevalence in patients with incurable cancer: a systematic review. J Pain Symptom Manage. 2007;34:94-104.

123. Dudgeon DJ, Kristjanson L, Sloan JA, Lertzman M, Clement K. Dyspnea in cancer patients: prevalence and associated factors. J Pain Symptom Manage. 2001;21:95-102.

124. Tanaka K, Akechi T, Okuyama T, Nishiwaki Y, Uchitomi Y. Prevalence and screening of dyspnea interfering with daily life activities in ambulatory patients with advanced lung cancer. J Pain Symptom Manage. 2002;23:484-9.

125. Chan K-S, Sham MMK, Tse DMW, Thorsen AB. Palliative medicine in malignant respiratory diseases. In: Doyle D, Hanks GW, Cherny N, Calman KC (eds) Oxford Textbook of Palliative Medicine. Oxford University Press Oxford, 2004:587-618.

126. Bower JE, Ganz PA, Desmond KA, Bernaards C, Rowland JH, Meyerowitz BE, Belin TR. Fatigue in long-term breast carcinoma survivors: a longitudinal investigation. Cancer. 2006;106:751-8.

127. Hickok JT, Morrow GR, Roscoe JA, Mustian K, Okunieff P. Occurrence, severity, and longitudinal course of twelve common symptoms in 1129 consecutive patients during radiotherapy for cancer. J Pain Symptom Manage. 2005;30:433-42.

128. Theobald DE. Cancer pain, fatigue, distress, and insomnia in cancer patients. Clin Cornerstone. 2004;6 Suppl 1D:S15-21.

129. Savard J, Laroche L, Simard S, Ivers H, Morin CM. Chronic insomnia and immune functioning. Psychosom Med. 2003;65:211-21.

130. Savard J, Simard S, Blanchet J, Ivers H, Morin CM. Prevalence, clinical characteristics, and risk factors for insomnia in the context of breast cancer. Sleep. 2001;24:583-90.

131. Davidson JR, MacLean AW, Brundage MD, Schulze K. Sleep disturbance in cancer patients. Soc Sci Med. 2002;54:1309-21.

132. Hugel H, Ellershaw JE, Cook L, Skinner J, Irvine C. The prevalence, key causes and management of insomnia in palliative care patients. J Pain Symptom Manage. 2004;27: 316-21. 
133. Derogatis LR, Feldstein M, Morrow G, Schmale A, Schmitt M, Gates C, Murawski B, Holland J, Penman D, Melisaratos N, Enelow AJ, Adler LM. A survey of psychotropic drug prescriptions in an oncology population. Cancer. 1979;44:1919-29.

134. Stiefel FC, Kornblith $A B$, Holland JC. Changes in the prescription patterns of psychotropic drugs for cancer patients during a 10-year period. Cancer. 1990;65:1048-53.

135. Roscoe JA, Kaufman ME, Matteson-Rusby SE, Palesh OG, Ryan JL, Kohli S, Perlis ML, Morrow GR. Cancer-related fatigue and sleep disorders. Oncologist. 2007;12 Suppl 1:35-42.

136. Carroll JK, Kohli S, Mustian KM, Roscoe JA, Morrow GR. Pharmacologic treatment of cancerrelated fatigue. Oncologist. 2007;12 Suppl 1:43-51.

137. Behl D, Jatoi A. Pharmacological options for advanced cancer patients with loss of appetite and weight. Expert Opin Pharmacother. 2007;8:1085-90.

138. Berenstein EG, Ortiz Z. Megestrol acetate for the treatment of anorexia-cachexia syndrome. Cochrane Database Syst Rev. 2005;CD004310.

139. Lichter I. Results of antiemetic management in terminal illness. J Palliat Care. 1993;9:19-21.

140. Solomon R, Cherny NI. Constipation and diarrhea in patients with cancer. Cancer J. 2006;12:355-64.

141. Rosenoff S. Resolution of refractory chemotherapy-induced diarrhea (CID) with octreotide long-acting formulation in cancer patients: 11 case studies. Support Care Cancer. 2004;12:561-70.

142. Szilagyi A, Shrier I. Systematic review: the use of somatostatin or octreotide in refractory diarrhoea. Aliment Pharmacol Ther. 2001;15:1889-97.

143. Sweeney MP, Bagg J, Baxter WP, Aitchison TC. Oral disease in terminally ill cancer patients with xerostomia. Oral Oncol. 1998;34:123-6.

144. Davies AN, Broadley K, Beighton D. Xerostomia in patients with advanced cancer. J Pain Symptom Manage. 2001;22:820-5.

145. Oneschuk D, Hanson J, Bruera E. A survey of mouth pain and dryness in patients with advanced cancer. Support Care Cancer. 2000;8:372-6.

146. Jellema AP, Langendijk H, Bergenhenegouwen L, van der Reijden W, Leemans R, Smeele L, Slotman BJ. The efficacy of Xialine in patients with xerostomia resulting from radiotherapy for head and neck cancer: a pilot-study. Radiother Oncol. 2001;59:157-60.

147. Momm F, Volegova-Neher NJ, Schulte-Monting J, Guttenberger R. Different saliva substitutes for treatment of xerostomia following radiotherapy. A prospective crossover study. Strahlenther Onkol. 2005;181:231-6.

148. Johnson JT, Ferretti GA, Nethery WJ, Valdez IH, Fox PC, Ng D, Muscoplat CC, Gallagher SC. Oral pilocarpine for post-irradiation xerostomia in patients with head and neck cancer. $\mathrm{N}$ Engl J Med. 1993;329:390-5.

149. LeVeque FG, Montgomery M, Potter D, Zimmer MB, Rieke JW, Steiger BW, Gallagher SC, Muscoplat CC. A multicenter, randomized, double-blind, placebo-controlled, dose-titration study of oral pilocarpine for treatment of radiation-induced xerostomia in head and neck cancer patients. J Clin Oncol. 1993;11:1124-31.

150. Levin T, Kissane DW. Psychooncology - the state of its development in 2006. European Journal of Psychiatry. 2006;20:183-97.

151. Pirl WF. Evidence report on the occurrence, assessment, and treatment of depression in cancer patients. J Natl Cancer Inst Monogr. 2004;32-9.

152. Massie MJ. Prevalence of depression in patients with cancer. J Natl Cancer Inst Monogr. 2004;57-71.

153. Pasquini M, Biondi M. Depression in cancer patients: a critical review. Clin Pract Epidemol Ment Health. 2007;3:2.

154. Kerrihard T, Breitbart W, Dent R, Strout D. Anxiety in patients with cancer and human immunodeficiency virus. Seminars in Clinical Neuropsychiatry. 1999; 4:114-32.

155. Prieto JM, Atala J, Blanch J, Carreras E, Rovira M, Cirera E, Espinal A, Gasto C. Role of depression as a predictor of mortality among cancer patients after stem-cell transplantation. $\mathrm{J}$ Clin Oncol. 2005;23:6063-71.

156. Zabora J, BrintzenhofeSzoc K, Curbow B, Hooker C, Piantadosi S. The prevalence of psychological distress by cancer site. Psychooncology. 2001;10:19-28. 
157. Korfage IJ, Essink-Bot ML, Janssens AC, Schroder FH, Koning de HJ. Anxiety and depression after prostate cancer diagnosis and treatment: 5-year follow-up. $\mathrm{Br} \mathrm{J}$ Cancer. 2006;94:1093-8.

158. Symreng I, Fishman SM. Anxiety and Pain. Pain, clinical Updates. 2004;12:1-6.

159. Teunissen SC, de Graeff A, Voest EE, de Haes JC. Are anxiety and depressed mood related to physical symptom burden? A study in hospitalized advanced cancer patients. Palliat Med. 2007;21:341-6.

160. Wilson KG, Chochinov HM, Skirko MG, Allard P, Chary S, Gagnon PR, Macmillan K, De Luca M, O'Shea F, Kuhl D, Fainsinger RL, Clinch JJ. Depression and anxiety disorders in palliative cancer care. J Pain Symptom Manage. 2007;33:118-29.

161. Bastecky J, Tondlova H, Vesela J, Brizekova S, Boleloucky Z. Prevalence of psychopathology in patients suffering from breast and gastrointestinal cancer. Patient Educ Couns. 1996;28:175-8.

162. Tagay S, Herpertz S, Langkafel M, Erim Y, Bockisch A, Senf W, Gorges R. Health-related Quality of Life, depression and anxiety in thyroid cancer patients. Qual Life Res. 2006;15: 695-703.

163. Grassi L, Travado L, Moncayo FL, Sabato S, Rossi E. Psychosocial morbidity and its correlates in cancer patients of the Mediterranean area: findings from the Southern European Psycho-Oncology Study. J Affect Disord. 2004;83:243-8.

164. Strong V, Waters R, Hibberd C, Rush R, Cargill A, Storey D, Walker J, Wall L, Fallon M, Sharpe M. Emotional distress in cancer patients: the Edinburgh Cancer Centre symptom study. Br J Cancer. 2007;96:868-74.

165. Mehnert A, Koch U. Prevalence of acute and post-traumatic stress disorder and comorbid mental disorders in breast cancer patients during primary cancer care: a prospective study. Psychooncology. 2007;16:181-8.

166. Smith EM, Gomm SA, Dickens CM. Assessing the independent contribution to quality of life from anxiety and depression in patients with advanced cancer. Palliat Med. 2003;17:509-13.

167. Trimbos Instituut. Netherlands Institute of Mental Health and Addiction. Depressie. 2007; www.trimbosinstituut.nl.

168. Burgess C, Cornelius V, Love S, Graham J, Richards M, Ramirez A. Depression and anxiety in women with early breast cancer: five year observational cohort study. BMJ. 2005;330:702.

169. Kissane DW, Grabsch B, Love A, Clarke DM, Bloch S, Smith GC. Psychiatric disorder in women with early stage and advanced breast cancer: a comparative analysis. Aust $\mathrm{N} \mathrm{Z} \mathrm{J}$ Psychiatry. 2004;38:320-6.

170. Ola BA, Adewuya AO, Ajayi OE, Akintomide AO, Oginni OO, Ologun YA. Relationship between depression and quality of life in Nigerian outpatients with heart failure. J Psychosom Res. 2006;61:797-800.

171. Uguz F, Dursun R, Kaya N, Cilli AS. Quality of life in patients with Behcet's disease: the impact of major depression. Gen Hosp Psychiatry. 2007;9:21-4.

172. Stafford L, Berk M, Reddy P, Jackson HJ. Comorbid depression and health-related quality of life in patients with coronary artery disease. J Psychosom Res. 2007;62:401-10.

173. Ashbury FD, Madlensky L, Raich P, Thompson M, Whitney G, Hotz K, Kralj B, Edell WS. Antidepressant prescribing in community cancer care. Support Care Cancer. 2003;11:278-85.

174. Watson M, Haviland JS, Greer S, Davidson J, Bliss JM. Influence of psychological response on survival in breast cancer: a population-based cohort study. Lancet. 1994;354:1331-6.

175. Rodin G, Lloyd N, Katz M, Green E, Mackay JA, Wong RK. The treatment of depression in cancer patients: a systematic review. Support Care Cancer. 2007;15:123-36.

176. Spiegel D, Bloom JR, Kraemer HC, Gottheil E. Effect of psychosocial treatment on survival of patients with metastatic breast cancer. Lancet. 1989;2:888-91.

177. Richardson JL, Shelton DR, Krailo M, Levine AM. The effect of compliance with treatment on survival among patients with hematologic malignancies. J Clin Oncol. 1990;8:356-64.

178. Fawzy FI, Canada AL, Fawzy NW. Malignant melanoma: effects of a brief, structured psychiatric intervention on survival and recurrence at 10-year follow-up. Arch Gen Psychiatry. 2003;60:100-3. 
179. Kuchler T, Henne-Bruns D, Rappat S, Graul J, Holst K, Williams JI, Wood-Dauphinee S. Impact of psychotherapeutic support on gastrointestinal cancer patients undergoing surgery: survival results of a trial. Hepatogastroenterology. 1999;46:322-35.

180. Cunningham AJ, Edmonds CV, Jenkins GP, Pollack H, Lockwood GA, Warr D. A randomized controlled trial of the effects of group psychological therapy on survival in women with metastatic breast cancer. Psychooncology. 1998;87:508-17.

181. Goodwin PJ, Leszcz M, Ennis M, Koopmans J, Vincent L, Guther H, Drysdale E, Hundleby M, Chochinov HM, Navarro M, Speca M, Hunter J. The effect of group psychosocial support on survival in metastatic breast cancer. N Engl J Med. 2001;345:1719-26.

182. Kornblith AB, Herndon JE, 2nd, Weiss RB, Zhang C, Zuckerman EL, Rosenberg S, Mertz M, Payne D, Jane Massie M, Holland JF, Wingate P, Norton L, Holland JC. Long-term adjustment of survivors of early-stage breast carcinoma, 20 years after adjuvant chemotherapy. Cancer. 2003;98:679-89.

183. Deimling GT, Bowman KF, Sterns S, Wagner LJ, Kahana B. Cancer-related health worries and psychological distress among older adult, long-term cancer survivors. Psychooncology. 2006;15:306-20.

184. Verhoeven K, Crombez G, Van Damme S. Angst voor tergkeer van borstkanker na genezing: de rol van somatosensore amplificatie en trekangst. Gedrag en Gezondheid. 2005;33:27-32.

185. Meyer L, Aspegren K. Long-term psychological sequelae of mastectomy and breast conserving treatment for breast cancer. Acta Oncol. 1989;28:13-18.

186. King MT, Kenny P, Shiell A, Hall J, Boyages J. Quality of life three months and one year after first treatment for early stage breast cancer: influence of treatment and patient characteristics. Qual Life Res. 2000;9:789-800.

187. Mast ME. Survivors of breast cancer: illness uncertainty, positive reappraisal, and emotional distress. Oncol Nurs Forum. 1998;25:555-62.

188. Humphris GM, Rogers S, McNally D, Lee-Jones C, Brown J, Vaughan D. Fear of recurrence and possible cases of anxiety and depression in orofacial cancer patients. International Journal of Oral \& Maxillofacial Surgery. 2003;32:486-91.

189. Leake RL, Gurrin LC, Hammond IG. Quality of life in patients attending a low-risk gynaecological oncology follow-up clinic. Psychooncology. 2001;10:428-35.

190. Fitch M, Gray RE, Franssen E. Perspectives on living with ovarian cancer: young women's views. Can Oncol Nurs J. 2000;10:101-8.

191. Fitch MI, Gray RE, Franssen E. Perspectives on living with ovarian cancer: older women's views. Oncol Nurs Forum. 2001;28:1433-42.

192. Wenzel LB, Donnelly JP, Fowler JM, Habbal R, Taylor TH, Aziz N, Cella D. Resilience, reflection, and residual stress in ovarian cancer survivorship: a gynecologic oncology group study. Psychooncology. 2002;11:142-53.

193. Northouse LL, Schafer JA, Tipton J, Metivier L. The concerns of patients and spouses after the diagnosis of colon cancer: a qualitative analysis. J Wound Ostomy Continence Nurs. 1999;26:8-17.

194. Utley R. The evolving meaning of cancer for long-term survivors of breast cancer. Oncol Nurs Forum. 1999;26:1519-23.

195. Ellman R, Thomas BA. Is psychological wellbeing impaired in long-term survivors of breast cancer? J Med Screen. 1995;2:5-9.

196. Glynne-Jones R, Chait I, Thomas SF. When and how to discharge cancer survivors in long term remission from follow-up: the effectiveness of a contract. Clin Oncol ( $R$ Coll Radiol). 1997;9:25-9.

197. Thomas SF, Glynne-Jones R, Chait I, Marks DF. Anxiety in long-term cancer survivors influences the acceptability of planned discharge from follow-up. Psychooncology. 1997;6:190-6.

198. Mehta SS, Lubeck DP, Pasta DJ, Litwin MS. Fear of cancer recurrence in patients undergoing definitive treatment for prostate cancer: results from CaPSURE. J Urol. 2003;170:1931-3.

199. Polinsky ML. Functional status of long-term breast cancer survivors: demonstrating chronicity. Health Soc Work. 1994;19:165-73. 
200. Gil KM, Mishel MH, Belyea M, Germino B, Porter LS, LaNey IC, Stewart J. Triggers of Uncertainty About Recurrence and Long-Term Treatment Side Effects in Older African American and Caucasian Breast Cancer Survivrs. Oncology Nursing Forum. 2004;31:633-9.

201. Stanton AL. Psychosocial concerns and interventions for cancer survivors. J Clin Oncol. 2006;24:5132-7. 
Samenvatting 
162 


\section{Samenvatting}

Door vroege opsporing en verbeterde behandeling is de overleving voor verschillende vormen van kanker de laatste jaren aanzienlijk gestegen. ${ }^{1}$ Naar verwachting zal het aantal mensen dat recent of langer geleden de diagnose kanker heeft gekregen tussen 2000 en 2015 toenemen van 366.000 tot 692.000 . $^{1}$ Patiënten met kanker hebben vaak meerdere symptomen die een negatieve invloed hebben op hun gevoel van welzijn en hun fysieke en sociale functioneren.

In dit proefschrift proberen wij inzicht te geven in de prevalentie van symptomen bij patiënten met kanker en de invloed hiervan op hun kwaliteit van leven. Beschreven worden zowel fysieke als psychologische symptomen bij patiënten met kanker in alle ziekte stadia: van genezen tot terminaal ziek.

\section{Hoofdstuk 1}

\section{Introductie}

In de introductie schetsen wij de aanleiding voor dit proefschrift. Ondanks de overvloedige hoeveelheid literatuur over dit onderwerp is de prevalentie van pijn bij patiënten met kanker niet goed bekend. De vroegste studies (19591975) spreken over een prevalentie van pijn van $52-77 \% \%^{2-6}$ Studies na 2004 laten een pijnprevalentie van $24-60 \%$ zien bij patiënten tijdens actieve antikanker behandeling ${ }^{7-10}$ en van $62-86 \%$ bij patiënten met een vergevorderd stadium van de ziekte. ${ }^{11-16}$ Deze cijfers staan in schril contrast met de snel groeiende interesse in pijn en pijnbehandeling in de laatste twee decennia. Blijkbaar hebben het grotere inzicht in de pathosfysiologische mechanismen van pijn en de grotere beschikbaarheid van verschillende soorten pijn medicatie, zoals opioïden, co-analgetica en NMDA-receptor-antagonisten, niet geleid tot een daling in de prevalentie van pijn bij patiënten met kanker. Dit, terwijl een goed gebruik van de WHO-pijnladder zou kunnen leiden tot adequate pijnverlichting bij $70-90 \%$ van de patiënten. ${ }^{17-20}$

Over fysieke symptomen anders dan pijn is in de literatuur veel minder te vinden. De studies die naar andere symptomen gekeken hebben betreffen meestal patiënten met vergevorderde of terminale kanker. ${ }^{11,21-25}$ In een recente review $^{26}$ bleken vijf symptomen (vermoeidheid, pijn, gebrek aan energie, zwakte en verlies van eetlust) bij meer dan $50 \%$ van de patiënten met vergevorderde ziekte voor te komen. Studies naar niet-pijn fysieke symptomen bij niet-terminale patiënten zijn schaars en focussen meestal op één symptoom bij één soort kanker o.a. benauwdheid bij patiënten met longkanker ${ }^{27}$ of vermoeidheid bij borstkanker. ${ }^{28}$ 
Kanker gerelateerde psychologische stress wordt gezien bij eenderde van de patiënten. ${ }^{29}$ De prevalentie van depressie wordt geschat op 10-25\%, die van angststoornissen op $15-28 \% .^{29}$ Deze schattingen berusten echter op onderzoeken uitgevoerd op een tijdstip rond de diagnose. Veel minder is bekend over psychologische problemen jaren na de diagnose. Studies met een longitudinaal karakter spreken elkaar tegen: psychologische problemen nemen af in de loop van de tijd $^{30,31}$ ten opzicht van: geen verschil in prevalentie van angst en depressie tussen vroege en late borstkanker ${ }^{32}$ of chronische lymfatische leukemie. ${ }^{33}$

De oorzaken voor de nog steeds zeer hoge prevalenties van fysieke symptomen bij patiënten met kanker zijn het best bestudeerd bij pijn. De kloof tussen wat mogelijk is in pijnbestrijding en wat wordt bereikt wordt veroorzaakt door vele zowel patiëntgerelateerde, hulpverlener gerelateerde als logistiek gerelateerd factoren. "Een goede patiënt" willen zijn en angst voor medicatie in het algemeen en opioïden in het bijzonder bij patiënten en gebrek aan kennis en "vragen naar" bij de hulpverleners zijn bekende barrières voor adequate pijnbehandeling. ${ }^{34-43}$

In een recente review ${ }^{44}$ van interventies gericht op het verbeteren van de behandeling van pijn, kon geen enkele interventie gevonden worden welke zich specifiek op medici richtte. Didactische interventies bij verpleegkundigen verhoogden de kennis van de verpleegkundigen en rekende af met een aantal mythes. Echter, deze interventies lieten geen verbetering van de pijn bij patiënten zien, noch een grotere patiënt tevredenheid. Verschillende studies lieten zien dat interventies gericht op patiënten wel de pijnscores kunnen verbeteren en negatieve gevoelens over pijnmedicatie kunnen veranderen. ${ }^{44}$

\section{Hoofdstuk 2}

\section{Prevalentie van pijn bij patiënten met kanker: een systematische review over de afgelopen 40 jaar}

(Prevalence of pain in patients with cancer: a systematic review of the past 40 years. Annals of Oncology, 2007;18:1437-1449)

In hoofdstuk 2 beschrijven wij een systematische review naar de prevalentie van pijn bij patiënten met kanker. Bij een search in Medline 1966-Sept 2005, Embase 1989- Sept 2005, Pubmed1975- Sept 2005, Cinahl 1982- Sept 2005, Cochrane Systematic reviews, Cochrane Central en de Cancer Library 2002 met de zoektermen "pain" en "prevalence", of "symptom" en "prevalence" in combinatie met de volgende termen: "cancer", "neoplasm", "terminal", "end- 
stage", "advanced", "hospice" of "palliative" werden 160 studies naar de prevalentie van pijn bij patiënten met kanker geïdentificeerd. De voorafgestelde kwaliteitsnorm (gebaseerd op Leboeuf-Yde ${ }^{45}$ ) werd gehaald door 54 artikelen (34\%).

De prevalentie van pijn was 33\% bij patiënten na curatieve antitumor therapie, $59 \%$ bij patiënten tijdens antitumor therapie en $64 \%$ bij patiënten voor wie antitumor behandeling geen optie meer was. In slechts 17 studies werd ook de ernst van de pijn gerapporteerd. In de groep tijdens antitumor therapie bleek $36 \%$ van de patiënten matig tot ernstige (VAS>4) pijn te ervaren, in de uitbehandelde groep was dit $45 \%$.

In de bivariate analyse bleek dat noch type kanker noch periode van publicatie, continent, leeftijd, type gemeten prevalentie noch gebruik van al dan niet gevalideerde vragen lijsten een significante invloed had op de prevalentie van pijn.

In de discussie gaan wij in op de barrières voor adequate pijn bestrijding en doen wij aanbevelingen voor verder onderzoek.

\section{Hoofdstuk 3}

\section{Hoge prevalentie van pijn bij patiënten met kanker in een grote population-based studie in Nederland}

(High Prevalence of Pain in Patients with Cancer in a Large Population-Based Study in the Netherlands. Pain 2007;132:312-320)

In hoofdstuk 3 beschrijven wij de resultaten van een onderzoek naar prevalentie van pijn en de kwaliteit van pijn behandeling bij patiënten met kanker in de regio van het Integraal Kankercentrum Limburg (IKL). Een representatieve groep van 1429 patiënten (response $76 \%$ ) met kanker vulden een vragenlijst in bestaande uit de Brief Pain Inventory (BPI), de Pain Management Index (PMI) en de EORTC-C30 (pijn en kwaliteit van leven).

Van de totale onderzoeksgroep rapporteerde $44 \%$ matig tot ernstige pijn. De onderzoekspopulatie werd gesplitst in 4 groepen: groep 1a: patiënten voor wie curatieve behandeling $>6$ maanden geleden was afgerond, groep $1 \mathrm{~b}$ : patiënten tijdens curatieve antitumor therapie of behandeling $\leq 6$ maanden geleden afgerond, groep 2: patiënten tijdens palliatieve antitumor behandeling en groep 3: patiënten voor wie antitumor behandeling geen optie meer was. De pijnpercentages in deze groepen was respectievelijk: $49 \%, 57 \%, 56 \%$ en $75 \%$. Patiënten met lagere opleidingsniveaus hadden significant meer kans op pijn. Patiënten met gastro-intestinale tumoren, mamma carcinoom en 
hematologische maligniteiten (zonder maligne lymfomen) hadden significant meer kans op matig tot ernstige pijn dan patiënten met prostaat carcinoom.

Pijnbehandeling was inadequaat bij $42 \%$ van de respondenten. Opnieuw gaf een laag opleidingsniveau een grotere kans op onderbehandeling. Ook patiënten in groep $1 \mathrm{~b}$ (tijdens curatieve antitumor therapie) hadden een significante hogere kans op onderbehandeling van de pijn.

In de discussie gaan wij in op de onderverdeling van pijn in mild, matig en ernstig, bespreken we kort de beperkingen van de Pain Management Index (PMI) en zoeken wij naar een verklaring voor de grotere kans op pijn en onderbehandeling van patiënten met een lager opleidingsniveau en de grotere kans op onderbehandeling van patiënten in groep $1 \mathrm{~b}$.

Wij concluderen dat aandacht voor pijn in alle ziektestadia een stringente noodzaak is en dat in de curricula voor medische professionals meer aandacht moet komen voor pijn- en pijnbehandeling.

\section{Hoofdstuk 4}

\section{Prevalentie van niet-pijn fysieke symptomen en psychologische symptomen en hun invloed op kwaliteit van leven bij patiënten met kanker.}

(Prevalence of Non-pain Physical Symptoms and Psychological Symptoms and their influence on Quality of Life in Patients with Cancer. Journal of Pain and Symptom Management; in press)

In hoofdstuk 4 beschrijven wij de resultaten van een onderzoek naar de prevalentie van niet-pijn fysieke symptomen en psychologische symptomen bij patiënten met kanker in de regio van het Integraal Kankercentrum Limburg (IKL). Een representatieve groep van 1429 patiënten (response $76 \%$ ) met kanker vulden een vragenlijst in bestaande uit de EORTC-C30 (kwaliteit van leven en fysieke symptomen) en de Hospital Anxiety and Depression Scale (HADS). De onderzoekspopulatie werd gesplitst in vier groepen: groep 1a: patiënten voor wie curatieve behandeling $>6$ maanden geleden was afgerond, groep $1 \mathrm{~b}$ : patiënten tijdens curatieve antitumor therapie of behandeling $\leq 6$ maanden geleden afgerond, groep 2: patiënten tijdens palliatieve antitumor behandeling en groep 3: patiënten voor wie antitumor behandeling geen optie meer was.

Behalve bij diarree nam de prevalentie van matig tot ernstige fysieke symptomen (braken, obstipatie, misselijkheid, sufheid, slaapproblemen, benauwdheid, gebrek aan eetlust, droge mond, zwakte, vermoeidheid en behoefte om te rusten) significant toe met de ernst van de ziekte. Braken was 
het minst frequente symptoom in alle groepen (1-10\%). Matig tot ernstige klachten van zwakte, vermoeidheid en de behoefte om te rusten waren het meest frequent aanwezig: respectievelijk 16-24\% in groep 1a en $65-74 \%$ in groep 3.

Behalve geïrriteerdheid namen ook de psychologische symptomen (moeite met herinneren, depressie, gespannen, moeite met concentreren, angst en zorgen) significant toe met de ernst van de ziekte. Geïrriteerdheid was in alle groepen het minst voorkomende symptoom. Zorgen was het meest frequent voorkomende symptoom (20-55\%). Diarree was het meest prevalent bij patiënten met gastro-intestinale tumoren en droge mond en angst het meest prevalent bij patiënten met hoofd-hals tumoren.

Patiënten met gastro-intestinale tumoren, maligne lymfomen en andere hematologische tumoren hadden een significant slechter kwaliteit van leven dan patiënten met een prostaat carcinoom. De symptomen vermoeidheid, pijn, gebrek aan eetlust, obstipatie, angst en depressie hadden een significante negatieve invloed op de kwaliteit van leven. Voor $45-90 \%$ van de matig tot ernstige symptomen werden patiënten niet behandeld, met name de symptomen met de meest negatieve invloed op de kwaliteit van leven werden het minst frequent behandeld.

In de discussie relateren wij de prevalentie van de verschillende symptomen aan die in de algemene bevolking en vergelijken onze cijfers met eerdere studies.

Wij concluderen dat patiënten met kanker vaak polisymptomatisch zijn en dat veel symptomen onbehandeld blijven, ondanks hun negatieve invloed op kwaliteit van leven. Meer aandacht voor de verschillende fysieke en psychologische symptomen in alle stadia van de ziekte is van groot belang voor de kwaliteit van leven van patiënten met kanker.

\section{Hoofdstuk 5}

\section{Een randomised contolled trial (RCT) naar het effect van een intensieve verpleegkundige interventie bij patiënten met kanker en pijn in de thuissituatie.}

(A randomised controlled trial of an intensive nursing intervention for cancer outpatients suffering from pain and other symptoms. submitted)

In hoofdstuk 5 beschrijven wij een RCT naar de effecten van een verpleegkundige interventie bij patiënten met pijn of andere symptomen als gevolg van kanker of kanker therapie in de thuissituatie. Honderdtwintig patiënten werden gerandomiseerd naar de interventiegroep of de 
controlegroep. De interventie (Pain Education Program PEP) bestond uit drie huisbezoeken van 1 tot 1,5 uur waarin 1. met behulp van een pijnbrochure de patiënt onderwijs werd gegeven over pijn en pijnbehandeling, 2. de patiënt werd geïnstrueerd hoe een pijndagboek bij te houden en 3. de patiënt werd gestimuleerd contact te zoeken met zijn of haar behandelaar bij matig tot ernstige symptomen. Na het eerste en derde huisbezoek werd een schriftelijk verslag en zonodig suggesties voor veranderingen in de behandeling opgestuurd naar de behandelaar. De patiënten in de controlegroep kregen care-as-usual.

Pijnkennis nam significant toe in de interventiegroep. Bij alle patiënten in de interventiegroep was er een significante afname van de pijn score op korte termijn (vier weken). Alleen bij de patiënten met een hoge pijnscore (VAS 7-10) bij aanvang van de studie bleef deze significante daling bestaan op de lange termijn (acht weken). Geslacht, leeftijd, opleidingsniveau, angst en depressie bij aanvang hadden geen significante invloed op de afname van de pijnscore op korte en lange termijn. Er werd geen correlatie gevonden tussen toename van kennis en afname van pijn.

Van de in totaal 37 geformuleerde medicatie adviezen werden er 22 niet opgevolgd en van 8 adviezen is onbekend of deze opgevolgd werden.

Alle patiënten gaven aan andere patiënten te willen aanraden om deel te nemen aan het scholingsprogramma. Zesenzestig procent van de patiënten wilde graag doorgaan met het programma, $34 \%$ vond drie sessies voldoende. In de discussie pleiten wij voor een betere patiënt selectie voor educatie programma's, bediscussiëren wij het ontbreken van de correlatie tussen toename van pijnkennis en afname in pijn en bepleiten wij een intensievere samenwerking tussen de behandelaren, waardoor mogelijk medicatie aanpassingen sneller en adequater kunnen worden doorgevoerd.

\section{Hoofdstuk 6}

\section{Zorgen van voormalige borstkanker patiënten over een mogelijke terugkeer van de ziekte: een validatie en prevalentie studie}

(Concerns of former breast cancer patients about disease recurrence: a validation and prevalence study. Psycho-Oncology, 2008;17:1137-1145)

In hoofdstuk 6 beschrijven wij de validatie van de Nederlandse versie van de Concerns About Recurrence Scale (CARS) en rapporteren wij over de prevalentie van angst voor terugkeer van borstkanker en de invloed hiervan op kwaliteit van leven. 
Voor het meten van angst voor terugkeer van borstkanker werd gekozen voor de oorspronkelijk Amerikaanse vragenlijst CARS omdat dit het enige beschreven multi-dimensionele instrument is. Naast vier vragen over overall angst voor terugkeer voor borstkanker bekijkt de CARS ook waar patiënten met name bang voor zijn in 4 subdomeinen: vrees voor gezondheid, vrouwelijkheid, rol-functioneren en dood. De CARS werd vertaald en de psychometrische eigenschappen onderzocht. De confirmerende factor analyse liet een adequate lading van alle items zien op de verschillende domeinen. De interne consistentie (Cronbach's alfa) van de domeinen was adequaat. De intraclass coëfficiënten (ICC) van $0.77-0.89$ gaven aanwijzingen voor een goede testhertest stabiliteit. De constructvaliditeit werd bevestigd dor adequate Spearman's correlaties met de Hospital Anxiety and Depression Scale (HADS), de Pain Catastrophizing Scale (PCS) en de Life Orientation Test (LOT).

Van de participerende vrouwen $(n=136$, reponse rate $90 \%)$ gaf $56 \%$ matige tot ernstige overall angst voor terugkeer van de borstkanker aan. Met name vrees voor gezondheid en dood waren prominent aanwezig (respectievelijk $63 \%$ en $61 \%$ ). Pijn was een onafhankelijke voorspeller voor de angst voor terugkeer, oudere vrouwen hadden significant minder vrees voor gezondheid, rolfunctioneren en dood. Er was geen significante relatie tussen tijd verlopen sinds laatste behandeling en de mate van vrees voor terugkeer.

Alle domeinen van de CARS waren negatief gecorreleerd met kwaliteit van leven, waarbij rol-functioneren de meeste invloed had op de kwaliteit van leven.

\section{Hoofdstuk 7}

\section{Algemene discussie}

In de algemene discussie bespreken wij allereerst enige methodologische aspecten van dit proefschrift.

\section{Groepsgrootte}

Groep 3 (patiënten voor wie antitumor therapie niet meer geïndiceerd is) is relatief klein en mogelijk niet representatief. Het is onduidelijk op welke wijze dit de uitkomsten van de studie beïnvloedt. Sommige studies laten een afname van pijn zien in de laatste twee weken van het leven, hetgeen zou betekenen dat wij een overschatting van de prevalentie van pijn maken. Andere studies echter, laten een toename van pijn zien in de laatste twee weken. Er zijn slechts weinig studie naar andere symptomen in de laatste twee weken. Eén studies liet een toename zien van de prevalentie van verwardheid, anorexie en slikklachten, een andere studie een afname van depressie, hoest en misselijkheid, terwijl een derde studie een toename van de prevalentie van 
dyspnoea, maar gelijkblijvende prevalentie van alle andere symptomen liet zien.

Er zou een vraagteken geplaatst kunnen worden bij het aantal patiënten geïncludeerd in de validatie studie van de CARS. Echter, de rationale voor de regel dat voor een factor analyse tien deelnemers per vraag benodigd zijn is onduidelijk. Meer recent werd aangetoond dat bij communaliteiten van $\geq 0.6$ relatief kleine aantallen $(<100)$ voldoende kunnen zijn voor een adequate factor analyse.

\section{Kwaliteitscriteria}

De kwaliteitscriteria voor de beoordeling van prevalentie studies gebruikt in hoofdstuk 2 werden gebaseerd op het werk van Leboeuf-Yde and Lauritsen. Wij hebben deze criteria aangepast door gewicht toe te kennen aan de afzonderlijke criteria en de specifieke items over lage rug pijn te vervangen door kankerspecifieke items. Wij bevelen een verdere verfijning van deze criteria aan door oa minder gewicht toe te kennen aan retrospectieve studies en studies die gebruik maken van proxy-reporting of medische dossiers. Meer gewicht zou toegekend mogen worden aan een adequate beschrijving van het ziektestadium van de patiënten en het item gebruik van al-dan-niet gevalideerde vragenlijsten lijkt overbodig.

\section{Wanneer noem je een symptoom mild, matig of ernstig?}

Om een betekenisvolle classificatie van de ernst van symptomen te maken werden de NRS en VAS schalen (0-10) omgezet in woorden: geen, mild, matig en ernstig door koppeling van de NRS- en VAS schalen aan de mate waarin een symptoom een patiënt in het dagelijks leven beperkt. De onderverdeling in mild, matig en ernstig blijft echter een punt van discussie: $m n$ is een NRS/VAS van 4 mild of matig en, in mindere mate, is een NRS/VAS van 7 matig of ernstig? Voor de review (hoofdstuk 2) hebben wij gekozen voor de indeling van Serlin ( $4=$ mild, 7 = ernstig). Echter, in onze prevalentie studie (hoofdstuk 3 ) gaven de patiënten aan een NRS van 4 als matige pijn te beoordelen. Dit was reden om in de hoofdstukken 3 en 4 de indeling NRS 1-3 = mild, 3-6 = matig en 7-10 = ernstig aan te houden.

\section{Algemene discussie}

In de algemene discussie gaan we allereerst uitgebreid in op de mogelijke oorzaken (barrières) van de nog altijd te hoge prevalenties van pijn en andere symptomen. Oorzaken kunnen gevonden worden op drie niveaus: 1 . artsen en verpleegkundigen hebben te weinig aandacht voor en te weinig kennis van symptomen en symptoom controle, 2. patiënten melden hun klachten onvoldoende bij behandelaren en zijn therapie ontrouw, vaak op basis van 
allerlei mythes welke over medicatie bestaan en 3 . binnen het gezondheidssysteem is het voor een patiënt vaak onduidelijk bij wie hij/zij voor welke klacht moet zijn en is er te weinig tijd om een gedegen pijn/symptoom anamnese af te nemen.

Vervolgens worden de verschillende symptomen afzonderlijk besproken.

De conclusie luidt:

De afgelopen decennia is er veel progressie geboekt in de genezing van patiënten met kanker. Echter op het gebied van "care" valt nog veel te winnen. Meer en betere educatie over symptomen en symptoombestrijding van allen die professioneel met patiënten met kanker te maken krijgen is een randvoorwaarde voor de verbetering van de kwaliteit van leven van deze patiënten.

In iedere setting moeten symptomen systematisch bij ieder patiënt contact genoteerd worden, b.v. via een korte vragenlijst of door een nurse-practitioner.

Patiënten moeten worden aangemoedigd hun klachten te uiten bij hun behandeld arts en zouden beter geïnstrueerd moeten worden over het hoe en waarom van medicatie om de therapietrouw te verbeteren.

Tenslotte zou iedere patiënt, laagdrempelig, toegang moeten hebben tot een telefoonnummer voor vragen of opmerkingen over hun symptomen en/of medicatie. 


\section{Referenties}

1. Coebergh JWW. Kanker in Nederland, trends, prognoses en implicaties voor zorgvraag. 2004, Den Haag: KWF kankerbestrijding.

2. Aitken-Swan J. Nursing the late cancer patient at home; the family's impressions. Practitioner. 1959;183:64-9.

3. Sung JL, Wang TH, Yu JY. Clinical study on primary carcinoma of the liver in Taiwan. Am J Dig Dis. 1967;12:1036-49.

4. Lempinen M. Carcinoma of the stomach. I. Diagnostic considerations. Ann Chir Gynaecol Fenn. 1971;60:135-40.

5. Ross AP, Braasch JW, Warren KW. Carcinoma of the proximal bile ducts. Surg Gynecol Obstet. 1973;136:923-8.

6. Twycross RG. The terminal care of patients with lung cancer. Postgrad Med J. 1973;49: 732-7.

7. Pignon T, Fernandez L, Ayasso S, Durand MA, Badinand D, Cowen D. Impact of radiation oncology practice on pain: a cross-sectional survey. Int J Radiat Oncol Biol Phys. 2004;60: 1204-10.

8. Puts MTE, Versloot J, Muller MJ, van Dam FS. De opinie over de zorgverlening van patiënten met kanker die op de dagbehandeling een palliatieve behandeling ondergaan. Nederlands Tijdschrift voor Geneeskunde. 2004;148:277-80.

9. Rietman J, Dijkstra P, Debreczeni R, Geertzen J, Robinson D, De Vries J. Impairments, disabilities and health related quality of life after treatment for breast cancer: a follow-up study 2.7 years after surgery. Disabil Rehabil. 2004;26:78-84.

10. Taylor KO. Morbidity associated with axillary surgery for breast cancer. ANZ J Surg. 2004;74: 314-7.

11. Bradley N, Davis L, Chow E. Symptom distress in patients attending an outpatient palliative radiotherapy clinic. J Pain Symptom Manage. 2005;30:123-31.

12. Di Maio M, Gridelli C, Gallo C, Manzione L, Brancaccio L, Barbera S, Robbiati SF, lanniello GP, Ferrau F, Piazza E, Frontini L, Rosetti F, Carrozza F, Bearz A, Spatafora M, Adamo V, Isa $L$, laffaioli RV, Di Salvo $E$, Perrone $F$. Prevalence and management of pain in Italian patients with advanced non-small-cell lung cancer. Br J Cancer. 2004;90:2288-96.

13. Wilson KG, Graham ID, Viola RA, Chater S, de Faye BJ, Weaver LA, Lachance LA. Structured interview assessment of symptoms and concerns in palliative care. Can $\mathrm{J}$ Psychiatry. 2004;49:350-8.

14. Hwang SS, Chang VT, Cogswell J, Alejandro Y, Osenenko P, Morales E, Srinivas S, Kasimis B. Study of unmet needs in symptomatic veterans with advanced cancer: incidence, independent predictors and unmet needs outcome model. J Pain Symptom Manage. 2004; 28:421-32.

15. Stromgren AS, Groenvold M, Petersen MA, Goldschmidt D, Pedersen L, Spile M, IrmingPedersen G, Sjogren P. Pain characteristics and treatment outcome for advanced cancer patients during the first week of specialized palliative care. J Pain Symptom Manage. 2004; 27:104-13.

16. Lin MH, Wu PY, Tsai ST, Lin CL, Chen TW, Hwang SJ. Hospice palliative care for patients with hepatocellular carcinoma in Taiwan. Palliat Med. 2004;18:93-9.

17. Ventafridda V, Tamburini M, Caraceni A, De Conno F, Naldi F. A validation study of the WHO method for cancer pain relief. Cancer. 1987;59:850-6.

18. Walker VA, Hoskin PJ, Hanks GW, White ID. Evaluation of the WHO analgesic guidelines for cancer pain in a hospital-based palliative care unit. J Pain Symptom Manage. 1988;3:145-9.

19. Goisis A, Gorini M, Ratti R, Luliri P. Application of a WHO protocol on medical therapy for oncologic pain in an internal medicine hospital. Tumori. 1989;75:470-2. 
20. Caraceni A, Martini C, Zecca E, Portenoy RK, Ashby MA, Hawson G, Jackson KA, Lickiss N, Muirden N, Pisasale M, Moulin D, Schulz VN, Rico Pazo MA, Serrano JA, Andersen H, Henriksen HT, Mejholm I, Sjogren P, Heiskanen T, Kalso E, Pere P, Poyhia R, Vuorinen E, Tigerstedt I, Ruismaki P, Bertolino M, Larue F, Ranchere JY, Hege-Scheuing G, Bowdler I, Helbing F, Kostner E, Radbruch L, Kastrinaki K, Shah S, Vijayaram S, Sharma KS, Devi PS, Jain PN, Ramamani PV, Beny A, Brunelli C, Maltoni M, Mercadante S, Plancarte R, Schug S, Engstrand P, Ovalle AF, Wang X, Alves MF, Abrunhosa MR, Sun WZ, Zhang L, Gazizov A, Vaisman M, Rudoy S, Gomez Sancho M, Vila P, Trelis J, Chaudakshetrin P, Koh ML, Van Dongen RT, Vielvoye-Kerkmeer A, Boswell MV, Elliott T, Hargus E, Lutz L; Working Group of an IASP Task Force on Cancer Pain. Breakthrough pain characteristics and syndromes in patients with cancer pain. An international survey. Palliat Med. 2004;18:177-83.

21. Hoekstra J, Vos de R, Duijn van NP, Schade E, Bindels PJ. Using the symptom monitor in a randomized controlled trial: the effect on symptom prevalence and severity. J Pain Symptom Manage. 2006;31:22-30.

22. Lai YH, Keefe FJ, Sun WZ, Tsai LY, Cheng PL, Chiou JF, Wei LL. Relationship between pain-specific beliefs and adherence to analgesic regimens in Taiwanese cancer patients: a preliminary study. J Pain Symptom Manage. 2002;24:415-23.

23. Moro C, Brunelli C, Miccinesi G, Fallai M, Morino P, Piazza M, Labianca R, Ripamonti C. Edmonton symptom assessment scale: Italian validation in two palliative care settings. Support Care Cancer. 2006;14:30-7.

24. Tsai JS, Wu CH, Chiu TY, Hu WY, Chen CY. Symptom patterns of advanced cancer patients in a palliative care unit. Palliat Med. 2006;20:617-22.

25. Stromgren AS, Brunelli C, Miccinesi G, Fallai M, Morino P, Piazza M, Labianca R, Ripamonti C. Symptom priority and course of symptomatology in specialized palliative care. J Pain Symptom Manage. 2006;31:199-206.

26. Teunissen SC, Wesker W, Kruitwagen C, de Haes HC, Voest EE, de Graeff A. Symptom prevalence in patients with incurable cancer: a systematic review. J Pain Symptom Manage. 2007;34:94-104.

27. O'Driscoll $\mathrm{M}$, Corner $\mathrm{J}$, Bailey $\mathrm{C}$. The experience of breathlessness in lung cancer. Eur $\mathrm{J}$ Cancer Care (Engl). 1999;8:37-43.

28. Carpenter JS, Elam JL, Ridner SH, Carney PH, Cherry GJ, Cucullu HL. Sleep, fatigue, and depressive symptoms in breast cancer survivors and matched healthy women experiencing hot flashes. Oncol Nurs Forum. 2004;31:5591-8.

29. Levin T, Kissane DW. Psychooncology - the state of its development in 2006. European Journal of Psychiatry. 2006;20:183-97.

30. Burgess C, Cornelius V, Love S, Graham J, Richards M, Ramirez A. Depression and anxiety in women with early breast cancer: five year observational cohort study. BMJ. 2005;330:702.

31. Korfage IJ, Essink-Bot ML, Janssens AC, Schroder FH, Koning de HJ. Anxiety and depression after prostate cancer diagnosis and treatment: 5-year follow-up. $\mathrm{Br} \mathrm{J} \mathrm{Cancer.}$ 2006;94:1093-8.

32. Kissane DW, Grabsch B, Love A, Clarke DM, Bloch S, Smith GC. Psychiatric disorder in women with early stage and advanced breast cancer: a comparative analysis. Aust $\mathrm{N} \mathrm{Z} \mathrm{J}$ Psychiatry. 2004;38:320-6.

33. Prieto JM, Atala J, Blanch J, Carreras E, Rovira M, Cirera E, Espinal A, Gasto C. Role of depression as a predictor of mortality among cancer patients after stem-cell transplantation. $\mathrm{J}$ Clin Oncol. 2005;23:6063-71.

34. Von Roenn JH, Cleeland CS, Gonin R, Hatfield AK, Pandya KJ. Physician attitudes and practice in cancer pain management. A survey from the Eastern Cooperative Oncology Group. Ann Intern Med. 1993;119:121-6.

35. Ward SE, Goldberg N, Miller-McCauley V. Patient-related barriers to management of cancer pain. Pain. 1993;52:319-24.

36. Glajchen M, Fitzmartin RD, Blum D, Swanton R. Psychosocial barriers to cancer pain relief. Cancer Pract. 1995;3:76-82.

37. Grossman SA. Undertreatment of cancer pain: barriers and remedies. Support Care Cancer. 1993;1:74-8. 
38. Johnson DC, Kassner CT, Houser J, Kutner JS. Barriers to effective symptom management in hospice. J Pain Symptom Manage. 2005;29:69-79.

39. Lin CC. Barriers to the analgesic management of cancer pain: a comparison of attitudes of Taiwanese patients and their family caregivers. Pain. 2000;88:7-14.

40. Miaskowski C, Dodd MJ, West C. Lack of adherence with the analgesic regimen: a significant barrier to effective cancer pain management. J Clin Oncol. 2001;19:4275-9.

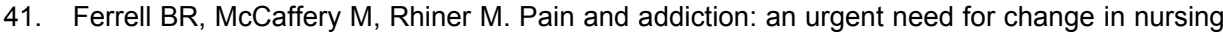
education. J Pain Symptom Manage. 1992;7:117-24.

42. Paice JA, Toy C, Shott S. Barriers to cancer pain relief: fear of tolerance and addiction. J Pain Symptom Manage. 1998;16:1-9.

43. Pargeon KL, Hailey BJ. Barriers to effective cancer pain management: a review of the literature. J Pain Symptom Manage. 1999;18:358-68.

44. Goldberg GR, Morrison RS. Pain management in hospitalized cancer patients: a systematic review. J Clin Oncol. 2007;25:1792-801.

45. Leboeuf-Yde C, Lauritsen JM. The prevalence of low back pain in the literature. A structured review of 26 Nordic studies from 1954 to 1993. Spine. 1995;20:2112-8. 
Appendices 
${ }_{176} \mid$ 


\section{Appendix I}

\section{Quality criteria for prevalence studies of pain in patients with cancer (adapted from Leboeuf-Yde) ${ }^{1}$}

\begin{tabular}{|c|c|}
\hline $\begin{array}{l}\text { A. The final sample should be representative of } \\
\text { the target population }\end{array}$ & $\begin{array}{l}\text { 1. At least one of the following should apply for } \\
\text { the study: an entire target population, } \\
\text { randomly selected sample, or sample stated } \\
\text { to represent the target population ( } 2 \text { points). } \\
\text { 2. At least one of the following: reasons for non- } \\
\text { response described, non-responders } \\
\text { described, comparison of responders and } \\
\text { non-responders, or comparison of sample } \\
\text { and target population ( } 2 \text { points). } \\
\text { 3. Response rate } \geq 90 \% \text { ( } 2 \text { points). } \\
\text { Response rate } 70-90 \% \text { (1 point). } \\
\text { Response rate }<70 \% \text { ( } 0 \text { point). }\end{array}$ \\
\hline B. Quality of Data & $\begin{array}{l}\text { 4. Were the data primary from a prevalence } \\
\text { study ( } 2 \text { points) or was it taken from a survey } \\
\text { not specifically designed for that purpose ( } 1 \\
\text { point)? } \\
\text { 5. The same mode of data collection should be } \\
\text { used for all subjects ( } 2 \text { points) if not (1 point). } \\
\text { 6. The data have been collected directly from } \\
\text { the patient by means of a validated } \\
\text { questionnaire/interview ( } 3 \text { points). } \\
\text { No validated questionnaire/interview ( } 2 \\
\text { points). } \\
\text { Data have been collected from proxies or } \\
\text { retrospectively from medical record (1 point). }\end{array}$ \\
\hline $\begin{array}{l}\text { C. General description of the method and } \\
\text { results should include: definitions of pain } \\
\text { prevalence }\end{array}$ & $\begin{array}{l}\text { 7. Description of the target population and } \\
\text { setting where patients were found ( } 2 \text { points). } \\
\text { 8. Description of stage of disease, type of } \\
\text { cancer, sex, age. All: } 2 \text { points, } 2 \text { or } 3: 1 \text { point. } \\
\text { 9. Final sample size ( } 1 \text { point). } \\
\text { 10. Prevalence recall periods should be stated ( } 1 \\
\text { point). }\end{array}$ \\
\hline
\end{tabular}

1. Leboeuf-Yde, C. and J.M. Lauritsen, The prevalence of low back pain in the literature. A structured review of 26 Nordic studies from 1954 to 1993. Spine 1995;20:2112-8. 
${ }_{178} \mid$ 


\section{Appendix II}

\section{Dutch version of the CARS ${ }^{1}$}

\section{Zorgen over het terugkomen van de kanker}

Met de volgende vragen verzoeken wij $u$ aan te geven of $u$ wel eens bezorgd bent dat de borstkanker terugkomt. Onder terugkomen bedoelen we dat de kanker terug komt in dezelfde borst, of op een andere plek van het lichaam of een nieuwe borstkanker in de andere borst.

Alhoewel de meeste vrouwen bij wie borstkanker in een vroeg stadium is ontdekt nooit meer een probleem met kanker zullen krijgen, weten we dat veel vrouwen zich toch zorgen maken over het terugkomen van de kanker. Er zullen ook vrouwen zijn die zich helemaal geen zorgen maken. Hoe dan ook, uw antwoorden op de volgende vragen zijn voor ons erg belangrijk. We begrijpen dat $u$ van streek kan raken door te denken aan of antwoord te geven op vragen over de mogelijkheid van het terugkomen van de kanker. We hebben uw hulp echter nodig om te begrijpen hoe vrouwen denken over deze mogelijkheid.

Wij vragen $u$ bij de volgende vier vragen het nummer te omcirkelen welke het beste aansluit bij uw gevoel. Bijvoorbeeld, bij de eerste vraag moet u "1" omcirkelen wanneer $u$ nooit denkt aan de mogelijkheid van het terugkomen van de kanker. Omcirkel een "6" wanneer u constant denkt aan het terugkomen van de kanker, of omcirkel "2 ", "3", "4" of " 5 " als de tijd dat u hieraan denkt hier ergens tussenin zit.

1. Hoe vaak denkt $u$ aan de mogelijkheid dat de borstkanker terug kan komen?

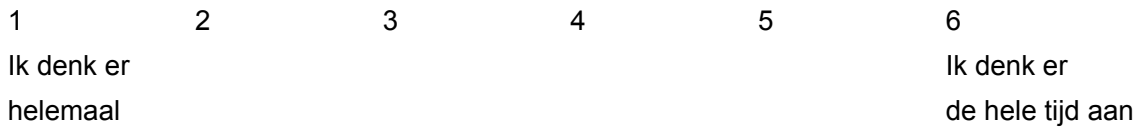

niet aan

2. Hoe erg maakt de mogelijkheid dat de borstkanker kan terugkomen u van streek?

$\begin{array}{llll}1 & 3 & 4 & 5\end{array}$


3. Hoe vaak maakt u zich zorgen over de mogelijkheid dat de borstkanker terug zal komen?

$\begin{array}{lllll}1 & 3 & 4 & 5 & 6 \\ \text { Ik maak mij } & & & \text { Ik maak mij } \\ \text { helemaal geen } \\ \text { zorgen }\end{array}$

4. Hoe bang bent $u$ dat de borstkanker terug zal komen?

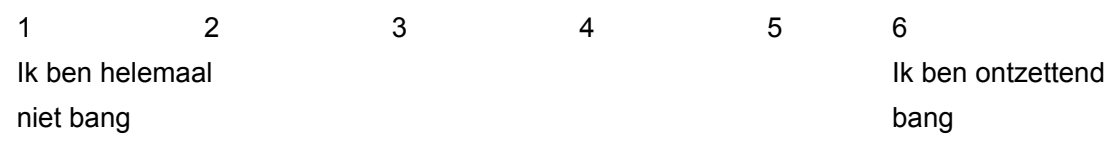

Wij zijn nu geïnteresseerd in uw zorgen ten aanzien van een mogelijke terugkeer van de borstkanker. Wanneer $u$ denkt aan een mogelijke terugkeer van de borstkanker, waar maakt u zich dan het meest zorgen over?

Alhoewel elk van de volgende beweringen het gevolg zouden kunnen zijn van het terugkomen van de kanker, willen wij specifiek weten of $u$ zich nu hierover ook echt zorgen maakt. $U$ zou bijvoorbeeld kunnen geloven dat wanneer de borstkanker terug zou komen een (nieuwe) operatie nodig is. Wij willen graag weten of $u$ zich ook echt zorgen maakt over deze mogelijkheid.

Omcirkel bij de volgende vragen alstublieft het cijfer dat aangeeft hoeveel zorgen u zich maakt over de achtereenvolgende beweringen. Wanneer u zich geen zorgen maakt of wanneer $u$ denkt dat een bewering niet op $u$ van toepassing is kunt u een "0" omcirkelen voor "helemaal niet".

$0=$ helemaal niet

$1=$ een klein beetje

$2=$ matig

$3=$ veel

$4=$ ontzettend veel 


\section{Ik maak me zorgen dat het terugkomen van de kanker:}

5. mij emotioneel van streek zou maken.

$\begin{array}{lllll}0 & 1 & 2 & 3 & 4\end{array}$

6. mij zou afhouden van dingen die ik van plan was te doen. $\begin{array}{lllllll}0 & 1 & 2 & & 3 & 4\end{array}$

$\begin{array}{llllllll}\text { 7. mijn lichamelijke gezondheid zou bedreigen. } & 0 & 1 & 2 & 3 & 4\end{array}$

$\begin{array}{llllllll}\text { 8. mij minder vrouw zou doen voelen. } & 0 & 1 & 2 & 3 & 4\end{array}$

$\begin{array}{lllllll}\text { 9. chemotherapie nodig zou maken. } & 0 & 1 & 2 & 3 & 4\end{array}$

10. nadelig zou zijn voor mijn relaties met vrienden en familie. $\begin{array}{lllllll}0 & 1 & 2 & 3 & 4\end{array}$

11. mij het gevoel zou geven dat ik geen controle $\begin{array}{lllllll}\text { meer heb over mijn leven. } & 0 & 1 & 2 & 3 & 4\end{array}$

12. mijn identiteit zou bedreigen (hoe ik mijzelf zie). $\quad \begin{array}{lllllll}0 & 1 & 2 & 3 & 4\end{array}$

13. in zou grijpen op mijn lichamelijk vermogen tot het $\begin{array}{lllllll}\text { uitvoeren van dagelijkse bezigheden. } & 0 & 1 & 2 & 3 & 4\end{array}$

$\begin{array}{lllllll}\text { 14. mijn leven zou bedreigen. } & 0 & 1 & 2 & 3 & 4\end{array}$

$\begin{array}{lllllll}\text { 15. mijn zelfvertrouwen zou beschadigen. } & 0 & 1 & 2 & 3 & 4\end{array}$

16. ernstiger zou zijn dan de eerste keer. $\quad \begin{array}{llllll}0 & 1 & 2 & 3 & 4\end{array}$

17. financiële problemen voor mij zou veroorzaken. $\quad \begin{array}{lllllll}0 & 1 & 2 & 3 & 4\end{array}$

18. in zou grijpen op mijn gevoel van seksualiteit. $\quad \begin{array}{lllllll}0 & 1 & 2 & 3 & 4\end{array}$

$\begin{array}{lllllll}\text { 19. bestraling nodig zou maken. } & 0 & 1 & 2 & 3 & 4\end{array}$

20. mij pijn en lijden zou brengen. $\quad \begin{array}{llllll}0 & 1 & 2 & 3 & 4\end{array}$

21. zou betekenen dat ik mijn borst(en) verlies. $\quad \begin{array}{llllll}0 & 1 & 2 & 3 & 4\end{array}$

22. In zou grijpen in mijn vermogen plannen te maken $\begin{array}{lllllll}\text { voor de toekomst. } & 0 & 1 & 2 & 3 & 4\end{array}$

23. mijn spiritualiteit of geloofsovertuiging zou bedreigen. $\begin{array}{lllllll}0 & 1 & 2 & 3 & 4\end{array}$ 
24. mij ervan zou weerhouden belangrijke rollen te vervullen (op mijn werk of thuis).

$\begin{array}{lllll}0 & 1 & 2 & 3 & 4\end{array}$

25. er voor zou zorgen dat ik mij minder vrouwelijk zou voelen. $\begin{array}{lllllll}0 & 1 & 2 & 3 & 4\end{array}$

26. een (nieuwe) operatie nodig zou maken.

$\begin{array}{lllll}0 & 1 & 2 & 3 & 4\end{array}$

27. de oorzaak van mijn overlijden zou zijn.

$\begin{array}{lllll}0 & 1 & 2 & 3 & 4\end{array}$

28.mijn romantische relaties zou beschadigen.

$\begin{array}{lllll}0 & 1 & 2 & 3 & 4\end{array}$

29. mij er van zou weerhouden om mijn verantwoordelijkheden na te komen (op mijn werk of thuis).

$\begin{array}{lllll}0 & 1 & 2 & 3 & 4\end{array}$

30. mij een naar gevoel zou geven

over hoe mijn lichaam eruit ziet of voelt.

$\begin{array}{lllll}0 & 1 & 2 & 3 & 4\end{array}$

1. Vickberg SM, The Concerns About Recurrence Scale (CARS): a systematic measure of women's fears about the possibility of breast cancer recurrence. Ann Behav Med 2003;25:1624. 
Dankwoord 
${ }_{184} 1$ 


\section{Dankwoord}

Aan een mooie tafel eet je nooit alleen!

En een mooie tafel is het geworden, zeker met alle initiatieven, mede geïnitieerd op basis van dit proefschrift, om ervoor te zorgen dat we over tien jaar niet weer met dezelfde prevalentie cijfers hoeven te komen.

Dank, dank, dank aan mijn co-promotores: Marjan de Rijke en Jaap Patijn.

Marjan, ik zie ons nog in de auto zitten op de weg terug van een deelnemende locatie: beiden met een vreselijke hoofdpijn, maar wel opgetogen: weer mensen enthousiast gekregen! Zonder jou was dit project al heel vroeg gestrand. Je fungeerde, zeker in de beginfase, regelmatig als bliksemafleider. Je maakte me wegwijs in SPSS en je hebt me veel geleerd door de helicopterview vast te houden: wat willen we nu eigenlijk zeggen? Je stuurde me steeds met heldere blik, vastberaden, maar altijd alsof ik het ook zelf een beetje had bedacht, de goede kant op. Jouw vertrek naar Zeeland (alhoewel van harte gegund) was voor mij een aderlating.

Jaap, ieder mens heeft zo zijn gebruiksaanwijzing en dat geldt zeker ook voor ons beiden. Nu we de handleidingen hebben doorgenomen is er iets moois ontstaan. Allereerst ben jij de grote initiator van dit proefschrift. Jouw vragen die geen vragen waren, dwongen me steeds opnieuw tot verder nadenken. "Dat staat er niet" is niet één van mijn meest geliefde uitspraken geworden, maar, eerlijk is eerlijk: door jouw inbreng werden de artikelen alleen maar beter en beter. Daarnaast heb ik veel respect gekregen voor je uitstekende klinische blik. De wekelijkse gezamenlijke "pijnvisites" zijn goed voor de patiënten en altijd leerzaam voor ons allen.

Dank aan mijn promotores: Maarten van Kleef en Harry Schouten.

Alhoewel jullie enige afstand hadden van de dagelijkse gang van zaken wisten jullie steeds de puntjes op de i te zetten als er weer een lap tekst op de mail stond. Dank voor jullie hulp bij het vinden van de juiste fora voor de artikelen, zodat we denk ik ook de mensen hebben bereikt die we wilden bereiken. Maarten, ik ben er trots dat ik mij als internist staflid anesthesie mag noemen. Moge dit leiden tot een betere behandeling van pijn bij patiënten met kanker.

Mijn speciale dank gaat uit naar alle patiënten die geparticipeerd hebben aan de verschillende onderzoeken. De mensen die het gehele traject van kanker en behandeling (soms al jaren) achter de rug hadden: een nieuwe confrontatie met deze periode was misschien niet altijd gemakkelijk. De patiënten die ernstig ziek waren en toch de moeite hebben genomen onze vragenlijsten in te vullen. En de patiënten die nog midden in het traject zaten en al veel te veel 
"ziekenhuis" aan hun hoofd hadden. Wij zullen er alles aan doen dit onderzoek zijn vruchten te laten afwerpen.

Dank aan twee heren bij wie ik regelmatig met grote ogen en, naar ik vrees, open mond heb gezeten: Fons Kessels en Erik Schouten. Erik dank voor de factor analyse van de Cars. Fons, naast jouw verhelderende commentaar op de diverse concepten heb jij me door de rest van de statische geheimen geloodst. En alhoewel je dat misschien betwijfelt: ik heb veel van je geleerd.

Dank aan twee dames die beiden grote bijdragen hebben geleverd aan twee van de in dit boekje beschreven artikelen: Madelon Peters en Evelien van der Peet. Madelon, tussen alle professerabele activiteiten door vond je steeds de tijd snel en adequaat suggesties te doen voor het CARS-artikel. Evelien, jouw naam staat als eerste op het artikel van hoofdstuk 5. En terecht, ook nadat jouw dienstverband er al lang opzat heb je doorgebeten en de interventie studie beschreven in een duidelijk artikel. Hartelijk dank.

Mijn dank gaat ook uit naar de leden van de beoordelingscommissie, prof. dr. M.F. von Meyenfeldt, prof. dr. C.D.A. Stehouwer, prof. dr. R. de Wit, prof. dr. W.W. Zuurmond en prof. dr. S.H. Ahmedzai. Ik wil hen bedanken voor de aandacht die zij aan mijn proefschrift hebben geschonken en voor hun bereidheid om het te beoordelen.

Dank aan de lokale coördinatoren van het Atrium Centrum te Heerlen, het Maaslandziekenhuis te Sittard, het Laurentius Ziekenhuis te Roermond, het St. Jans Gasthuis te Weert, de huisartsenvereniging, de diverse verpleeghuizen en thuiszorgorganisaties:

AVRJ Bell, FLJ Custers, JJ Jager, JCAH van de Loo, Mw HJMM Mertens, Mw $B$ van Doorn, Mw M Vromen, Mw L Ars, Mw W Habets, M vandenHoff, R Persoon, F Slot, Mw P Vleugels en Mw R Palmen: dank voor jullie tijd en inzet.

Dank aan onze student hulptroepen en in het bijzonder aan Jeroen Delbeke, de leider van onze ondersteuners. Yvonne, Lilly, Karien, Katrin, Mirella, Elsbeth, Eveliene, Danielle, Stijn, Esther, Dominique en Mirjam dank voor het verzorgen van de logistiek op de diverse locaties, het plegen vele telefoontjes, het versturen van alle vragenlijsten en het met precisie invoeren van alle gegevens. Ik hoop dat deze ervaring jullie niet afhoudt van een wetenschappelijke carrière: het ga jullie goed.

Dank aan Tiny Wouters. Daar sta je weer achterin een boekje. Dank voor de fraaie lay-out en de razendsnelle correcties. Het geeft veel rust te weten dat jij in de lay-out fase de leiding hebt. 
Dank aan Judith Abma: met alleen middelbare school Engels blijven tijden en voorzetsels moeilijk. Dankzij jou zal ook een native speaker zijn/haar rode pen in de zak kunnen houden.

Annemie Courtens, Riet Janssen, Eliane Perree, Paul Oyen, Pauline Vleugels, Marjan van Dijk en Melanie van der Pol, samen zijn wij HET palliatieteam! De het staat niet voor niets in hoofdletters. Ik ben zeer blij dat ik deel mag uitmaken van een team dat kwalitatief en kwantitatief op een hoog niveau presteert, in een sfeer die meer dan aangenaam is. Wij zijn kritisch naar onszelf en naar elkaar, wat zeer stimulerend werkt. Wij hebben wat voor elkaar over en dat maakt werken binnen deze club zeer waardevol.

Riet, we zien elkaar te weinig: sparren met jou levert altijd nieuwe gezichtspunten en helaas ook heel veel nieuwe vragen op. We zijn nog lang niet uit-onderzocht: jouw beurt?

Paul en Eliane, wanneer jullie zagen dat ik achter mijn laptop zat, begon ieder overleg standaard met "opslaan"! Dat heeft me veel ellende bespaard.

Een speciaal woord van dank ook voor Hans Fiolet die mij op het pad der palliatieve geneeskunde heeft gezet. Je hebt het gemerkt: eerst sprak het vak me aan, nu heeft het me gegrepen. Dank voor de ruimte en het vertouwen dat ik steeds van je heb gekregen.

Lieve mama, gaan studeren was in ons gezin normaal. Er werd dan ook niet veel over gesproken. Het was belangrijker dat je goed in je vel zat en je je gelukkig voelde met de mensen om je heen. En dat is, zeker ook in onze jeugd, uitstekend geslaagd. Het is ontzettend jammer dat papa niet heeft meegemaakt hoe eerst zijn jongste zoon, en nu zijn oudste dochter de s van hun titel hebben afgehaald. Maar ik weet zeker dat hij ergens trots zit te glimlachen.

Lieve mannen, Joop, Sef, Wisse en Dirk.

Eerlijk gezegd denk ik dat jullie niet zo heel veel last hebben gehad van deze exercitie. De jongens hebben wel eens getwijfeld aan mijn vaardigheden als arts: "mama, nu ben je zo vaak bij mevrouw..... geweest en nu is ze toch overleden!" Inmiddels begrijpen jullie veel beter wat ik doe en waarom: zoveel hebben jullie wel meegekregen van dit boekje.

Joop, eens in de zoveel tijd krijg je een avondje ellende over je uitgestort. Met name patiënten die me geraakt hebben door hun moed en kracht ondanks de ellendige situatie waarin zij verkeren komen dan (anoniem uiteraard) langs. Een luisterend oor is dan goud waard.

Maar het allerbelangrijkste is natuurlijk dat ik gewoon heel gelukkig ben met jullie en dat nog in lengte van jaren hoop te blijven. 

Curriculum vitae 


\section{Curriculum vitae}

Marieke van Everdingen werd op 20 oktober 1960 geboren te Utrecht. Na het behalen van het Gymnasium- $\beta$ diploma in 1979 aan het Maurick college te Vught, studeerde zij Geneeskunde aan de Rijksuniversiteit Utrecht. Zij behaalde haar artsexamen in 1986, waarna zij als arts-assistent ging werken op de intensive care in het Catharina ziekenhuis te Eindhoven. Een jaar later startte zij met de opleiding interne geneeskunde. Na twee jaar in het Juliana ziekenhuis, thans Gelre ziekenhuizen, te Apeldoorn (opleider dr. A. van Gelder) werd de opleiding vervolgd in het Catharina ziekenhuis te Eindhoven (opleider prof. dr. H.F.P. Hillen) en het academisch ziekenhuis Maastricht (opleider prof. Dr. J.A. Flendrig). De registratie als algemeen internist vond plaats in 1992. Zij werkte één jaar op de intensive care van het academisch ziekenhuis Maastricht en daarna gedurende vijf jaar als algemeen internist in ziekenhuis de Wever te Heerlen (thans Atrium Medisch Centrum Heerlen).

In 1998 startte zij bij het Centrum Ontwikkeling Palliatieve Zorg (COPZ) in Maastricht. In 2000 behaalde zij het "Diploma Palliative Care" te Cardiff. Momenteel is zij werkzaam als algemeen internist bij het regionaal palliatie team en bij de Maastricht Pain Collaboration

Zij is zeer gelukkig getrouwd met Joop van den Beuken en samen hebben zij drie zonen: Sef (1993), Wisse (1994) en Dirk (1997). 
